\title{
Die eiszeitliche und die gegenwärtige Vergletscherung im Mittelmeerraum
}

Bruno Messerli

\section{Vorwort}

Ich danke dem Schweizerischen Nationalfonds zur Förderung der wissenschaftlichen Forschung, der meine Feldarbeit großzügig unterstützte und die Drucklegung der Ergebnisse in dieser Form ermöglichte. Die Schweizerischen Botschaften in Ankara und Beirut öffneten viele offiziell verschlossene Türen und erleichterten mir die Vorbereitung und Durchführung der verschiedenen Expeditionen. Herrn Prof. Gygax, Direktor des Geographischen Institutes, danke ich für sein Entgegenkommen und meinen Begleitern P. Hubacher, R. Kunz und $\mathrm{H}$. Zumbühl für ihre wertvolle Mitarbeit in schwer begehbaren Bergen und Tälern. Mein größter Dank aber gilt meiner Frau, die mich auf den anstrengenden Reisen begleitete, an der Arbeit teilnahm und die Ubersetzungen betreute. Ihr sei diese Arbeit gewidmet.

Die vorliegende Arbeit haben wir in drei Teile gegliedert:

Im ersten Teil besprechen wir einige ausgewählte
Publiziert mit Unterstützung des Schweizerischen Nationalfonds zur Förderung der wissenschaftlichen Forschung

Gebirge, indem wir uns auf weniger bekannte Regionen des östlichen Mittelmeerraumes beschränken. Aus früheren Publikationen über den LibanonHermon und die Sierra Nevada fügen wir die $\mathrm{Zu}$ sammenfassungen bei.

Im zweiten Teil haben wir die einzelnen Regionen des Mittelmeerraumes bearbeitet. Zahlreiche eigene Beobachtungen aus den Bergen Montenegros (Durmitor, Orjen, Lovcen), dem Gran Sasso d'Italia und dem Hohen Atlas sind hier eingeflochten, weil wir nicht unser gesamtes Untersuchungsmaterial im einzelnen darstellen konnten. Eine Gesamtschau der eiszeitlichen und gegenwärtigen Vergletscherung schließt diesen Abschnitt.

Im dritten Teil sind die allgemeinen Erscheinungen und Probleme zusammengefaßt. Die eiszeitlichen und gegenwärtigen Schneegrenzen werden diskutiert und ihre geomorphologische und klimatologische Aussage interpretiert. Viele Fragen des quartären Landschaftswandels bleiben aber offen; eine $\mathrm{Zu}$ sammenarbeit der verschiedensten Fachrichtungen wird sie in Zukunft einer Lösung näherbringen.

\section{INHALTSVERZEI CHNIS}

I. Teil: Die einzelnen Untersuchungsgebiete

\section{Erciyas Dagh}

1.1. Der Aufbau und seine Bedeutung für die Glazialmorphologie

1.2. Das Klima und seine Bedeutung für die Vergletscherung

1.3. Die heutige Vergletscherung und das Problem der rezenten Schneegrenze

1.4. Die würmeiszeitliche Vergletscherung und ihre Schneegrenze

1.5. Spuren einer älteren Vergletscherung

1.6. Verwitterung und Blockgletscher

1.7. Solifluktionsgrenze und Waldgrenze

1.8. Schneegrenzen und Schneegrenzdepression

1.9. Résumé, Summary

\section{Mittlerer Taurus: Hoher Bolkardagh}

2.1. Der Aufbau und seine Bedeutung für die Glazialmorphologie
2.2. Das Klima im Vergleich mit dem Erciyas Dagh und dem Libanon

2.3. Spuren einer rezenten Vergletscherung und Probleme der Schneegrenzbestimmung

2.4. Die würmeiszeitliche Vergletscherung und ihre Schneegrenze

2.5. Hangasymmetrie, Strukturböden und Waldgrenze

2.6. Schneegrenzen und Schneegrenzdepression

2.7. Résumé, Summary

\section{Ak Dagh und Bey Dagh in Lykien}

3.1. Oberflächengestalt und Aufbau

3.2. Klimatische Grundzüge

3.3. Die würmeiszeitliche Vergletscherung des Ak Dagh

3.4. Die würmeiszeitliche Vergletscherung des westlichen Bey Dagh 
3.5. Strukturböden, Glatthänge und Waldgrenze

3.6. Rezente Formen und das Problem der rezenten Schneegrenze Türkei

3.8. Résumé, Summary

4. Ulu Dagh (Mysischer Olymp)

4.1. Grundlagen

4.2. Die regionale Schneegrenze

4.3. Strukturböden und Waldgrenze

4.4. Résumé, Summary

5. Der thessalische Olymp

5.1. Einige Hinweise zum Aufbau

5.2. Die klimatischen Verhältnisse

5.3. Die eiszeitliche Vergletscherung

5.4. Die eiszeitliche Schneegrenze Griechenlands und das Problem der Aegäis

5.5. Résumé, Summary

6. Sierra Nevada (Andalusien)

Zusammenfassung, Résumé, Summary

\section{Libanon und Hermon}

Zusammenfassung, Résumé, Summary
3.7. Die Schneegrenzen der südwestlichen

5.2. Die rezente Schneegrenze

II. Teil: Die Schneegrenzen in den einzelnen Regionen des Mittelmeeres

1. Die Schneegrenzen im östlichen Mittelmeerraum

1.1. Die würmeiszeitliche Schneegrenze

1.2. Die rezente Schneegrenze

1.3. Die Schneegrenzdepression

1.4. Die vergletscherten Gebirge (Verzeichnis)

2. Die Schneegrenzen im Balkan

2.1. Die würmeiszeitliche Schneegrenze

2.2. Die rezente Schneegrenze

2.3. Die vergletscherten Gebirge des Balkans (Verzeichnis)

3. Die Schneegrenzen auf der Apenninen-Halbinsel

3.1. Die würmeiszeitliche Schneegrenze

3.2. Die rezente Schneegrenze

3.3. Die Schneegrenzdepression

3.4. Die vergletscherten Gebirge auf der Apenninen-Halbinsel (Verzeichnis)

4. Die Schneegrenzen auf der Iberischen Halbinsel

4.1. Die würmeiszeitliche Schneegrenze

4.2. Die rezente Schneegrenze

4.3. Die Schneegrenzdepression

4.4. Die vergletscherten Gebirge auf der Iberischen Halbinsel (Verzeichnis)

5. Die Schneegrenzen in Nordafrika

5.1. Die würmeiszeitliche Schneegrenze
5.3. Die Schneegrenzdepression

5.4. Die vergletscherten Gebirge Nordafrikas (Verzeichnis)

6. Die Schneegrenzen im gesamten Mittelmeerraum

6.1. Der allgemeine Verlauf der würmeiszeitlichen Schneegrenzen (Karte 1)

6.2. Der allgemeine Verlauf der rezenten Schneegrenzen (Karte 2)

6.3. Die Schneegrenzdepressionen

III. Teil: Die Schneegrenzen und ihre klimamorphologische Bedeutung

1. Die eiszeitliche Schneegrenze und ihre regionale Bestimmung

1.1. Die lokale Schneegrenze 188

1.2. Die Expositionsunterschiede

1.3. Die regionale Schneegrenze

190

2. Die rezente Schneegrenze und ihre klimatische Bestimmung

2.1. Die lokale Schneegrenze

2.2. Die Expositionsunterschiede

2.3. Die klimatische Bestimmung der Schneegrenze

3. Zur Problematik des Schneegrenzbegriffs: Bisherige und zukünftige Definitionen

3.1. Schneegrenze - Gleichgewichtslinie Niveau 365

3.2. Eindeutige Begriffe zur Abgrenzung der nivalen Stufe

3.3. Probleme und Begriffe in unserer Arbeit 198

4. Die klimamorphologische Bedeutung der Schneegrenzen

4.1. Schneegrenzen - Expositionsunterschiede - Kaltzeitliche Klimaverhältnisse

4.2. Nivale Stufe - Frostschuttstufe - Kaltzeitliche Klimaverhältnisse

5. Die klimamorphologische Höhenstufung in den mediterranen Hochgebirgen

5.1. Obere Waldgrenze - Rezente Schneegrenze

5.2. Solifluktionsgrenze - Schneegrenze

202

6. Schneegrenzdepression und kaltzeitliche Klimaverhältnisse

6.2. Schwankungen der Schneegrenzdepression

6.1. Probleme der Schneegrenzdepression 204

6.3. Temperaturdepression und Schneegrenzdepression

7. Das Mittelmeer zur Eiszeit und in der Gegenwart 
7.2. Zirkulation und Klima

209

7.3. Vergletscherung und Vergletscherungsformen

212

Zusammenfassungen

214

Résumés

216

219

Summaries

221

Literaturverzeichnis

\section{Verzeichnis der Karten und Figuren}

Karte 1 Würmeiszeitliche Gebirgsvergletscherungen und Schneegrenzen im Mittelmeerraum $164 / 165$

Karte 2 Heutige Gebirgsvergletscherungen und Schneegrenzen im Mittelmeerraum

$164 / 165$

Fig. 1 Erciyas Dagh, Vergletscherungskarte

Fig. 2 Hoher Bolkardagh. Geologische Profile

Fig. 3 Karte der würmeiszeitlichen Endmoränen

Fig $4 \mathrm{a}, \mathrm{b}$ Zurundungsmorphogramme aus den Endmoränen des Hohen Bolkardagh $130 / 131$

Fig. 5 Ubersichtskarte. Ak Dagh und Bey Dagh in Lykien

Fig. 6 Die würmeiszeitliche Vergletscherung des Ak Dagh

Fig. 7 Zurundungsmorphogramme Ak Dagh und Bey Dagh
Fig. 8 Geologische Karte und Profile des Ulu-Dagh-Massivs (nach Pfannenstiel)

Fig. 9 Olymp. Eiszeitliche Vergletscherung

Fig. 10 Kleinasien. Die Gebirgsvergletscherung der letzten Eiszeit und der Verlauf der regionalen Schneegrenzen

Fig. 11 Die rezenten Schneegrenzen in Anatolien

Fig. 12 Schneegrenzen und Waldgrenzen in Anatolien (Profil S-N)

Fig. 13 Schneegrenzen und Waldgrenzen in Anatolien (Profil W-E)

Fig. 14 Der Gletscher am Triglav (Julische Alpen) (nach Sifrer)

Fig. 15 Der Calderone-Gletscher am Gran Sasso d'Italia (nach Tonini)

Fig. 16 Die Gletscher der Pyrenäen (nach Taillefer)

Fig. 17 Schneegrenzen und Waldgrenzen im westlichen Mittelmeerraum (Profil $\mathrm{N} \_\mathrm{S}$ )

Fig. 18 Eiszeitliche und rezente Schneegrenzen im Mittelmeerraum (3 Profile W-E)

Fig. 19 Expositionsunterschiede in den mediterranen Gebirgsvergletscherunget

Fig. 20 Die Temperaturen an der Schneegrenze

Fig. 21 Höhe der 4,5-Isotherme des wärmsten Monats

Fig. 22 Glazialgeschichte der mediterranen Hochgebirge

\section{DIE EINZELNEN UNTERSUCHUNGSGEBIETE}

\section{Erciyas Dagh}

Als Wahrzeichen der Stadt Kayseri hebt sich der 3916 m hohe Erciyas Dagh mit einer Grundfläche von fast $1200 \mathrm{~km}^{2}$ aus der über $1000 \mathrm{~m}$ hohen Bekkenzone Anatoliens heraus. Schon im 1. Jahrhundert vor Christus hat der griechische Geograph Strabo den Argaeus und seine letzten Eruptionen geschildert (11), und sogar auf antiken Münzen soll der Vulkan zur Darstellung gekommen sein (307). Die folgenden Jahrhunderte überliefern uns keinen Bericht mehr, bis der berühmte Berg schließlich vor 100 Jahren neu «entdeckt», bestiegen und beschrieben wurde (122, 336, 337, 340). 1905 wird die erste Karte veröffentlicht (267), und 1934/35 erhalten wir die erste genauere Untersuchung des Erciyas und seiner Umgebung von Bartsch (11). In der Folge beschäftigen sich zahlreiche Autoren mit seiner Erforschung, so Blumenthal, Louis, Erinç, Klaer und andere $(17,185,80,147,307$ u. a.). Schließlich wird in diesen Jahren im Auftrag der türkischen geologischen Landesanstalt eine Detailkartierung im Maßstab 1:25000 vorgenommen, die einen wesentlichen Beitrag bedeutet. Zahlreiche Probleme sind noch nicht geklärt, so vor allem das Zusammenspiel von endogenen und exogenen Kräften, die komplexe Verflechtung von Vulkanismus und Eiszeiten. 


\subsection{Der Aufbau und seine Bedeutung für die Gla- zialmorphologie}

Wir besprechen im folgenden einige Probleme des Aufbaus, die für jede glazial- und klimamorphologische Betrachtung unumgängliche Voraussetzungen enthalten.

\section{Tektonische Grundlagen}

Die Ebenen nördlich und südlich des Erciyas werden von einem tektonischen Graben- und Bruchsystem gequert, das im Süden fast N_S verläuft und dann in unserem Untersuchungsgebiet langsam nach NE umbiegt. Diese Bruchlinien haben im jüngeren Tertiär bereits vulkanische Horizonte verworfen, sind aber selber von vulkanischem Material in der Hauptphase der Erciyas-Bildung wieder verschüttet worden. Tektonische Lineamente sind angelegt, sie prägen das heutige Oberflächenbild durch Bruchstufen und Bruchlinien, wie zum Beispiel der TekirBruch im Paßübergang zwischen Erciyas und Koç Dagh (Fig. 1). Tektonische Richtungen zeigen sich aber auch in der linienhaften Anordnung von Parasitärkegeln, am deutlichsten auf der NW-Seite (Fig. 1). Tektonische Bewegungen spielen bis in die heutige Zeit, wie das Erdbeben vom 20. Februar 1940 beweist (307). Dabei war auffallend, daß nur die Dörfer am Gebirgshang in Mitleidenschaft gezogen wurden und im Gipfelgebiet einige Felsköpfe zum Einsturz kamen. Ein Zusammenhang mit vulkanischen Vorgängen ist unwahrscheinlich, vielmehr handelt es sich um den Ausgleich von tektonischen Spannungen in diesem labilen Raum. Für unsere Arbeit ist dieses Geschehen insofern von Bedeutung, als die markante Großgliederung des Vulkans und vor allem des Gipfelmassivs nicht allein mit exogener Überformung erklärt werden kann. So sind die eindrücklichen Karformen im Gipfelraum nicht einfach Zeugnisse einer gewaltigen Glazialerosion. In ihrer primären Anlage müssen wir sie zweifellos auf tektonische Schwächezonen zurückführen; diese haben den Vulkankörper während und nach der Entstehung gegliedert und seine künftige Überformung vorausbestimmt. Diese Aussage läßt sich nur nooh an wenigen Stellen nachweisen. So hat sich zum Beispiel die markante Zweiteilung des Gipfelmassivs auf die Karanordnung der Nord- und Südseite ausgewirkt (Abb. 1, 2, 7 und Fig. 1). Sie ist tektonisch-vulkanisch bedingt, was an den Materialdifferenzierungen erkennbar ist. In den meisten Fällen lassen sich aber die ursprünglichen Strukturen nicht mehr rekonstruieren, weil das wenig resistente Material einer so gewaltigen Abtragung unterlag, wie wir sie kaum in einem andern Gebirge des anatolischen und mediterranen Raumes feststellen konnten.

\section{Das geförderte Material}

Der Erciyas ist ein komplex zusammengesetzter Stratovulkan. Neben älteren, größtenteils andesitischen Lavadecken finden wir jüngere Ergüsse basaltischen und andesitischen Charakters, ferner Lokkermaterial verschiedenster Art und verschiedensten Alters (Tuffe, Lapilli, Bimsstein usw.). Diese Materialvielfalt, in rascher Folge wechselnd, vor allem in höheren Lagen durch mächtige Lockermaterialschichten unterbrochen, bot der intensiven Verwitterung in einem kontinentalen Klima äußerst günstige Bedingungen. Viele Fragen sind noch ungeklärt, zum Beispiel die Entstehung der vulkanischen Breccie in den Hängen des Ostkars und unmittelbar auf dem Gipfel. Jedenfalls ist es auch ein Material, das leicht zerfällt und rasch abgetragen wird. Diese Zusammenhänge zwischen Gestein und Klima werden für die Deutung der gewaltigen Kubaturen des abtransportierten Materials, der besonderen Ablagerungsformen, der Entstehung der Blockgletscher und der quantitativen Erfassung der postglazialen Verwitterung von höchster Bedeutung sein. Probleme, die wir im Rahmen unserer Arbeit nicht alle gründlich diskutieren können, sondern einzeln zu einem späteren Zeitpunkt wieder aufgreifen möchten.

\section{Endogene und exogene Kräfte im Zusammenspiel (Abb. 1)}

Tertiäre und quartäre Ablagerungen sind mit vulkanischen Vorgängen aufs engste verknüpft. Wir haben die einzelnen Entstehungsphasen vom Tertiär bis zum Beginn der geschichtlichen Zeit an anderer Stelle diskutiert und veröffentlicht (205). Wir wollen auf diesen Teil unserer Feldarbeiten nicht mehr eingehen, nur das für uns wesentliche Ergebnis festhalten: Der Erciyas hat seit der Würmeiszeit, sehr wahrscheinlich sogar seit der Rißeiszeit, seine Grundgestalt und vor allem seine Höhenlage nicht mehr wesentlich verändert. Trotz den eindeutig nachweisbaren postglazialen Eruptionen können die glazial- und geomorphologischen Höhenstufen in die großräumigen eiszeitlichen und rezenten $\mathrm{Zu}$ sammenhänge eingeordnet werden.

\section{Vulkanform und Vergletscherung}

An einem regelmäßig geformten Vulkankegel gibt es keine Täler im alpinen Sinne, die eine bedeutende Eintiefung und eine klar vorgezeichnete Entwässerungsrichtung aufweisen. Nur ausnahmsweise entstanden am Erciyas schwache Talungen, zum Beispiel in der Fortsetzung der drei Gipfelkare im NE, NW und SW (Abb. 6 und 7, Fig. 1). Diese einigermaßen gerichteten Eisströme erreichten denn auch die tiefsten Endlagen und unterschieden sich deut- 
lich von den breit ausfächernden Eiskuchen im Osten und Süden (Abb. 4 und 8, Fig. 1). Die letzteren verloren nach dem Verlassen der Hochkare jegliche Seitenbegrenzung, flossen fladenartig auseinander, legten ihr Material ungeordnet $a b$, waren auf dem offenen Vulkansockel einer intensiven Strahlung ausgesetzt und büßten ihre ungezielte Fließkraft rasch ein. Zahlreiche Probleme sind in dieser kurzen Darstellung angedeutet: die besonderen Ablagerungsformen, die verminderte Erosionswirkung, eine fragliche Festlegung der Schneegrenze mit den üblichen Mittelwerten usw. So sind Zusammenhänge zwischen Aufbau und Vergletscherung gegeben; wir werden die knapp skizzierten Strukturgrundlagen immer wieder zu überdenken haben, um die Formenwelt richtig zu verstehen und zu interpretieren.

\subsection{Das Klima und seine Bedeutung für die Ver- gletscherung}

Für die Bestimmung des Gebirgsklimas fehlen uns die Höhenstationen. Ein Basieren auf den umliegenden offiziellen Talstationen ist schwierig und fehlerhaft. Wir beschränken uns auf einige Angaben, die für unsere Fragestellung unumgänglich sind.

\subsubsection{Die Niederschläge}

Jahresniederschlag. Im langjährigen Mittel (1929_ 1960) erhält Kayseri 366,5 mm Niederschlag (212). Der Jahresverlauf ist durch einen trockenen Hochsommer (Juli und August) und einen niederschlagsreichen Winter mit einer durchschnittlichen Spitze im Frühling (April) gekennzeichnet. Der Jahreswert zeigt, daß die Niederschlagsmengen Inneranatoliens außerordentlich gering sind, was für die Beurteilung einer Vergletscherung bedeutungsvoll und problematisch zugleich ist.

Exposition: Wir vergleichen die Werte der drei offiziellen Stationen Kayseri im N, Develi im S und Inçesu im W des Erciyas $(211,212)$. Leider verfügen wir in Inçesu nur über drei Jahreswerte, so daß wir aus Vergleichsgründen alle Stationen auf die Jahre 1959-1961 beschränken:

Kayseri $370 \mathrm{~mm}$ (langjähriges Mittel $366,5 \mathrm{~mm}$ ) Develi 375 mm (Mittel 1951-1961 364,8 mm) Inçesu $304,3 \mathrm{~mm}$

Die Stationen im $\mathrm{N}$ und $\mathrm{S}$ sind fast ausgeglichen, währenddem Inçesu im W, wahrscheinlich im Niederschlagsschatten des Tekke Dagh $(1830 \mathrm{~m})$, erstaunlicherweise die geringsten Mengen erhält. Diese Ergebnisse zeigen uns, daß der verschiedene Formenschatz der Sonn- und Schattseite nicht auf ein unterschiedliches Niederschlagsregime, sondern vorwiegend auf die ungleichen Strahlungs- und in der Folge Temperaturbedingungen zurückzuführen ist.

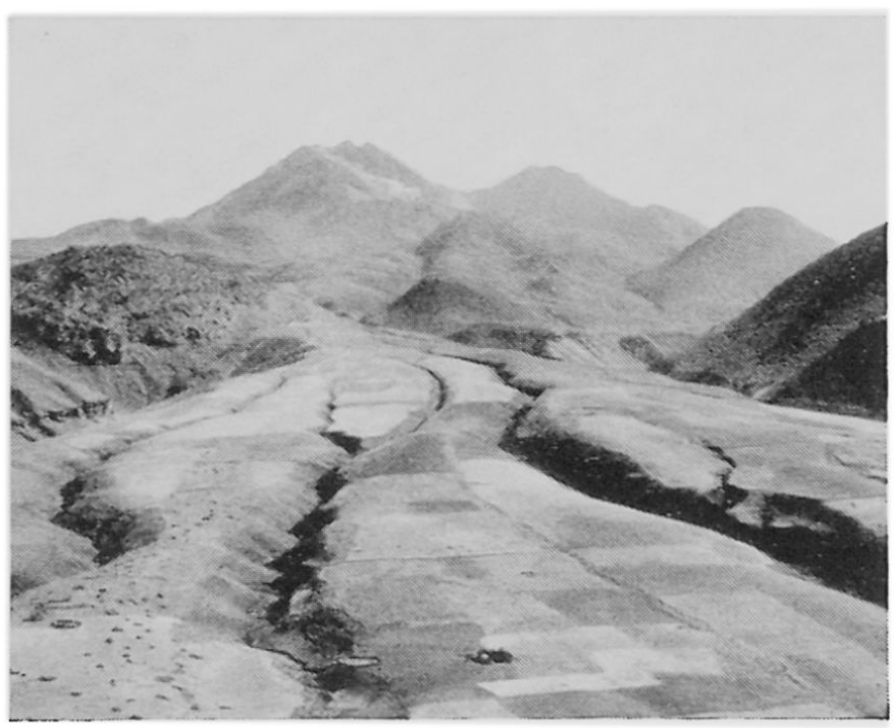

Abb. 1 Blick nach SSE zum Erciyas-Gipfel. Links die Blocklava des Perikartini, rechts der Sekundärkegel des Kefeli. Mächtige tertiäre bis altquartäre Ablagerungen, die mit den Verebnungsflächen am Fuß des Gipfelaufbaus in Zusammenhang stehen. Die Parasitärkegel rechts sind vor oder mit den Ablagerungen entstanden, die Blocklava links hat die Akkumulationen später durchstoßen und das bestehende Entwässerungsnetz unterbrochen (vgl. Lit. 205).

Diese Folgerung müssen wir allerdings einschränken: Die niederschlagsbringenden Windrichtungen aus SW, möglicherweise sogar S, haben sich in den Schneeanwehungen in Lee morphologisch bedeutsam ausgewirkt.

Die Niederschläge in der Höhe: In den letzten Jahren hat man Jahrestotalisatoren entlang der Paßstraße auf $1900 \mathrm{~m}$ (PTT-Station) und $2150 \mathrm{~m}$ (Berghaus) aufgestellt. Die ersten $5 \mathrm{Me}$ jahre stehen uns zur Verfügung (211), wobei sich die Werte nur auf das Winterhalbjahr beziehen (ca. 200 Tage). Wir vergleichen die Ergebnisse mit den zeitlich entsprechenden Daten von Kayseri und Develi.

$\begin{array}{clll}\text { 1960-1964 } & \text { Berghaus } & 2150 \mathrm{~m} & 871 \mathrm{~mm} \\ & \text { PTT-Station } & 1900 \mathrm{~m} & 376 \mathrm{~mm} \\ \text { Kayseri } & 1071 \mathrm{~m} & 300 \mathrm{~mm} \\ & \text { Develi } & 1181 \mathrm{~m} & 327 \mathrm{~mm}\end{array}$

Die Ergebnisse sind schwer zu interpretieren, vor allem ist die geringe Zunahme für die Station auf $1900 \mathrm{~m}$ auffallend. Als Erklärung seien die viel zu exponierten Standorte und die Fehler bei der Messung von Schneemengen genannt. Da aber gerade der größte Teil der gemessenen Winter-Niederschläge in fester Form fällt, sind diese Werte zweifellos zu niedrig. Berücksichtigen wir die täglich gemessenen Mengen von Kayseri, und vergleichen wir die Höhenzunahme mit den Alpen (227), der Sierra Nevada (204) und dem Libanon, so muß der Nieder- 
schlag im Höhenbereich über $3000 \mathrm{~m}$ mindestens $1500 \mathrm{~mm}$ betragen und auf keinen Fall nur 1000 mm, wie Reichel vermutet (297).

Schneefall: Die Niederschlagsverteilung im Jahresverlauf zeigt, daß rund 50 Prozent in den Monaten November bis März fallen und weitere 32 Prozent in den Übergangsmonaten April/Mai und Oktober. Nach der offiziellen meteorologischen Statistik fällt in Kayseri an 20 von durchschnittlich 97 Niederschlagstagen Schnee (212). Nach einer neueren $\mathrm{Zu}$ sammenstellung des Schneefalls in der Türkei (213) müßte Kayseri sogar über 35 Schneefalltage aufweisen und der Erciyas sogar über 75. Diese Angabe bezweifeln wir für Kayseri, halten sie aber im Erciyas-Hochbereich ohne weiteres für möglich. Ganz sicher fällt in Hochgebirgslagen über $3000 \mathrm{~m}$ der gesamte Niederschlag von November bis März in fester Form, dazu kommt periodischer Schneefall in der Übergangszeit. Gesamthaft dürften in der Region über $3000 \mathrm{~m}$ im Mittel mehr als 70 Prozent des Niederschlages als Schnee fallen, das heißt mindestens $1000 \mathrm{~mm}$.

Verglichen mit den Alpen ist das wenig, aber bezogen auf eine geographische Breite von $38,5^{\circ}$ und auf eine völlig kontinentale Lage ist es doch eine ganz respektable Menge, die zum Verständnis der Vergletscherung Wesentliches beitragen kann.

\subsubsection{Die Temperaturen}

Der Temperaturverlauf in Kayseri schwankt im langjährigen Mittel zwischen $-1,7^{\circ}$ im Januar und $22,8^{\circ}$ im Juli; die große Amplitude von $24,5^{\circ}$ weist auf den kontinentalen Klimacharakter hin.

Tagesschwankung und Frostwechsel: Die Zahl der Frostwechseltage ist in der kontinentalen Lage Anatoliens zweifellos größer als in unseren Mittelbreiten; aber es fehlen uns die Stationen, um diese Aussage für die höheren Bereiche genauer zu belegen. Für Kayseri ermittelten wir ca. 100-125 Frostwechseltage im Jahr (212). Diese Anzahl dürfte sich mit zunehmender Höhe noch bedeutend vergrößern, doch können wir den Höhenbereich mit der optimalen Auswirkung nicht festlegen.

\section{Temperaturgradient und Schneegrenze}

Eine Schneegrenzberechnung mit Hilfe der Sommertemperaturen stößt auf größte Schwierigkeiten, weil wir keine gesicherten Höhenwerte zur Verfügung haben. Ziehen wir als Notlösung einige höher gelegene inneranatolische Stationen heran, so ergeben sich als neue Fehlerquelle allzu große Horizontaldistanzen. Da wir aber nur die reliefbeeinflußte Höhenstufe zwischen 1000 und ca. $2000 \mathrm{~m}$ bestimmen wollen und alle Stationen dem gleichen kontinentalen Temperaturregime unterliegen, dürfte ein Vergleich mit Ulukisla im Süden und Erzurum im Osten gut vertretbare Werte ergeben (212).
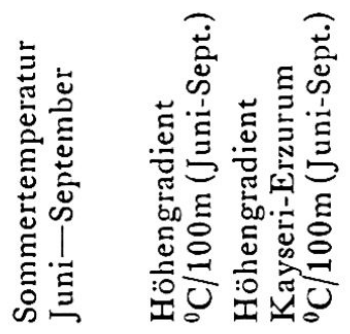

Kayseri $\quad 1071 \mathrm{~m} \quad 22,8^{\circ} \mathrm{C} \quad 20,6^{\circ} \mathrm{C}$

Ulukisla $1430 \mathrm{~m} \quad 21,5^{\circ} \mathrm{C} \quad 19,3^{\circ} \mathrm{C}$

Erzurum $1893 \mathrm{~m} \quad 19,1^{\circ} \mathrm{C} \quad 17,2^{\circ} \mathrm{C}$

0,36

0,46

0,41

Eine schwache Erhöhung der Gradienten zeichnet sich von der unteren zur oberen Höhenstufe ab; als Ganzes entspricht jedoch der Temperaturgradient zwischen Kayseri und Erzurum ganz genau dem Mittel zwischen den beiden Stufengradienten. Vergleichen wir den Wert von $0,41 \% / 100 \mathrm{~m}$ mit den aerologischen Aufstiegsmessungen der beiden kontinentalen Stationen Madrid und Bagdad, so ergeben sich unter Berücksichtigung der verschiedenen geographischen Breiten erstaunliche Übereinstimmungen. Madrid liegt ca. $2^{\circ}$ nördlicher und hat für Sommertemperaturen zwischen 1000 und $2000 \mathrm{~m}$ einen Gradienten von $0,33^{\circ} / 100 \mathrm{~m}$. Bagdad befindet sich gegenüber Kayseri ca. $3^{\circ}$ südlicher und registriert zwischen Bodenhöhe und $1600 \mathrm{~m}$ einen Gradienten von $0,50 \% / 100 \mathrm{~m}(29)$.

Nur eines bleibt unsicher: die Schichtung der Luft und die Höhe, in welcher sich der Temperaturgradient ändert. Die Aufwölbung der sommerlichen Isothermen über dem anatolischen Hochland führt zur Ausbildung eines warmen Höhenhochdruckgebietes. Die Grundschichtinversion ist weniger intensiv und durch die absolute Höhe Anatoliens vermutlich erst über $2000 \mathrm{~m}$ anzutreffen. Das mag uns das Recht geben, erst oberhalb dieser Höhenstufe einen erhöhten Temperaturgradienten in Rechnung zu setzen. Wenn wir im folgenden $0,7^{\circ} / 100 \mathrm{~m}$ annehmen (als Analogie zu Madrid und Bagdad in Lit. 29, zu den Angaben Flohns über Hochasien Lit. 359 und zu unseren Berechnungen im Libanon), so werden wir eher zu vorsichtige Werte erhalten, wie eigene Messungen in verschiedenen Höhenstufen und selbst auf dem Gipfel bestätigen. Berechnen wir ferner nach den freien Aufstiegsmessungen der WMO (Beispiele Aleppo und Kairo, 214) aufgrund der $700 \mathrm{mb}$ Fläche auf ca. $3100 \mathrm{~m}$ die Julitemperatur in Gipfelhöhe, so ergeben sich erstaunlich gute Vergleichswerte.

Sommer-
temperatur

\begin{tabular}{|c|c|c|c|}
\hline Kayseri & $1071 \mathrm{~m}$ & $20,6^{\circ}$ & $22,8^{\circ}$ \\
\hline Erciyas & $2000 \mathrm{~m}$ & $16,8^{\circ}$ & \\
\hline Erciyas & $3100 \mathrm{~m}(700 \mathrm{mb}$ & & $9,1^{\circ}$ \\
\hline Erciyas & 3916 m Gipfel & $3,4^{\circ}$ & $4,2^{\circ}$ \\
\hline
\end{tabular}

Die Frage ist gestellt, wie diese Temperaturen mit einer Schneegrenze in Beziehung zu setzen sind. 
Die bisherigen Berechnungen sind noch recht widerspruchsvoll (359, 313, 161 usw.). Wir verweisen auf die Arbeit über den Libanon und auf die allgemeine Diskussion dieses Problems auf Seite 193. Diesen Ubberlegungen vorgreifend, dürfen wir feststellen, daß unsere errechneten Gipfeltemperaturen ungefähr einer Schneegrenzhöhe entsprechen. Das heißt: Die regionale Schneegrenze müßte am Erciyas Dagh mindestens auf Gipfelhöhe liegen.

\subsection{Die heutige Vergletscherung und das Problem der rezenten Schneegrenze}

\subsubsection{Der Gletscher im NW-Kar und seine lokale Schneegrenze (Abb. 2 und 3)}

Wir haben in einer früheren Publikation den berühmten Gletscher am Erciyas Dagh eingehend beschrieben, seine Veränderungen seit der Jahrhundertwende dargestellt und die Problematik seiner Entstehung und Ernährung diskutiert (203). Es ist ein Wandfußgletscher in bester klimatischer und morphologischer Gunstlage des Gipfelraumes, wie wir ihn an mehreren Orten des subtropisch-mediterranen Raumes finden können. Alle diese Eismassen sind mit ihrer Existenz auf einen kleinen, gut eingerahmten Karboden angewiesen. Sie können bei einem Höherrücken der Schneegrenze kaum ausweichen, höchstens vollständig verschwinden, und umgekehrt werden bei einem Absinken der Schneegrenze die über die Gunst- und Schutzlage hinausstoßenden Gletscherpartien von einer viel intensiveren Ablation erfaßt. Eine Verschiebung der Schneegrenze wird sich bei diesen bescheidenen Wandfußgletschern nicht primär in einer Veränderung der Längenausdehnung und der Höhe der Endlage, sondern vielmehr in einer Verminderung oder Zunahme der Eismächtigkeit und des vergletscherten Areals zeigen (vgl. Seite 191).

Diese Aussage belegen die Moränenwälle der letzten Hochstände. 1902 ist uns auf Photographien überliefert (Lit. 267 und Abb. 3). Die Ablagerungen von 1850 liegen unmittelbar davor und sind mit dem abgebildeten Gletscherende verzahnt. Klaer hat die seitlich erhöhten Moränen als Fernau-Stadium datiert (147, S. 63). Auch dieser Gletscherstand hatte eine ähnliche Länge und Endlage, nur die Eismächtigkeit und das vergletscherte Areal innerhalb der Schutzzone des Karraumes waren bedeutend gröBer.

Beim Gletscherrückgang tritt eine weitere Erscheinung dazu: Die Steilwände im Karraum werden schnee- und eisfrei; die Lokaltemperaturen reichen für Permafrostbildungen im Felsgefüge nicht mehr aus. Wenig resistentes Gestein, große Temperaturschwankungen und bedeutende Schmelzwassermen-

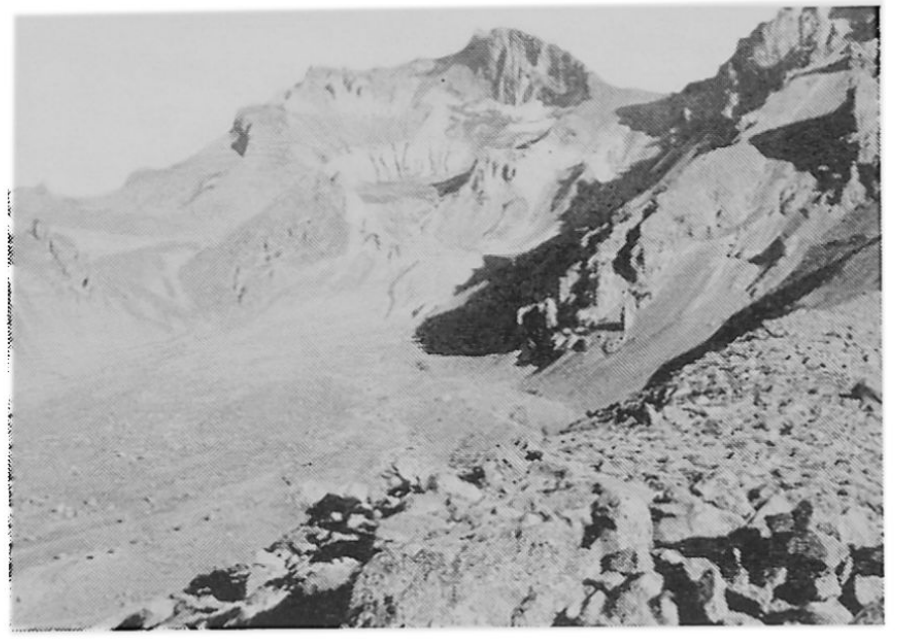

Abb. 2 Der rezente Gletscher mit einer streng lokalen Schneegrenze von $3650 \mathrm{~m}$. Die Zunge ist unter Blockschutt vollständig begraben; sie liegt dort, wo schon die rezenten Hochstände einen bedeutenden Stirnwall aufgeschüttet haben. In der Karmulde links ist ein Blockgletscher, der schon auf der Photo Penthers die gleichen Ausmaße zeigt. Photo 16. August 1962.

gen fördern die Auflockerung und den Abtrag. Fast schlagartig setzt ein übermäßiger Schuttanfall ein, der durch den stagnierenden Gletscher nicht mehr bewältigt werden kann. Die gesetzmäßige Beziehung zwischen dem schuttüberdeckten Gletscherareal und der klimabedingten Schneegrenzänderung löst sich auf. Es stellt sich die Frage, ob nicht in diesen Momenten und auf diese Weise Blockgletscher entstehen können. Wir wollen auf diese Frage zurückkkommen.

Bei allen mediterranen Gletschern ist das Nährgebiet in den letzten Jahrzehnten sehr klein geworden,

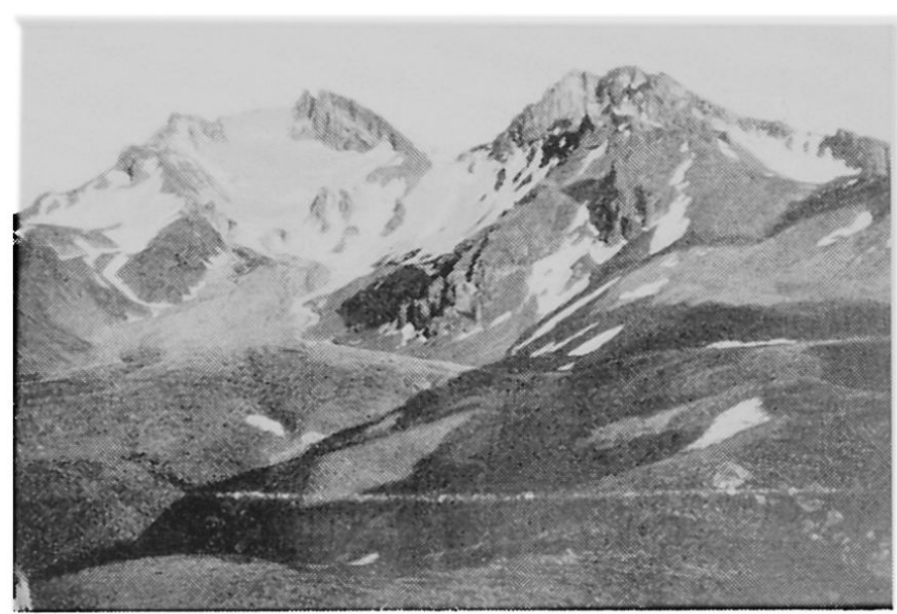

Abb. 3 Photo Penther 20. Juli 1902. Der rezente Gletscher setzt noch auf dem höchsten Gipfelkamm ein. In der Karmulde links außen der Blockgletscher mit der Doppelzunge. 
oder es existiert möglicherweise überhaupt nicht mehr. Das heißt: Die strenge Abhängigkeit vom Klima wird durch Schneeanhäufungen und Lawinen ersetzt. Wir sollten also nicht mehr von einem Nährgebiet, sondern von einem Regenerationsgebiet sprechen. Diese Überlegungen zielen dahin, daß wir uns von der Existenz dieser letzten Gletscher nicht allzu sehr beeindrucken lassen und aus diesen lokalbedingten Eismassen nicht auf eine allzu tiefe rezente Schneegrenze schließen. Wir schätzen sie auf $3650 \mathrm{~m}$. (Ausführliche Diskussion in Lit. 203).

\subsubsection{Die regional gültige Schneegrenze}

Weitere Firn- oder Eisfelder finden wir auf der Nordseite in mehreren Karmulden, aber immer in Verbindung mit Blockgletschern. In der Wurzelzone dieser bewegten Blockmassen liegen vielfach kleine Firnfelder, die allmählich in blankes Gletschereis übergehen (Abb. 11, 12). Alle dieseVorkommen haben wir auf der Vergletscherungskarte (Fig. 1) eingetragen, sie liegen in $W$-, $N$ - und E-Exposition. Es wäre aber falsch, diese Blockgletscher mit einer rezenten Schneegrenze in Beziehung zu setzen. Die kleinen Firnfelder unmittelbar am Fuß der Karwände ernähren sich aus Schneeanhäufungen und Schneerutschungen; die Eiskörper unter dem Blockschutt bleiben über lange Zeiträume hinweg vor Ablation geschützt. Aus den ersten photographischen und kartographischen Aufnahmen zu Beginn unseres Jahrhunderts ersehen wir, daß die Blockgletscher schon damals in den heutigen Ausmaßen existierten (11 und 267, Abb. 2 und 3). Eine Entstehung erst in der Vorstoßphase 1850 kommt nicht in Frage, da für die Bereitstellung und den Transport der gewaltigen Schuttkubaturen die kurze Zeitspanne nicht genügte. Wir kommen bei der Besprechung der Blockgletscher und der postglazialen Verwitterung nochmals auf solche Datierungsfragen zurück. Eines aber ist sicher: Wir dürfen die schuttbedeckten Eismassen nicht mit den heutigen Klimabedingungen in einen direkten Zusammenhang bringen.

Diese Úberlegung bestätigt sich übrigens bei einer Untersuchung der Karwände. Weder Firn noch Eis, höchstens einige perennierende Schneeflecken stellen wir unterhalb $3800 \mathrm{~m}$ fest, abgesehen von den erwähnten Eisbildungen in der Wurzelzone der Blockgletscher. Betrachten wir schließlich das NE$\mathrm{Kar}$, so gewahren wir in günstigen Hochsommern nur zwei perennierende Firn- oder Schneeflecken auf ca. $3800 \mathrm{~m}$ Höhe, obschon die allgemeine Exposition eine genau gleiche klimatische Begünstigung wie in der NW- oder E-Talung ergeben sollte (Abb. 6). Gesamthaft gesehen ist der heutige Gletscher mit seiner lokal tiefen Schneegrenze keineswegs für die ganze $\mathrm{N}$-Seite repräsentativ. Die mitt- lere Schneegrenze der gesamten Schattseite muß zweifellos noch etwas höher sein als der übermäßig lokal begünstigte Wert von $3650 \mathrm{~m}$ im NW-Kar; wir schätzen sie auf ca. $3800 \mathrm{~m}$.

Das schwierigste Problem ist die Bestimmung der sonnseitigen Schneegrenze, die nirgends im mediterran-subtropischen Raum an einem realen Gletscher ermittelt werden kann. Es wäre aber nicht richtig, als Analogieschluß die eiszeitliche Differenz zwischen $\mathrm{N}$ - und S-Seite zu übernehmen; die Gründe haben wir an anderer Stelle diskutiert (203). Es bleibt uns nichts anderes übrig, als neben einer allgemeinen geomorphologischen und klimatischen Beurteilung die Erfahrungswerte aus den höheren Gebirgen Hochasiens zu übernehmen. Die $400 \mathrm{~m}$ von Wissmann (359) scheinen uns ein minimaler Wert zu sein, eher vermuten wir am Erciyas eine Schneegrenzdifferenz von $500 \mathrm{~m}$, die in einer ähnlichen geographischen Breite auch am Hindukusch ermittelt wurde (233). Betrachten wir die Südseite des Erciyas, so stellen wir ein Verschwinden der letzten Schneereste im Spätsommer fest. Auch an den morphologischen Gunstorten des Gipfelraumes ist nicht der geringste Hinweis auf eine nahe Schneegrenze zu finden, sie muß bedeutend über dem Gipfelniveau liegen (Abb. 7, 8, 10). 400-500 m höher als auf der Schattseite ergibt einen sonnseitigen Wert von 4200-4300 m.

Wenn wir schließlich im Mittel eine rezente Schneegrenze von $4000 \mathrm{~m}$ bestimmen, so ist dieser regional gültige Wert kaum zu hoch gegriffen. Er entspricht der heutigen klimatischen Situation in Zentralanatolien. Wir werden auf Seite 192 das Problem der Expositionsdifferenzen zusammengefaßt nochmals diskutieren.

\subsection{Die würmeiszeitliche Vergletscherung und ihre Schneegrenze}

Unsere Feldaufnahmen sind auf der Vergletscherungskarte (Fig. 1) eingetragen. Wir müssen aber die Kartierungsschwierigkeiten besonders erwähnen, weil alle unsere Höhen- und Ortsangaben durch die soeben aufgenommenen Karten 1:25000 beträchtliche Korrekturen erfahren dürften. Vorläufig sind diese wertvollen Blätter militärisch streng geheim und selbst für wissenschaftliche Zwecke unmöglich zu erhalten. Wir rechnen damit, daß einzelne unserer Höhenangaben, basierend auf den bis heute verfügbaren Karten (vgl. 205) und eigenen Messungen bis zu maximal $100 \mathrm{~m}$ korrigiert werden könnten, was für den Gang und den Sinn unserer Arbeit eine erschreckende Fehlergröße bedeutet. Aus diesem Grunde müssen wir die 5 Großkare im eigentlichen Gipfelbereich, 3 auf der Schattseite (E, NE und NW) und 2 auf der Sonnseite (SW und $S)$, ganz besonders hervorheben. Es sind die mar- 


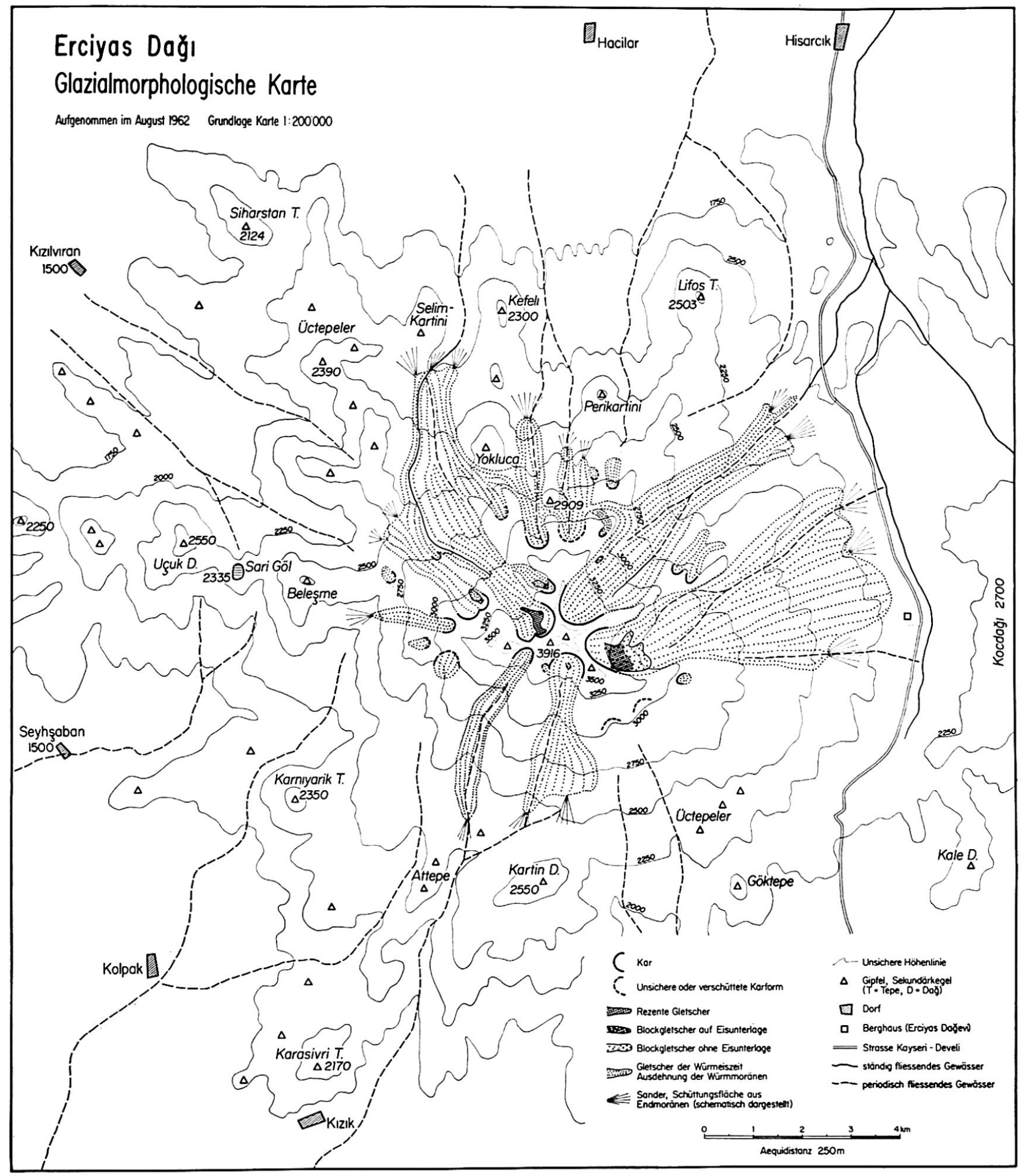

Fig. 1 Erciyas Dagh Vergletscherungskarte

kanten Orientierungspunkte in Anbetracht der mangelhaften Karte und der Vielzahl und Vielfalt der Karformen, die sich orts- und höhenmäßig nur ungenau lokalisieren lassen.

Für eine wissenschaftlich einwandfreie Feldaufnahme ergaben sich aber noch andere Schwierigkeiten: Wir glaubten anfänglich, mit der Schotteranalyse die verschiedenen Ablagerungsformen zu erfassen. Aber das vulkanische Material ist so fein differenziert, daß wir es makroskopisch vielfach nicht be- stimmen konnten, und die notwendige Beschränkung auf einen Gesteinstyp zur Unmöglichkeit wurde. Dazu zeigen zahlreiche Ergußgesteine eine bestimmte Zurundung als Verwitterungseffekt, und schließlich war eine nachträgliche Aufsplitterung in kantige oder plattige Formen so weit verbreitet, daß eine morphometrische Auszählung endgültig scheitern mußte. Mit Sicherheit ließen sich nur gewisse Größenunterschiede, Materialsortierungen, Lagerungsverhältnisse und ein allgemeiner Zurun- 
dungszustand feststellen und interpretieren. Eine wissenschaftlich-statistische Aufnahme fehlte aber, und das vermißten wir besonders in den kritischen Ubergangszonen und vor allem bei der Beurteilung der eiszeitlichen Ablagerungen in den tiefgelegenen Gehängenischen, die gerade für die Bestimmung der Schneegrenze von größter Bedeutung waren.

Im folgenden besprechen wir ganz kurz im Rundgang die einzelnen eiszeitlichen Gletscher des Erciyas; wir beginnen auf der Ostseite, durchqueren die Nordabdachung und drehen über die Westexposition zum Schluß auf die Südseite.

\subsubsection{Die einzelnen wïrmeiszeitlichen Gletscher} (Fig. 1)

\section{Der Ostgletscher (Abb. 4 und 11)}

Gegen Osten öffnet sich das größte Kar des Erciyas mit einer Weite von ca. $700 \mathrm{~m}$. Unter dem Gipfel setzt der eiszeitliche Gletscher ein und bedeckt die tiefe Karmulde mit bedeutender Mächtigkeit. Nach dem Verlassen der seitlich begrenzenden Karwände floß die Eismasse über dem offenen Vulkansockel fächerförmig auseinander, eine gewaltige Deponie bis in die Tekir-Talung auf 2150 bis $2250 \mathrm{~m}$ ausbreitend. Bartsch hat dieses $5 \mathrm{~km}$ lange Moränenfeld, in dem sich unzählige Wall- und Hügelformen folgen, bereits beschrieben (11). Nach unserer Meinung entstand dieser Formenschatz durch blockstromartige, partielle Massenbewegungen unmittelbar nach dem Gletscherrückgang. Der genau gleiche Prozeß spielt sich heute innerhalb des Kares $\mathrm{ab}$, wir werden auf diese Probleme zurückkommen.

Die breiten Moränenfelder enden vielfach in einem Steilrand. Darunter beginnen die Sanderfelder mit einem maximalen Böschungswinkel von $7^{\circ}$, der sich bis zur Tekir-Talung langsam ausflacht (Abb. 4). Die Schüttungsrichtung kann an einigen Orten mit einer Durchbruchstelle im Moränenrand in Zusammenhang gebracht werden. Sanderstruktur und Schüttungsrichtung sind aber nicht einfach zu bestimmen, weil diese Flächen heute stark verschwemmt, von Vegetation überzogen, von Verwitterungsschutt bedeckt und teilweise von letzten Lockermaterialeruptionen überschüttet sind (205). Zusammengefaßt hat sich aus dem größten Kar auch der größte eiszeitliche Gletscher des Erciyas entwickelt, der eine Länge von 5-6 km erreichte und eine Fläche von mindestens $10 \mathrm{~km}^{2}$ bedeckte, wobei die gewaltige Kubatur der transportierten und abgelagerten Schuttmassen jedem Beobachter zu denken geben muß.

\section{Kleinkare zwischen E- und NE-Gletscher (Abb. 5)}

Zwei kleine Kare liegen weit vorgestaffelt zwischen den beiden großen Eisströmen, das östliche auf ca.

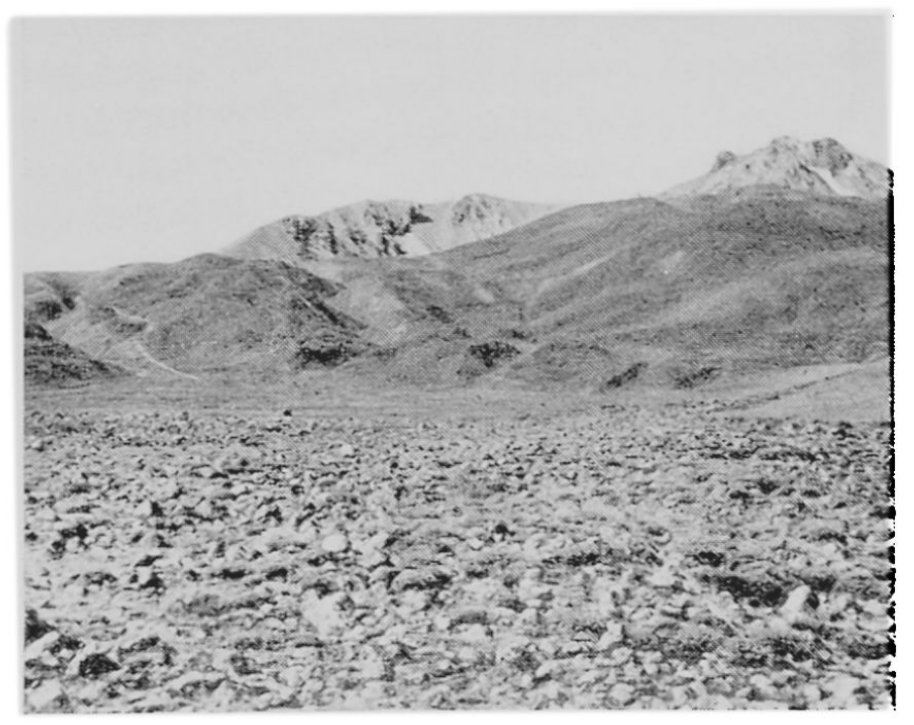

Abb. 4 Rechts hinten der Gipfel des Erciyas Dagh, der nach links in den Ostgrat übergeht, dazwischen das große Ostkar. Im Mittelgrund der linken Bildhälfte die Moränenhügel des Ostgletschers. Im Vordergrund die würmeiszeitliche Sanderfläche.

2900 m, das westliche auf ca. 2800 m. Die Karnischen sind wenig deutlich ausgeformt und zum Teil stark verschüttet. Aber es kann eindeutig nachgewiesen werden, daß in diesen Formen zwei kleine Gletscher entstanden, die sich in ihrem Lauf vereinigten und auf 2600-2700 $\mathrm{m}$ wieder in zwei Zungen auflösten (Länge etwas mehr als $1 \mathrm{~km}$ ). Möglicherweise kam es sogar zu einem Zusammenfluß mit dem großen NE-Gletscher.

\section{Der NE-Gletscher (Abb. 6)}

Der Gletscherlauf wird durch zwei seitliche Höhenzüge eingerahmt. Es wäre aber falsch, diese als Seitenmoränen zu bezeichnen, obschon ihre Höhe vom Würmgletscher erreicht und überschüttet worden ist. Wir erkennen ganz deutlich die anstehenden Gesteine, die strukturbedingt mit den auslaufenden seitlichen Karwänden in Zusammenhang stehen. Die glaziale Erosion hat sich hier gewissen tektonischen Gegebenheiten angepaßt; es ist im Unterschied zur E-Seite ein richtiger Talgletscher entstanden. Wie weit im oberen Teil der Talung gelegene Längsmoränen als Rückzugsphasen zu bezeichnen sind (11, S. 121), ist nicht eindeutig zu entscheiden. In tieferen Lagen geht die Moränendecke, die sich wiederum durch eine gewaltige Materialmasse auszeichnet, in die üblichen ungeordneten Hügel- und Wallformen über. Ein besonderes Problem bildet die Festlegung des Gletscherendes in der Nähe der Paßstraße. Links des Baches läßt sich ein Moränenzug bis auf $2050 \mathrm{~m}$ verfolgen, der in der Größe, Zurundung und Sortierung des Materials deutlich von den fluvial transportierten und sanderartig abgelegten Komponenten zu unterscheiden ist. Im ge- 
samten erhalten wir eine Gletscherlänge von ca. 6,5 $\mathrm{km}$, etwas mehr als der E- und NW-Gletscher, obschon sein Einzugsgebiet viel kleiner ist. Die seitlich begrenzenden Höhenzüge verhinderten ein fächerförmiges Auseinanderfließen, und durch diese Konzentration in der Fließrichtung entstand der längste Gletscher des Erciyas.

\section{Die Kare zwischen NE- und NW-Gletscher}

Dieser Raum ist besonders schwierig zu besprechen, weil die bis heute verfügbaren Karten weder eine Orientierung noch eine Eintragung ermöglichen. Wir unterscheiden zwei größere Gletscher. Der erste bildete sich östlich P. 2909 und endete in mehreren Zungen zwischen 2350 und $2500 \mathrm{~m}$. Der zweite wurzelte in einem höher gelegenen Kar westlich $P$. 2909 und wurde in seinem Mittellauf durch den Sekundärkegel Yokluca in zwei Arme aufgeteilt. Der linke Teil ergoß sich in den großen NW-Eisstrom, eine auffällig mächtige Seitenmoräne bildend. Der rechte endete auf ca. $2200 \mathrm{~m}$, wobei Gefällsknick, Material- und Farbwechsel den Übergang zum Sander anzeigen. Dieser wiederum verliert sich in einer tertiären oder altquartären, gut geschichteten Akkumulationsmasse, die sich durch tiefe Erosionsrinnen auszeichnet. Zahlreiche Datierungsfragen werden in Zukunft hier zu lösen sein (205; Gebiet der Abb. 1 und 9).

Besonders interessant sind die tiefgelegenen Glazialbildungen in diesem Raum. Südlich des Perikartini finden wir ein Kar auf 2750 m, aus dem nordwärts ein kleiner Gletscher ausströmte. Unmittelbar westlich daneben ist eine winzige karähnliche Mulde noch auf $2700 \mathrm{~m}$ anzutreffen, die ebenfalls eine eigene Firn- oder Eismasse hervorbrachte, wie die Ablagerungen eindeutig beweisen. Ja, wir haben zwischen Perikartini und Yokluca sogar Nivationsformen auf $2350 \mathrm{~m}$ gefunden. Selbst wenn wir diese letzten Erscheinungen ausschließen, so ergeben sich gerade in diesem Raum klare Beweise für eine erstaunlich tiefe nordseitige Schneegrenze. Betrachten wir den gesamten Abschnitt auf der Vergletscherungskarte, so fallen uns vor allem die Transfluenzen auf. Der Vulkanhang wurde durch zahlreiche Parasitärkegel durchbrochen, so daß zwischen ihnen je nach Gefällsverhältnissen ein Eisstromnetz in kleinster Form entstand.

\section{Der NW-Gletscher (Abb. 2)}

Auch dieser Gletscher war durch seitliche Höhenzüge klar begrenzt. Verlassen wir die Stirnwälle der rezenten Hochstände, so betreten wir ein weites Sanderfeld, das wohl vom Spätglazial bis zum Beginn unseres Jahrhunderts periodisch immer wieder überschüttet wurde. Unmittelbar darunter beginnen die spät- bis postglazial eingetieften Erosionsrinnen, die in den unteren Partien sogar das anstehende Ge-

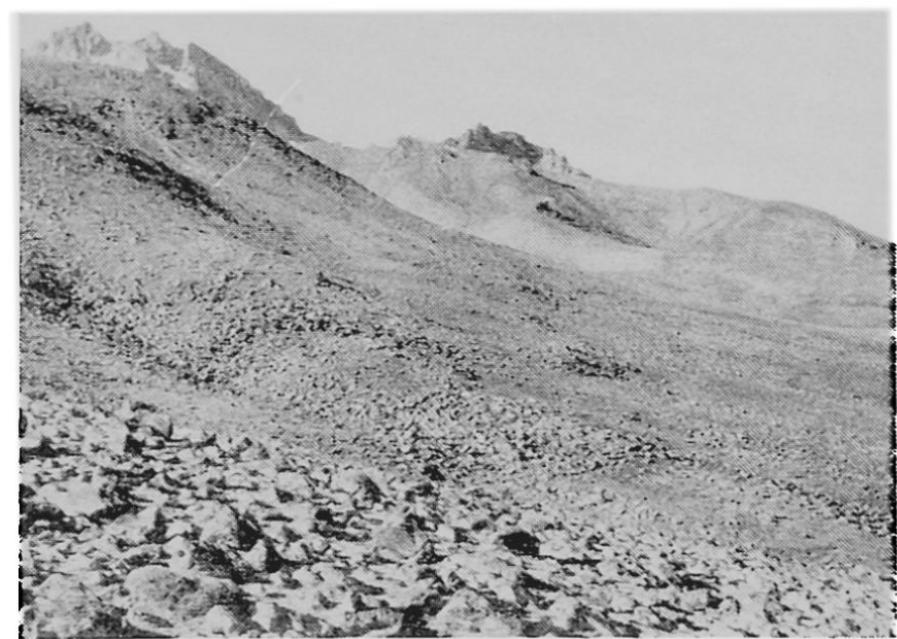

Abb. 5 Karformen im Vulkansockel zwischen NEund E-Gletscher auf 2800-2900 m. Die glaziale Ausformung ist bescheiden, doch sind diese Nischen interessante Zeugen einer relativ niedrigen eiszeitlichen Schneegrenze. Im Vordergrund periglaziale Schuttzungen.

stein freilegen. Die würmeiszeitliche Gletscherzunge löste sich vor der Blocklava des Selimkartini auf, und der Sander umspülte diese Ausbruchsmasse. Deutlich steigen vom Yokluca her die Seitenmoränen des zuströmenden Gletschers ab, währenddem ein Zufluß des Westgletschers in der Morphologie weniger deutlich in Erscheinung tritt. Die Gletscherlänge dürfte ca. $6 \mathrm{~km}$ betragen haben, die Endlage

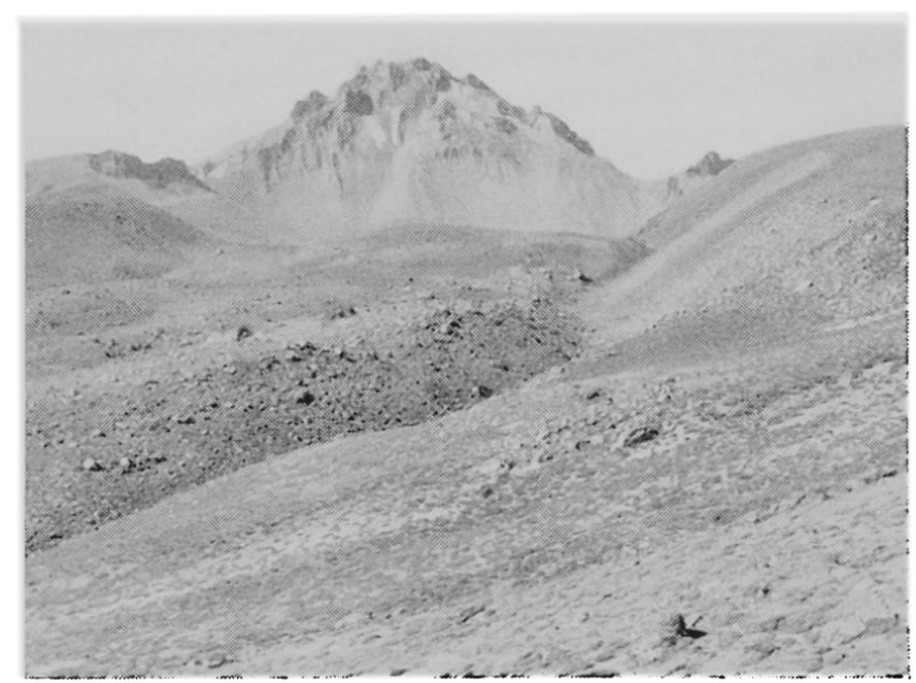

Abb. 6 Der große NE-Gletscher. In der Karwand zwei perennierende Firnfleoken auf ca. $3800 \mathrm{~m}$. Die Schutthalden steigen bis ca. $3500 \mathrm{~m}$ auf und haben den Karboden vollständig überschüttet. Einziges Kar der Nordseite ohne Blockgletscher. Die abgelagerten Moränen sind hügelig und zum größten Teil ungeordnet. Die seitlichen Höhenrücken sind alte Verebnungsflächen, die aber vom würmeiszeitlichen Gletscher randlich überschüttet wurden. 
geben wir mit 2000 bis $2100 \mathrm{~m}$ an. Neben der Unsicherheit der Karte kann der tiefste Punkt der Gletscherzunge auch materialmäßig nicht genau fixiert werden, weil rezente Erosion und Akkumulation eine Ubergangszone geschaffen haben, in der sich die letzten Moränenkomponenten in weiter Streuung verlieren. Sicher aber ist das Gletscherende von Bartsch mit $2300 \mathrm{~m}$ zu hoch angegeben. Im Zungenbereich schließt wieder eine Sanderfläche an, die bei der Wasserfassung und der Yayla beginnt und sich mit ca. $4^{\circ}$ Neigung bis zum Engpaß zwischen Selimkartini und Kefeli absenkt, wo grundsätzlich neue Erosions- und Akkumulationsverhältnisse entstehen.

\section{Die Kare auf der Westseite}

Nach WNW öffnet sich im Kaya Tepesi, dem Westgipfel des Erciyas, ein großes Kar auf 3100_ $3200 \mathrm{~m}$. Aus ihm floß ein Gletscher, der sich im Vorland rasch verfächerte und im östlichen Teil in den NW-Strom einmündete. Die Gletscherlänge betrug wenig mehr als $2,5 \mathrm{~km}$, die breite Front endete durchschnittlich auf $2500 \mathrm{~m}$. Sehr interessant ist eine weit nach vorn abgesetzte Hohlform östlich des Belesme, deren Boden auf ca. $2650 \mathrm{~m}$ liegt und einen eigenen kleinen Gletscher hervorgebracht hat. Damit ist ein Argument von Bartsch in Frage gestellt, daß der unvergletscherte Belesme $(2750 \mathrm{~m})$ eine darüberliegende Schneegrenze anzeige. Wir werden auf dieses Problem zurückkommen. Im übrigen finden wir westlich des Belesme den Bergsee Sari Göl, der aber mit einer glazialen Entstehung nichts zu tun hat (205).

In genauer Westrichtung bildete sich ein $2 \mathrm{~km}$ langer Gletscher, seine Zunge lag auf $2450 \mathrm{~m}$. Schließlich treffen wir auch in SW-Exposition auf 2900 und $3000 \mathrm{~m}$ Karnischen an, die ebenfalls kleine Eismassen beherbergten. Ihre kartographische Darstellung ist problematisch, aber ihre Bedeutung für die Schneegrenze der Südseite höchst wichtig.

\section{Der westliche Südgletscher (Abb. 7)}

Die Eintiefung zwischen dem Hauptgipfel und dem westlichen Vorgipfel des Kaya Tepesi bildete ein ideales Einzugsgebiet für einen eiszeitlichen Gletscher. Eng begrenzt durch absteigende Felsrippen, die auf dem Vulkansockel in breite Hochrücken auslaufen, blieb das Gletscherbett relativ schmal, steil und im oberen Teil gut geschützt. Ganz ähnlich wie beim NE-Gletscher wurde der Bewegungsablauf konzentriert, die Stoßkraft erhöht und dementsprechend die Endlage tief. Die Gletscherlänge betrug weniger als $4 \mathrm{~km}$; aber die Zunge lag auf 2300 Meter in einer Mulde zwischen Parasitärkegeln im Raum Attepe und Kartin Dagh. Die längsgerichteten Moränenzüge, die langsam im Sander ertrinken, gehören zu den besterhaltenen Glazialformen im

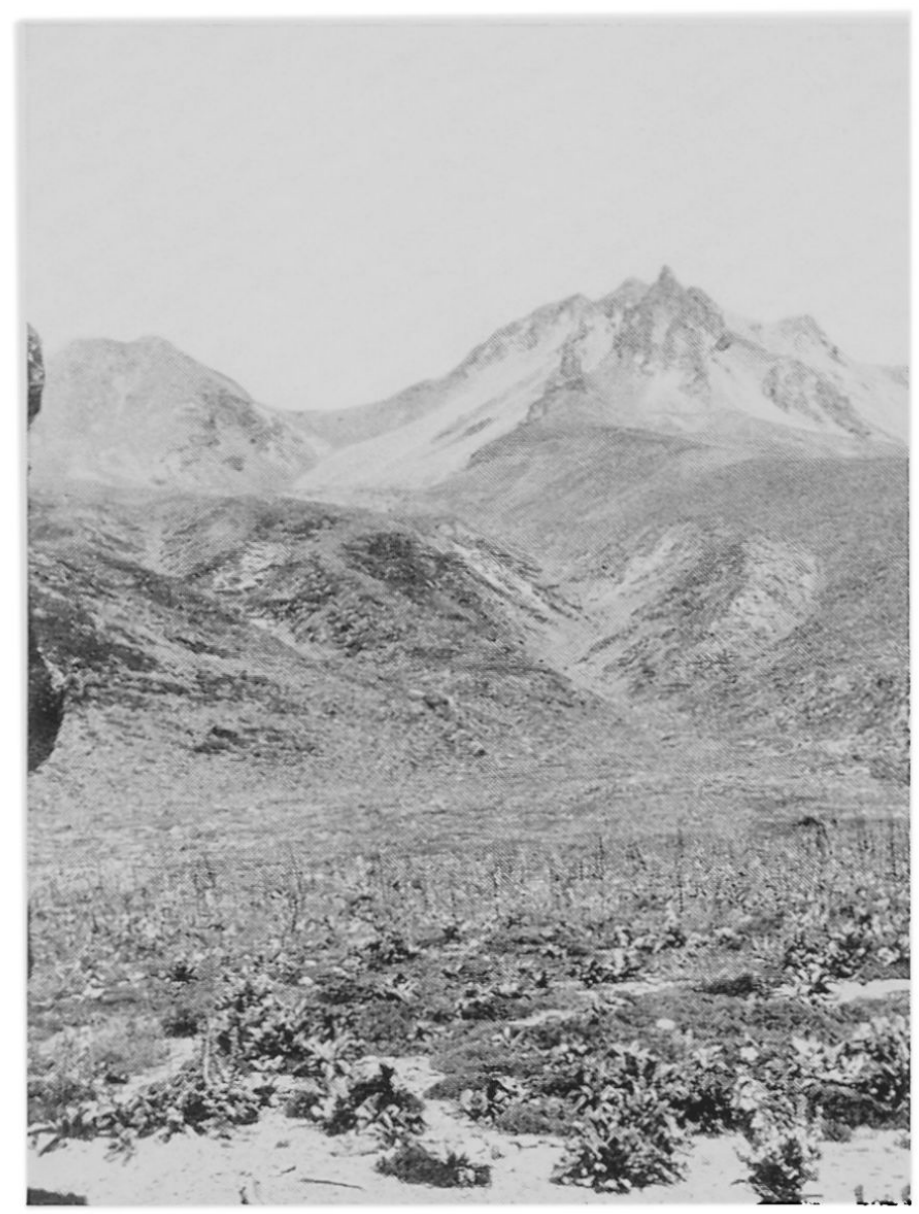

Abb. 7 Der westliche Südgletscher. Einzugsgebiet in der strukturbedingten, heute von postglazialem Verwitterungsschutt überdeckten Karmulde zwischen Kaya Tepesi (links) und Erciyas Hauptgipfel (rechts). Im Mittelgrund die auslaufenden, längsgerichteten Moränenzüge, die in der Sanderfläche enden (Vordergrund).

würmeiszeitlichen Bereich des Erciyas. Eindrücklich ist vor allem die tiefe Endlage auf der Südseite, und erstaunlich ist die Tatsache, daß dieser Gletscher von den bisherigen Autoren überhaupt nicht erwähnt oder kartiert wurde $(11,17,147)$.

\section{Der große Sïdgletscher (Abb. 8)}

Zwischen dem Hauptgipfel und dem Ostgrat ist das große Südkar eingebuchtet, von Verwitterungsmaterial völlig zugeschüttet. Die Austrittstellen des Gletschers lassen sich dank den mächtigen glazialen Ablagerungen deutlich rekonstruieren. Wie beim Ostgletscher floß auch diese Eismasse auf dem offenen Hang wie ein Fladen auseinander und endete in einer breiten Front auf $2500 \mathrm{~m}$. Die anschließende Sanderfläche ist durch ihre helle Farbe gut erkennbar. Am rechten Gletscherrand stieß eine Zunge in günstigen Gefällsverhältnissen auf eine tiefere Geländestufe vor und endete auf $2400 \mathrm{~m}$.

Der gesamte Raum nördlich und östlich des Kartin Dagh dürfte bei künftiger genauerer Kartierungsmöglichkeit und besserer Materialkenntnis zu einer 
Schlüsselstelle werden. Der würmeiszeitliche «Outwash" ist an der Blocklava des Kartin Dagh aufgestoßen und gut erhalten. Unmittelbar westlich davon erfolgten rezente Erosions- und Akkumulationsvorgänge, und östlich davon sind in tiefen Rinnen ältere Schüttungshorizonte aufgeschlossen, die vorläufig noch nicht geklärt und datiert sind. Das Zusammenspiel all dieser Phasen muß noch offen bleiben, aber die Frage nach einer älteren Eiszeit wird hier gestellt.

\section{Kleine Kare auf der Südseite (Abb. 10)}

Im ganzen gesehen weckt die Südseite den Eindruck, als ob hier überhaupt keine Vergletscherung möglich gewesen sei. Aber die auf beiden Gebirgsseiten seit dem Hochglazial verschieden ablaufenden Verwitterungs- und Abtragungsvorgänge täuschen uns ein falsches Bild vor. Mehrere kleine Karnischen sind erhalten, zum Beispiel auf $2900 \mathrm{~m}$ im SE. Wir fragen uns aber, ob nicht noch mehr karähnliche Mulden oder Nivationsformen vorhanden waren, die heute weitgehend zugeschüttet sind. Zum Beispiel zeigt Abb. 10 ganz deutlich eine Einbuchtung im Hang, darüber die wenigen noch anstehenden Felsbänder und darunter die versteilte Rückwand einer Hohlform, aus der ein Schuttstrom ausgeflossen ist. Wenn wir die spät- bis postglaziale $\mathrm{Zu}$ schüttung der Großkare (SW, S, NE) bedenken, dann müssen wir uns ernsthaft fragen, ob nicht zur Eiszeit noch mehr Hohlformen als Zeugen einer glazialen Formbildung und als Beweise einer südseitig relativ tiefen Schneegrenze freilagen.

\subsubsection{Die würmeiszeitliche Schneegrenze}

Wie schon bei der Bestimmung der rezenten Schneegrenze stellt sich auch hier die Frage, welche Methoden anzuwenden sind (Seite 188). Bartsch entschied sich für die Partsch-Brücknersche Gipfelmethode $(11$, S. 122). Dieses Vorgehen ist aber in einem vulkanischen Gebiet nicht sehr glücklich. Die Gipfel in der kritischen Höhenzone, die für eine Vergletscherung in Frage kommen, sind durchwegs Parasitärkegel. Diese regelmäßigen Formen eignen sich für Schneeansammlungen und Eisbildungen sehr schlecht. Ganz anders das Massiv des $2700 \mathrm{~m}$ hohen Koçdagh (östlich der Tekir-Straße), das unvergletschert blieb und auf eine würmzeitliche Schneegrenze mindestens auf dieser Höhe hinweist.

Wenden wir die meistbenutzte Methode Höfers an, der die Schneegrenze aus dem arithmetischen Mittel zwischen der mittleren Höhe des Kammes, welcher das Nährgebiet des Gletschers begrenzt (in unserem Falle ca. $3800 \mathrm{~m}$ ), und der Höhe des Gletscherendes bestimmt. Am Erciyas enden die Gletscher auf der Nordseite zwischen 2000 und 2200 m, auf der Süd-

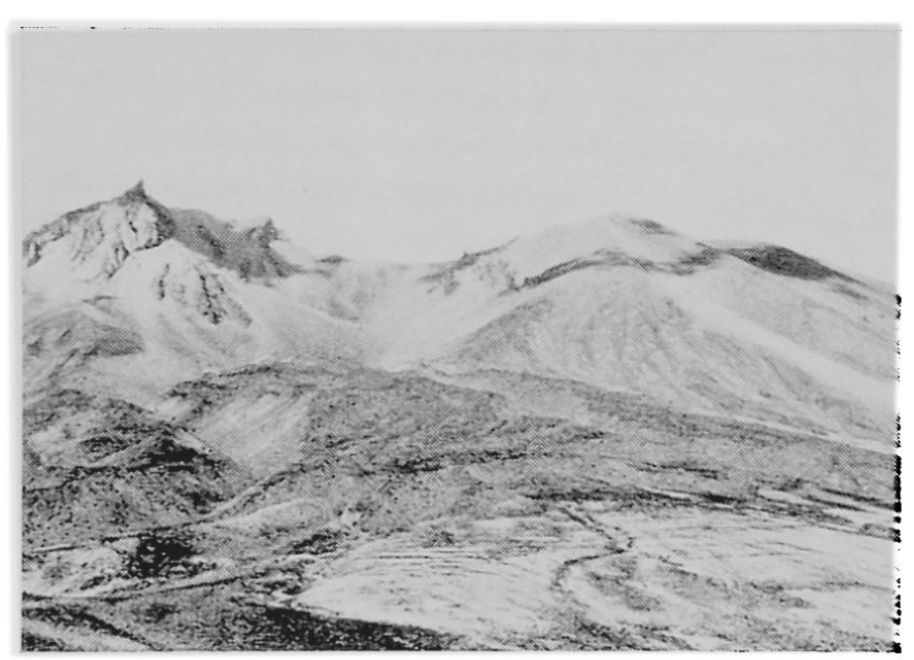

Abb. 8 Der große Südgletscher. Das Kar ist zwischen Erciyas-Hauptgipfel (links) und dem Ostgrat (rechts) eingebuchtet, heute durch die intensive spätbis postglaziale Verwitterung zugeschüttet. Auf dem Vulkansockel fächern die glazialen Ablagerungen breit auseinander und gehen an ihrem Ende in eine deutlich sichtbare, helle Sanderfläche über (2500 $\mathrm{m})$. Links ein Moränenzug, der seitlich eine tiefere Geländestufe erreicht $(2400 \mathrm{~m})$.

seite zwischen 2300 und $2500 \mathrm{~m}$, das ergibt eine mittlere Differenz zwischen Sonn- und Schattseite von $300 \mathrm{~m}$. Für die Schneegrenze der Nordseite erhalten wir somit $2900-3000 \mathrm{~m}$, für die Südseite 3050-3150 m.

Aber auch dieses Ergebnis müssen wir in Frage stellen, weil Kleinkare unterhalb dieser berechneten Schneegrenze selbständige Gletscher entwickelt haben. Es sind zwar eher Hohlformen, wir dürfen kaum von Karformen sprechen. Sie befinden sich aber in keiner besonderen Gunstlage, ihre Höhe beträgt auf der Nordseite $2700 \mathrm{~m}$, auf der Westseite sogar $2650 \mathrm{~m}$ und auf der Südseite $2950-3000 \mathrm{~m}$. Zwischen Schatt- und Sonnseite ergeben sich wiederum Differenzen von ca. $300 \mathrm{~m}$. Diese Formen zeugen eindeutig dafür, daß die klimatischen Bedingungen zur Gletscherbildung auf ihrer Höhe erfüllt waren. Mit den vorsichtigeren Werten gerechnet, muß die Schneegrenze der letzten Eiszeit auf der Nordseite in $2700 \mathrm{~m}$, auf der Südseite in $3000 \mathrm{~m}$ gelegen haben.

Diese Widersprüche in der Schneegrenzbestimmung führen uns zu einer wesentlichen Aussage. Ein alpiner Talgletscher ist seitlich begrenzt und durch die Eintiefung vor allzu intensiver Strahlung geschützt; Eismächtigkeit und Gefälle geben ihm eine bestimmte, gerichtete Fließkraft und eine relativ niedrige Endlage. Die Gletscherbildung an offenen Hängen, geradezu typisch an einem regelmäßigen Vulkankegel, muß mit ganz andern Bedingungen rechnen. Nach dem Verlassen der schützenden Gipfelkare fließt der Gletscher fächerförmig auseinan- 
der, verliert seine gerichtete Fließkraft und schmilzt unterhalb der Schneegrenze rasch aus. Die Schneegrenze kann in den sich nach unten gewaltig verbreiternden Eiskuchen keineswegs in der Mitte zwischen Umrahmung des Nährgebietes und dem Gletscherende liegen. Den Beweis dafür liefern uns ganz eindeutig die tiefsten Kleinkare mit den schwachen, aber sicheren Gletscherbildungen. Wenn wir die Schneegrenze für die letzte Eiszeit nordseitig auf $2700 \mathrm{~m}$, südseitig auf $3000 \mathrm{~m}$, im Mittel auf $2850 \mathrm{~m}$ festlegen, so sind diese Werte eher vorsichtig formuliert und dürften vielleicht in Zukunft bei genaueren topographischen Aufnahmemöglichkeiten geringe Tiefenkorrekturen erfahren.

\subsection{Spuren einer älteren Vergletscherung (Abb. 9)}

Verschiedene, zum Teil aber noch unsichere Indizien deuten auf eine ältere Kaltzeit hin, die zweifellos unserer Rißeiszeit entspricht.

Auf der Nordseite, besonders beidseits des Nordosttales, sind breite Hochrücken erhalten, die über dem sichtbar anstehenden Gestein außerhalb des Würmbereiches eine Streu von auffällig gerundetem Material tragen. Die Zurundung an wenig widerstandsfähigem vulkanischem Gestein läßt aber keinen eindeutigen Schluß zu. Immerhin haben die Würmgletscher die schwachen Taleintiefungen vollständig aufgefüllt und die Randhöhe teilweise überschritten, so daß eine umfassendere Eisbedeckung des höheren Vulkansockels durch eine ausgedehntere Eiszeit ohne weiteres möglich wäre.

In den Ablagerungsräumen unterhalb der würmeiszeitlichen Endmoränen finden wir an zahlreichen Stellen Indizien einer älteren Vereisung. Auf der Südseite sind in rezent eingetieften Rinnen schwach geschichtete und mit groben Blöoken durchsetzte Horizonte aufgeschlossen. Sind hier torrentielle Abtragungsvorgänge im Spiel, oder liegen ältere glaziale Ablagerungen vor? Wir wissen noch zu wenig genau, wie der Vulkan in dieser Zeit ausgesehen und was für Material er gefördert hat. Gleichen Problemen begegnen wir in der Tekir-Ebene, wo beim Bau des neuen Berghauses vieldeutige, aber infolge der geringen Tiefe nicht eindeutige Aufschlüsse freigelegt wurden.

Die überzeugendsten Formen befinden sich in der Talung zwischen Perikartini und Kefeli, unmittelbar nordwestlich des Perikartini, auf einer Höhe von ca. $1900 \mathrm{~m}$. Auf dem vorwiegend tertiären Ablagerungsmaterial fällt eine lokal begrenzte Blockstreu auf; die größten Exemplare haben eine Kubatur von über $100 \mathrm{~m}^{3}$ (Abb. 9). Weder Sturz noch fluvialer oder solifluidaler Transport sind möglich, eine glaziale Umlagerung rückt als Erklärung in den Vordergrund. Wir befinden uns ca. $2 \mathrm{~km}$ vom würmeiszeitlichen Gletscherende entfernt, der Hö-

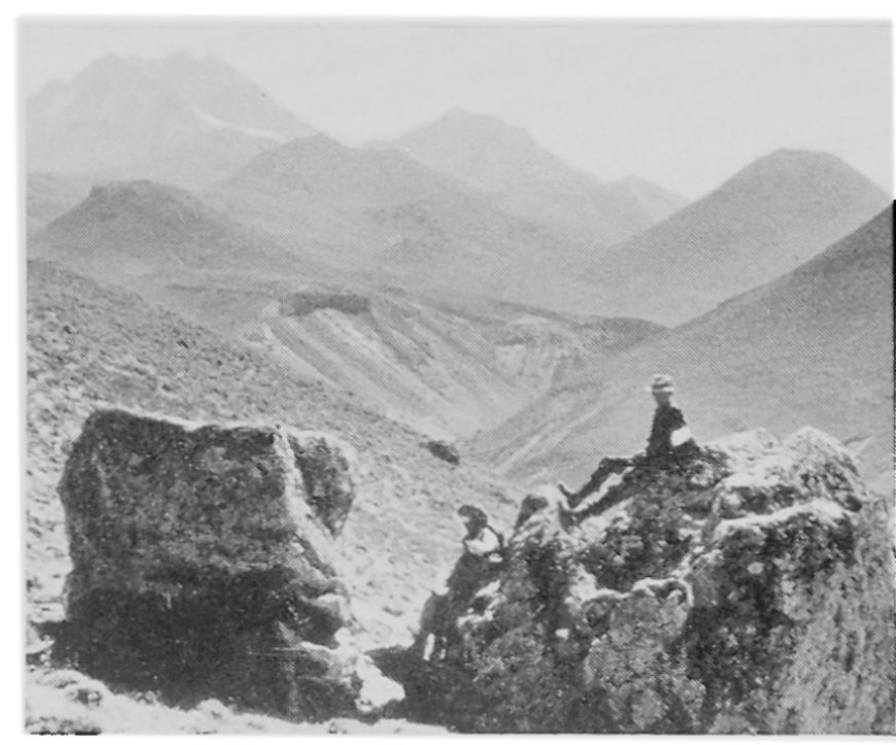

Abb. 9 Großblöcke eines fremden Materials nordwestlich Perikartini auf ca. 1900 m Höhe. Rechts der Abhang des Sekundärvulkans Kefeli, in der Mitte eine Erosionsrinne im tertiären Aufschüttungsmaterial. Die Blöcke sind sehr wahrscheinlich Relikte einer älteren und ausgedehnteren Eiszeit (Riß).

henunterschied beträgt $300 \mathrm{~m}$. Diese Distanz- und Höhendifferenz gegenüber der letzten Eiszeit ist ohne weiteres denkbar; ähnliche Werte ergeben sich in der Sierra Nevada (204) und aus der Arbeit Spreitzers im Ala Dagh (324). Die Schneegrenze der Rißeiszeit mußte ca. $200 \mathrm{~m}$ tiefer liegen als in der Würmeiszeit. Wir erwähnen schließlich auch noch die Ergebnisse von Bartsch (11), der aus der Dreigliederung der fluviatilen Terrassen in der TekirEbene auf die Abfolge mehrerer Kaltzeiten geschlossen hat.

Alle diese Aussagen verlangen aber, daß der Erciyas seit der Rißeiszeit keine großen Höhenveränderungen erfahren hat, was durch die nachgewiesenen jüngeren Eruptionen fraglich ist. Diese Probleme haben wir an anderer Stelle diskutiert (205). Sie sind bis heute nicht eindeutig gelöst und verlangen in Zukunft noch genauere Untersuchungen und Datierungen.

\subsection{Verwitterung und Blockgletscher}

\subsubsection{Verwitterung und Hangasymmetrie}

(Abb. 10, 11)

Die gewaltigen Massen der glazialen Ablagerungen sind am Erciyas beeindruckend. Die petrographischen und klimatischen Bedingungen für eine rasche Auflockerung und Abtragung müssen vor und während bestimmter Phasen der letzten Kaltzeit äußerst günstig gewesen sein. Aber auch seit dem ausklingenden Hochglazial, in den Rückzugsphasen und in 
den Perioden der ausapernden Karwände, wurden größte Verwitterungsleistungen erreicht (vgl. das aktuelle Beispiel im NW-Kar, Lit. 203). Dieser spätbis postglaziale Verwitterungsschutt, der von den Gletschern nicht mehr abtransportiert wurde, ist hauptsächlich in den zwei Akkumulationsformen der Schutthalden und Blockgletscher enthalten. Der fluviale Abtransport blieb relativ bescheiden.

Schutthalden und Blockgletscher als klar faßbare Formen geben uns Hinweise auf die Ausmaße und die Bedeutung der Verwitterungsvorgänge nach dem Hochglazial. Es wäre zwar möglich, daß Schutthalden von einem eiszeitlichen Gletscher nicht weggeführt, sondern nur überfahren wurden. Die aktuellen Beispiele zeigen uns aber, daß Restbestände dieser Art unwesentlich sind (NW-Kar Erciyas und Veleta-Kar Sierra Nevada: Eis und Firn liegen direkt auf dem aufgeschlossenen Felsuntergrund).

Betrachten wir die verschiedenen Kare, so finden wir die mächtigsten Schutthalden im NE-, im SWund im S-Kar, also dort, wo es keine oder nur ganz unbedeutende Blockgletscher gibt (Fig. 1). Schutthalden und Blockgletscher scheinen quantitativ in einem gewissen reziproken Verhältnis zu stehen. Wenn auch Schutthalden und Blockgletscher genetisch miteinander verknüpft sind, so müssen doch für das Zustandekommen der Massenbewegungen ganz bestimmte Bedingungen erfüllt sein. Nur in den Steilwänden der Nordseite liegen perennierende Schnee-, Firn- und Eisflecken; nur dort stehen genügende Schmelzwassermengen für die Bildung von langsamen Massenbewegungen zur Verfügung. Abweichungen ergeben sich selbstverständlich dort, wo Schneeanhäufungen die SE-Exposition begünstigen (z. B. Libanon, Sierra Nevada).

Abb. 10 und 11 stammen vom gleichen Standort auf dem Ostgrat: Klassische Hangasymmetrie zwischen Sonn- und Schattseite. Auf der Südseite erkennen wir die Anhäufung des Trockenschutts und das Höherwachsen der Schuttdecken bis in die Gipfelregion; der mittlere Böschungswinkel schwankt zwischen 30 und $33^{\circ}$. Im Unterschied dazu zeigt die Nordseite mit den herausragenden Verwitterungshärtlingen eine konvexe Form mit einem Winkel von $38-40^{\circ}$. Der Vergleich der beiden Hangneigungen beweist uns, wie die Südseiten durch den intensiveren Verwitterungsgang rascher ausgeglichen werden und zu größerer Stabilität tendieren, währenddem die steileren Nordflanken durch ein ständiges Abgleiten und Umlagern des Materials charakterisiert sind. Gerade am Erciyas ist diese Formendifferenz qualitativ und quantitativ besonders eindrücklich, weil nicht die Schichtung oder Klüftung des Gesteins, sondern vorwiegend der lokalklimatische Gegensatz dafür venantwortlich ist. (Im Unterschied zum Bolkardagh-Taurus, wo viel-

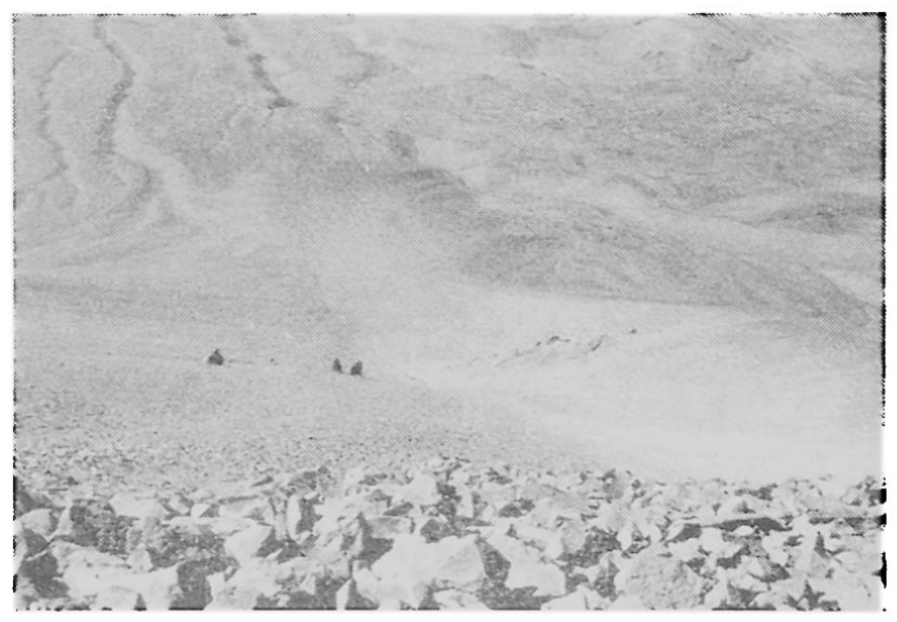

Abb. 10 Südseite des Erciyas Dagh. Blockiger Verwitterungsschutt steigt bis zum Ostgrat auf. Letzte Verwitterungshärtlinge markieren eine Hangleiste. Darunter zeichnet sich eine schwache, stark verschüttete Hohlform ab.

fach die Faltenstrukturen mit ihrem Schichtfallen die Hangasymmetrie beeinflussen und verstärken.)

Die bedeutenden Schuttmassen, vor allem in Südexposition, weisen auf einen äußerst intensiven, frostbedingten Verwitterungsgang hin. Die Hangüberdeckung (Abb. 10) und vor allem die Zuschüttung der würmzeitlichen Glazialformen (Südglet-

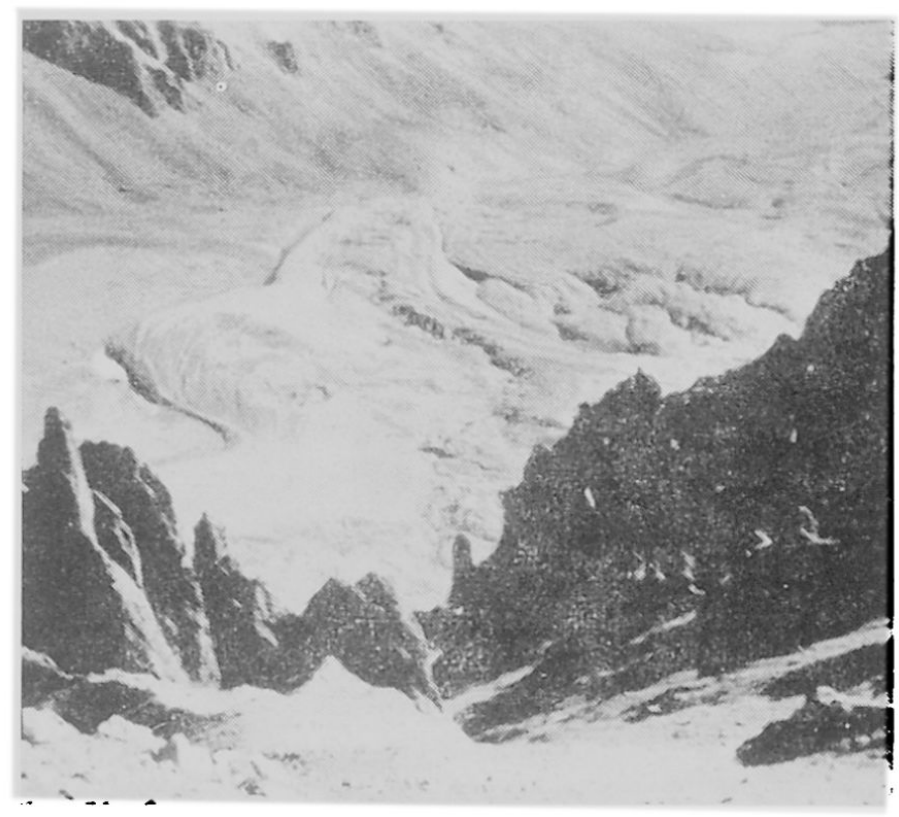

Abb. 11 Teilansicht des großen Blockgletschers im Ostkar. Entstehung in Nordexposition, nicht am Fuß der großen Schutthalden in der Fallinie des Gipfels. Die zonale Gliederung durch verschiedene Bewegungsrichtungen und verschiedene Bewegungsgeschwindigkeiten zeichnet sich in den Oberflächenformen ab. Talauswärts Übergang zu fossilen Formen. 
scher, Abb. 8) weisen darauf hin, daß unmittelbar nach dem Hochglazial eine rasche Ausaperung erfolgte, so daß ein Teil des Spätglazials mit kalttrockenem Klima an dieser Verwitterungsleistung mitwirkte. Jedenfalls können wir die gewaltigen Materialkubaturen, die in Blockgletschern und Schutthalden konserviert sind, nicht ausschließlich der kurzen und mehrheitlich warmen Postglazialzeit zuordnen.

\subsubsection{Das Problem der Blockgletscher}

(Abb. 11, 12, 13)

Wir können in diesem Abschnitt nicht das gesamte komplexe Problem der Entstehung, Bewegung und Datierung der Blockgletscher diskutieren. Unsere Arbeit verlangt aber doch jetzt schon einige Überlegungen, die für die klimamorphologischen $\mathrm{Zu}-$ sammenhänge von Bedeutung sind.

\section{Entstehung und Exposition}

Die Terminologie ist bis heute unklar geblieben. Die Begriffe Blockgletscher und Blockströme treten miteinander auf und haben bis heute keine klare Definition erfahren. Die Unsidherheit hängt zweifellos mit den teilweise noch unbefriedigenden Kenntnissen über das Wesen und die Entstehung dieser Massenbewegungen zusammen. Nach den meisten Autoren entstanden Blockgletscher in den Rückzugsphasen der Gletscher, indem kleine Eismassen im Karhintergrund durch den anfallenden Verwitterungsschutt überdeckt wurden $(277,28$, 147). Das Eis blieb vor Ablation geschützt, die Schuttbedeckung nahm zu, eine Bewegung kam in Gang. Wir fragen uns, ob nicht im Augenblick ähnliche Prozesse beim rezenten Gletscher im NW-Kar ablaufen (203). Genügen aber diese Erklärungen?

Betrachten wir den Blockgletscher im Ostkar, so stellen wir eine zusammenhängende Eisunterlage von der Wurzelzone bis zum markanten Eissee über eine Distanz von $680 \mathrm{~m}$ fest. Die Schuttbedeckung beträgt zuoberst $0-50 \mathrm{~cm}$, nimmt dann talwärts ständig zu und erreicht beim Eissee 3,5-5 m (Abb. 12), teilweise sogar bis $\mathrm{zu} 10 \mathrm{~m}$. Ist dieses gesamte Eisfeld überschüttet worden oder ist der ehemalige Eiskörper talwärts geflossen? Hat er sich dabei ausgeflacht oder ist das abfließende Eis in der Wurzelzone neu ersetzt worden?

Auf Abb. 11 zeichnet sich in der deutlich sichtbaren Doppelzunge mit den aktiven Fließformen eine Bewegungsrichtung nach Norden quer durch den Karboden $a b$, nur durch das natürliche Gefälle etwas talwärts abgelenkt. Das bedeutet, daß im weiten Ostkar die N- bis E-Exposition eine Sonderstellung einnimmt. Die Blockgletscher entstehen nicht in der Fallinie des Gipfels, wo sich die mächtigsten Schutthalden befinden, sondern am Fuß der nord-

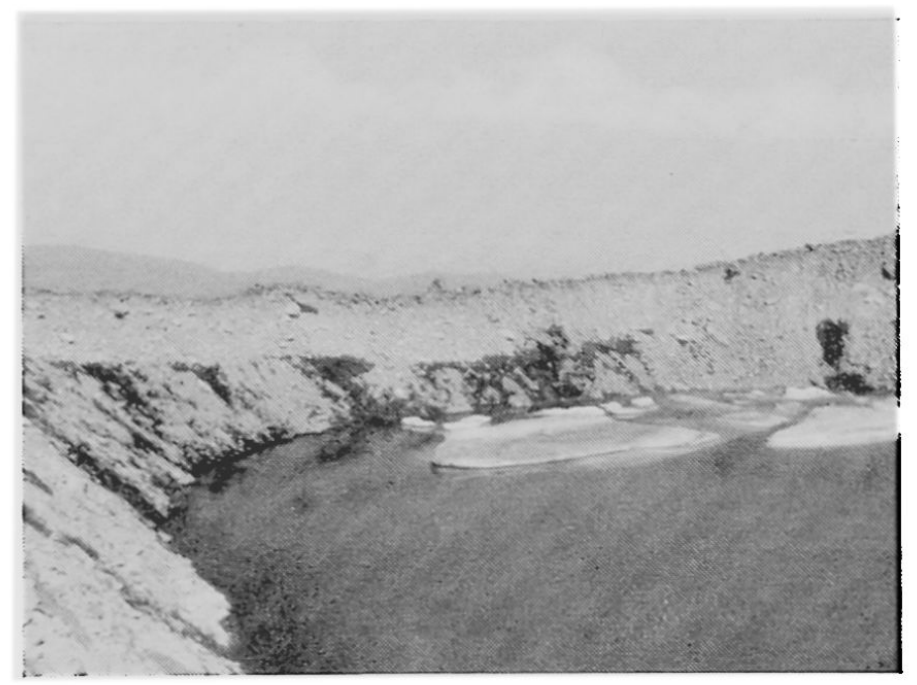

Abb. 12 Eissee im Zentrum des aktiven Blockgletschers. Die Oberfläche des Eises isí am scharf gezeichneten Feuchtigkeitshorizont deutlich zu erkennen.

exponierten Steilhänge mit den lange liegenden Schneeflecken. Ein Blockgletscher bildet sich nicht am Fuß einer stabilisierten Schutthalde, sondern er verlangt eine Ernährungsstelle, die periodisch (vor allem zur Zeit der Schneeschmelze) oder regelmäßig (je nach Höhenbereich und perennierender Schneelage) eine beträchtliche Schuttmasse liefert. Dazu gehört fast durchwegs eine zerrüttete Felszone, die sich noch aus den Schuttdecken heraushebt und das anfallende Material steinschlagartig bis auf das Wurzelgebiet des Blockgletschers abgibt. In der Gunstexposition, in der wir jeden aktiven Blockgletscher finden, steht aber auch ganzjährig Schmelzwasser zur Verfügung. Firn- oder Schneeflecken gehören zum Charakteristikum jeder Wurzelzone, ganz unabhängig von der Eisunterlage. Wir haben im Hochsommer in den oberen Bereichen richtige Bäche zwischen Eis und Schuttdecke festgestellt (ca. 600 Minutenliter), die dann zum kleineren Teil an der Stirn des Blockgletschers sehr diffus als kleine Quellen von ca. 5 Minutenliter ausflossen (Abb. 13). Der größte Teil dieser Wassermenge trat überhaupt nicht mehr als sichtbarer $\mathrm{Ab}$ fluß in Erscheinung.

Das führt uns zum Bewegungsproblem. Nach unserer Meinung ist der Bewegungsvorgang nicht allein auf die Eisunterlage angewiesen. Durch Block- und Eisbewegung ist ein Feinhorizont entstanden, der nun die Funktion des Eises übernimmt, der durch Frostwechsel aktiviert wird, und infolge des meist großen Gefälles einen beschränktenGleitvorgang der auflagernden Blockmasse erlaubt. Diese gut durchfeuchteten Gleithorizonte können wir in jeder Blockgletscherstirn beobachten, ganz unabhängig, vom Gestein (vulkanisches Material am Erciyas, Kalk am 
Taurus, Kristallin am Kaçkar Dagh). Immerhin muß beim Ostkar-Blockgletscher eine gewaltige zusammenhängende Eisunterlage vorhanden sein, wie zahlreiche Aufschlüsse an Schmelzwasserrinnen und Eisseen (Abb. 12) bis ins Zentrum der Blockmasse beweisen. Dort, wo die Eisunterlage aufhört, treten bis zu $10 \mathrm{~m}$ tiefe Einsturztrichter (Sölle) auf, die absolut trocken sind. Daß sich aber diese eisfreien Teile des Blockgletschers auch noch bewegen, sehen wir an den oberflächlichen Bewegungsformen und an den 10-25 m hohen Stirnseiten. Ihre frontalen Böschungswinkel von ca. $39-42^{\circ}$ entsprechen einem labilen Zustand, das heißt, durch die nachdrückenden Gesteinsmassen können sie gar nicht in den stabilen Zustand übergehen (Abb. 13). Diese Messungen haben wir an den verschiedensten Blockgletschern mit ganz unterschiedlichem Material durchgeführt und kamen immer auf die Werte, die nach Piwowar bereits dem instabilen Zustand entsprechen (279).

\section{Das Problem der Datierung}

Wir können den theutigen Blockgletschern nicht nur ein Alter von 100 Jahren geben, wie es in der Literatur häufig geschehen ist und wie es auch am Erciyas versucht wurde. Durch eine Photo Penthers ist uns der Stand eines Blockgletschers von 1902 überliefert worden (vgl. Abb. 2, 3). Ein ganz genauer Vergleich mit den heutigen Ausmaßen läßt sich auf der Photo nicht anstellen, aber Zungenform und -lage entsprechen ungefähr dem heutigen Zustand. Die Veränderungen in den letzten 60 Jahren sind so unbedeutend, $\mathrm{da} \beta$ die Blockmasse auch nicht in den 50 Jahren vorher seit dem Hochstand 1850 entstanden sein kann. Die Länge beträgt ca. $300 \mathrm{~m}$, die durchschnittliche Breite im unteren Teil ca. $130 \mathrm{~m}$; die Wurzel liegt auf $3250 \mathrm{~m}$, das untere Ende auf $3100 \mathrm{~m}$. Allein die Kubatur des Blockgletschers spricht gegen eine Entstehung in 50 Jahren, und wir sehen selbst bei einem Vergleich der klimatischen Bedingungen gar nicht ein, warum er sich in der Zeit vor 1900 bewegt haben sollte, nachher aber nicht mehr. Im übrigen bestätigt auch Klaer diesen Stillstand der Stirn seit den Aufnahmen Penthers 1902, plädiert aber für ein Alter, das dem Hochstand 1850 entspricht. Beweis: «Wäre er älter, lieBen sich die frischen Formen nicht erklären» (147). Diese Datierung würde eine Vorrückungsgeschwindigkeit in der Periode 1850 bis 1900 von mindestens $6 \mathrm{~m}$ pro Jahr verlangen. So etwas ist meines Wissens noch nie gemessen worden $(28,277)$, ganz abgesehen davon, daß wir uns den explosiven Verwitterungsvorgang nicht vorstellen können, der in kürzester Zeit diese gewaltige Schuttmasse bereitgestellt hätte. Eine Datierung mit den größten postglazialen Vorstößen, wenn nicht sogar spätglazial, ist unbedingt notwendig. Können wir die Blockgletscher überhaupt auf diese Weise datieren?

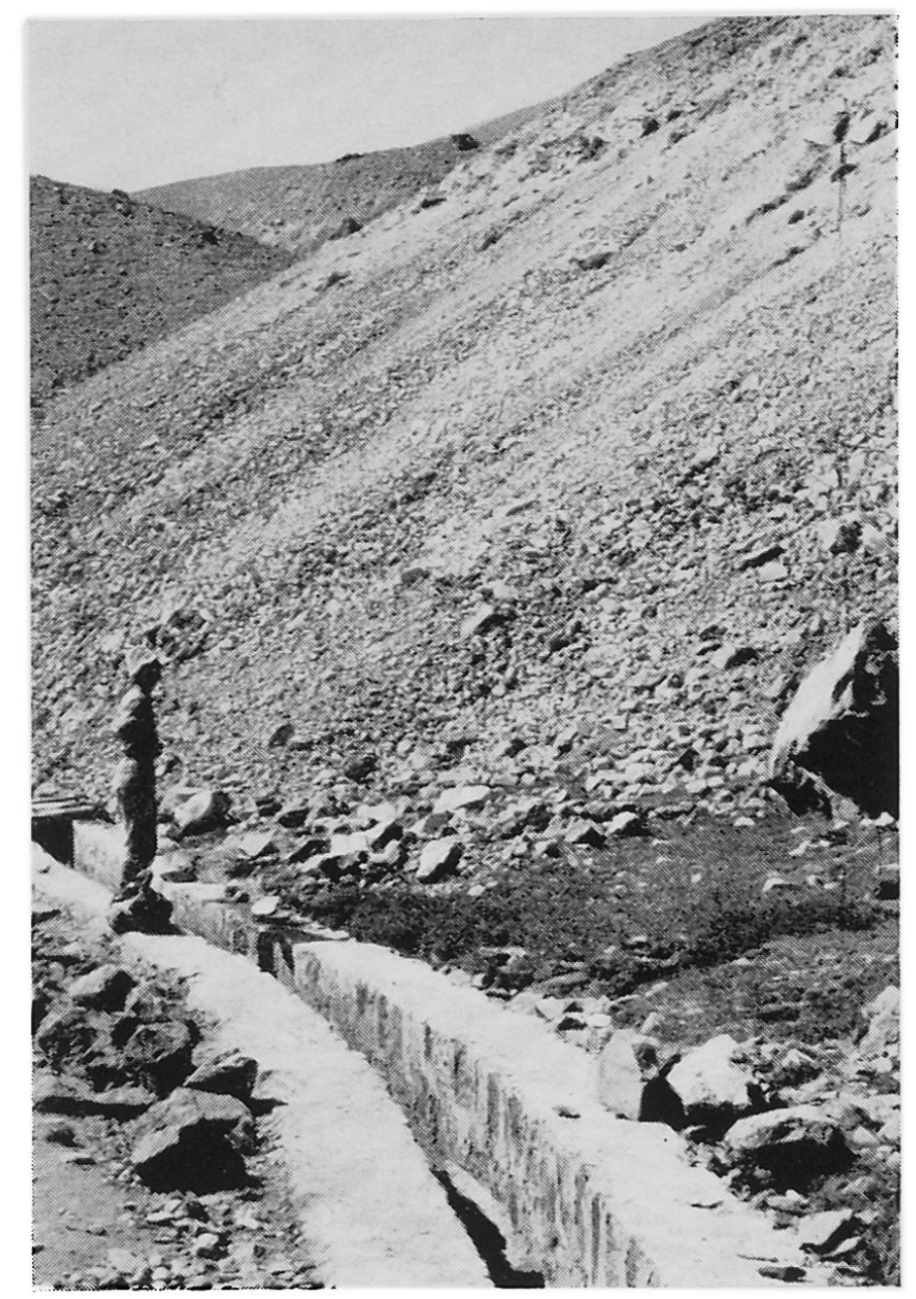

Abb. 13 Die instabile Stirn des Blockgletschers. Der Gleithorizont mit dem auffallend hellen Feinmaterial ist am oberen rechten Bildrand zu erkennen. (Böschungswinkel 38_42 ${ }^{\circ}$.) Die überdeckende Blockmasse ist nicht sichtbar. Im unteren Teil der Stirn häuft sich der beim langsamen Vorrücken anfallende Schutt an. An der Sohle kleine Quellen.

Wir stellen uns die Frage, ob nicht Blockgletscher richtige Stillstandsphasen durchmachen können, sei es als Ganzes oder nur zonal, um bei günstigeren Klimabedingungen wieder reaktiviert $\mathrm{zu}$ werden. Zum Beispiel zeigt der besprochene Blockgletscher in der Front fast einen Stillstand seit 1902. Wir sagen nur «fast»; denn der stirnseitige Böschungswinkel von $39^{\circ}$ sagt uns, daß ein instabiler Zustand herrscht und offenbar ein völliges Absetzen und Stabilisieren nicht möglich ist. Die Vorrückungsgeschwindigkeit ist vielleicht auf die Größenordnung von Zentimetern pro Jahr beschränkt (vgl. Pillewizer 277). Im zentralen Teil muß sie etwas größer sein; denn die frischen Wallformen bis zu doppelter Mannshöhe weisen auf aktive Stau- und Scherzonen hin. Als Ganzes kann der Blockgletscher über längere Zeiträume stagnieren. Zur Reaktivierung 
braucht es vielleicht nur bescheidene Klimaveränderungen; zum Beispiel häufigere Frostwechsel, längere Schneelagen mit größeren Schmelzwassermengen oder sogar Neubildungen von Eis, sei es in der Wurzelzone direkt oder als Wasser- und Kaverneneis unter der Blockmasse. Die Schichtung der Blockmasse ist so angelegt, daß sie jederzeit wieder eine Bewegung übernehmen kann, selbst wenn durch die Stagnation ein äußerlicher Zerfall eingetreten ist. Damit glauben wir auch das Problem der Eisunterlage gelöst zu haben. Eis ist bei der Entstehung eines Blockgletschers nötig, aber die Ablösung seiner Funktion durch die aufgearbeiteten Feinhorizonte ist ohne weiteres möglich. Eine Bewegung ohne Eisunterlage kommt durch den auflastenden Druck, das notwendige Gefälle und sehr wahrscheinlich durch eine bestimmte Frostwechselwirkung zustande: Probleme, die in Zukunft noch genauer untersucht werden müssen.

\section{Das Problem der fossilen Formen}

Wenn wir die weit ausgebreiteten Formen der glazialen Ablagerungen des Ostgletschers betrachten, müssen wir den eng gefaßten Begriff des Blockgletschers in Frage stellen. Die vielzitierten, unüberblickbaren und ungeordneten Hügelformen mahnen uns an einen zerfallenen Blockgletscher, wie wir es im Zungenbereich aktueller Beispiele beobachten können. Stellen wir uns den eiszeitlichen Ostgletscher vor: er mußte mit Schutt so gewaltig beladen sein, daß hin und wieder kaum eine Eisdecke sichtbar war. Wie spielte sich der Rückzug ab? Ganz sicher nicht als ein regelmäßiges Zurückschmelzen, sondern als ein zonales Auflösen der Eisunterlage. Eisreste blieben unter der Blockmasse liegen. Gefälle und Gewicht des auflastenden Schuttes lösten eigenständige Massenbewegungen aus. Es entstanden blockgletscherartige Formen und Umlagerungen. Mit der andauernden Klimaverbesserung und dem abgeschlossenen Ausschmelzen der isolierten Eiskörper kam die Bewegung zonenweise zum Stillstand. Als Ganzes ergibt sich heute ein morphologischer Zusammenhang von den fossilen Formen auf dem offenen Vulkansockel zu den aktiven Formen im innersten Karraum.

Zusammengefaßt: Fossile Blockgletscher treten im Rand- und Rückzugsbereich der würmzeitlichen Gletscher auf. Aktive Blockgletscher sind an die Rand- und Rückzugsbereiahe der rezenten und subrezenten Gletscherhochstände gebunden, sie sind in spät- und postglazialen Kältephasen entstanden. Alle aktiven Blockgletscher enden über oder nur ganz knapp unter $3000 \mathrm{~m}$, das heißt, sie sind keinesfalls Zeugen einer rezenten Schneegrenze, sondern höchstens Beweise für eine Schneegrenzsenkung während ihrer Entstehungsphase.

\subsection{Solifluktionsgrenze und Waldgrenze}

Rezente Solifluktionserscheinungen in Form von Girlanden- und Fließerdeböden haben wir vereinzelt und schwach ausgeprägt bereits auf $2300 \mathrm{~m}$ festgestellt. Deutlicher ausgeformt trafen wir sie erst auf 2500-2600 $\mathrm{m}$ an, wobei sich die Vorkommen hauptsächlich auf die Nordseite des Erciyas konzentrierten und an den schuttbedeckten Hängen der Südseite kaum zu finden waren.

Eine auffallende Erscheinung sind die kleinen Schuttströme und Schuttzungen, die von rezenten bis zu fossilen Formen sämtliche Übergänge zeigen. Sie sind im Höhenbereich $2500-2700 \mathrm{~m}$ besonders häufig (Abb. 5). In tieferen Lagen bis auf $2000 \mathrm{~m}$ (zum Beispiel in der Umgebung des Sari Göls) zeigt die Überwachsung den fossilen Zustand an. Davon sind murgangartige Schuttspülungen deutlich zu unterscheiden, die wir an schuttreichen Sekundärkegeln westlich des Sari Göls beobachten konnten und die mit Frosterscheinungen nichts zu tun haben.

Gesamthaft gesehen legen wir die Untergrenze der deutlichen Solifluktionsformen auf $2500 \mathrm{~m}$ fest, wobei schwache Ausbildungen noch in $2300 \mathrm{~m}$ anzutreffen sind.

Die Waldgrenze kann heute am Erciyas Dagh nur noch an wenigen Restbeständen ermittelt werden. Bartsch hat das Problem eingehend besprochen (11, S. 129) und zitiert auch die Aussage Strabos, daß "der Argaeus einen ihn rings umgebenden Wald" getragen habe. Eine geschlossene Waldgrenze existiert nicht mehr. Der Mensch hat zerstörend eingegriffen, vor allem in der gut zugänglichen TekirEbene. Einzelne Restbestände am Lifos und Kartin Dagh lassen die obere Waldgrenze auf $2500 \mathrm{~m}$ vermuten, die untere Waldgrenze schätzt Bartsch auf $1400 \mathrm{~m}$ (11, S. 130).

Aus den wenigen Angaben ergeben sich interessante Zusammenhänge in der allgemeinen Höhenstufung des Erciyas. Die heute unsichtbare obere Waldgrenze befindet sich auf $2500 \mathrm{~m}$, wo wir auch die Untergrenze der deutlichen Solifluktionserscheinungen festlegen. Die obere Waldgrenze ist somit $1500 \mathrm{~m}$ unter der rezenten regionalen Schneegrenze, ein Wert, der mit dem Libanon und dem Taurus sehr gut vergleichbar ist. Damit zeigen sich auffallende Ubereinstimmungen Waldgrenze_Schneegrenze, die wir schon bei der Besprechung des Libanons diskutiert haben.

\subsection{Schneegrenzen und Schneegrenzdepression}

Die rezente Schneegrenze schätzen wir auf $4000 \mathrm{~m}$, die würmeiszeitliche haben wir mit 2850 m nachgewiesen, das ergibt eine letzteiszeitliche Schneegrenzdepression von $1150 \mathrm{~m}$. Mögliche Fehler eines um 
50-100 m zu hohen rezenten Wertes könnten durch einen um 50-100 $\mathrm{m} \mathrm{zu}$ hohen eiszeitlichen Wert ausgeglichen werden. Deshalb betrachten wir die Schneegrenzdepression von über $1000 \mathrm{~m}$ in der GröBenordnung als richtig. Nun stellt sich aber die interessante Frage, warum die Schneegrenzdepression am Erciyas größer ist als am Taurus und im Libanon. Wissmann weist doch deutlich nach, daß die Schneegrenzdepression in ariden Gebieten kleiner ist als in humiden $(359$, S. 216), das heißt, daß die eiszeitliche Schneegrenze über den Trockengebieten wesentlich stärker aufgewölbt war als heute. Wenn dies für den Erciyas nicht zutrifft, dann gibt es nur eine Erklärung: Der Erciyas befand sich zur Eiszeit in einer humideren Zone als heute, die eine allzu starke Aufwölbung der Schneegrenze verhinderte.

Diese Folgerung wird auch durch andere Untersuchungen in Anatolien bestätigt. Die ausgedehnten Seenbildungen (183) und vor allem die torrentiellen Ablagerungen bei Ankara in Form von Terrassen lassen auf eine veränderte Niederschlagstätigkeit schließen (45, S. 88). Auch wenn Butzer diese Niederschlagssteigerung in Form von heftigen, unregelmäßigen Gußregen sieht, so hatte sie doch zweifellos einen Einfluß auf die Schneemenge und die Schneegrenzlage. Im übrigen verweisen wir auf die Arbeit von Wright in Kurdistan, der Schneegrenzdepressionen von $1200-1800 \mathrm{~m}$ angibt, was im Widerspruch zu den Ergebnissen Bobeks steht (45, 147, 361). Allerdings scheint mir, daß seine Schneegrenzdaten keine regional gültigen Mittelwerte aus Sonnund Schattseite wiedergeben und deshalb mit Vorsicht aufzunehmen sind (361, S.132). Immerhin verlangt auch Wright eine erhöhte Niederschlagstätigkeit für die kurdischen Gebirge, was trotz der unterschiedlichen orographischen Situation gewisse Hinweise auf unser Untersuchungsgebiet gibt.

Die Klimaverhältnisse der Eiszeit brachten Anatolien nicht nur einen Temperaturfall, sondern auch eine veränderte Niederschlagstätigkeit. Damit wird eine Berechnung der eiszeitlichen Temperaturdepression aus der ermittelten Schneegrenzdepression schwierig. Jedenfalls weist die hohe Schneegrenzdepression auf die unterschiedlichen Klimaverhältnisse hin, in die der Erciyas Dagh in der Eiszeit und in der Gegenwart hineingestellt war und ist. (Vgl. Seite 120.)

\subsection{Zusammenfassungen}

\subsubsection{Résumé Erciyas Dagh}

Les traits principaux volcaniques et tectoniques de l'Erciyas Dagh sont fortement effacés par d'intensifs phénomènes de désagrégation, de dénudation et d'érosion. Les relations entre les processus internes et externes nous fournissent d'intéressantes possibilités de datation. L'altitude de l'Erciyas Dagh n'ayant pas changé depuis l'époque Würm, peut-être même depuis l'époque Riss, les résultats de géomorphologie glaciaire peuvent être insérés dans une vaste vue d'ensemble des zones d'altitude à l'époque glaciaire et actuelle.

Nous évaluons les précipitations dans les régions au-dessus de $3000 \mathrm{~m}$ au moins à $1500 \mathrm{~mm}$, dont plus de $1000 \mathrm{~mm}$ tombent sous forme de neige. Avec un gradient des températures fort différencié, nous déterminons une température de juillet de $4,2^{\circ} \mathrm{C}$ pour l'altitude du sommet de l'Erciyas, ce qui présume une ligne des neiges récente fort élevée.

Le glacier actuel avec sa ligne des neiges strictement locale de $3650 \mathrm{~m}$ n'est pas représentatif pour tout le versant nord. Les glaces sous les glaciers de pierre n'ont pas non plus de relation directe avec une ligne des neiges. Nous délimitons celle-ci à $3800 \mathrm{~m}$ pour le versant nord, à 400-500 m plus haut pour le versant sud, ce qui correspond à une limite des neiges moyenne régionale d'au moins $4000 \mathrm{~m}$.

Nous avons dressé une carte de la glaciation würmienne des versants nord et sud. Des glaciers d'une longueur allant jusqu'à $6,5 \mathrm{~km}$ et d'une étendue de $10 \mathrm{~km}^{2}$ se formèrent. La définition de la ligne des neiges au moyen des méthodes classiques conduit à des contradictions. Les masses de glace s'étendant largement en éventail sur le socle libre du volcan fondent rapidement au-dessous de la ligne des neiges. Celle-ci se trouve plus bas que la moitié entre la ligne de faîte de la région d'alimentation et le front du glacier, ce qui est prouvé par de petits cirques avec formation de glaciers indépendants. La ligne des neiges würmienne se trouve à $2700 \mathrm{~m}$ sur le versant nord, à $3000 \mathrm{~m}$ sur le versant sud, en moyenne à $2850 \mathrm{~m}$.

De nombreux indices en partie encore incertains témoignent d'une glaciation plus ancienne (Riss).

Les processus météoriques postglaciaires ont surtout fourni des talus d'éboulis et des coulées de pierre qui peuvent naître les uns à côté des autres et ensemble, et qui montrent pourtant une certaine relation réciproque. Une asymmétrie dans la formation des versants nord et sud par suite d'un processus de désagrégation différent est nettement manifeste.

Les glaciers de pierre sont liés à des situations particulièrement favorables avec des névés et des taches de neige pérennes, et à des points d'alimentation recevant beaucoup d'éboulis. Ils se meuvent aussi sans fondation de glace sur des horizons fins du genre des moraines de fond. Nous ne pouvons lier leur apparition au maximum de 1850 . Les glaciers de pierre peuvent être stagnants pendant d'assez longues périodes et être réactivés sous de meilleures conditions climatiques. Ils ne témoignent en aucun cas d'une ligne des neiges récente, mais prouvent 
tout au plus un abaissement de la ligne des neiges pendant la phase de leur naissance.

La limite inférieure des formes de solifluction nettement apparentes se trouve à $2500 \mathrm{~m}$. A cette altituse situe également la limite de la forêt. La différence entre la limite supérieure de la forêt et la ligne des neiges récente est de $1500 \mathrm{~m}$, un chiffre qui correspond de manière frappante avec le Liban et le Taurus.

La dépression de la ligne des neiges de $1150 \mathrm{~m}$ est plus grande que dans le Taurus et le Liban. Cela signifie que l'Anatolie fut sujette à d'autres conditions circulatoires avec augmentation des précipitations pendant les époques glaciaires.

\subsubsection{Summary Erciyas Dagh}

The actual glacier with its strictly local snow-line of $3650 \mathrm{~m}$ is not representative of the whole northern mountain-side. Neither have the ice-bases of the rock-streams a direct connection with a snow-line.

\section{Mittlerer Taurus: Hoher Bolkardagh}

Der Hohe Bolkardagh wird im Westen durch die Depression von Silifke-Karaman und im Osten durch die Kilikische Pforte begrenzt. In dem $180 \mathrm{~km}$ langen und durchschnittlich $100 \mathrm{~km}$ breiten Gebirgsraum untersuchen wir ganz speziell das Gebiet des Medetsiz (3585 m). In der Umgebung dieses höchsten Gipfels des mediterranen Taurus finden wir die bedeutendsten Spuren einer rezenten und eiszeitlichen Vergletscherung (Fig. 3).

\subsection{Der Aufbau und seine Bedeutung für die Gla- zialmorphologie}

In einer umfangreichen Arbeit hat Blumenthal seine langjährigen Feldarbeiten im Hohen Bolkardagh ausgewertet und zusammengestellt. Voller Achtung greifen wir heute zu diesem Werk, das uns eine genaue geologische Information erlaubt und das auch die ersten Hinweise auf die Glazialmorphologie enthält (20). Eine Zusammenfassung dieser Ergebnisse finden wir ebenfalls bei Klaer (147, Karte IV), so daß wir auf eine erneute geologische Beschreibung verzichten und die Grundlagen des Aufbaus voraussetzen können. Wir halten nur einige Merk-
We place this at $3800 \mathrm{~m}$ for the northern mountainside, $500 \mathrm{~m}$ higher for the southern one. This gives us a mean regionally valid snow-line of at least $4000 \mathrm{~m}$.

We have drawn a map of the Würm glaciation on the northern and southern side. There were glaciers as long as $6,5 \mathrm{~km}$ with an area of $10 \mathrm{~km}^{2}$. The determination of a snow-line by means of classical methods leads to contradictions. The ice-masses which extend broadly, fan-like on the open base of the volcano rapidly melt underneath the snow-line. It lies further down than the middle between the crestline of the feeding ground and the end of the glacier, as is proved by little cirques with independent formation of glaciers. The snow-line of Würm-glaciation may be found at $2700 \mathrm{~m}$ on the northern side, at $3000 \mathrm{~m}$ on the southern side, an average of $2850 \mathrm{~m}$.

Numerous signs point to an earlier glaciation (Riss). The snow-line depression of $1150 \mathrm{~m}$ is greater than in the Taurus and Lebanon. This means that Anatolia was subject to other circulatory conditions with increased precipitations during the glacial periods.

punkte fest, die für das Verständnis der glazial- und klimamorphologischen Formen wesentlich sind.

\section{Gesteinsmaterial}

Die verbreitetste Einheit ist ein metamorpher palöozoischer Kalk, der Bolkardagh-Marmor (Karbon, evtl. Devon), begrenzt durch nördliche und südliche Phyllitzonen. Neben verschiedenen Schieferserien folgen im Süden die Permkalke. Größere Ophiolithmassen treten im N, E und W des Gebirgskörpers auf, Granitstöcke sind vorhanden (unteres HorozTal), vereinzelte Basalt- und Quarzporphyrstücke finden wir sogar in der Gipfelzone. Trotz dieser Materialvielfalt ist es im heutigen Zeitpunkt noch nicht möglich, die Moränen nach dem Gesteinsinhalt $\mathrm{zu}$ analysieren und die erratischen Komponenten überall $\mathrm{zu}$ bestimmen. Die bisherigen geologischen Feldaufnahmen und Karten sind für ein solches Vorgehen noch zu wenig genau, und auch wir konnten unsere beschränkte Zeit nicht für eine Detailarbeit ohne Kartierungsmöglichkeit hergeben. Immerhin hat uns die Gesteinsvielfalt schon beim heutigen Stand der Kenntnisse wertvolle Anhaltspunkte geliefert, wir werden bei der Besprechung der einzelnen Täler darauf zurückkommen.

Unter dem Stichwort "Gestein» müssen wir noch 
auf eine andere Schwierigkeit hinweisen. Den größten und durchwegs vorkommenden Materialanteil liefert der paläozoische Kalk, deshalb versuchten wir auch nur an diesem Gestein die morphometrische Schotteranalyse anzuwenden $(16,51,291)$. Wir mußten aber feststellen, daß Lösungsvorgänge die Zurundung beeinflussen können und deshalb die Resultate je nach Orts- und Höhenlage auf ihre Brauchbarkeit zu prüfen sind (Fig. 4).

\section{Tektonik (Fig. 2)}

Aus der Arbeit Blumenthals geht deutlich hervor, daß die eigentliche Hochgebirgszone durch mehrere Falten und Schuppen gegliedert wird. Der Autor unterscheidet eine südliche Axialkette, in der sich der höchste Gipfel des Medetsiz befindet, und eine nördliche Frontalkette, die steil ins Madental abfällt. Dazwischen liegt eine 2900-3100 m hohe Muldenzone, die in den Kaltzeiten ein beträchtliches Eisreservoir gebildet hat (Abb. 24). Ferner ist deutlich zu erkennen, daß die gesamte BolkardaghAntiklinale eine asymmetrische Falte ist, mit einem langsamen Ansteigen von SE und einem raschen Abfallen und Überkippen nach NW. Von S her sind zahlreiche Schuppen aufgeschoben worden, die im heutigen Relief teilweise als tafelartige Hochflächen hervortreten. Demgegenüber ist die nach $\mathrm{N}$ vorgestoßene Front durch einen gewaltigen Felsabsturz von $1700 \mathrm{~m}$ Höhe gekennzeichnet, davorliegende tertiäre und mesozoische Sedimente wurden steilgestellt. Diese wenigen Angaben sollen für unseren glazial- und klimamorphologischen Zusammenhang folgendes zeigen:

Die Asymmetrie in der Hangbildung ist im wesentlichen tektonisch bedingt. Es wäre falsch, die wuchtige, hochgebirgsähnliche Nordfront und die monotone, schuttbedeckte Südabdachung allein klimagenetisch zu erklären.

Eine Bestandsaufnahme von Verebnungsflächen muß mit größter Vorsicht geschehen, weil im Süden wenig oder überhaupt nicht gefaltete Schuppen ein Abtragungsniveau vortäuschen.

Der Hohe Bolkardagh ist eine Großfalte mit einer markanten Einmuldung in der Hochzone, die einer Vergletscherung bedeutende Nährgebiete zur Verfügung gestellt hat.

Verschiedenste und rasch wechselnde Gesteinsserien haben zusammen mit bruchtektonisch bedingten Richtungen den exogenen Kräften zahlreiche Schwächezonen bereitgestellt, die zu einem dichten und kräftig eingetieften Talnetz umgestaltet wurden.

\section{Orogenese}

Nach unbedeutenden Vorstufen erfolgte die Hauptgebirgsbildung präoligozän in der pyrenäischen Phase. Bedeutende Hebungen spielten sich aber erst nach dem Miozän ab, und es ist wohl möglich, daß dieser Prozeß bis ins ältere Diluvium angedauert

\section{Hoher Bolkardagh}

(Vereinfacht nach Blumenthal 1955)
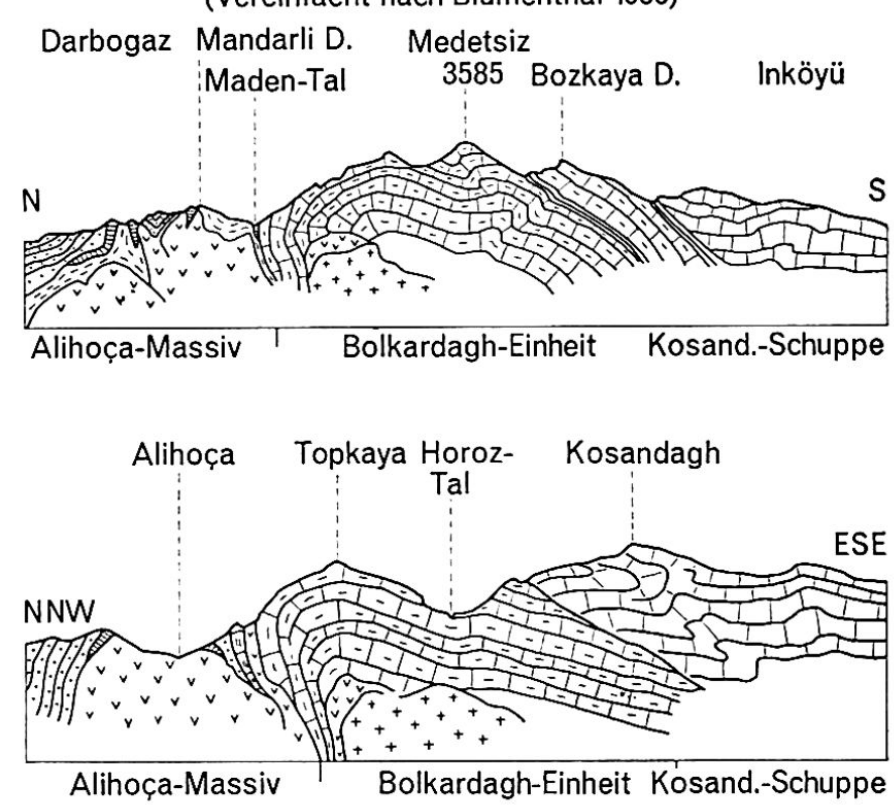

$\therefore$ Oligozäne Sedimente

面 Eozäne und paläozäne Kalke

$=1 \exists$ Mesozoische Schichtserie

E-:-7 Paläozoikum der nördl.Randketten

Permkalke und -schiefer

두럭 Bolkardagh-Marmor

Phyllitische Zwischenlagen

$++^{+}$Granitstock (teils hypothetisch)

$v_{v}$ Ophiolika und Begleitgesteine

$\begin{array}{llllll}0 & 1 & 2 & 3 & 4 & \mathrm{~km}\end{array}$

Fig. 2 Hoher Bolkardagh. Vereinfacht nach Blumenthal 1955.

hat (20). Ob dieser Vorgang einen Einfluß auf die ältesten Eiszeiten gehabt hat (147, S. 72), kann wohl im heutigen Zeitpunkt noch nicht entschieden werden. Ganz sicher aber ist die letzte und sehr wahrscheinlich auch die vorletzte Eiszeit von diesen Vorgängen nicht mehr berührt worden.

\section{Karst}

Betreten wir die Hochmulde zwischen Frontal- und Axialkette oder sogar den Gipfel des Medetsiz (Abb. 14, 24), so sind wir von der prächtigen Rundbuckellandschaft und den hochalpinen Karformen beeindruckt. Wir haben uns gefragt, wie weit hier Lösungsvorgänge größten Ausmaßes mithelfen konnten, diese Formbildungen zu verstärken. Die ständigen Schmelzwassermengen fördern den Karstprozeß ganz wesentlich. In der Hochzone geht der größte Teil des Abflusses als Versickerung weg und tritt in einzigartigen Stromquellen am Fuß des Gebirges aus. (Zum Beispiel an der Hauptstraße zwischen Ciftehan und Pozanti in Akköprü, in den obersten Serien des Bolkardagh-Marmors.) Die ak- 
tiven Dolinenformen verstärken das Bild der Rundbuckellandschaft und betonen den Gegensatz zwischen der wasserreichen Nord- und der trockenen Südseite. Es scheint mir kaum mögiich, den Karstproze $\beta$ und die Glazialerosion an den heutigen Oberflächenformen anteilmäßig zu erfassen, denn die beiden Vorgänge sind komplex miteinander verbunden. Ganz sicher aber haben wir in einem Gebirge diese Lösungsvorgänge zu berücksichtigen, wenn wir den morphologischen Gegensatz zwischen einer schnee- und wasserreichen Schattseite und einer trockenen und schuttreichen Südseite betrachten und verstehen wollen.

\subsection{Das Klima im Vergleich mit dem Erciyas Dagh und dem Libanon}

\subsubsection{Der Niederschlag (212)}

Nordseite:

Ulukisla $\quad 1430 \mathrm{~m}$ Mittel 1929-1960 377,6 mm Nigde $\quad 1208 \mathrm{~m}$ Mittel 1935-1960 356,6 mm

Südseite:

Adana $\quad 20 \mathrm{~m}$ Mittel 1931-1960 610,9 mm

Mersin $6 \mathrm{~m}$ Mittel 1929-1960 595,8 mm

Diese Daten zeigen uns die Differenz zwischen den inneranatolischen und den küstennahen Stationen. Die ungleiche Beregnung der beiden Gebirgsseiten zeigt sich noch deutlicher in den folgenden Werten (211):

\section{Nordseite:}

Ulukisla $1430 \mathrm{~m}$ Mittel 1957-1961 341,0 mm

Südseite:

Gülek ca. $950 \mathrm{~m}$ Mittel 1957-1961 907,6 mm

Die südseitige Niederschlagszunahme von der Küste bis zur Höhenlage $950 \mathrm{~m}$ ist beachtenswert, ähnliche Mengen kennen wir höchstens aus dem östlichen Vorland des Ala Dagh (Feke in $1300 \mathrm{~m}$ Höhe = $1010 \mathrm{~mm}$ ). Eine solche Niederschlagssteigerung ist am Erciyas undenkbar.

Die winterlich - mediterrane W-E - Zyklonenbahn teilt sich über der Aegäis in zwei Zugstraßen auf. Die nördliche führt über das Marmarameer ins Schwarze Meer; die südliche folgt der Mittelmeerküste, betritt bei Iskenderun den Kontinent und zieht den orographischen Leitlinien entlang nach Osten. Im Gebiet des Hohen Bolkardagh ergeben sich Niederschläge aus W bis SW. Die Küstenländer und der südliche Gebirgsfuß des mittleren Taurus liegen im großregionalen Niederschlagsschatten der weit nach Süden vorspringenden Landmasse von Silifke-Anamur. Mit zunehmender Höhe schwächt sich diese Schattenwirkung $a b$, und wir erreichen sehr rasch die höheren Niederschlagsbereiche, wie es die Niederschlagskarte richtig zeigt (212), und wie es auch die Meßwerte von Gülek beweisen (211). Es kann kein Zweifel bestehen, daß die Hochgebirgszone über $3000 \mathrm{~m}$ die Zwei-Meter-Niederschlagsgrenze überschreitet, ganz ähnlich wie im Libanon. Dementsprechend wird der Niederschlag in fester Form mindestens $500 \mathrm{~mm}$ größer sein als auf gleicher Höhe am Erciyas Dagh, und diese bedeutende Differenz muß den Verlauf der rezenten Schneegrenzen wesentlich beeinflussen.

\subsubsection{Temperatur (212)}

\begin{tabular}{|c|c|c|c|c|}
\hline \multicolumn{2}{|c|}{ Nordseite: } & 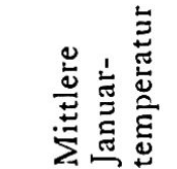 & 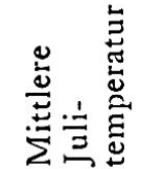 & 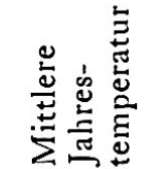 \\
\hline Ulukisla & $1430 \mathrm{~m}$ & $-2,1^{\circ} \mathrm{C}$ & $21,5^{\circ} \mathrm{C}$ & $9,6^{\circ} \mathrm{C}$ \\
\hline Kayseri & $1071 \mathrm{~m}$ & $-1,7^{\circ} \mathrm{C}$ & $22,8^{\circ} \mathrm{C}$ & 10,8 \\
\hline \multicolumn{5}{|l|}{ Südseite: } \\
\hline $\begin{array}{l}\text { Adana } \\
\text { Mersin }\end{array}$ & $20 \mathrm{~m}$ & & & \\
\hline
\end{tabular}

Wir verzichten auf die Berechnung eines Temperaturgradienten, weil uns keine einzige Höhenstation auf der maritimen Südseite zur Verfügung steht. Es wäre sicher falsch, die gleichen Werte wie am Erciyas Dagh zu verwenden, ein Vergleich mit dem Libanon ist dagegen viel naheliegender:

Maritime Seite:

Beyruth $34 \mathrm{~m}$, mittlere Julitemperatur $27,1^{\circ} \mathrm{C}$ Mersin $6 \mathrm{~m}$, mittlere Julitemperatur $27,6^{\circ} \mathrm{C}$

Kontinentale Seite:

Ksara $920 \mathrm{~m}$, mittlere Julitemperatur $24,1^{\circ} \mathrm{C}$ Ulukisla $1430 \mathrm{~m}$, mittlere Julitemperatur $21,5^{\circ} \mathrm{C}$

(Ksara, umgerechnet auf die Höhe von Ulukisla mit dem kontinentalen Höhengradienten Les CèdresKsara $=0,55^{\circ} / 100 \mathrm{~m}$, ergibt eine Julitemperatur von $21,3^{\circ} \mathrm{C}$.)

Es ist auffallend, wie die Julitemperaturen beidseits des Hohen Bolkardagh mit den Werten beidseits des Hochlibanons übereinstimmen. Wir neigen zur Ansicht, daß die Höhenstufung der Temperatur in den beiden Gebirgsräumen fast gleich verlaufen muß. Ziehen wir schließlich noch das ähnliche Niederschlagsgeschehen mit zunehmender Höhe in Betracht, so ergibt sich als Ganzes eine erstaunliche klimatische Übereinstimmung, die sich zweifellos auch auf die Schneegrenzverhältnisse der Eiszeit und der Gegenwart auswirken mußte. 


\subsection{Spuren einer rezenten Vergletscherung und Pro- bleme der Schneegrenzbestimmung}

Wir haben die Hochtalung zwischen Axial- und Frontalkette und den Gipfelraum des Medetsiz im September 1962 begangen und den vorhandenen Eisflecken besondere Aufmerksamkeit geschenkt. Dabei zeigte sich, daß von den 4 bedeutenderen Eisund Firnresten die größten in der Fußzone des Medetsiz und des Arpalik zu finden sind (Fig. 2, 3). Die östliche Hochgebirgszone vom Kara Göl bis zum Aydos Dagh haben wir nicht untersucht (Aydos Dagh $3488 \mathrm{~m}$, ca. $24 \mathrm{~km}$ ESE vom MedetsizGipfel).

Betrachten wir den winzigen Wandfußgletscher des Medetsiz etwas näher (Abb. 14, 15), so stellen wir folgende Ausmaße fest: In den untersten Wandpartien auf ca. $3200 \mathrm{~m}$ setzt das blanke Eis in einzelnen Kegelformen je nach Felsgesimse ein, erreicht nach ca. $10 \mathrm{~m}$ einen kleinen Bergschrund und verliert sich abwärts unter Schutthalden und Altschnee. 50-100 m vom Wandfuß entfernt häufen sich bereits die Schuttmassen der Moränen und Blockgletscher an. Darunter haben wir eine zusammenhängende Eisdecke festgestellt, die in einem See von $20 \mathrm{~m}$ Durchmesser unter einer Schuttbedeckung von 5-6 $\mathrm{m}$ aufgeschlossen ist. Selbstverständlich sind diese überschütteten Eisunterlagen für die Bestimmung einer Schneegrenze nicht direkt brauchbar, wie wir es am Erciyas Dagh eingehend besprochen haben.

Konzentrieren wir uns allein auf die Eisreste im Karhintergrund. Das blanke Gletschereis ist, in kegelförmige Teile aufgelöst, auf einer Breite von ca. $100 \mathrm{~m}$ und in einer Längsausdehnung von ca. $30 \mathrm{~m}$ sichtbar. Allein diese Ausmaße zeigen, daß das Eis an eine extreme Gunstlage gebunden ist. Die Eisreste oberhalb und knapp unterhalb des Bergschrundes sind am Fuß der ca. 200-350 m hohen Steilwand genau so gelagert, daß sie den größten Teil des Tages im Schatten liegen und von der direkten Strahlung kaum betroffen werden. Die tieferen Eispartien, die auf dem Schuttkegel aus dem Wandschatten hervortreten und täglich mehrere Stunden besonnt werden, sind bereits von Schutt und Altschnee überdeckt. Die gleiche Situation könnten wir für die Fußzone des Arpalik und die Eisreste in den andern Hochkaren schildern. Daraus ergibt sich folgendes:

Die rezente Schneegrenze, die wir aus diesen Eisflecken ermitteln, ist praktisch bedeutungslos. Den Beweis sehen wir in der großen Höhenstreuung. In einigen Karen liegt ein Eis- oder Firnfleck auf $3000 \mathrm{~m}$, in anderen auf $3300 \mathrm{~m}$, aber allen ist gemeinsam, daß sie nur gerade in der hintersten Schattlage als blankes Eis existieren. Wäre zum Beispiel das unterste Eisvorkommen auf $3000 \mathrm{~m}$ bereits ein Wahrzeichen der rezenten Schneegrenze,

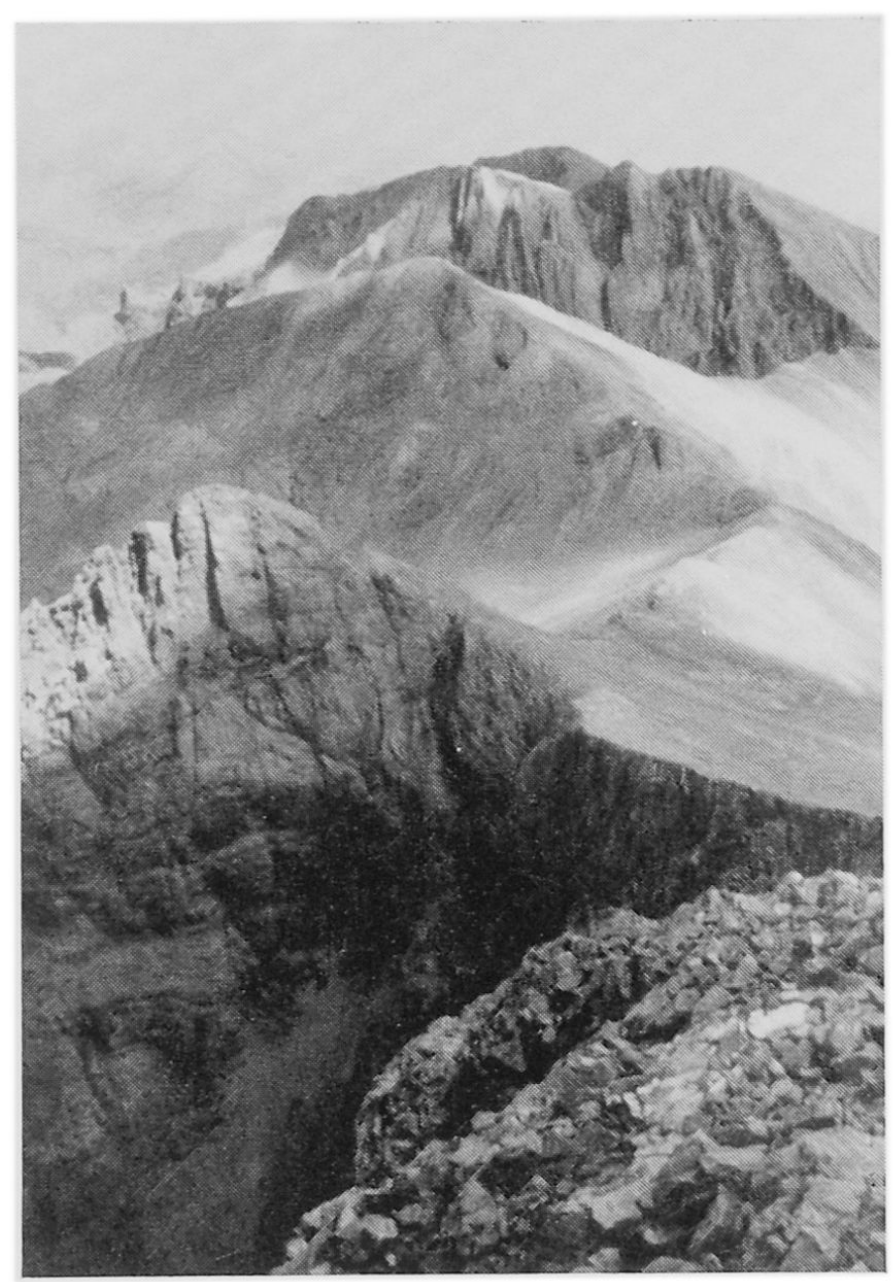

Abb. 14 Blick vom Medetsiz (3585 m) nach ENE über die höchsten Gipfel der Axialkette bis zum Tekirköprü Dagh. Prächtige Karformen auf der Nordseite, ausgeglichene und monotone Schuttund Glatthänge auf der Südseite.

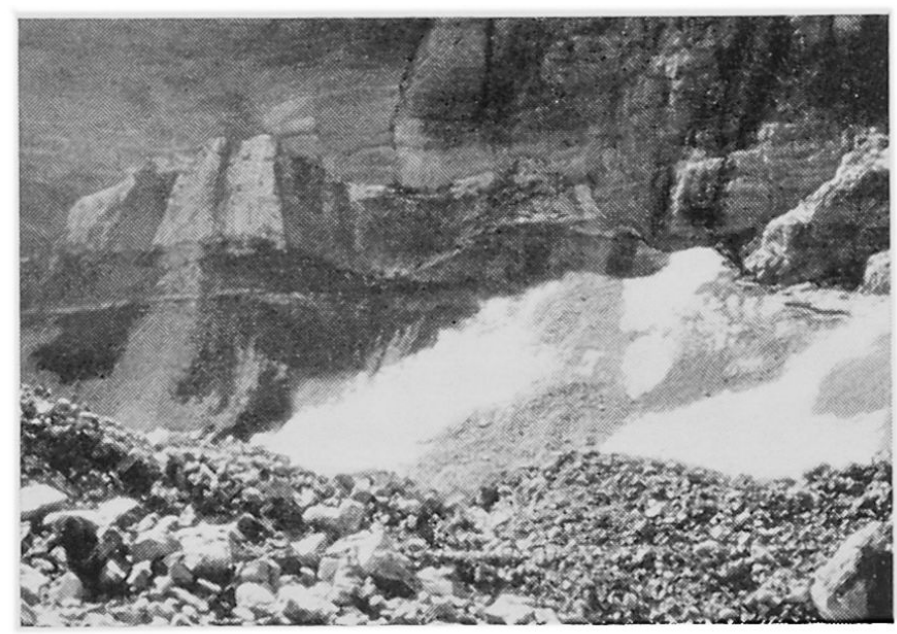

Abb. 15 Wandfußgletscher Medetsiz, Aufnahme 9.9. 62, ca. 11 Uhr. Das blanke Eis oberhalb und knapp unterhalb des kleinen Bergschrundes liegt fast den ganzen Tag im Schatten der Wand. Schuttüberdeckung und Altschnee schützen vor Ablation. 


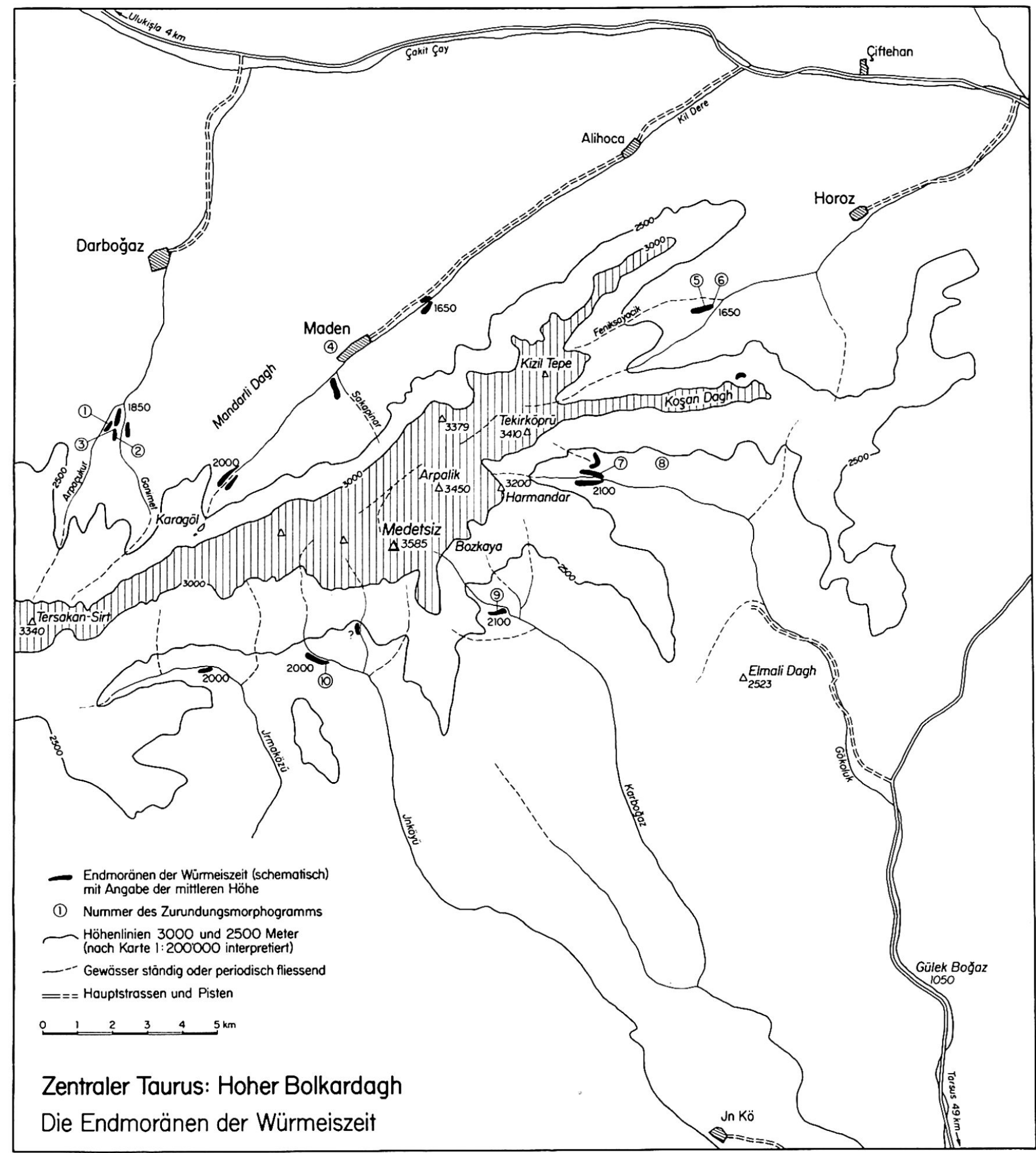

Fig. 3

dann müßten die höher gelegenen Firn- und Eisflecken mindestens mit einer schwachen Mächtigkeitszunahme oder Arealvergrößerung reagieren. Das ist nirgends der Fall, die rezente Schneegrenze muß noch höher liegen.

Wir sind uns bewußt, daß die Beurteilung der orographischen Begünstigung ein äußerst subjektives Kriterium ist. Wir wollen aber ebenso klar festhalten, daß eine Wand von 200-300 m Steilabfall mit einem Neigungswinkel, der auch in subtropischen
Breiten einen fast ganztägigen Schattenwurf bewirkt, eine eindeutig übermäßige Gunstlage erzeugt. Liegt das Nährgebiet, vielleicht sollten wir besser von Regenerationsgebiet sprechen (Seite 191), im ständigen Schatten der Wand, so ist ein Eisfleck sicher nicht repräsentativ für eine Schneegrenze, ja er kann sogar mehrere hundert Meter unterhalb der Schneegrenze liegen. Diese Situation ist im Hohen Bolkardagh ganz eindeutig gegeben.

Wir stellen uns nach diesen Ausführungen die Fra- 
ge, ob sich der Hochstand von 1850 wirklich in 100 $-300 \mathrm{~m}$ vorgestaffelten Moränen abzeichnete (147). Der Erciyas Dagh hat uns gezeigt, daß die rezenten Vorstöße genau gleich wie der heutige Stand auf die Schutzzone des Karraumes angewiesen waren. Die Moränendatierung nach Aussehen und Pflanzenbewuchs scheint mir noch zu wenig verläßlich und muß genauer untersucht werden.

Schließlich wollen wir die Tatsache festhalten, daß alle diese Karformen der Entstehung von Blockgletschern äußerst günstige Bedingungen boten. Blumenthal hat bereits auf diese Massenbewegungen hingewiesen, und auch Klaer hat interessante Erscheinungen entdeckt und beschrieben.

Nach einer genauen Beobachtung der Schattenhänge legen wir die rezente Schneegrenze auf der Nordseite in $3450 \mathrm{~m}$ Höhe fest, also ca. 100-200 m über den höchsten Eisflecken (203). Auf der Südseite muß die Schneegrenze bedeutend höher liegen. Eine Begehung zeigt uns, daß sie selbst in orographischen Gunsträumen nicht im geringsten angedeutet ist (z. B. Karbogaz oder Inköyü, Abb. 25), und daß sie zweifellos über dem Gipfelniveau verlaufen muß. Wir übernehmen gezwungenermaßen den Erfahrungswert aus Hochasien von Wissmann, der in subtropischen Breiten einen Unterschied Sonnseite_Schattseite von $400 \mathrm{~m}$ festlegte (359). Ob diese Differenz infolge des größeren südseitigen Niederschlages zu hoch gegriffen ist, können wir nicht entschieden. Deshalb muß die mittlere rezente und regionale Schneegrenze von $3650 \mathrm{~m}$ mit allem Vorbehalt aufgenommen werden.

Jedenfalls ergibt sich eine auffallende Ưbereinstimmung mit der Sierra Nevada, wo der Firnfleck des Veletakars am Fuße der 200-300 m hohen Gipfelwand auf $3100 \mathrm{~m}$ liegt ( «südlichster Gletscher Europas», Lit. 204). Auch dort haben wir die Schneegrenze auf $3650 \mathrm{~m}$ festgelegt, das heißt, der Firnfleck existiert 500_600 $\mathrm{m}$ unterhalb der heutigen regionalen Schneegrenze. Die beiden Gebirge liegen ungefähr auf dem gleichen Breitengrad (ca. $37^{\circ}$ ), erreichen ähnliche Höhen (Mulhacen $3478 \mathrm{~m}$, Medetsiz $3585 \mathrm{~m}$ ) und zeigen auch gewisse klimatische UUbereinstimmungen, so daß ein Vergleich der rezenten Schneegrenze naheliegend und aufschlußreich ist.

\subsection{Die würmeiszeitliche Vergletscherung und ihre Schneegrenze}

Wenn wir nacheinander die einzelnen Täler kurz besprechen, so beschränken wir uns vorwiegend auf die Untersuchung und Darstellung der Endmoränen. Dieses Vorgehen hat die folgenden Gründe:

- Zum ersten ist die Ausdehnung des Gebirges so groß, daß eine vollständige Begehung zeitlich nicht möglich war. Wir denken ganz besonders an die Südtäler, die teilweise fast weglose Anmarschstrecken von $25 \mathrm{~km}$ verlangten und in den interessanten Höhenlagen über $2000 \mathrm{~m}$ nur unter schwierigen Bedingungen passierbar waren (z. B. Inköyü).

- Zum zweiten aber ist eine vollständige Begehung im heutigen Zeitpunkt kaum sinnvoll, weil jegliche vernünftige Kartierungsmöglichkeit fehlt. Die amtliche Karte 1:200 000 ist absolut unbrauchbar; weder das Flußnetz noch der Kettenverlauf sind einigermaßen richtig wiedergegeben. Unter diesem Problem leiden alle bisherigen Arbeiten, und wir wollen auch für unsere Kartenbeilage (Fig. 3) klarstellen, daß alle Orts- und Höhenangaben fehlerhaft sind und beim Erscheinen eines neuen Kartenwerkes überarbeitet werden müssen. Aus diesem Grund verzichten wir auf die Eintragung des gesamten morphologischen Foimenschatzes und konzentrieren uns auf die präzise Untersuchung und Beschreibung der Endmoränen. Ergänzungen über besondere Karformen und Ablagerungen sollen das Bild vervollständigen, so daß doch als Ganzes eine sehr genaue Bestimmung der eiszeitlichen Schneegrenze möglich sein wird.

Wir beginnen unseren glazialmorphologischen Rundgang beim Darbogaz im Norden, wenden uns dann über Maden und Horoz nach den Südtälern Gökoluk, Karbogaz, Inköyü und Irmaközü. Die Ergebnisse sind auf Figur 3 eingetragen und die morphometrischen Auszählungen in den Zurundungsmorphogrammen der Figur 4 zusammengestellt.

\subsubsection{Die einzelnen Haupttäler}

Darbogaz (Fig. 3, Abb. 16, Morphogramme 1, 2, 3). Zwischen dem Karsee Karagöl und dem Tersakan Sirt heben sich mehrere Gipfelstöcke aus dem allgemeinen Gratprofil heraus. Auf ihrer Nordseite ist eine prächtige Karserie eingetieft, die einen hochalpin anmutenden Formenschatz von Moränen, Blockgletschern, Karseen, Rundbuckeln usw. enthält. In diesem Bereich haben sich zwei große Talgletscher entwickelt: der westliche Arpaçukur und der östliche Ganimet.

Die Endmoränen haben wir zwischen $2100 \mathrm{~m}$ und dem Zusammenfluß der beiden Bäche auf ca. $1850 \mathrm{~m}$ untersucht. (Die Höhenzahl $1850 \mathrm{~m}$ nach Karte 1 : 200000 scheint uns fraglich.) Die Ablagerungen des Arpaçukur-Gletschers fallen besonders auf, indem paläozoische Kalke aưf erhöhten Ophiolithstöcken liegen, deutlich abgehoben vom rezenten Schüttungsniveau des Baches (Abb. 16, Morphogramm 1). Gute Wallformen sind beidseits des Ganimet-Baches erhalten (in ca. $2000 \mathrm{~m}$ ), die schon von Blumenthal kartiert und beschrieben worden sind (20, Morphogramm 2). Die beiden würmeiszeit- 
1. Darbogaz -Tal

Arpaçukur $2000 \mathrm{~m}$

Moränen

Mittelwert 0,088

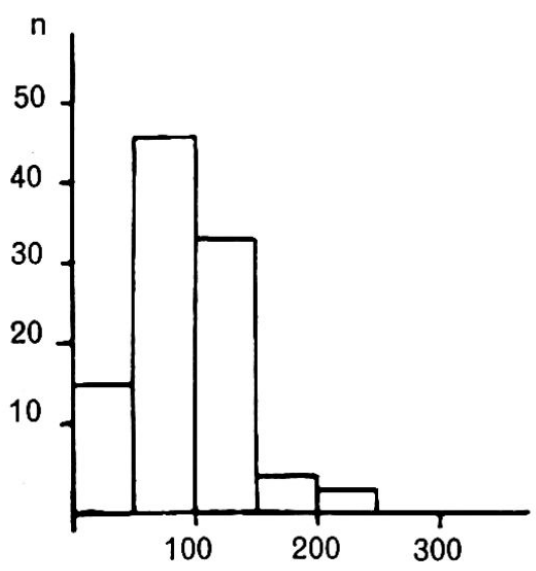

2. Darbogaz - Tal

Ganimet $2030 \mathrm{~m}$

Moränen

Mittelwert 0,094

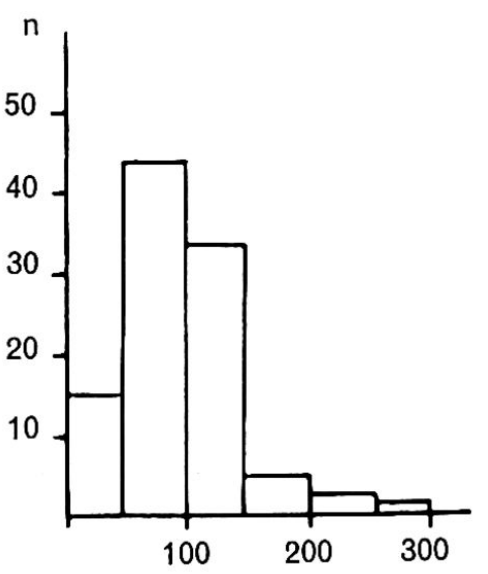

3. Darbogaz-Tal

Ganimet $2030 \mathrm{~m}$

Konglomerat

Mittelwert 0,137

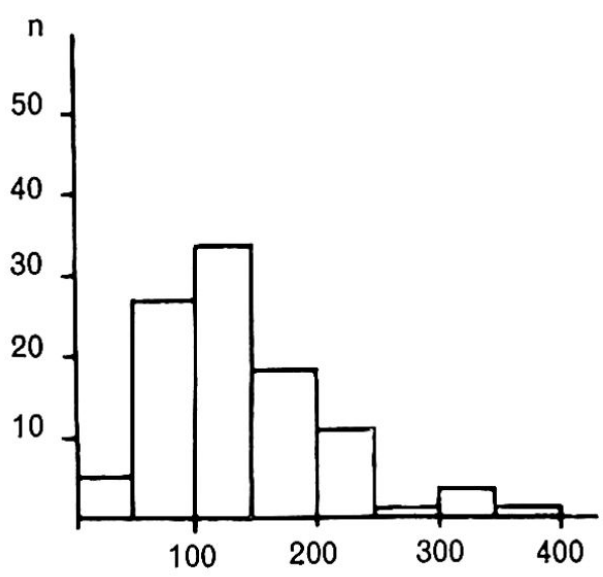

\section{Maden: Kil-Tal}

Oberhalb Maden (1790 m)

Fragliche Rissmoräne

Mittelwert 0,234

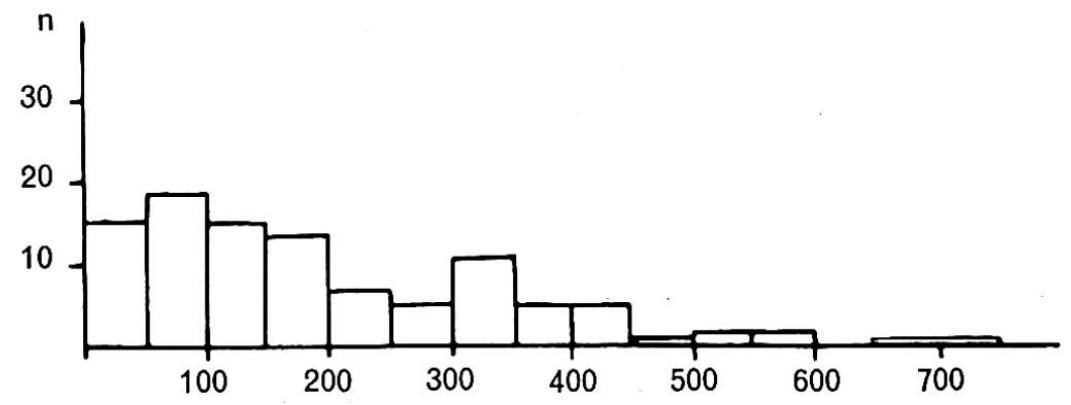

\section{Horoz-Tal}

Linke Talseite $1700 \mathrm{~m}$

Verbackene und aufgewitterte Moräne

Mittelwert 0,077

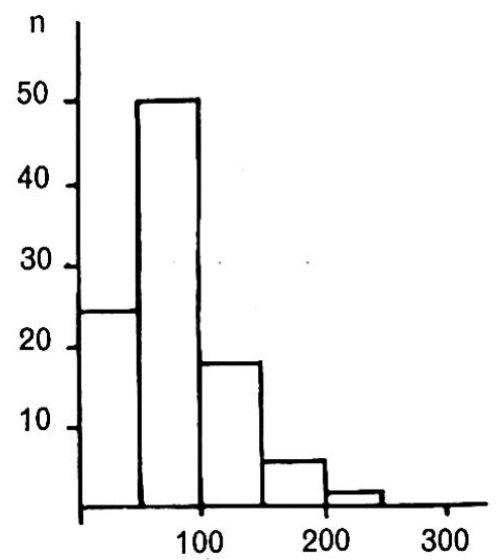

6. Horoz-Tal

Linke Talseite

Aufschluss aus dem Innern der gleichen Moräne

Mittelwert 0,099

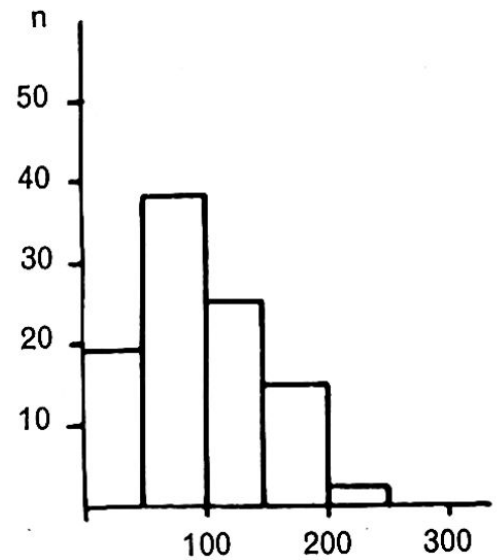

Fig. 4a Zurundungsmorphogramme aus den Endmoränen des Hohen Bolkardagh. 
7. Gökoluk-Tal

Haupttal $2260 \mathrm{~m}$

Seitenmoräne

Mittelwert 0,079

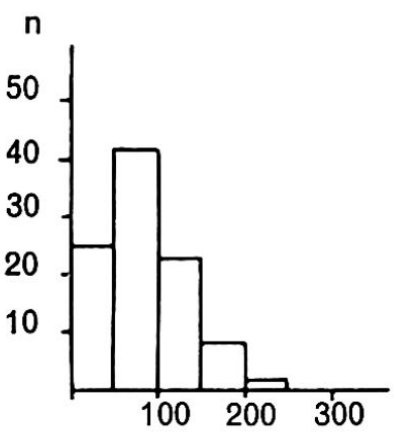

8. Gökoluk-Tal

Linke Seite $2200 \mathrm{~m}$

Sackungsmasse

Mittelwert 0,068

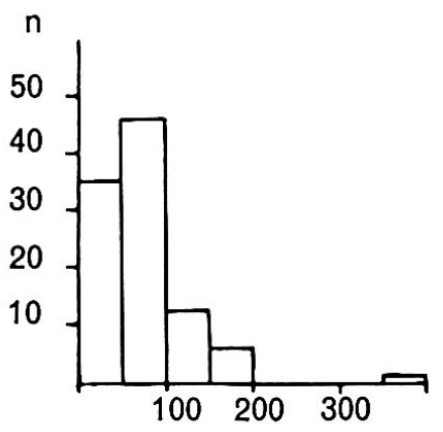

9. Karbogaz-Tal

Schlucht $2160 \mathrm{~m}$

Moräne

Mittelwert 0,091

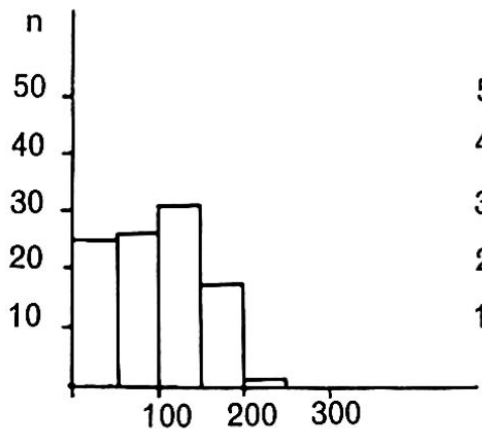

10. Inköyü-Tal

Westliches Seitental

Seitenmoräne

Mittelwert 0,075

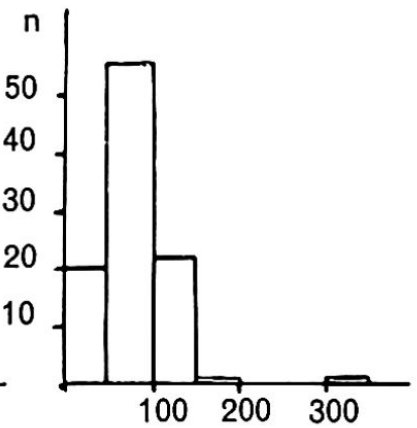

Fig. 4b Zurundungsmorphogramme aus den Endmoränen des Hohen Bolkardagh.

lichen Gletscher haben sich in ihrem Zungenbereich vereinigt und sind im Bereich des heutigen Zusammenflusses auf ca. $1850 \mathrm{~m}$ ausgeschmolzen.

Besonders interessant ist eine $5 \mathrm{~m}$ mächtige Konglomeratbank, die vom Würmgletscher überdeckt worden ist (Höhe $2030 \mathrm{~m}$, links des Ganimet-Baches, Morphogramm 3). Einregelung und Abplattung sind kaum feststellbar, höchstens eine schwache Schichtung. Die stark verbackenen kalkigen und kristallinen Komponenten schwanken von Nuß- bis Kopfgröße. Die Interpretation ist an dieser Stelle nicht ganz eindeutig. Sehr wahrscheinlich handelt es sich um eine präwürme Akkumulation, charakterisiert durch einen kurzen Transportweg und eine torrentielle Ablagerung.

Eine weitere Besonderheit bilden die äußerst tief gelegenen Nivationsnischen zwischen Arpaçukur und Ganimet, die wir funktional der Würmeiszeit zuordnen müssen. Berechnen wir zum Schluß die Schneegrenze für die vereinigten Darbogaz-Gletscher nach der HöferschenMethode, so ergibt sich ein streng lokaler Wert zwischen 2500 und $2550 \mathrm{~m}$ (Mittel aus 3200 und $1850 \mathrm{~m}$ ), was mit der glazialen Überformung außerhalb des Gletscherlaufes gut übereinstimmt.

Maden (Fig. 3, Abb. 17, Morphogramm 4)

Das Maden- oder Kil-Tal ist über $20 \mathrm{~km}$ lang, beginnt oberhalb des Karagöls, zieht sich dem imposanten Felsabsturz der Frontalkette entlang und endet im Zusammenfluß mit dem Çakit Çay westlich Çiftehan. Die glazialmorphologische Situation ist schon von Louis (185), Blumenthal (20) und Klaer (147) beschrieben worden. Zwei würmeiszeitliche Gletscher sind zu unterscheiden:

-Zum ersten der bedeutendere Sakapinar-Gletscher, dessen Nährgebiet durch das durchschnittlich 2,5 km lange Hochbecken (20) bis an den Fuß des Medetsiz reichte (Abb. 24). Zwischen 1 und $2 \mathrm{~km}$ tal- aufwärts vom Dorf Maden brandete der mächtige, steil herabfallende Eisstrom im Talboden auf und legte in diesem Gefällsknick eine gewaltige Materialdeponie ab. Die Mächtigkeit dieser linken Seitenmoräne war so groß, daß die natürliche Längstalung in den Maximalphasen abgesperrt wurde, was sich in den aufstoßenden Stauschottern zeigt. Das Zungenbecken liegt unterhalb des Dorfes Maden. Die Endmoränen sind aber mit Sturz- und Sakkungsmaterial vermengt und nicht mehr eindeutig zu erkennen. Deshalb wurden sie wohl weder von Blumenthal noch von Louis erwähnt. An dieser Stelle verändert sich auch das Querprofil des Tales, die breite Sohle geht in ein enges, klammartiges Bachbett über. Die Höhe beträgt nach der amtlichen Karte 1600-1650 m.

- Zum zweiten der unbedeutendere Gletscher im obersten Kil-Tal, der in der Frontalkette über den beiden Karseen Çinilgöl und Karagöl einsetzte, ein breites Hochbecken durchfloß und seine letzten sichtbaren Moränen auf ca. 2000 m ablegte. Ob wir diese Ablagerungen wirklich als Endmoränen bezeichnen können, wie Blumenthal und Klaer es tun, scheint uns noch sehr fraglich. Es ist anzunehmen, daß die steilen Rinnen der Frontalkette kleine Eisströme bis in die Talsohle geführt und den Talgletscher verstärkt haben. Ferner müssen wir bedenken, daß das Haupttal unterhalb $1800 \mathrm{~m}$ in das Stauniveau der Sakapinar-Moräne gelangte, wo ganz andere Sedimentationsbedingungen entstanden. Da sich aber diese Überlegungen nicht eindeutig beweisen lassen, ferner das Einzugsgebiet des Gletschers nicht sehr groß und vor allem nicht sehr hochgelegen war, beschränken wir uns in der Kartenbeilage mit der Darstellung der Moränen auf $2000 \mathrm{~m}$.

Nach dieser Beschreibung der würmeiszeitlichen Gletscher bleiben immer noch zahlreiche Probleme 
offen. Vor allem haben die Ablagerungsformen am Nordhang oberhalb Maden bis heute keine eindeutige Interpretation gefunden. Louis sieht in den paläozoischen Kalken, die ortsfremd diesen Hang bedecken, einesteils bis auf $1750 \mathrm{~m}$ eine natürliche Fortsetzung der linken Sakapinar-Seitenmoräne (Dorfhöhe Maden ca. $1700 \mathrm{~m}$ ), andererseits in höheren Lagen die Reste einer älteren Moräne, die aus einem stellenweise noch sichtbaren festverkitteten Konglomerat auswittert (185, S. 466). Klaer deutet dieses erratische Material bis zu 90 m über der Talsohle ganz eindeutig als Relikt einer älteren Eiszeit $(147$, S. 83$)$. Wir haben eine morphometrische Auszählung vorgenommen und erhalten einen außerordentlich hohen Mittelwert von 0,234 (Morphogramm 4), also viel stärkere Bearbeitung als das Konglomerat im Darbogaz (Morphogramm 3). Die Frage ist gestellt, ob es sich überhaupt um Moräne handelt.

In der Staulage oberhalb des talsperrenden Sakapinar-Walles können wir verschiedene Schotterlagen unterscheiden, die andersartig verfestigt und gerundet sind. Hat sich dieser Stauprozeß mehrmals wiederholt, und lassen sich dementsprechend mehrere Phasen erkennen? Verschiedene Altersserien lassen sich auf engstem Raum sicher unterscheiden, die möglichweise mit älteren Kaltzeiten zu korrelieren sind.

Wir müssen diese komplexen Probleme im heutigen Zeitpunkt noch offen lassen. Ohne eine sehr genaue sedimentologische Untersuchung und Kartierung kann kein gültiger Entscheid gefällt werden. Nach unserer Meinung bildet die Umgebung des Dorfes Maden eine Schlüsselstelle, die im Vergleich mit andern Tälern künftighin interessante Ergebnisse zur Quartärgeschichte des Taurus liefern wird.

Kommen wir auf die Frage der lokalen Schneegrenze im Madental zurück. Die prächtigen Wannenund Karformen unterhalb und oberhalb des Karagöls zeigen uns an, daß die Höhenlage 2600_2700 m bereits beträchtlich über der Schneegrenze liegen mußte. Umgekehrt hat der Mandarli Dagh nördlich des obern Madentales (Fig. 3) mit einer Höhe von $2500 \mathrm{~m}$ keine Vergletscherungsspuren aufzuweisen. Diese Indizien engen die mögliche würmeiszeitliche Schneegrenze bereits auf den Höhenbereich 2500_2600 m ein. Dazu kommt ein auffälliges Ausapern der Seitenmoräne im obersten Kil-Tal unterhalb $2500 \mathrm{~m}$, was ebenfalls ein Unterschreiten der Schneegrenze andeutet. Berechnen wir schließlich die Schneegrenze nach der Höferschen Methode für den Sakapinar-Gletscher, so erhalten wir aus dem Mittel zwischen 3400 m (mittlere Kammhöhe in der Umrandung des Nährgebietes) und $1650 \mathrm{~m}$ (Endlage) den Wert von 2500 bis $2550 \mathrm{~m}$. Als Ganzes betrachten wir eine würmeiszeitliche Schneegrenze im Raume Darbogaz-Maden von $2500 \mathrm{~m}$ bis $2550 \mathrm{~m}$ als gut gesichert.

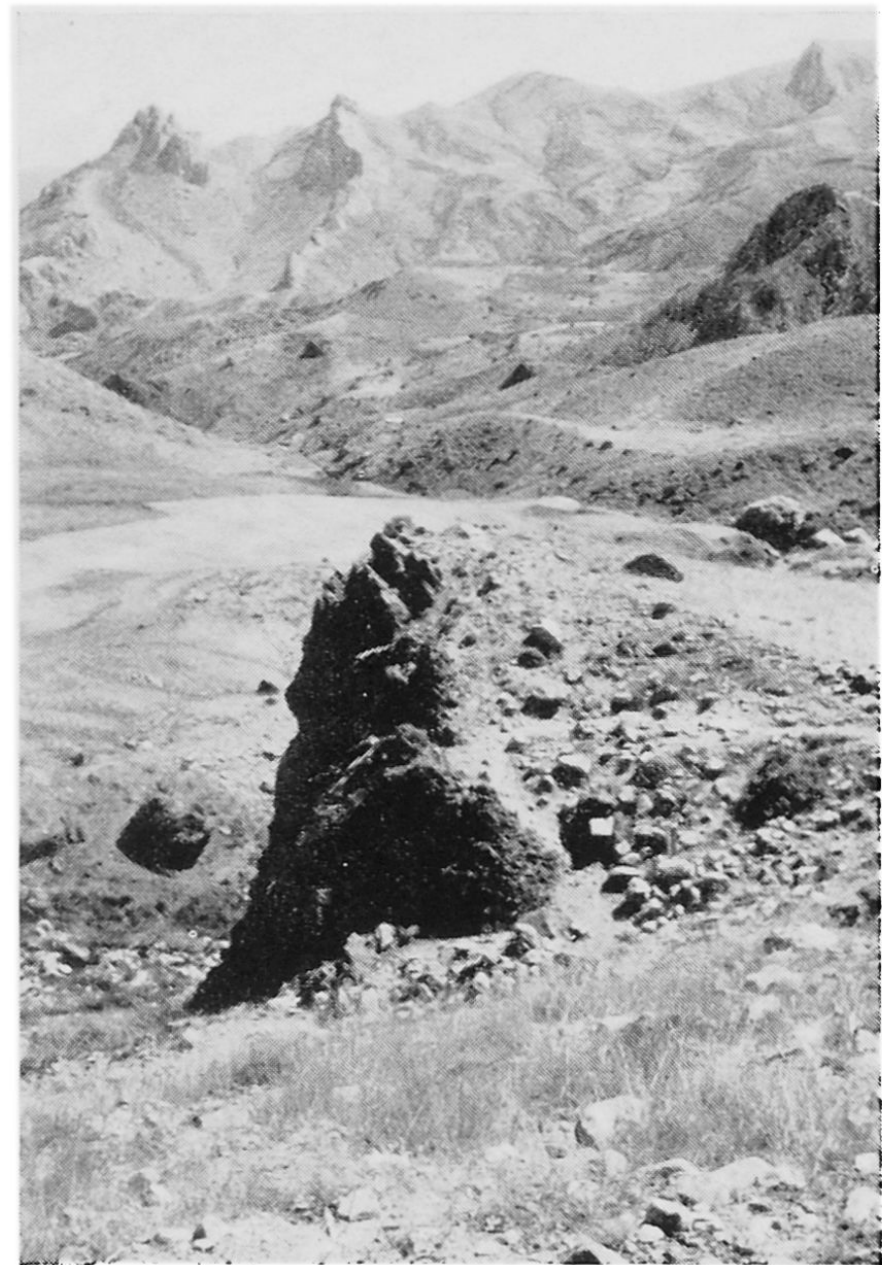

Abb. 16 Darbogaz. Wir stehen auf der Endmoräne des eiszeitlichen Arpaçukur-Gletschers. Im Vordergrund anstehender Ophiolithstock, darauf glazial transportierte paläozoische Kalke aus der Frontalkette. Talabwärts die Endmoränen im Zusammenfluß Arpaçukur_Ganimet auf ca. $1850 \mathrm{~m}$.

\section{Horoz (Fig. 3, Abb. 18, Morphogramme 5, 6)}

Die kartographischen Unterlagen sind in diesem interessanten Tal sehr schlecht und die Höhenlinien der amtlichen Karte unbrauchbar. Unsere Aufzeichnungen und besonders die Höhenangaben sind deshalb mit größtem Vorbehalt aufzunehmen.

Steigen wir vom Dorf Horoz ca. $2 \mathrm{~km}$ talaufwärts, so erreichen wir eine markante Talgabelung. Folgen wir nun der Haupttalung, die in das Hochbekken des Gebirges führt, so erreichen wir über eine Breccien- und Konglomeratterrasse auf der nördlichen Talseite nach weiteren $2-3 \mathrm{~km}$ einen auffallenden Wall in ca. 1650-1750 m. Diese Stelle wollen wir genauer untersuchen, indem wir am höchsten Punkt bei den anstehenden Felsen beginnen und stufenweise bis zum Bachniveau absteigen:

- Anstehende Kalkbänke mit einem Schichtfallen von $25^{\circ} \mathrm{NE}$. Felssackungen sind möglich.

- Auf 1800 m Übergang zu einer Hangbreccie. Größe der Komponenten stark variierend, gut verkittet. 
Vorwiegend Kalk, sehr selten ein kristallines Stück. (Diese Grüngesteine am Kizil Tepe und im Seitental des Feniksayacik anstehend, vgl. Blumenthal 20, Tafel 11.) Alle kristallinen Komponenten sind bearbeitet, kantenbestoßen oder sogar leicht gerundet. Neigungswinkel der Hangbreccie an der Ansatzstelle $26^{\circ}$, unten noch $22^{\circ}$.

- Auf $1760 \mathrm{~m}$ beginnt eine Übergangszone, die Hangschuttbreccie löst sich auf, darüber liegt eine lockere Materialstreu. Kristalline Blöcke von über $1 \mathrm{~m}^{3}$ treten auf, das Material ist kantenbestoßen. Der Neigungswinkel der Oberfläche nimmt weiter ab und endet in einer Verflachung auf dem Grat (Standort einer Yayla mit Laubhütten, in der Nähe eine kleine Quelle).

- Von $1740 \mathrm{~m}$ an, unterhalb der Yayla, stellen wir einen deutlichen Abfall des Walles bis auf $1630 \mathrm{~m}$ fest. Der scharf gezeichnete Grat, im Mittel $50 \mathrm{~m}$ hoch, weicht um $40^{\circ}$ von der Talrichtung ab und tendiert abwärts zur Talmitte. Die Materialzusammensetzung hat gewechselt, der kristalline Anteil hat sich verstärkt. Kalkblöcke bis zu $6 \mathrm{~m}^{3}$, Kristallinblöcke bis zu $4 \mathrm{~m}^{3}$ Inhalt fallen auf. An der Oberfläche tritt eine Konglomeratplatte auf, gut verbacken, partiell stark aufgelöst. Das oberflächliche Material stammt offenbar aus dieser verkitteten Deckschicht (Morphogramm 5), wie anhaftende Reste des Bindemittels beweisen.

- Fußpunkt des Walles auf $1630 \mathrm{~m}$. Hier haben die Hirten einen künstlichen Aufschluß gegraben, um Wasser zu gewinnen (Abb. 18). Erstaunlicherweise ist von dem Konglomerat nichts mehr zu sehen, sondern es erscheint eine Gesteins- und Feinerdepakkung, die wir nach der Größenverteilung, Zurundung und Materialzusammensetzung nur als Moräne bezeichnen können (Morphogramm 6). Die heraussickernde Wassermenge ist gemäß der Lage ganz unbedeutend.

- Darunter folgt ein imposanter Felsabsturz von über $100 \mathrm{~m}$ bis zum Bachniveau, der durch eine äußerst kompakt verbackene Breccie gebildet wird. Blumenthal bezeichnet sie als Bergfußbreccie. Die Komponenten sind teilweise sehr groß, eckig und unbearbeitet.

Dieses äußerst interessante Querprofil deuten wir beim heutigen Stand der Kenntnisse folgendermaBen:

-Die Bergfußbreccie ist an Ort und Stelle entstanden, sonst müßte ein großer kristalliner Materialanteil eingeschlossen sein. Die Entstehung dieser Ablagerungsform verlangt größere Niederschläge, vielleicht eine Pluvialzeit im Sinne Blumenthals. Noch genauer: Kein Gletschervorstoß hat vor und während ihrer Bildung den Talboden erreicht, ein Abfluß und Materialtransport vom Hochbecken her existierte noch nicht. Die im Tertiär angelegte Talung wurde im älteren Diluvium durch Gehänge-

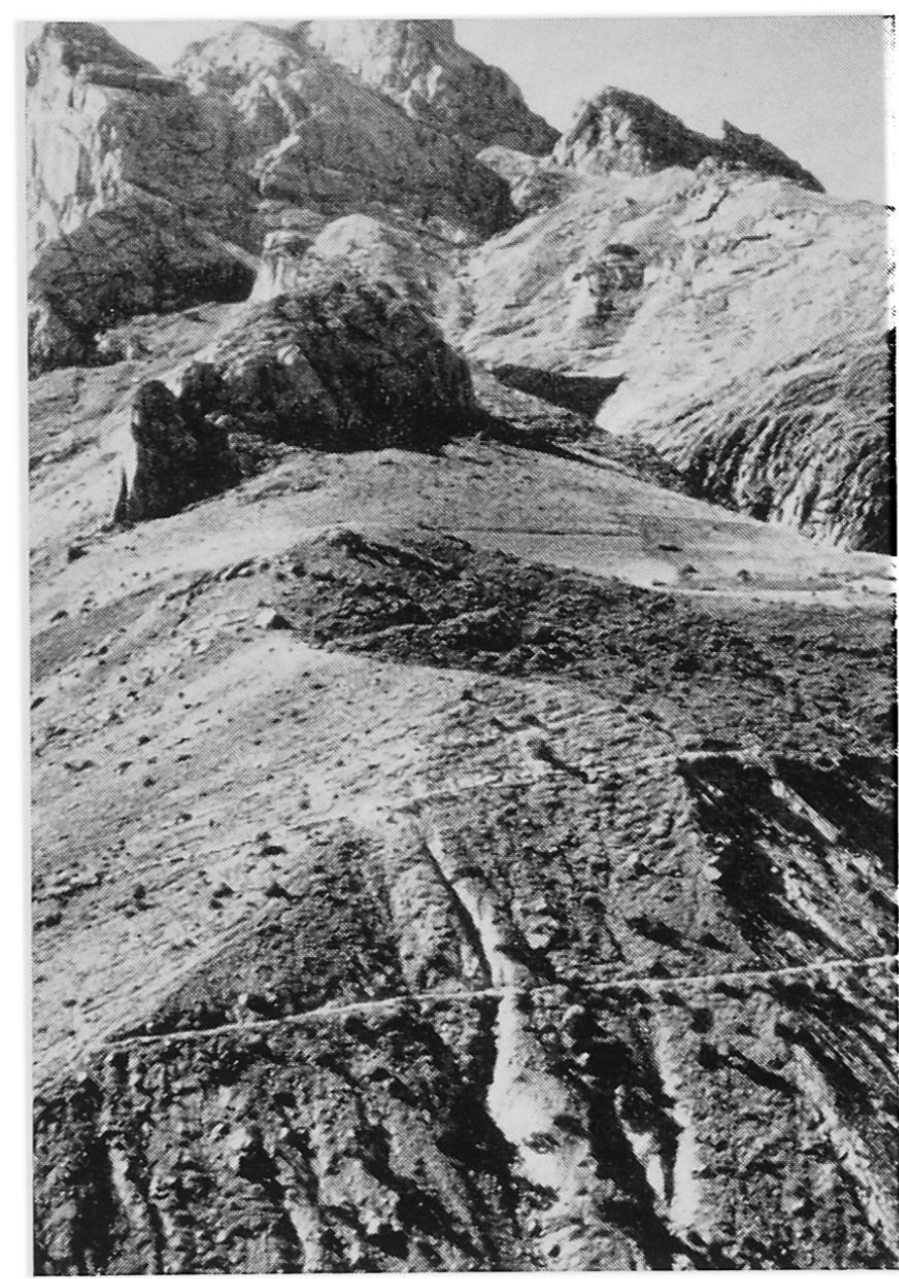

Abb. 17 Maden. Links Seitenmoräne des Sakapinar-Gletschers. Sie beginnt an einem Felssporn der Frontalkette und hat bis zu unserem Photostandort auf dem Gegenhang das Madental gesperrt. Der Bach aus dem oberen Madental hat diesen Querwall durchbrochen. Photo in der Haupt-Talrichtung bei Klaer, Abb. 31.

schutt eingedeckt. Zusammenhänge mit orogenetischen Vorgängen, vor allem Hebungen, sind denkbar. Der heutige Bachlauf hat sich 100-200 m eingeschnitten, was durch die eiszeitlichen Gletschervorstöße und ihre Schmelzwassermengen möglich war. (Ohne Gletscher vorwiegend Karstentwässerung.)

- Altere Moränenreste sind abtransportiert oder in spätere Konglomeratbänke einzementiert worden.

- Die Würmmoräne ist ganz deutlich erhalten, schräg in der Talrichtung liegend, mit $50 \mathrm{~m}$ Höhe aus dem Breccienplateau herausgehoben. Wenn es sich nur um den Rest einer ehemaligen Konglomeratplatte handeln würde, so hätte sich kein scharfgeschnittener Grat gebildet, sondern eher eine geneigte und aufgelösteFläche, die keinesfalls als Wasserreservoir dienen könnte. Ferner ergäbe ein fluvioglazial gebildetes Konglomerat einen andern $\mathrm{Zu}$ - 
rundungsgrad (Morphogramm 5 und 6, 3 und 4, Lit. 16).

- Die Hangbreccie ist während der Kaltzeiten auBerhalb der gletscherbedeckten Flächen in tieferen und wärmeren Lagen gebildet worden. Einzelne ortsfremde Komponenten stammen aus einem Maximalstand des Würm- oder Rißgletschers. Sie blieben in erhöhter Lage liegen und wurden in die Hangbreccie einzementiert.

Die niedrige Endlage im Horoz-Tal erstaunt uns nicht, obschon Blumenthal die Gletscherzunge in $2200 \mathrm{~m}$ vermutet hat (20, S. 151). Dieser Eismasse stand wohl das größte Einzugsgebiet aller Bolkardagh-Gletscher zur Verfügung. Nach den glazialen Erosionsformen auf der südexponierten Seite des Kizil Tepe betrug die Gletscherhöhe beim Austritt aus dem Hochbecken mindestens $250 \mathrm{~m}$. Der nun folgende enge, tiefe und gefällsstarke Talschlauch des oberen Horoz-Tales gab dem Gletscher eine konzentrierte Fließkraft und dementsprechend die Möglichkeit zu einer tiefen Endlage. Möglicherweise war die tiefe Schlucht im Zungenbereich verstopft, so daß wir diesen seitlichen Wall morphologisch noch viel besser verstehen und ihn mit größter Wahrscheinlichkeit als Endmoräne ansprechen dürfen. Die Gletscheilänge, beginnend am Fuß des Arpalik Dagh, betrug beinahe $9 \mathrm{~km}$ (vgl. Fig. 3).

Diese Gunstfaktoren haben eine Endlage bewirkt, die höhenmäßig dem Madental entspricht. Nach der Höferschen Methode ergäbe sich wiederum eine Schneegrenze von nahezu $2500 \mathrm{~m}(3300 \mathrm{~m}$ und $1650 \mathrm{~m})$. Wir befinden uns aber im Horoz-Tal, in einer gebirgsinternen Zone mit allen klimatischen und orographischen Nachteilen für eine Vergletscherungshöhe. Daß sie beträchtlich hinaufgedrückt wurde, beweisen uns die seitlichen, nordexponierten Kare am Kosan Dagh (ca. 2 km südlich der Endmoränen). Dort haben sich selbständige Gletscher mit präohtigen Moränenwällen gebildet, die Blumenthal auf $2750 \mathrm{~m}$ festlegte. Sie zeigen uns deutlich, daß der Talgletscher allein nicht repräsentativ ist für die Bestimmung der Schneegrenze. Wir vermuten sie daher eher im Höhenbereich 2600-2700 Meter.

\section{Gökoluk (Fig. 3, Abb. 19, Morphogramme 7, 8)}

Die Moränen im Gökoluk-Tal hat Blumenthal bereits erwähnt $(20$, S. 122,150$)$, und wir wollen sie nach eigener Begehung als die besterhaltenen Formen des Hohen Bolkardagh bezeichnen. Zwei würmeiszeitliche Gletscher gilt es zu unterscheiden:

- Zum ersten der Haupttalgletscher: seine Wurzel liegt in der Einmuldung zwischen der Axialkette (Medetsiz_Arpalik_Tekirköprü) und der BozkayaSchuppe (Bozkaya_Harmandar) auf über $3000 \mathrm{~m}$ Höhe (Fig. 3; 20, Tafel II). Die Endlage zeichnet

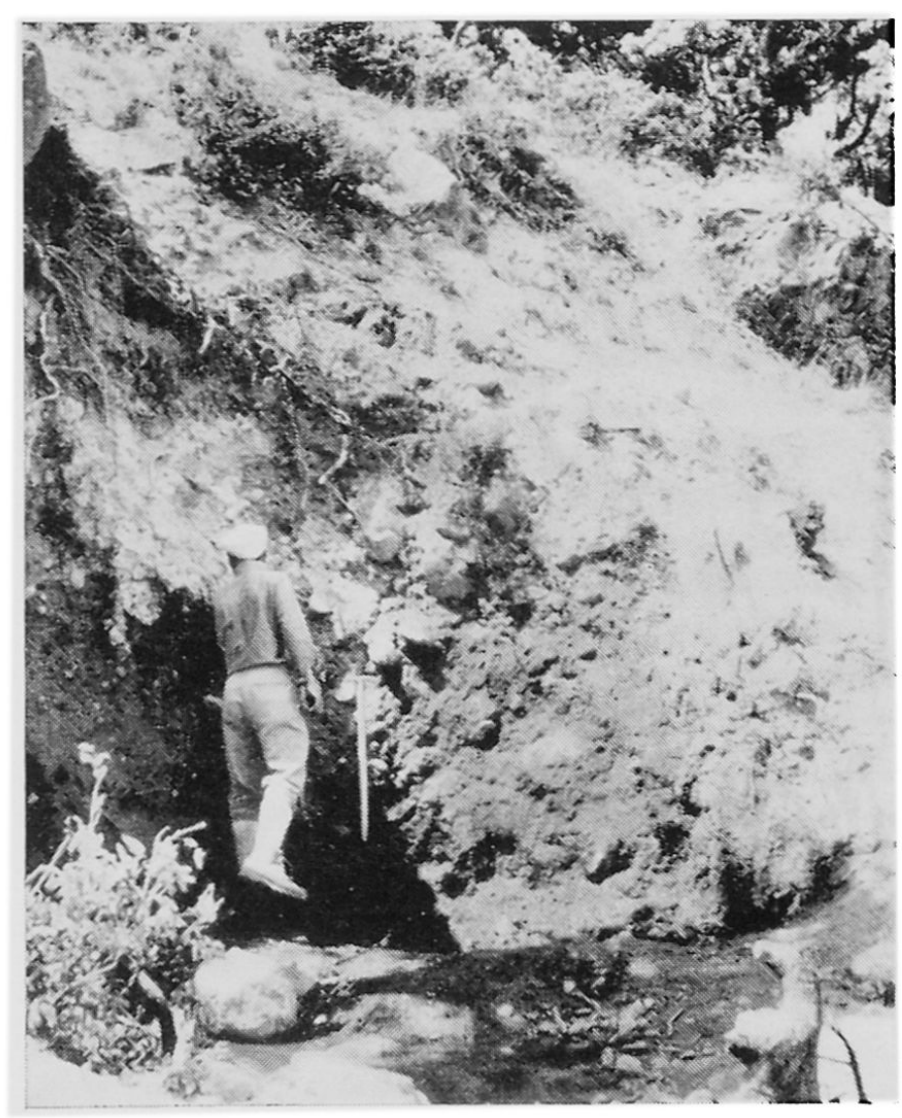

Abb. 18 Horoz. Endmoräne auf ca. 1650 m. Auf der Suche nach Wasser haben die Hirten einen eindeutigen Aufschluß geschaffen. Die Oberfläche des Moränenwalles mit einer verkitteten Deckplatte ist schwieriger zu interpretieren.

sich in den beiden prächtigen Seitenmoränen ab, die auf $2100 \mathrm{~m}$ auslaufen (Abb. 19, Morphogramm 7).

- Zum zweiten der Seitentalgletscher: aus dem Raum des Tekirkröpü fällt eine enge Talrinne in ESE-Richtung steil herunter. Hier mußte sich ein schmaler, aber kräftiger Gletscher gebildet haben, wie der schön geschlossene Endmoränenwall auf ca. $2300 \mathrm{~m}$ beweist (Abb. 19).

Neben dieser eindeutig klaren Situation finden wir talabwärts eine ausgedehnte Sackungsmasse, die mit ihrer Stirn auf $1900 \mathrm{~m}$ an den Gökoluk-Bach stößt. Moränenähnliche Wallformen treten auf, und eine morphometrische Analyse auf $2200 \mathrm{~m}$ ergab den erstaunlich hohen Mittelwert von 0,068 (Morphogramm 8). Aber im Vergleich mit den andern $\mathrm{Zu}$ rundungswerten ist es weitaus der niedrigste, keine andere Auszählung ergab ein Mittel unter 0,070. Der Materialinhalt dieser Massenbewegung ist sehr reichhaltig (paläozoische Kalke, Phyllite, Permkalke und Permschiefer) und entspricht der komplexen lokalen geologischen Situation. Die Schieferserien bieten ideale Gleithorizonte, und die Kontaktbereiche ergeben die nötigen Schwächezonen, um größere Massen in Bewegung zu setzen. Wir haben uns auf Grund der morphometrischen Auszählung 
höchstens gefragt, ob in diesem Material ältere Moränenteile enthalten sein könnten. Diese Vermutung können wir noch nicht eindeutig belegen, deshalb schließen wir sie vorläufig aus. Die Massenbewegung ist heute weitgehend zum Stillstand gekommen.

Fragen wir uns zum Schluß nach der Schneegrenze, so müssen wir wohl bedenken, daß sich das Einzugsgebiet des Gökoluk-Gletschers in den nordexponierten Flanken des $3200 \mathrm{~m}$ hohen Harmandar befand und nicht etwa in der Südauslage des höheren Tekirköprü. Offene und ungegliederte Südhänge fielen für eine Gletscherbildung weitgehend aus. Deshalb haben wir nach der Höferschen Methode $3200 \mathrm{~m}$ und $2100 \mathrm{~m} \mathrm{zu}$ mitteln, das ergibt einen mittleren Schneegrenzwert von $2650 \mathrm{~m}$. Für das ESE-gerichtete Seitental liegt die lokale Schneegrenze schon bedeutend höher. Diesen Wert können wir aber nicht bestimmen, weil wir das Einzugsgebiet zu wenig genau kennen. Im gesamten zeigt uns das Gökoluk-Tal die Größe und Bedeutung der würmeiszeitlichen Moränen selbst bei relativ kleinen Gletscherbildungen. Diesen Eindruck haben wir in die südseitigen Täler mitzunehmen, wo heute nur noch schwache Rudimente für das ehemalige eiszeitliche Geschehen zeugen.

\section{Karbogaz (Fig. 3, Abb. 20, Morphogramm 9)}

Dieses Südtal wurde bisher als moränenlos betrachtet und eine Vergletscherung überhaupt in Frage gestellt. Das Karbogaz erreichen wir sehr leicht vom Gökoluktal her. Der Übergang bietet einen einzigartigen Blick auf die Bozkaya, die südlichen Vorberge des Medetsiz (Abb. 20). Eine mächtige, gut gebankte Marmorserie steigt steil auf und wird durch eine Phyllitmulde vom Bolkardagh-Marmor des Medetsiz getrennt (20). Aus diesem imposanten Felsabsturz treten zwei Schluchten aus, die durchgehende Haupttalung ist am Wasserreichtum leicht zu erkennen.

In dieser Schlucht steigen wir empor und erreichen auf $2100 \mathrm{~m}$ den Fußpunkt eines $100 \mathrm{~m}$ hohen Walles auf der rechten Bachseite. Die obersten $30 \mathrm{~m}$ sind durch Sturzmaterial aus der steilen Felswand überschüttet, darunter aber tritt eine eindeutige Moränenpackung hervor. Sie läßt sich am Feinerdegehalt, an der stark variierenden Komponentengröße und vor allem am Zurundungsgrad erkennen (Morphogramm 9). Wie erklären wir uns die Ablagerung in dieser Klamm? Die beidseitigen Felswände boten einem Gletscher außerordentlich guten Schutz. Im oberen Tallauf läßt sich die glaziale Schleifwirkung deutlich von der fluviatilen Einkerbung unterscheiden. An der Ablagerungsstelle verbreitert sich die Schlucht, die Felswände weichen ein wenig zurück. Dieser freie Raum bewirkte eine Gesohwindigkeitsveränderung des Gletschers und dementsprechend eine Ablagerung des Materials. Wir könnten uns

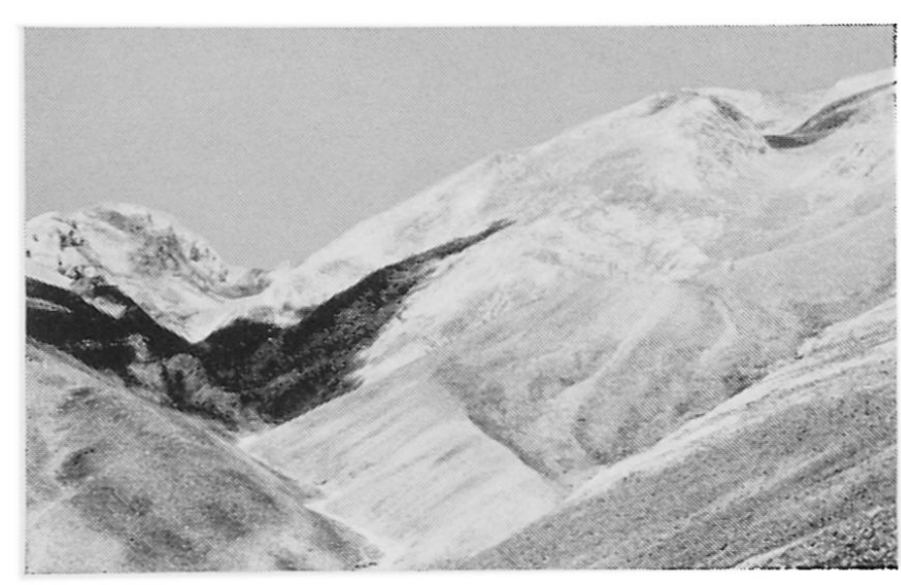

Abb. 19 Gökoluk. Links hinten der Harmandar, rechts oben, unsichtbar, der Tekirköprü Dagh. Die prächtigen Moränenwälle im Haupttal markieren die Endlage auf $2100 \mathrm{~m}$. Rechts kommt ein Seitentälchen vom Tekirköprü herunter und endet in einem geschlossenen Moränenwall auf ca. $2300 \mathrm{~m}$.

zwar einen Gletscheraustritt aus dem Engnis auf 2000 m während einer größeren Oszillation vorstellen, aber für längere Zeiten konnte sich eine so geringe Eismasse, breit auseinandergeflossen in der Höhenlage unter $2000 \mathrm{~m}$, nicht halten. Für die Beurteilung der Moränenlage ist eine weitere Überlegung wichtig: Eine so gewaltige Deponie kommt in einem solchen steilen Engpaß nur durch eine gewaltsam erzwungene Ablagerung zustande, keines-

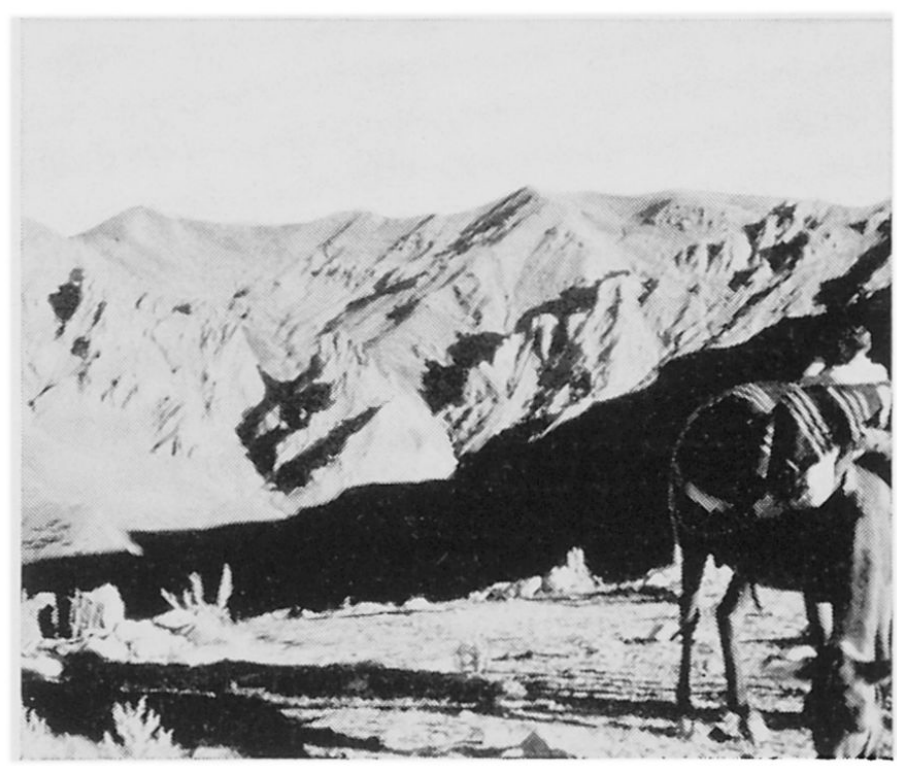

Abb. 20 Karbogaz. Die Axialkette von Süden, Medetsiz links außen. Davor die steilgestellten paläozoischen Kalke der Bozkaya-Schuppe, die als scharfe Felszacken von den Seiten her absteigen und in ihrem tiefsten Punkt die beiden KarbogazSchluchten austreten lassen. In der linken Klamm ist auf $2100 \mathrm{~m}$ eine Moräne erhalten. 
falls durch ein langsames fluviales Aufschütten. Die Verstopfung der Entwässerungsrinne könnte durch zwei Vorgänge bewirkt worden sein: Bergsturz oder Moräne. Das erste fällt materialmäßig eindeutig weg. Es kann sich nur um eine Moräne handeln, die in der Folgezeit durch den Bach wieder aufgerissen wurde. An der oberen Seite hat sich ein Prallhang gebildet mit einem Böschungswinkel von $38^{\circ}$, der uns den labilen Zustand und den heute noch wirkenden Abtragungsvorgang anzeigt.

Die Schneegrenze zu bestimmen ist möglich, aber nicht sehr vielsagend. Der lokal eng begrenzte Wert von ca. $2700 \mathrm{~m}$ bezieht sich nur auf diese Gunstlage.

\section{Inköyü (Fig. 3, Abb. 21, Morphogramm 10)}

Auch in diesem Tal, wie im Karbogaz, ist das offizielle Kartenbild unbrauchbar, unsere Darstellung beruht auf einer eigenen Geländeinterpretation.

In der großen Talverzweigung auf ca. $1700 \mathrm{~m}$ gehen drei Täler auseinander. Das östliche umgeht die steilen Marmorbänke der Bozkaya-Schuppe und führt, regelmäßig ansteigend, in die Hochtalung vor dem Medetsiz. In den ausgeglichenen und schuttüberdeckten Hangformen fehlen jegliche Glazialspuren.

Das mittlere Tal überwindet die Höhenstufe zwischen 1750 und 2200-2300 $\mathrm{m}$ in einer tiefen, unbegehbaren Schlucht. Die paläozoischen Kalke sind zu Glatthängen abgewittert, und die fluviatile Erosion hat sich außerordentlich tief eingeschnitten. Wir haben die untersten Schultern beidseits der tiefen Klamm begangen, aber keine glazialen Ablagerungen gefunden. Wir müssen daraus schließen, daß der Inköyü-Gletscher diese Schlucht kaum durchstoßen hat. Oberhalb der Klamm können Moränen beobachtet werden. Louis gab ihnen die Höhe 2500 m (185, S. 464), doch müssen sie nach unserer Schätzung mindestens $200 \mathrm{~m}$ tiefer liegen (Beobachtungsstandont, Gipfel: $2 \mathrm{~km}$ südlich Medetsiz; auf der Karte haben wir diese Moräne mit einem Fragezeichen versehen). Bleiben hier noch zahlreiche Probleme ungelöst, so zeigt dafür das westliche Inköyü-Tal die würmeiszeitlichen Ver'hältnisse ganz klar auf.

Am Südhang des Tales ist eine langgezogene und guterhaltene Seitenmoräne zu erkennen (Abb. 21). Die Wallhöhe beträgt 70-100 m über dem Bach, senkt sich dann vor einer quer im Tal liegenden Felsrippe rasch ab und endet auf ca. $2000 \mathrm{~m}$. Der Wechsel vom Sohlen- zum Kerbtal und die Epigenesen des Bachlaufes unterstreichen die Bedeutung der glazialen Ablagerungsformen. Im Materialinhalt fallen Stücke einer älteren Breccie auf, die sehr wahrscheinlich präwürm gebildet und würmeiszeitliah aufgearbeitet und umgelagert wurde. Demgegenüber ist ein jüngeres Konglomerat deutlich zu unterscheiden, das genau gleich wie im Horoz-Tal die Würmmoränen selber verkittet hat. Auf 2030 m haben wir

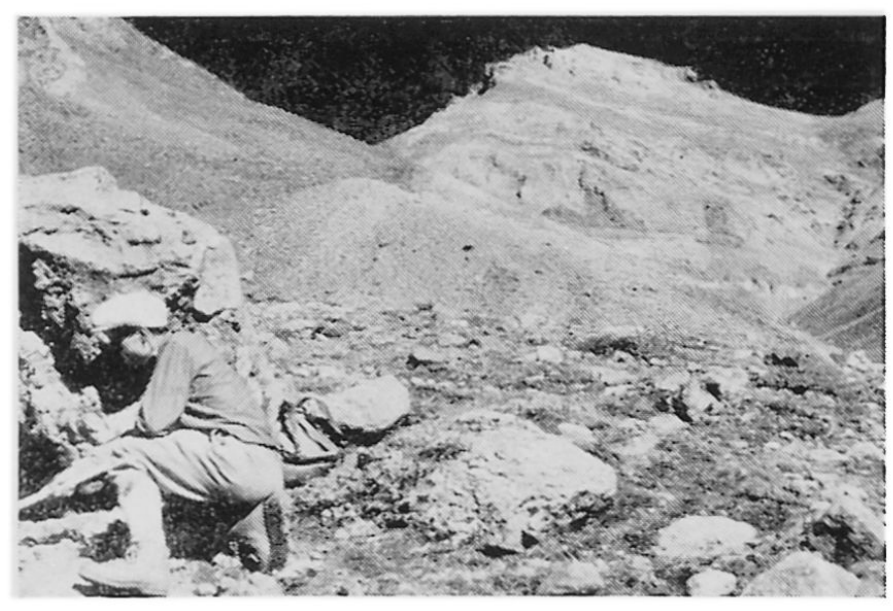

Abb. 21 Inköyü. Wir stehen auf der Endmoräne des westlichen Inköyü-Gletschers (Endlage $2000 \mathrm{~m}$ ). Sie ist durch einen seitlichen Graben unterbrochen, dahinter hebt sich die Fortsetzung als Seitenmoräne noch deutlich aus der Hangschuttfläche ab.

die Zurundung bestimmt, das Ergebnis gibt den Moränencharakter deutlich wieder (Morphogramm 10).

Gesamthaft gesehen haben uns nicht nur die gut erhaltenen Ablagerungen im Inköyü überrascht, sondern auch die glazialen Erosionsformen im Einzugsgebiet der beiden Gletscher. Wenn Louis und Klaer schreiben, daß bis $3000 \mathrm{~m}$ Höhe keine sicheren Glazialspuren vorhanden sind, so können wir uns damit nidht einverstanden erklären. Lassen wir uns von den Glatthangbildungen der Höhenrücken nicht täuschen: die oberen Bereiche des mittleren und östlichen Inköyü zeigen eine kräftige glaziale Uberformung, von Karformen auf $3000 \mathrm{~m}$ bis zu Rundbuckeln auf $2500 \mathrm{~m}$. Berechnen wir schließlich die Schneegrenze des westlichen Inköyü-Tales, so erhalten wir den erstaunlich geringen Wert von $2650 \mathrm{~m}$ (Mittel aus $3300 \mathrm{~m}$ und $2000 \mathrm{~m}$ ).

Irmaközü oder Kadinci-Irmak (Fig. 3, Abb. 22, 23)

Der oberste Tallauf folgt dem Südfuß der Bolkardagh-Marmore ungefähr in Westrichtung. Vor allem die südexponierten Hänge sind von Schutthalden überdeckt, die nach oben fast die Gipfelzone erreichen und nach unten den Talboden zu einer VForm zuschütten (Abb. 23). Die heute durchschnittlich abfließende Wassermenge reicht zum Abtransport des anfallenden Schuttmaterials nicht mehr aus. Wer würde beim Anblick dieser Talform glauben, daß hier ein eiszeitlicher Gletscher existieren konnte? Unmittelbar vor der Umbiegung nach Süden erhebt sich auf der rechten Bachseite ein Felssockel. Fein geschieferte Serien des Perms stehen an, und darauf liegt eine Deponie ortsfremden Materials. Die Größe der Komponenten schwankt von kleinsten Stücken bis zu $2 \mathrm{~m}^{3}$ Inhalt, und die Pak- 
kung zeichnet sich durch einen großen Feinerdegehalt aus. Es handelt sich um eine glaziale Ablagerung $70 \mathrm{~m}$ über dem Bachniveau auf einer Höhe von ca. $2000 \mathrm{~m}$. Eine rasche Absenkung des Walles läßt sich talauswärts gut erkennen.

Auch in diesem Tal stellen wir wiederum die eigenartige Situation fest, daß eine Moräne in Nordexposition erhalten blieb, währenddem sie offenbar in Südauslage vom unvergleichlich stärker anfallenden Verwitterungsschutt überdeckt und zerstört wurde. Berechnen wir schließlich noch die lokale Schneegrenze im Irmaközü, so ergibt sich wiederum ein Wert zwischen 2650 und $2750 \mathrm{~m}$.

\subsubsection{Die würmeiszeitliche Schneegrenze}

Blumenthal schätzt die Schneegrenze auf $2700 \mathrm{~m}$ (20, S. 149). Louis berechnet die nordseitige Schneegrenze auf 2600-2700, die südseitige auf $3000 \mathrm{~m}$ (185, S.467). Klaer entscheidet sich für die gleichen Werte (147). Besonders interessant sind die Angaben von Blumenthal, der die geschlossene Massenerhebung über $3000 \mathrm{~m}$ mit einer Fläche von 84,5 $\mathrm{km}^{2}$ und diejenige über $2750 \mathrm{~m}$ mit $343,8 \mathrm{~km}^{2}$ bestimmt (20, S. 149). Das ergibt ganz bedeutende Nährgebiete für die eiszeitlichen Gletscher, wie sie weder am Erciyas Dagh noch im Libanon vorhanden waren. Diese Tatsache hat sich zweifellos auch lokalklimatisch ausgewirkt und die abfließenden Talgletscher beeinflußt.

Die Schneegrenze der Nordseite: Im Darbogaz haben wir einen Wert von 2500-2550 m ermittelt, der offensichtlich im Widerspruch zu den bisherigen Angaben steht. Wie schon Klaer richtig schreibt, treten die beiden Gletscher nach wenigen hundert Metern in ein völlig offenes Gelände hinaus und legen dort ohne besondere klimatische oder morphologische Begünstigung noch eine Distanz von ca. $5 \mathrm{~km}$ zurück. In dieser Situation ist die Endlage von $1850 \mathrm{~m}$ wirklich ein repräsentativer Wert. Wenn wir aber wie Louis und Klaer die Höfersche Methode anwenden, so dürfen wir für die mittlere Kammhöhe in der Umrandung des Firngebietes sicher nicht mehr als 3200-3250 m annehmen. (Die höchsten Gipfel im Einzugsgebiet: Tersakan Sirt 3340 m, Ala Göz $3355 \mathrm{~m}$ und Yalim Dagh $3200 \mathrm{~m}$ ). Das Mittel ergibt 2500-2550 m, und wir haben nicht den geringsten Grund, diesen Wert wegen besonderer Begünstigung irgendwie zu erhöhen.

Dem Sakapinar-Maden-Gletscher haben wir einen ähnlichen Wert gegeben. Wollen wir ihm eine übermäßige lokalorographische Begünstigung einräumen (Louis 185), so müssen wir uns die Situation im intramontanen Hochbecken vor Augen halten. Das ausgedehnte Sammelgebiet liegt zwar über $3000 \mathrm{~m}$ hoch. Aber es ist offen, strahlungsexponiert und orographisch nicht im geringsten begünstigt (abge-

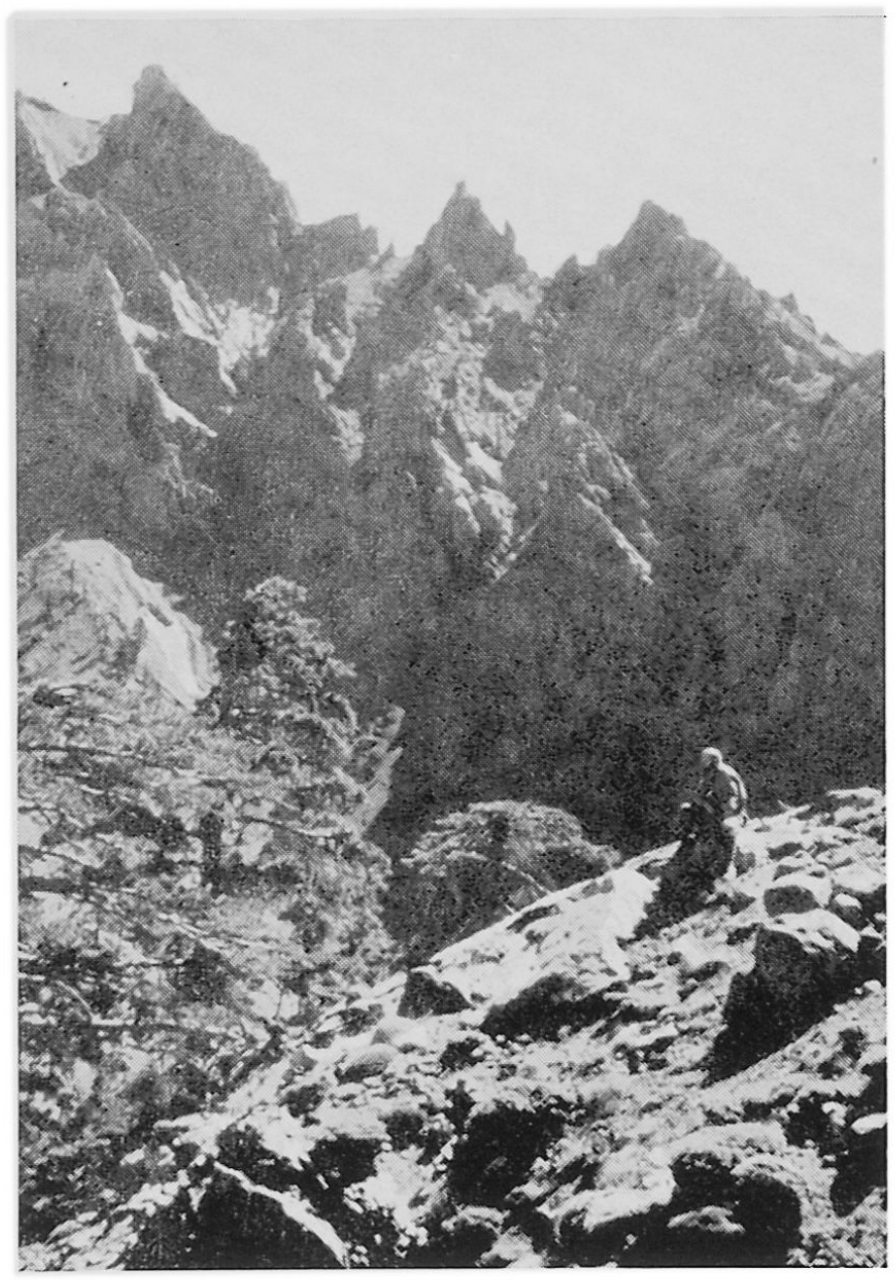

Abb. 22 Irmaközü. Endmoränenbereich auf 2000 Meter. Das Material ist ortsfremd und zeigt einen glazialen Transport an.

sehen von den flächenmäßig unwesentlichen Karräumen in der Axialkette, Abb. 24). Daraus floß der eiszeitliche Gletscher nach zwei Richtungen ab (Horoz und Sakapinar), wobei der Sakapinar-Strom eine südexponierte Schwelle zu überschreiten hatte. Schließlich aber brach der Gletscher nach seinem Aufstoßen im Madental nicht einfach zusammen, sondern er regenerierte sich und legte nach der totalen Richtungs- und Gefällsänderung noch eine Strecke von $3 \mathrm{~km}$ zurück. Seine tiefe Endlage ist nicht einfach die Wirkung außerordentlicher Gunstfaktoren. Im weiteren ist es nicht richtig, die mittlere Kammhöhe des Firngebietes nach den höchsten Gipfeln der Axialkette auszurichten, wir haben auch die andern Seiten sinngemäß zu berücksichtigen. Ein Wert von $3400 \mathrm{~m}$ scheint uns bereits an der oberen Grenze.

Gesamthaft gesehen vertreten wir für die Nordseite unseres Untersuchungsgebietes eine würmeiszeitliche Schneegrenze von 2500_2550 m.

Auf der Ostseite haben wir die Verhältnisse im Horoz- und im Gökoluk-Tal besprochen und eine Schneegrenze von $2600-2700 \mathrm{~m}$ festgelegt, die al- 
lerdings je nach Exposition und Einzugsgebiet groBen Schwankungen unterliegt.

Die Schneegrenze der Südseite: Louis und Klaer legen die Schneegrenze auf $3000 \mathrm{~m}$ fest; diesen Wert müssen wir entschieden bezweifeln. Stellen wir uns die folgende Frage: Wenn die Schneegrenze auf $3000 \mathrm{~m}$ lag, wie konnten dann die südexponierten Großkare mit einer Schwellenhöhe von $3000 \mathrm{~m}$ entstehen, und warum konnten sich daraus Gletscher entwickeln, die auf 2000-2200 m hinunterstießen? (Abb. 25) Selbst wenn im Vergleich mit der Nordseite die Karwände nicht so steil sind, die Schuttüberdeckung größer ist und perennierende Schneeflecken und Blockgletscher fehlen, so zwingen uns doch diese Formen zur Festlegung einer höhenmäßig angepaßten Schneegrenze. Eine Erklärung der Karböden mit alten Flächenresten genügt keineswegs. Wenn wir die Höfersche Methode auf der Nordseite mit Recht anwenden, dann haben wir geradezu die Pflicht, sie mit den gleichen Kriterien auf der Südseite anzuwenden. Übermäßige Begünstigung bedeutet eine Höhenkorrektur der Schneegrenze, geringere Begünstigung eine Tiefenkorrektur. Also haben die Talgletscher der Südseite mit ihrem Schneegrenzwert eine ganz bedeutende Aussagekraft. Anders gesagt: die lokalorographische und die lokalklimatische Begünstigung war in der sonnseitigen Exposition zweifellos geringer, und wenn sich trotzdem ein Großkar und ein Talgletscher bilden konnten, dann sind das eindeutige Indizien für die erfüllten klimatischen Bedingungen einer Schneegrenze. Es darf uns nicht stören, daß oberhalb der Schneegrenze offene und ungegliederte Hangflächen bis zur Gipfelhöhe hinauf unvergletschert blieben. Wir berechnen eine südseitige Schneegrenze nach Karformen und Talgletschern mit 2700-2800 m.

Aus Nord-, Ost- und Südseite ergibt sich eine würmeiszeitliche regionale Schneegrenze für den Hohen Bolkardagh von ca. $2650 \mathrm{~m}$.

\subsection{Hangasymmetrie, Strukturböden und Wald- grenze}

Die Oberflächenformung zeigt in jedem Fall eine Differenz zwischen Sonn- und Schattseite, ganz unabhängig von Struktur und Gestein. In den Kaltzeiten wurden die Nordhänge durch eine verstärkte Glazialerosion überformt (Abb. 14), die Südseite dagegen unterlag vermehnt den periglazial flächenhaften Abtragungsvorgängen. In den Warmzeiten bildeten sich auf der Nordseite am Fuß der Steilhänge und im Bereich der ständigen Schmelzwasser Massenbewegungen aller Art; auf der trockenen und strahlungsexponierten Südseite dagegen entwickelten sich Glatthänge und Schutthalden weiter

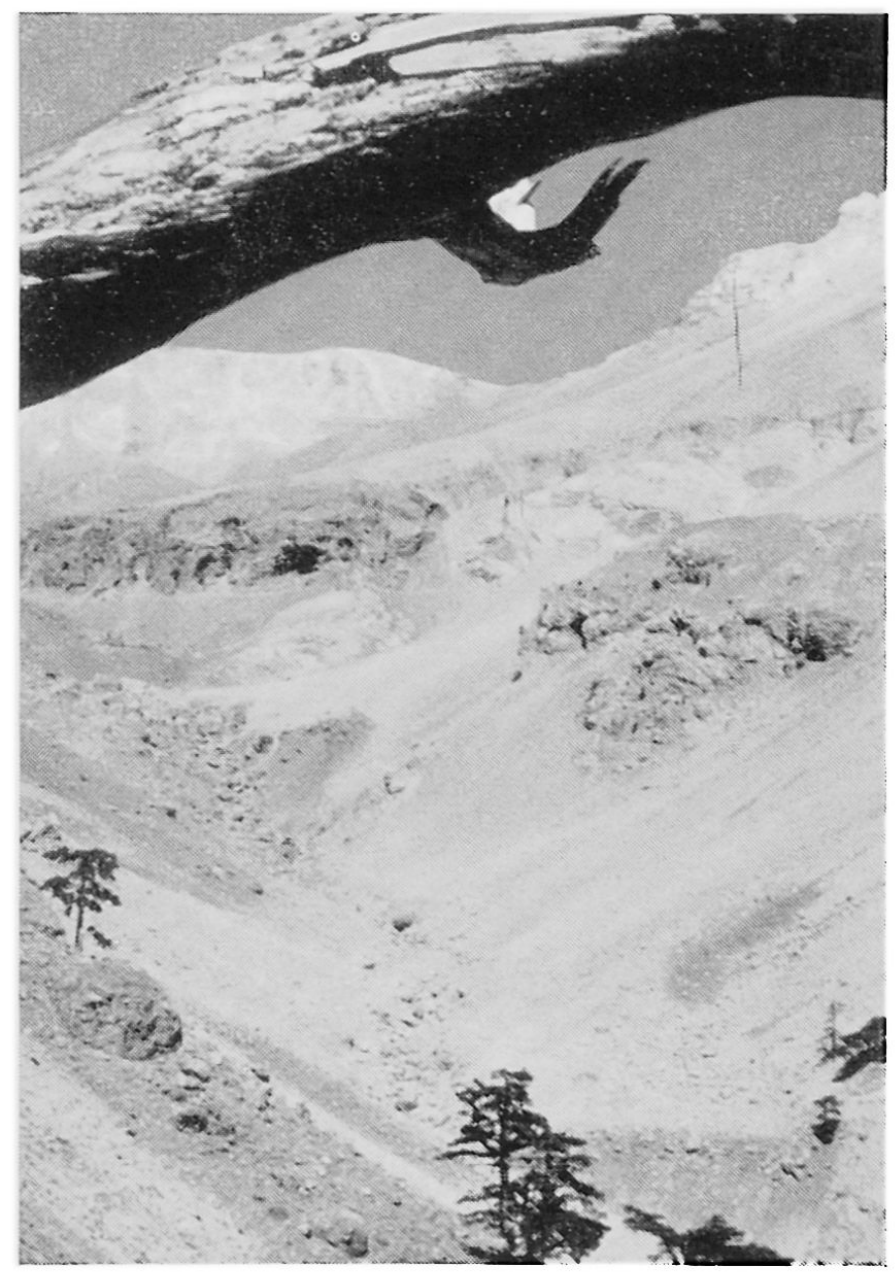

Abb. 23 Irmaközü. Blick talaufwärts vom Moränenstandort der Abb. 22 aus. Die postglaziale Verwitterung hat das Tal vollständig zugeschüttet. Am Gegenhang anstehende Bergfußbreccie. Oberste Bäume auf $2100 \mathrm{~m}$.

(Abb. 23). Selbstverständlich tendiert diese ungleiche Oberflächenformung auf eine Hangasymmetrie hin. Sie ist aber nur dann als unterschiedlicher Geländewinkel vergleichbar und meßbar, wenn alle tektonischen, stratigraphischen und petrographischen Bedingungen für beide Hangseiten die gleichen Voraussetzungen bieten. In diesem sehr seltenen Idealfall können wir die Hangasymmetrie als direkte Funktion der Klimadifferenz und der entsprechend verschiedenen Oberflächenformung ansprechen (vgl. Erciyas Dagh).

Es scheint uns aber nicht richtig, den Taurus als Musterbeispiel einer klimagenetischen Hanganalyse zu zitieren, weil der unterschiedliche Geländewinkel der beiden Gebirgsabdachungen vorwiegend und primär durch tektonische Gegebenheiten geprägt wird. Wir unterstreichen diese Tatsachen deshalb, weil im subtropisch-mediterranen Raum auch entgegengesetzte Asymmetrien auftreten können, zum Beispiel im Libanon und in der Sierra Nevada (204). In diesen beiden Gebirgen wirkt die Oberflächenformung genau gleich differenzierend; aber 
entscheidend für die Hangasymmetrie ist die strukturelle Anlage des Gebirges.

Strukturbodenformen in deutlicher Ausprägung haben wir erst oberhalb $2600 \mathrm{~m}$ festgestellt. Undeutliche Formansätze treten vereinzelt und in besonderer Gunstlage etwas tiefer auf.

Die Waldgrenze zeigt von Tal zu Tal und je nach Exposition große Schwankungen zwischen 2000 und maximal $2300 \mathrm{~m}$. Nach der offiziellen Karte müßten wir die Waldgrenze mindestens $300 \mathrm{~m}$ höher ansetzen. Diese Werte sind aber ganz unmöglich, sie würden teilweise sogar die Baumgrenze mit den höchsten Krüppelbäumen übersteigen. Der Mittelwert aus unseren Beobachtungen, der mit den Angaben von Hermes und Louis (126 und 184) gut übereinstimmt, ergibt wiederum die erstaunliche Bestätigung einer Höhendifferenz von ca. $1500 \mathrm{~m}$ zwischen der heutigen oberen Waldgrenze und der rezenten regionalen Schneegrenze.

\subsection{Schneegrenzen und Schneegrenzdepression}

Die rezente Schneegrenze haben wir auf $3650 \mathrm{~m}$ festgelegt. An diesem Wert haftet die große Unsicherheit, daß wir auf der Nordseite keinen eindeutigen und auf der Südseite überhaupt keinen Gletscher für die Schneegrenzbestimmung heranziehen konnten. Eine temperaturmäßige Berechnung und ein Zuhilfenehmen von Erfahrungswerten (203, $359)$ ist immer unbefriedigend. Wir haben deshalb eine mögliche Fehlergröße von $50-100 \mathrm{~m}$ in Rechnung zu setzen.

Die würmeiszeitliche Schneegrenze gründet auf präzisen Feldaufnahmen und erlaubt eine viel genauere Ermittlung. Die Differenz zwischen der Nordseite (2500-2550) und der Südseite (2700_ 2800 ) beträgt $200-250 \mathrm{~m}$ und ist etwas kleiner als am Erciyas Dagh $(300 \mathrm{~m})$. Die Ursachen liegen in den verschiedenen klimatischen Bedingungen. Der Erciyas hat auf allen Gebirgsseiten ein ähnliches Niederschlagsregime, im Taurus aber ist die Südseite stärker beregnet als der kontinentale Nordhang.

Diese Tatsache kommt zwar in der Hangformung kaum zum Ausdruck, weil die Strahlungswirkung auf den Südseiten alle andern Faktoren dominiert. Immerhin konnte es sich in einer verminderten Vergletscherungsasymmetrie zwischen $\mathrm{N}$ - und S-Seite auswirken.

Die Schneegrenzdepression beträgt ca. $1000 \mathrm{~m}$, sie ist etwas geringer als am Erciyas Dagh und ungefähr gleich groß wie im Libanon. Damit fügen sich die Ergebnisse der eiszeitlichen und rezenten Vergletscherung im östlichen Mittelmeerraum sinnvoll aneinander und ergeben ein widerspruchsloses und abgerundetes Bild.

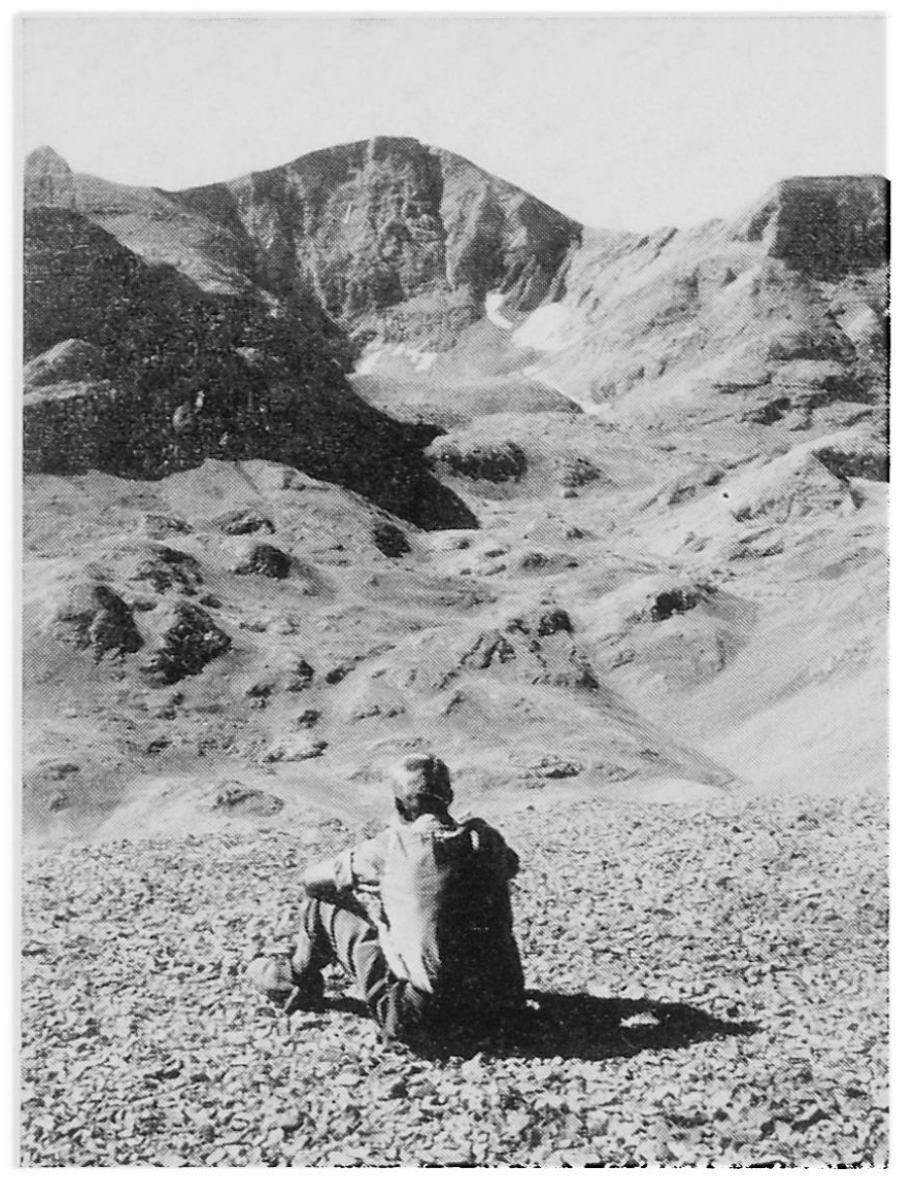

Abb. 24 Die Karformen der Nordseite. Im Hintergrund der Medetsiz-Gipfel (3585 m). Im Schatten der Wand kleine Eisflecken, auf dem Karboden rezente Wallformen und ein Blockgletscher, dessen Stirn deutlich sichtbar ist. Im Zentrum des Bildes die intramontane Hochmulde zwischen Axialkette (Medetsiz) und Frontalkette (Photo-Standort). Sie bildete das Einzugsgebiet des Sakapinar- und des Horoz-Gletschers.

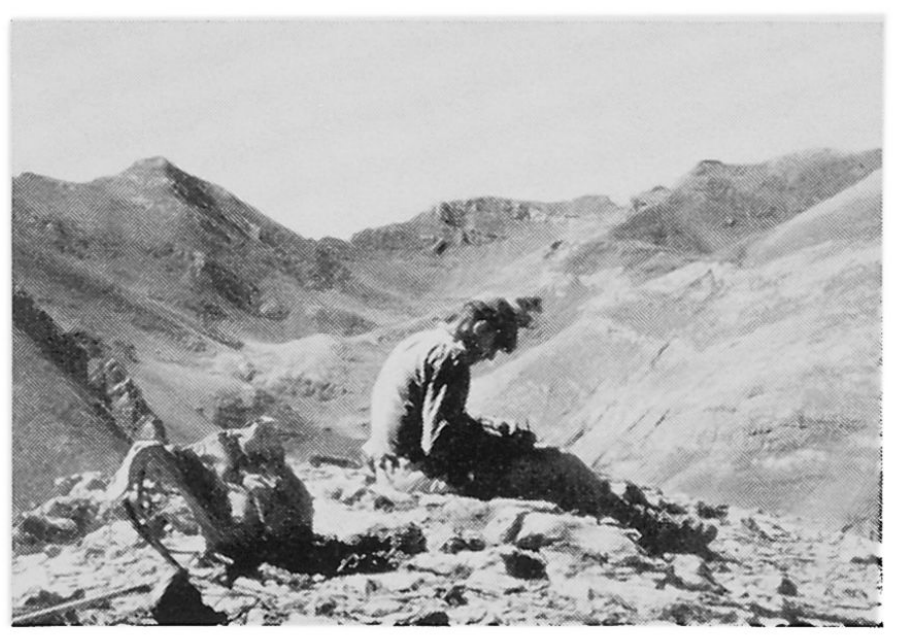

Abb. 25 Die Karformen der Südseite. Vom Medetsiz ist rechts im Bild nur noch der Bergfuß sichtbar. Wir blicken in das Einzugsgebiet des südseitigen Inköyü-Gletschers. Schutthalden und Glatthänge sind häufiger und verbreiteter als auf der Nordseite, aber die Glazialformen (Kare, Rundbuckel usw.) sind doch so deutlich, daß sie eine bedeutende Südvergletscherung anzeigen. 


\subsection{Zusammenfassungen}

\subsubsection{Résumé Haut Bolkardagh (Taurus)}

- La structure du massif nous donne des indications décisives pour comprendre les formes et les processus glaciaires et climat-morphologiques: la haute cuvette intramontane comme région d'alimentation des glaciers quaternaires, la variété des roches et la détermination de matériel erratique, les causes tectoniques de l'asymétrie des versants, la structure en écailles peu plissées ressemblant à des surfaces d'aplanissement, les phénomènes karstiques contribuant à la formation variée de la surface.

- La quantité des précipitations sur le versant sud augmente très rapidement avec l'altitude et montre des valeurs tout à fait semblables à celles du Liban. Les températures elles aussi ressemblent de manière frappante aux conditions du Liban pour les deux côtés de la montagne. Ces correspondances climatiques nous indiquent des conditions semblables pour la ligne des neiges.

- Nous ne pouvons lier la ligne récente des neiges aux taches de glace existantes. Celles-ci se trouvent toutes dans des situations orographiques particulièrement favorables. Qu'elles se trouvent à 3000 ou $3300 \mathrm{~m}$, leur importance ou surface ne diffèrent pas, elles existent sans dépendre de la ligne des neiges dans leur situation favorable isolée. La ligne des neiges récente se trouve à $3450 \mathrm{~m}$ pour le versant nord, $400 \mathrm{~m}$ plus haut environ pour le versant sud, en moyenne à $3650 \mathrm{~m}$.

- Nous avons examiné et décrit les moraines terminales des glaciers de vallée würmiens les uns après les autres. Contrairement aux lignes des neiges fixées jusqu'ici, nous obtenons des valeurs plus basses: $2500-2550 \mathrm{~m}$ pour le versant nord, 2700-2800 $\mathrm{m}$ pour le versant sud, $2650 \mathrm{~m}$ en moyenne. C'est surtout sur le versant sud que nous avons découvert des glaciers de vallée qui se terminent entre 2000 et 2200 m et qui témoignent d'une ligne des neiges extraordinairement basse. Si de grands cirques et des glaciers de vallée se formèrent malgré les conditions orographiques et climatiques locales désavantageuses, cela nous indique clairement que les conditions climatiques pour une ligne des neiges étaient données, même si des pentes non recouvertes de glace, lisses par action climatique se trouvent audessus.

- Des brèches de pente et des dépôts fluvioglaciaires de genre multiple et d'âge très varié témoignent de la succession de plusieurs époques glaciaires. Cette richesse en formes indique des périodes de précipitations accrues, et d'écoulement fluvial fort variable et en partie torrentiel. Des datations plus précises à l'intérieur des différentes formes d'accumulation ne seront possibles qu'après des examens sédimentologiques approfondis.

- Des formes de sols structurés se trouvent sporadiquement et faiblement marquées au-dessus de la limite de la forêt, et ne se forment nettement qu'à $2600 \mathrm{~m}$. La limite de la forêt varie suivant les vallées et l'epxosition entre 2000 et $2300 \mathrm{~m}$. Il s'en suit de nouveau une différence de $1500 \mathrm{~m}$ entre la limite supérieure de la forêt et la ligne des neiges récente.

- La dépression de la ligne des neiges est de $1000 \mathrm{~m}$. Le chiffre pour la ligne des neiges récente est moins sûr (possibilité d'erreur de 50-100 m) que celui pour l'époque glaciaire Wurm.

- Ces résultats s'insèrent de manière significative dans la détermination des zones d'altitude morphologiques glaciaires du domaine méditerranéen oriental.

\subsubsection{Summary High Bolkardagh (Taurus)}

- We cannot bind the recent snow-line to the existent ice-spots. They all lie in an exceptionnally favourable orographic situation. Whether they are formed at 3000 or $3300 \mathrm{~m}$, they show no difference in importance or area; therefore, they exist without relation to the snow-line in their isolated favourable situation. The recent snow-line lies at $3450 \mathrm{~m}$ on the northern mountain-side, about $400 \mathrm{~m}$ higher on the southern, an average of $3650 \mathrm{~m}$.

- We have examined and described one after another the end moraines of the Würm valley glaciers. Contrary to the hitherto existing determinations of the snow-line we obtain lower values: $2500-2550 \mathrm{~m}$ on the northern mountain-side, $2700-2800 \mathrm{~m}$ on the southern, $2650 \mathrm{~m}$ average. Mainly on the southern side he have found valley glaciers which end between 2000 and $2200 \mathrm{~m}$ and which attest to an extraordinarily low snow-line. If big cirques and valley glaciers could develop in spite of locally orographic and climatic disadvantages, it means that the climatic conditions for a snow-line were given, even if non-glaciated smooth slopes due to climatic actions may be found above this level.

- Slope breechies and fluvioglacial depositions in the most different forms and of the most varied ages attest to a succession of several glacial periods. This abundance of forms points to periods with heightened precipitations and of a very unsteady, partly torrential run-off. More exact datings within the 
different forms of accumulation will only be possible on the basis of detailed sedimentological examinations.

- The depression of the snow-line is about $1000 \mathrm{~m}$. The cipher of the recent snow-line is more uncer- tain (possible error $50-100 \mathrm{~m}$ ) than for the Würm glaciation.

- These results enter significantly into the glacialmorphological gradation of the altitudes in the eastern mediterranean area.

\section{Ak Dagh und Bey Dagh in Lykien}

Im Westtaurus oder im Gebirgsraum südwestlich Antalya erreichen nur zwei Massive eine Höhe von über 3000 m: der Ak Dagh 3024 m (Weißer Berg, Massikytos der Antike) und der Bey Dagh 3086 m («Herr» oder «Chef» Berg).

Wir haben uns vor allem mit der eiszeitlichen Vergletscherung des Ak Dagh beschäftigt, weil hier die schönsten und bedeutendsten Glazialspuren des gesamten lykischen Gebirgsraumes zu finden sind, die erstmals von Onde 1954 (249) erwähnt wurden. Wir verzichten auf eine gründliche Darstellung des Bey Dagh, weil Louis 1944 die glazialen Formen geschildert hat (185) und weitere Arbeiten über diesen Raum im Entstehen sind. Die Ergebnisse aus dem Ak Dagh wollen wir mit den Beobachtungen aus dem Bey Dagh nur so weit ergänzen, daß wir den Verlauf der glazial- und klimamorphologischen Höhengrenzen auf engstem Raum von West nach Ost, vom mehr maritimen zum eher kontinentalen Bereich verfolgen können.

Wieder müssen wir auf die besonderen kartographischen Schwierigkeiten hinweisen. Die einzige zur Verfügung stehende Karte 1:200000 ist für die Geländedarstellung des Ak Dagh und Bey Dagh unbrauchbar. Wir haben uns deshalb einige Punkte selber eingemessen und die glazialmorphologischen Ergebnisse in einfachen Geländeskizzen schematisch dargestellt (Fig. 6). Zu den aus der Karte übernommenen Höhenangaben müssen wir ein Fragezeichen setzen, ergaben sich doch aus eigenen $\mathrm{Hö-}$ henmessungen Differenzen von $100 \mathrm{~m}$ zwischen gewissen Talstationen (Elmali, Gömbe, Avlangölü usw.) und bestimmten Gipfelpunkten (Ak Dagh, Bey Dagh, Yumru Dagh usw.). Trotz diesen möglichen Fehlern haben wir unsere Höhenwerte auf die Isohypsen der Karte ausgerichtet und in Zweifelsfällen eigene Höhenmessungen, bezogen auf die Gipfelpunkte der Gebirge, in Text und Karten eingesetzt.

\subsection{Oberflächengestalt und Aufbau (Fig. 5)}

Von Korkuteli her beginnt ca. $18 \mathrm{~km}$ vor Elmali eine ausgedehnte NNE_SSW-angelegte Polje. Die
Spornlage Elmalis auf einem Ausläufer des Elmali Dagh bewirkt eine kleine Geländestufe, dann setzt nach SW eine noch größere Ebene ein, die als Großpolje den Raum zwischen Elmali, Gömbe und Avlangölü einnimmt. Die gesamte Depression von Elmali hat eine deutlich NE_SE-gerichtete Anlage, parallel zum Bey Dagh auf der einen und zu den Gipfelhöhen Ak-, Yumru- und Elmali Dagh auf der andern Seite. Diese dominante Richtung ist in Lykien weit verbreitet, wir finden sie im Streichen der Gebirge und im Verlauf der Täler.

Der Ak Dagh, hauptsächlich aus Kreidekalken und ältestem Tertiär aufgebaut, ist durch ein markantes Hochplateau auf 2500-2750 m charakterisiert. Blicken wir von Gömbe zum Ak Dagh hinauf, so sehen wir bloß die $2600 \mathrm{~m}$ hohe und über $4 \mathrm{~km}$ lange östliche Vorderkante der Hochfläche, der eigentliche Gipfelaufbau mit den schönen Karformen ist weiter zurückgesetzt und unsichtbar. Das auffallende Plateau setzt sich nach NNE in der Gipfelplatte des Yumru Dagh und weiterer Gipfelhöhen fort. Was aber auf der geologischen Karte $1: 500000$ (108) überhaupt nicht dargestellt ist, sind mächtige Serien von Peridotit, Pyroxenit, Serpentin usw., die den Südrand des Ak Dagh scharf begrenzen. Wir haben den Eindruck gewonnen, daß sehr wahrscheinlich tektonische Vorgänge mit dieser auffallenden Kontaktzone in Beziehung stehen müssen.

Im Bey Dagh thebt sich der Kizlar sivrisi als isolierter Gipfel (3086 m) aus einem mehrstöckigen Plateau heraus (Abb. 31). Die allgemeine NE_SWRichtung zeigt sich im Steilabfall des Hochplateaus gegen das Hochtal von Çamçukuru und schließlich gegen die Depression von Elmali. Die Karstentwässerung hat ihre eigenen Formen geschaffen, die mit weiträumigen Mulden und Wannen den Plateaucharakter zusätzlich betonen (Abb. 32).

Uber die Geologie dieses Raumes ist bis heute sehr wenig bekannt, erst in den letzten Jahren sind bedeutende Kartierungsarbeiten von der türkischen geologischen Landesanstalt aufgenommen worden. Im heutigen Zeitpunkt gilt immer noch die Feststellung Blumenthals: "Eine befriedigende Klarlegung der tektonischen und stratigraphischen Verhältnisse ist in diesem Gebiet noch nicht erreicht» 


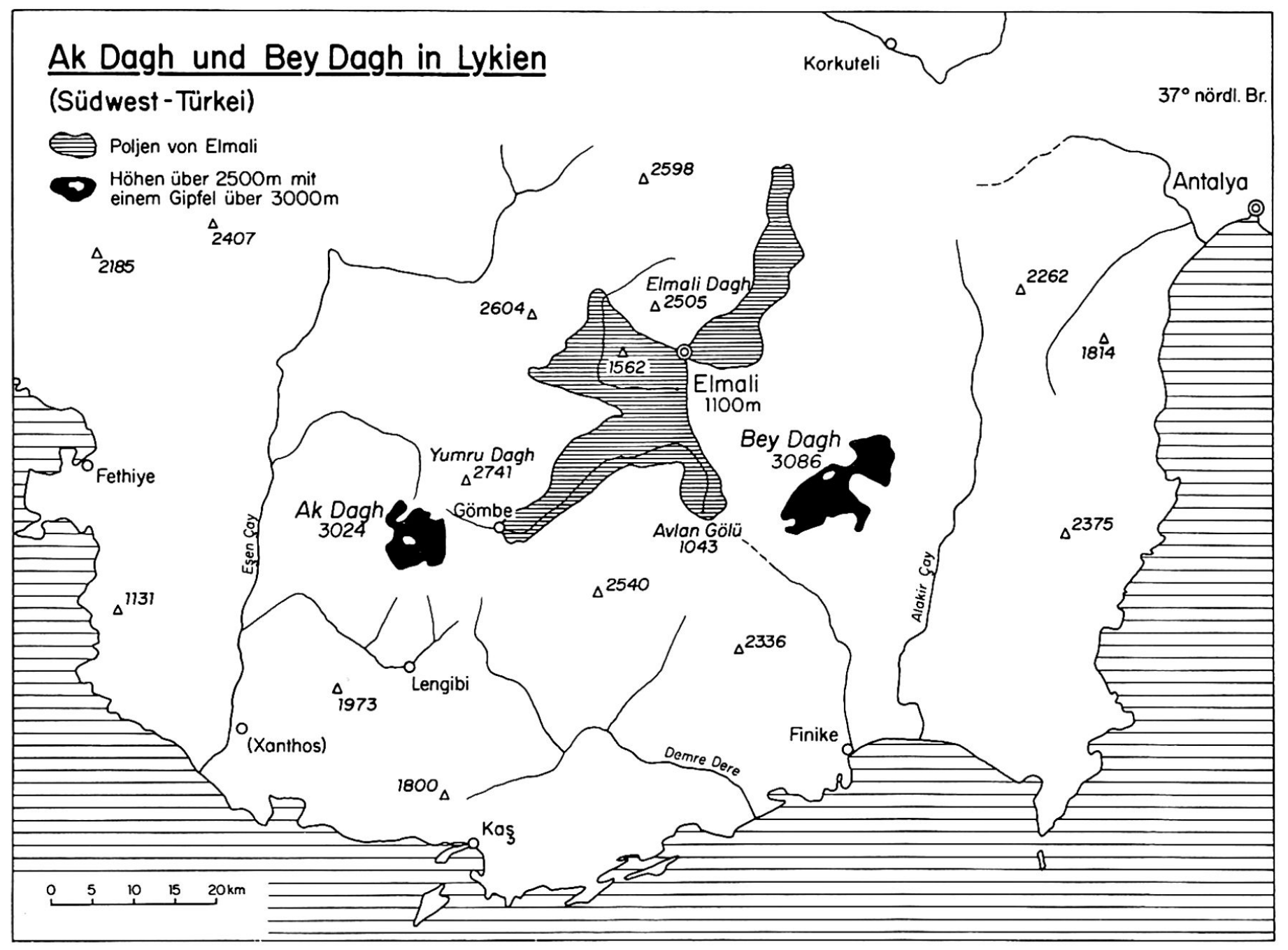

Fig. 5 Übersichtskarte

(4, S. 279). Und doch bestimmten die orographischen Verhältnisse das Ausmaß der eiszeitlichen Vergletscherung. Die Gipfelstöcke über $2750 \mathrm{~m}$ bildeten das ideale Nährgebiet der Gletscher, und in ihren Steilflanken entstanden die eigentlichen Karformen. Traten die Eisströme aber auf die Hochflächen aus, so blieben sie in den Mulden und Wannen stecken und ereichten kaum den Steilabfall. Eiszeitliche Gletscher mit niedrigen Endlagen waren nur dort möglich, wo die Plateauflächen nicht existierten oder wo die Abbruchränder rasch erreicht und durch präglaziale Einschnitte leicht überflossen werden konnten. In diesem Sinne werden wir die Strukturformen des Gebirges bei der Beurteilung der Endmoränenlagen zu berücksichtigen haben.

\subsection{Klimatische Grundzüge}

Onde hat die Niederschlags- und Abflußverhältnisse im Einzugsgebiet des Esen Çay besprochen und die Niederschlagsverteilung an einigen Stationen erläutert (249, S. 331).

\subsubsection{Die Niederschläge $(211,212)$}

Küstengegend:

Antalya $\quad 43 \mathrm{~m} 1956-61 \mathrm{im}$ Mittel $958,5 \mathrm{~mm}$ $(1931-60=1029,9 \mathrm{~mm})$ Fethye $\quad 1 \mathrm{~m} 1956-61$ im Mittel $841,2 \mathrm{~mm}$ $(1936-60=995,1 \mathrm{~m})$

Finike $\quad 25 \mathrm{~m} \mathrm{1956-61} \mathrm{im} \mathrm{Mittel} \mathrm{825,2} \mathrm{mm}$

\section{Landesinnere:}

Elmali $1110 \mathrm{~m} \quad 1956-61$ im Mittel 501,0 mm $(1956-63=503,7 \mathrm{~mm})$

Korkuteli 1020 m 1956-61 im Mittel 415,1 mm

Die Küstenräume zeigen relativ große Niederschlagsmengen, Onde gibt für das Bassin des Esen Çay sogar einen Mittelwert von $1100 \mathrm{~mm}$ an. Mit dem Überschreiten der Randketten nimmt dieser Wert schlagartig ab. Elmali, ca. $55 \mathrm{~km}$ vom Meer entfernt, erhält nur noch $500 \mathrm{~mm}$ und das $46 \mathrm{~km}$ weiter im NNE liegende Korkuteli $415 \mathrm{~mm}$. Vergleichen wir die beiden Gebirge miteinander, so steht der Ak Dagh den Niederschlägen nach W und $\mathrm{S}$ offen, der Bey Dagh dagegen ist mit einer kon- 
tinentalen Westseite benachteiligt. Für den winterlichen Niederschlag in fester Form werden diese ungleichen Lageverhältnisse noch dadurch verstärkt, daß der Ak Dagh für Schneeanlagerungen im Lee der Windrichtungen eine bessere Geländekonfiguration bietet als der langgestreckte Höhenrücken des Bey Dagh. Onde nimmt für den Ak Dagh einen Niederschlag von $1,5-2 \mathrm{~m}$ an. Wir sind überzeugt, daß die 2-m-Grenze überschritten wird. Die genauen Niederschlagsmessungen am Ulu Dagh bei Bursa werden uns auf diese Frage zurückführen. Wir sind aber keinesfalls mit der Niederschlagskarte einverstanden, die dem Ak Dagh und Bey Dagh gleiche Niederschlagsmengen von $1250-1500 \mathrm{~mm}$ zuordnet (212).

\subsubsection{Die Temperaturen $(211,212)$}

Die Temperaturverhältnisse des Küstensaumes sind durch die langjährigen Meßreihen der Stationen Antalya und Fethye gut belegt. Aus dem Landesinnern nehmen wir die Werte von Elmali und vergleichen sie mit Kayseri.

$\begin{array}{lrl} & & \begin{array}{l}\text { Mittlere } \\ \text { Julitemperatur }\end{array} \\ \text { Antalya } & 43 \mathrm{~m} & 28,2^{\circ} \\ \text { Fethye } & 1 \mathrm{~m} & 28,2^{\circ} \\ \text { Elmali } & 1112 \mathrm{~m} & 23,8^{\circ} \\ \text { Kayseri } & 1071 \mathrm{~m} & 22,8^{\circ}\end{array}$

Wir müssen auf die Berechnung einer Höhentemperatur verzichten, da uns die notwendigen Stationen fehlen. Eines aber wollen wir deutlich festhalten: Die Juli- und die Sommertemperaturen sind in Elmali höher als in Kayseri. Die sommerlichen Klimaverhältnisse des zentralen Lykiens sind extremer als in Inneranatolien. Das bedeutet nichts anderes, als daß auch die Schneegrenze im kontinentalen Bereich von Elmali durch diesen Temperaturverlauf kräftig in die Höhe gedrückt wird. Auf unsere beiden Gebirge bezogen: Der Bey Dagh schließt mit seiner langgestreckten Westseite an einen völlig kontinentalen Raum an, der Ak Dagh dagegen steht nach $W$ und $S$ dem maritimen Einfluß offen und grenzt nur mit seiner östlichen Leeseite an die kontinentale Klimaprovinz. Dieser Unterschied muß sich auf den Verlauf der eiszeitlichen und rezenten Schneegrenzen auswirken.

\subsection{Die würmeiszeitliche Vergletscherung des $A k$ Dagh}

Die Ergebnisse unserer Feldarbeit sind in Fig. 6 eingetragen und die morphometrischen Analysen in den Zurundungsmorphogrammen der Figur $7 \mathrm{zu}-$

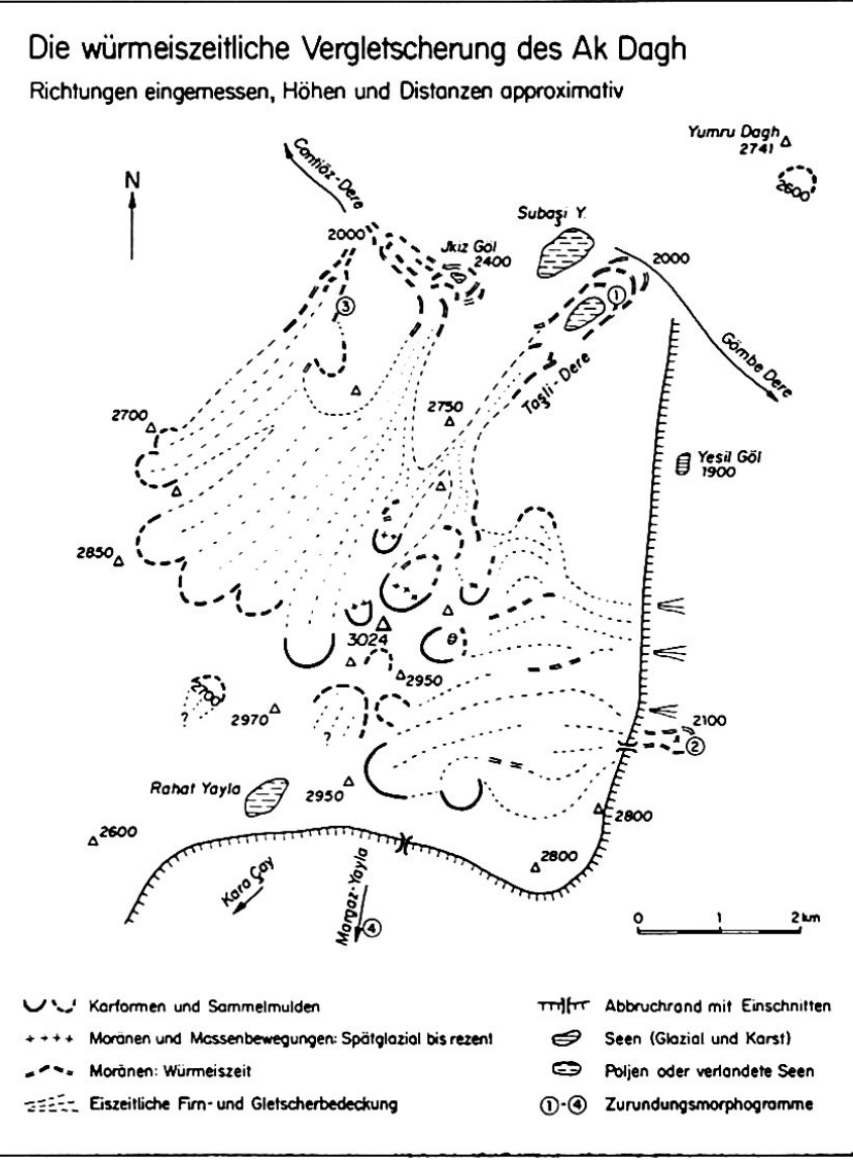

Fig. 6

sammengestellt (Nr. 1-4). Wir beginnen unsere Besprechung beim nordexponierten Tasli Dere, dann folgt die E- und W-Seite und am Schluß die Problematik der Südhänge.

\subsubsection{Die einzelnen Expositionen}

Nordseite: Tasli Dere (Fig. 6; Abb. 26, 27; Morphogramm 1).

Mit einer $200 \mathrm{~m}$ hohen und steilen Wand öffnet sich nordöstlich des Hauptgipfels das größte $\mathrm{Kar}$ des Ak Dagh. Hier begann der eiszeitliche Tasli-Gletscher, strömte auf das Niveau des Hochplateaus aus, verlor einen kleinen Teil seiner Eismasse nach Osten, stieß in einem engen Talschlauch nach Norden ausbiegend in dieTiefe und erreichte am Fuß des Yumru Dagh seine erstaunlich niedrige Endlage von ca. 2000 m, die tiefsten Komponenten sogar 1900 m. In den höheren Bereichen bezeichnen zahlreiche Moränenreste, Rundbuckel und Gletscherschliffe den ehemaligen Gletscherlauf. In ca. $2400 \mathrm{~m}$ setzen auf beiden Talseiten mächtige Ufermoränen des Maximalstandes ein und senken sich kontinuierlich bis zum prächtigen mehrgliedrigen Endmoränenkranz auf 2200 bis $2000 \mathrm{~m}$ ab. Die Gletscherzunge hat möglicherweise einmal tiefer in die Schlucht des 
1. Ak Dagh-Nord

Tasli Dere $2200 \mathrm{~m}$

Moräne

Mittelwert 0,089

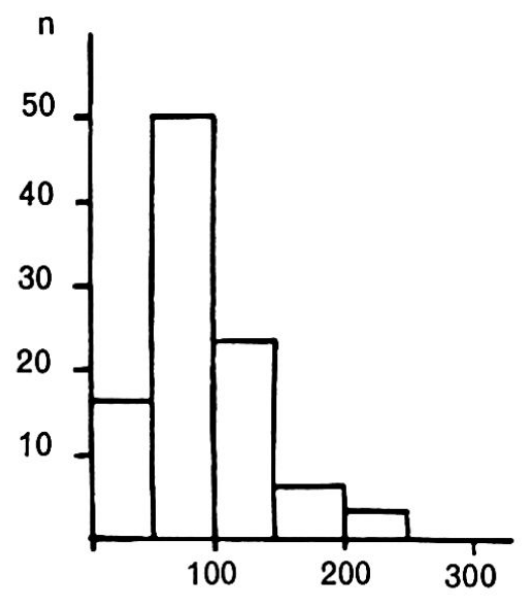

2. Ak Dagh-Ost

Weg Karagöl-Cayköy

Moräne $2200 \mathrm{~m}$

Mittelwert 0,080

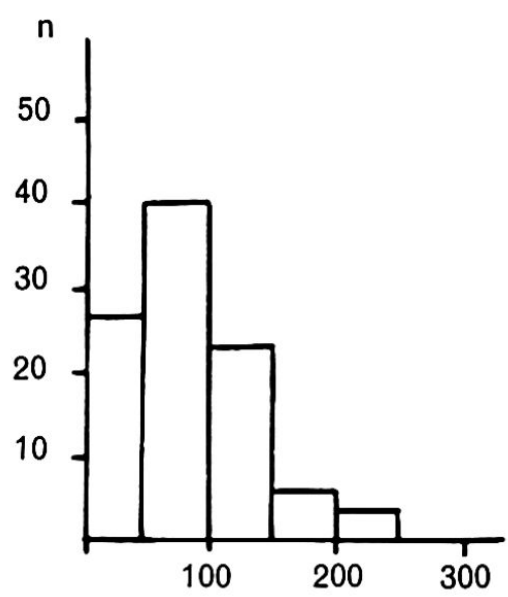

3. Ak Dagh-West

Cantiöz Dere $2340 \mathrm{~m}$

Moräne

Mittelwert 0,082

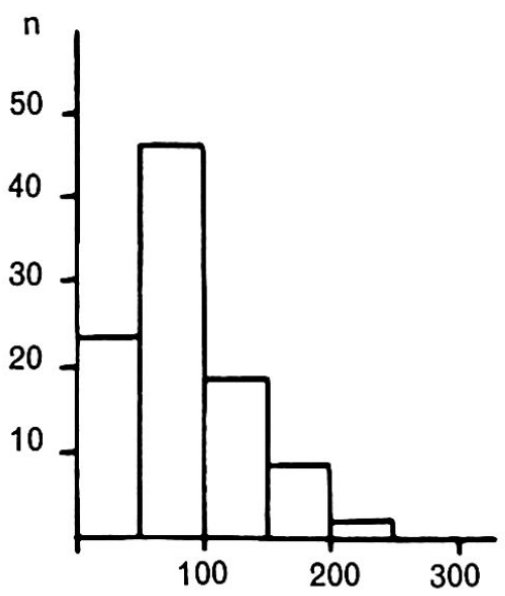

4. Ak Dagh-Süd

Ob. Margaz Tal

Sackungen, Solifluktion

(+ Moräne?)

Mittelwert 0,036

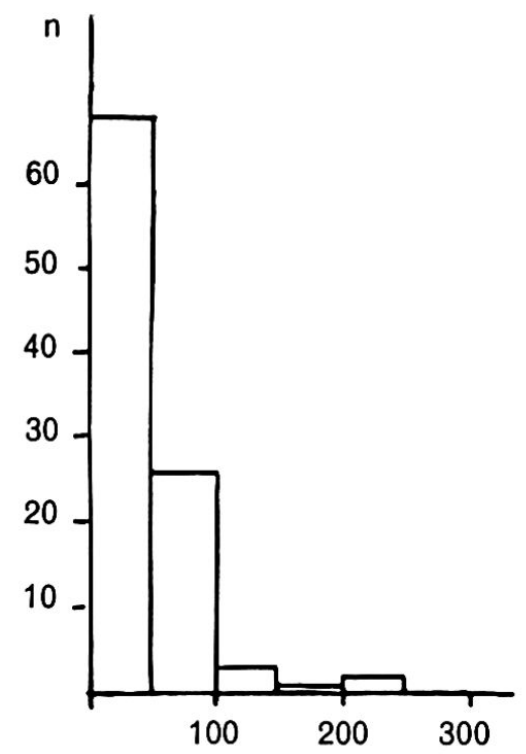

5. Bey Dadh

NW Fuss des Kizlar sivrisi

Moräne, (Sturz + Solifluktion ?)

Mittelwert 0,068

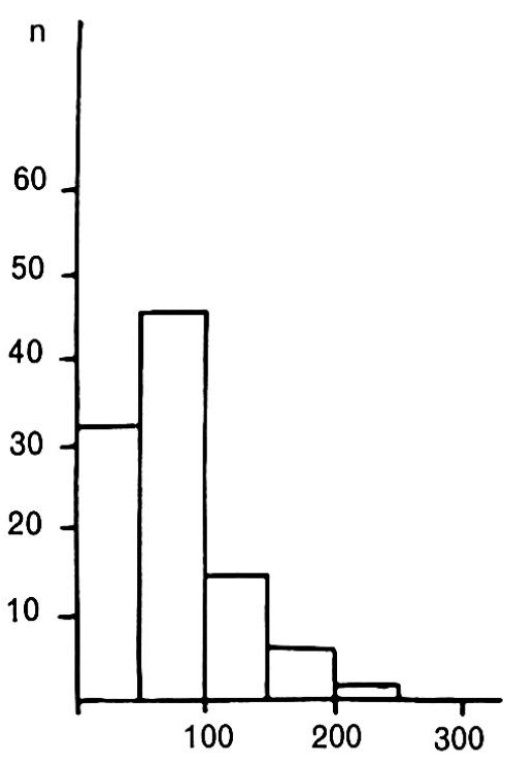

Fig. 7 Zurundungsmorphogramme Ak Dagh und Bey Dagh.

Gömbe Dere hineingehangen, doch kommt einer solchen Vermutung höhen- und materialmäßig keine große Bedeutung zu. Die Abhänge des Yumru Dagh sind von einer diluvialen, hangparallelen Breccie überzogen, so daß sich am Bergfuß Moränen und Hangbreccien als verschiedene Ablagerungsformen einer gleichen Entstehungszeit gegenüberstehen. Unterhalb der Endmoränen setzen in der GömbeSchlucht Konglomeratbänke ein, die mit gröberen und feineren Horizonten auf ein wechselndes Klimageschehen hindeuten. Eine ältere Moräne konnten wir nicht eindeutig nachweisen (249, S. 334). Nach der Würm-Maximalphase entstand im Endmoränenkranz des Tasli-Gletschers ein See, der heute in verlandetem Zustand den Weidgrund der Subasi Yayla bildet. Fragen wir uns nach der eiszeitlichen Schneegrenze dieses schönsten Talgletschers, so erhalten wir nach der Höferschen Methode einen 
minimalen Wert vor $2400 \mathrm{~m}$ (2900 und $1900 \mathrm{~m}$ ). Diese Schneegrenze stimmt mit dem Ausapern der Ufermoränen gut überein und wird auch von keinen niedrigeren Karformen unterschritten.

Ostseite: Hochplateau und Abbruchrand (Fig. 6; Morphogramm 2).

Zahlreiche Kare öffnen sich im Gipfelaufbau nach Osten gegen ein mehrfach gestuftes Hochplateau. Die ungeordneten Materialdeponien auf dieser Hochfläche zeugen von einer Gletscherbedeckung, die wir nicht mehr nach einzelnen Eisströmen differenzieren können. Verschiedene Bewegungsrichtungen sind aufeinandergestoßen, und größere Eismassen sind in präglazial angelegten Karstmulden ausgeschmolzen. Einzelne Höhenrücken, die sich heute scheinbar als Moränenzüge präsentieren, sind im Grunde genommen überschüttete Felsstufen oder -rippen, die für die Eismassen zu Leitlinien wurden. Gesamthaft gesehen wurde auf diesem Hochplateau das im Gipfelstock abgetragene Material nach kürzestem Transportweg wieder abgelagert.

Eine Ausnahme läßt sich feststellen. Im südöstlichen Teil ist der markante Abbruchrand durch einen Einschnitt geöffnet (Karte 1 : 200 000: Weg Karagöl_ Çayköy). Eine Klamm setzt auf ca. $2600 \mathrm{~m}$ ein, hat zuoberst ein Gefälle von fast $30^{\circ}$ und beginnt auf $2400 \mathrm{~m}$ auszuflachen. Auf $2350 \mathrm{~m}$ treffen wir die ersten kleinen Wallformen an. Sie wiederholen sich und enden in einem mächtigen Wall auf ca. $2100 \mathrm{~m}$. Das Material ist in tieferen Lagen häufig verkittet. Eine Auszählung ergab den Mittelwert von 0,080, was einem glazialen Transport entspricht.

Von dieser Ablagerung am Fuß des Einschnittes bis zum Yesil Göl (Grüner See) verläuft ein strukturel! bedingter Sims. Darauf liegen verschiedene Akkumulationsformen, auf deren Deutung wir nicht im Detail eintreten wollen. Der Yesil Göl (auf ca. $1800 \mathrm{~m}$ ) ist durch zwei Wälle von Sturzmaterial abgegrenzt. Er hat mit einer Karform nicht zu tun, höchstens mit einer Karstform (249).

Aus der Vergletscherung der Ostseite und den tiefsten Endmoränen leiten wir eine lokale Schneegrenze von ca. $2500 \mathrm{~m}$ ab.

Westseite: Cantiöz Dere (Fig. 6; Abb. 28; Morphogramm 3).

Vom südlichsten Teil des Gipfelmassivs zieht sich in der Höhenlage 2800-2900 m ein Kamm nach NW, in dessen Nordexposition zahlreiche Karund Nivationsformen eingetieft sind. Dort lag das Einzugsgebiet eines ausgedehnten eiszeitlichen Firnfeldes. Die Begehung dieses Raumes könnte an einer wirksamen Vergletscherung zweifeln lassen, denn nur vereinzelte Deponien, Seen und Rundbuckel zeugen von einer glazialen Überdeckung. Folgen wir aber den relativ engen und versteilten Ausgängen nach Norden, so erreichen wir auf ca.

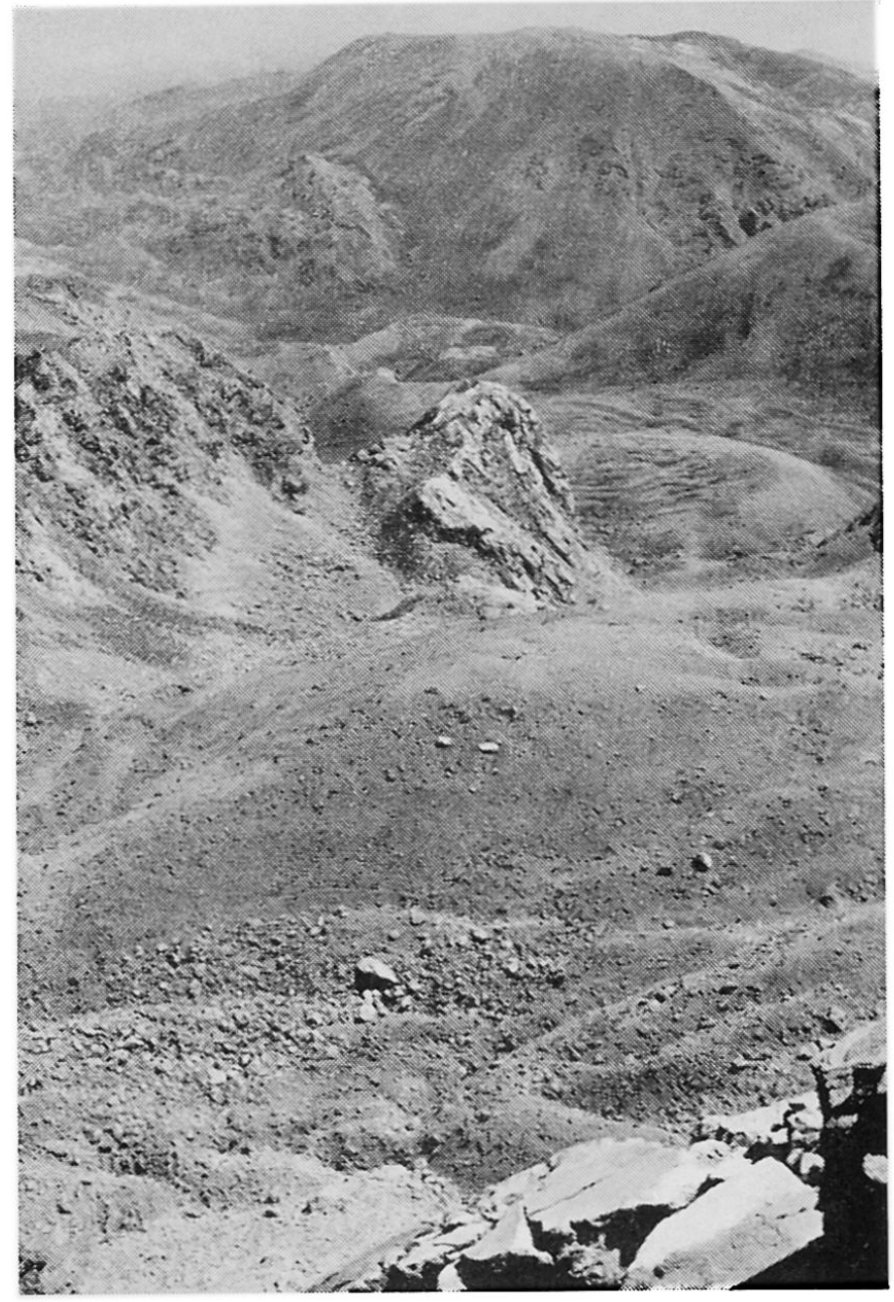

Abb. 26 Blick vom Ak Dagh Hauptgipfel (3024 m) nach NE zum Yumru Dagh (2741 m). Wir überblikken den gesamten Lauf des Tasli-Gletschers: Zu unseren Füßen im Gipfelkar frische Wallformen (Moränen, blockstromartig umgelagert), dann Rückzugsdeponien und schließlich die Seiten- und Endmoränen des maximalen Würmgletschers unmittelbar vor dem Hang des Yumru Dagh.

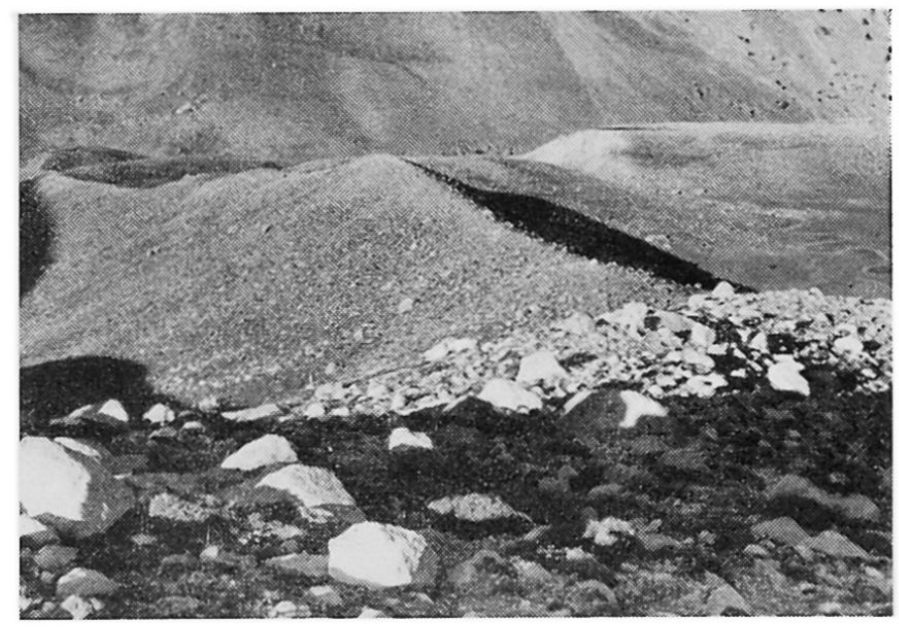

Abb. 27 Ak Dagh, mehrgliedriger Endmoränenkranz des Tasli-Gletschers, unmittelbar vor dem Hang des Yumru Dagh. 
$2500 \mathrm{~m}$ außerordentlich gut erhaltene Seitenmoränen. Wir unterscheiden zwei Gletscherarme (Fig. 6):

- Der westliche zeigt einen geraden, NE-gerichteten Verlauf, fällt auf ca. $2350 \mathrm{~m}$ steil ab und endet auf ca. $2000 \mathrm{~m}$. Wir haben auf $2340 \mathrm{~m}$ eine Materialanalyse vorgenommen, der Zurundungsgrad von 0,082 bestätigt den Moränencharakter.

- Am östlichen Arm in der Nachbarschaft des Tasli Dere beginnen die Seitenmoränen auf ca. $2500 \mathrm{~m}$ auszuapern. In der Umgebung des Ikiz Göl (kleiner See auf ca. $2400 \mathrm{~m}$ ) ist eine Vielzahl von Moränenwällen erhalten, weil die Verflachung und Rich-' tungsänderung den Gletscher zur Ablagerung zwang. Folgen wir dem ehemaligen Eisstrom ca. $800 \mathrm{~m}$ weiter talwärts, so erreichen wir den Steilabfall und die Endlage in ca. $2000 \mathrm{~m}$. Sanderartige Schüttungen zeigen den Zungenbereich an und weisen auf die Abflußrinne des Cantiöz Dere hin.

\section{Südseite: (Fig. 6, Abb. 30; Morphogramm 4)}

Die amtliche Karte gibt ein verwirrendes Bild dieser Gebirgsseite. Eine fahrbare Piste führt über Sütlegen zur Forststation Lengibi und durch das waldreiche Tal der Margaz Yayla auf eine Höhe von $1700 \mathrm{~m}$. Verlassen wir die obere Waldgrenze bei ca. $2000 \mathrm{~m}$, so überblicken wir die tektonisch schwer beanspruchte Kontaktzone des Abbruchrandes. Ausgeprägte "Badlandformen», Sackungen größten Ausmaßes, rezente Sturzvorgänge usw. charakterisieren diesen mobilen Raum, dessen Bedeutung und Besonderheit bis heute noch nirgends beschrieben ist.

- Im Gipfelmassiv des Ak Dagh lassen sich südexponierte Nivationsformen nachweisen, die untersten mit einer Schwellenhöhe von ca. 2700 m. Aber eindeutige Ablagerungsformen sind nicht erhalten, höchstens treten auf der verkarsteten Oberfläche vereinzelt bearbeitete Komponenten auf. Wir vermuten, daß die Südhänge in begünstigter Lage während der Kaltzeiten periodisch eine Firndecke getragen haben, die sich nirgends zu einem echten Gletscher verdichten konnte. Zugleich fehlten im Rückland Karwände und Felsabstürze als Materiallieferanten. Es fehlte also am Transportmittel und am Transportmaterial. Auf diese Weise deuten wir uns die spärliche Materialstreu. Wir werden bei der Besprechung des Olymps eingehender auf dieses Problem zurückkommen.

- Wenn wir oberhalb $2700 \mathrm{~m}$ mit Verfirnungen und schwachen Transportleistungen rechnen können, so hören solche Vorgänge an der Abbruchkante schlagartig auf. Auf $2300 \mathrm{~m}$ haben wir zwar verwirrende Wallformen gefunden, doch handelt es sich um Massenbewegungen, teilweise im Zusammenhang mit der letzten Kaltzeit, die aber mit einer Vergletscherung nichts zu tun haben. Wir haben eine solche Pseudomoräne analysiert, der Zurundungsgrad von

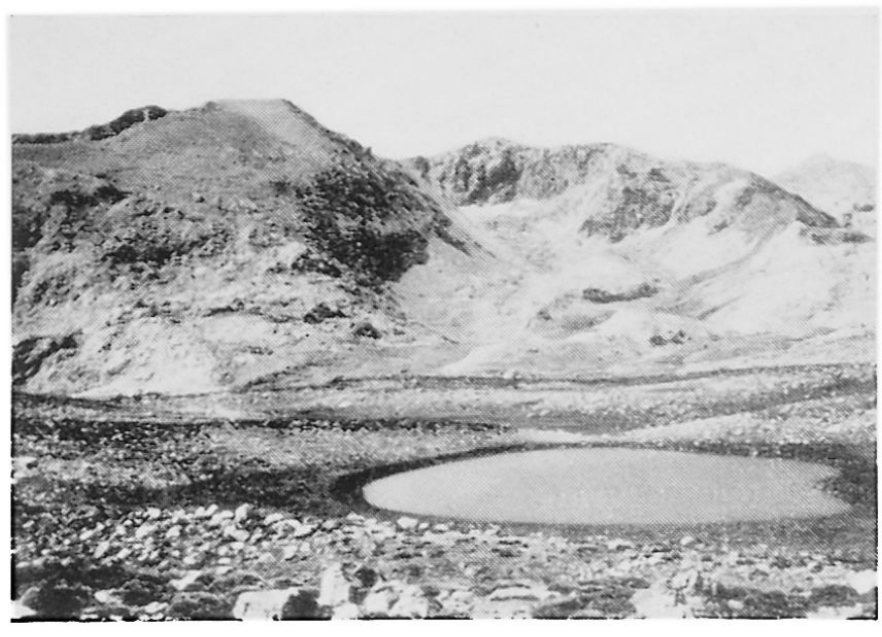

Abb. 28 Das Gipfelmassiv des Ak Dagh. Wir blikken vom östlichen Hochplateau, das vom würmeiszeitlichen Gletscher überdeckt war, zum Hauptgipfel (3024 m). (Nach links zeichnet sich das Gipfelkar des Tasli-Gletschers ab.)

0,036 schließt jeglichen glazialen Transport aus (Morphogramm 4).

Die Schneegrenzbestimmung ist äußerst heikel. Die einzigen sicheren Indizien bieten die Nivationsformen in $2700 \mathrm{~m}$, in der Südexposition des Yumru Dagh sogar auf $2600 \mathrm{~m}$ (Fig. 6).

\subsubsection{Die eiszeitliche Schneegrenze}

Onde hat nach der Begehung des Tasli Dere eine eiszeitliche Schneegrenze von 2200-2300 m bestimmt. Wie er selber schreibt, handelt es sich um

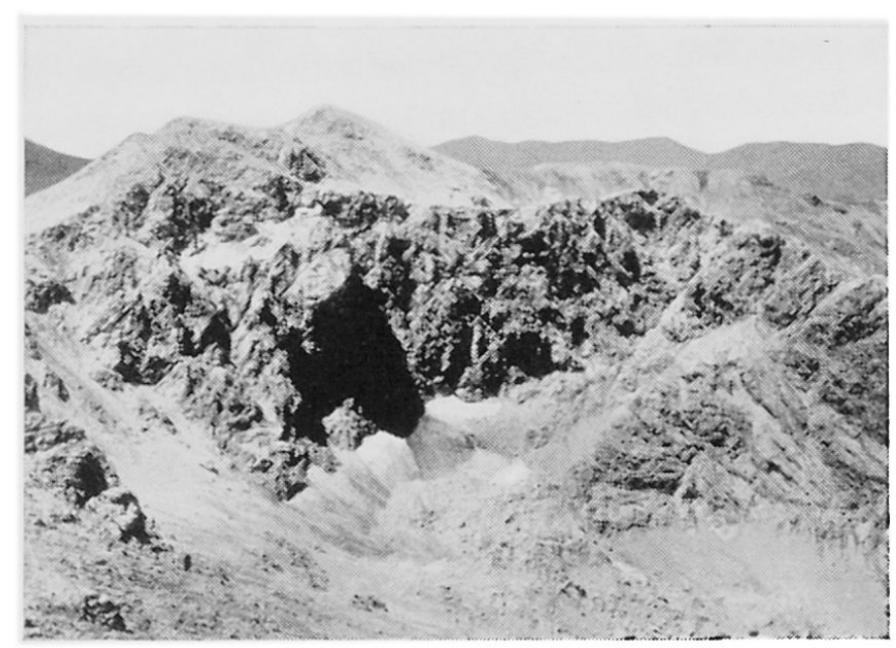

Abb. 29 Ostexponiertes Kar im Gipfelmassiv des Ak Dagh (Abb. 28). Firn- und Eisreste perennieren, rezente Ablagerungsformen sind sichtbar. Es handelt sich um Sturzmaterial, das in der Zeit der rezenten Hochstände zusammengeschoben und durch interne Massenbewegungen umgelagert wurde. 
eine lokale Schneegrenze. Planhol bezeichnet diese Angabe als Rückzugswert und legt die Schneegrenze auf 2200 m fest $(218$, S. 258).

Wenden wir die Höfersche Methode an, so erhalten wir 2400 m als unterste Grenze. Keine tieferen Karformen sind festzustellen und das Ausapern der Seitenmoränen weist auf die Richtigkeit dieser Höhenlage hin. Auf der niederschlags- und temperaturmäBig begünstigten Westseite erhalten wir den gleichen Wert, indem die orographischen Nachteile durch die klimatischen Vorteile aufgewogen werden. Die strukturell ungünstige Situation auf der Ostseite zeigt sich in der Anhebung der Schneegrenze auf $2500 \mathrm{~m}$. Die Südseite ist äußerst problematisch zu bestimmen. Firnbedeckung und Nivationsformen geben uns keine verläßlichen Ergebnisse. Wir werden auf Seite 189 die Probleme der Vergletscherungsasymmetrien und die Berücksichtigung der fehlenden S-Vergletscherung bei der Schneegrenzberechnung eingehend besprechen.

Am Ak Dagh schätzen wir die würmeiszeitlich regionale Schneegrenze auf 2500-2550 m.

\subsection{Die würmeiszeitliche Vergletscherung des westlichen Bey Dagh}

Auf der Karte $1: 200000$ sind im SW bis $\mathrm{S}$ des Kizlar sivrisi $(3086 \mathrm{~m})$ zwei weitere Gipfel eingetragen: der Alasan Tepe $(2850 \mathrm{~m})$ und der Ak Tepe (ca. $2890 \mathrm{~m}$ ). Diese drei Punkte sind zur allgemeinen Orientierung wichtig.

\subsubsection{Die NW-exponierten Gletscher (Abb. 31, Morphogramm 5 in Fig. 7)}

Am Nordwestfuß des Kizlar sivrisi liegen zahlreiche Moränenwälle, die im oberen Teil durch rezentes Sturzmaterial überschüttet sind. Die Steilwand des Kizlar sivrisi hat als Schneesammler gewirkt, an ihrem Fuß sind kleine Wandfußgletscher entstanden und haben das anfallende Sturzmaterial wenige $100 \mathrm{~m}$ hangabwärts bewegt. Auf $2300 \mathrm{~m}$ haben wir eine morphometrische Auszählung vorgenommen. Der Zurundungsgrad mit dem sehr kleinen Mittelwert von 0,068 weist auf den kurzen Transportweg hin (Morphogramm 5). Die tiefsten Ablagerungen liegen westlich des Hauptgipfels auf 1900-2000 m. Eine lokale Schneegrenzbestimmung scheint uns fragwürdig. Im übrigen hat die Steilwand mit einer Karform nichts zu tun, sie ist vielmehr tektonisch bestimmt und angelegt (Faltenstrukturen, evtl. Überschiebungen).

Unmittelbar südwestlich des Hauptgipfels befindet sich ein bedeutendes eiszeitliches Einzugsgebiet, das durch eine Karform und mehrere Sammelmul-

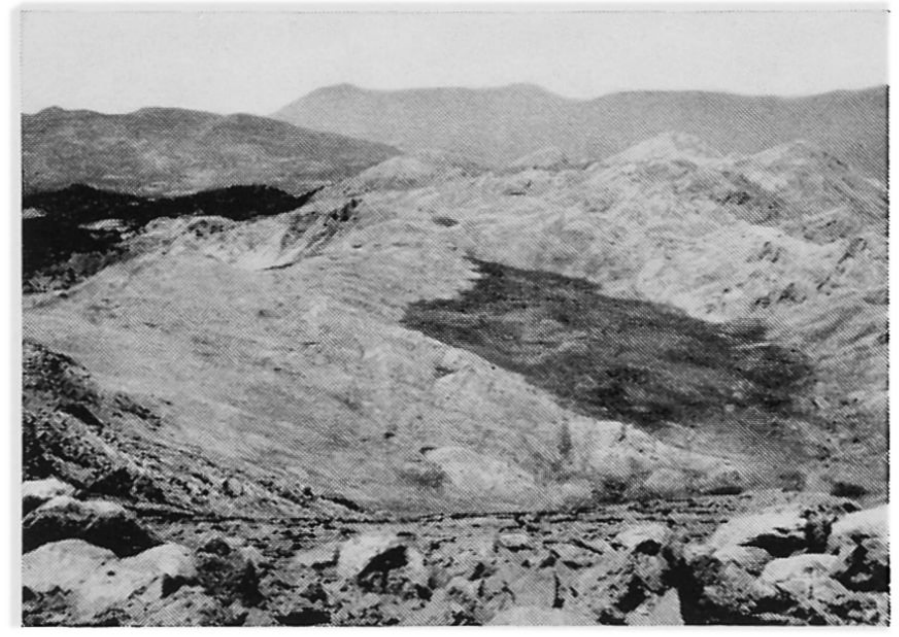

Abb. 30 Südseite des Ak Dagh. Blick auf die Polje der Rahat Yayla (Fig. 6). Der Abbruchrand ist in der linken Bildhäfte zu erkennen. Diese südexponierten Hänge waren nicht vergletschert, höchstens verfirnt.

den bestimmt ist. Ein schwacher Moränenschleier liegt auf der Plateaufläche, und die undeutlichen Wallfragmente weisen auf den Steilabsturz zur Hochtalung von Çamçukuru hin. In dieser Versteilung hat sich der eiszeitliche Gletscher sehr wahrscheinlich aufgelöst; denn in der Talniederung ist höchstens ein Schuttkegel, aber keine eindeutige glaziale Ablagerung mehr erhalten. Die letzten Komponenten liegen auf $2000 \mathrm{~m}$, doch ist das wirkliche Gletscherende kaum mehr zu rekonstruieren. Im Raum des Alasan Tepe sind zwei schöne, aber stark verschüttete Karformen erhalten (Abb. 32). Die größere hat eine Schwellenhöhe von ca.

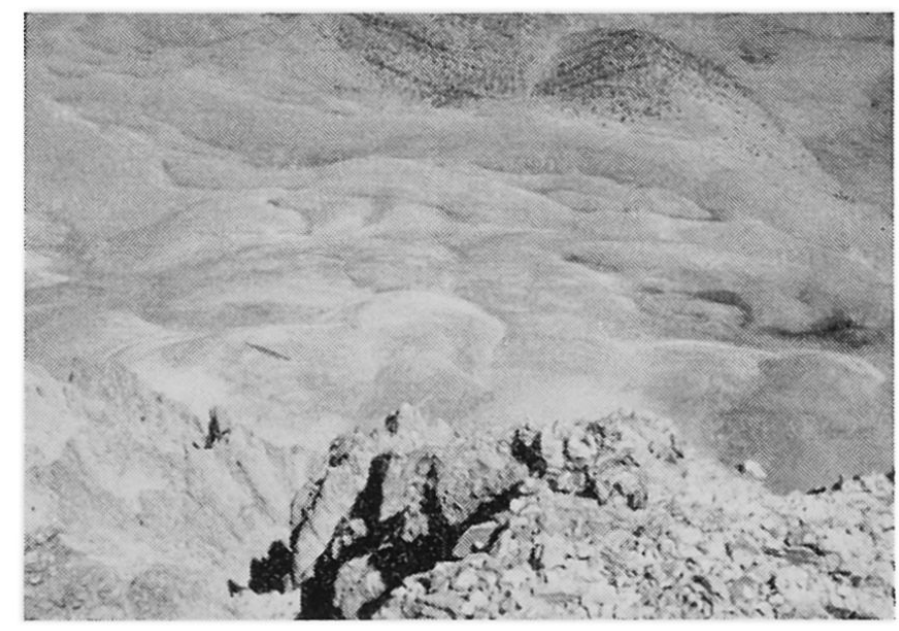

Abb. 31 Bey Dagh. Der nordwestliche Steilabfall des Kizlar sivrisi $(3086 \mathrm{~m})$ hat als Schneesammler gewirkt, ein eiszeitlicher Wandfußgletscher ist entstanden und die deutlich erkennbaren Moränenwälle zeugen von den bescheidenen Materialtransporten. 
$2600 \mathrm{~m}$. Aus ihr treten Wallformen aus, überqueren das Plateau in nordwestlicher Richtung und verlieren sich im Steilabsturz der Çamçukuru-Talung. Am Hangfuß setzt ein Schuttkegel ein und breitet sich in der Talung aus. Einige weit gestreute Großblöcke fallen besonders auf, aber eine richtige Endmoräne ist nicht erhalten.

Aus diesem gleichen Kar ist ein Seitenarm durch eine enge Talung nach $\mathrm{W}$ bis SW abgeflossen. Tiefstes kantenbestoßenes Material haben wir auf 2200 Meter gefunden, die endmoränenartigen Wallformen liegen zwischen 2300 und $2400 \mathrm{~m}$. Die glazialen Deponien sind nicht besonders mächtig. Wir müssen annehmen, daß dieser Gletscherarm in seinen Ausmaßen bescheiden und in seiner Transportkapazität beschränkt war.

\subsubsection{Die eiszeitliche Schneegrenze}

Für eine eindeutige Schneegrenzbestimmung fehlen uns am Bey Dagh Untersuchungsergebnisse von allen Gebirgsexpositionen. Immerhin ist den beschriebenen Nordwest-Gletschern gemeinsam, daß sie aus den Ursprungskaren auf eine Plateaufläche austreten, dabei stark ausschmelzen und nur mit geringer Eismächtigkeit den Steilabfall erreichen. Der dünne Moränenschleier, der kaum die anstehenden Kalkbänke überdeckt, bestätigt die schwache Vergletscherung. Ein nachträglicher Abtransport des Materials war ja nicht möglich, da in der postglazialen Wärmezeit die plateauinterne Karstentwässerung vorherrschte. Die gleiche Aussage einer relativ schwachen Vergletscherung bestätigen auch die Kare, die niemals den gleichen Ausformungsgrad wie im Ak Dagh erreicht haben.

Bestimmen wir die Schneegrenze der NW-exponierten Gletscher, so erhalten wir einen Wert von 2450 $-2550 \mathrm{~m}$. Im Vergleich mit der entsprechenden Exposition am Ak Dagh ergibt sich eine 50-150 m höhere Schneegrenze. Dieses Ergebnis, durch die unterschiedlichen Klimaverhältnisse bestimmt, bestätigt sich im Vergleich der glazialen Formen und Ablagerungen.

\subsection{Strukturböden, Glatthänge und Waldgrenze}

Am Ak Dagh treten Strukturböden oberhalb $2600 \mathrm{~m}$ auf. In auffallender Verbreitung haben wir Steinstreifen und Frostmusterböden auf dem Gipfelplateau zwischen 2750 und $3000 \mathrm{~m}$ in allen Expositionen beobachtet.

Glatthangbildungen sind im Bey Dagh viel häufiger als im Ak Dagh. Besonders schöne Beispiele liefert der SE-Hang des Kizlar sivrisi, indem hier der aktive Prozeß der Glättung an einigen ausstreichenden

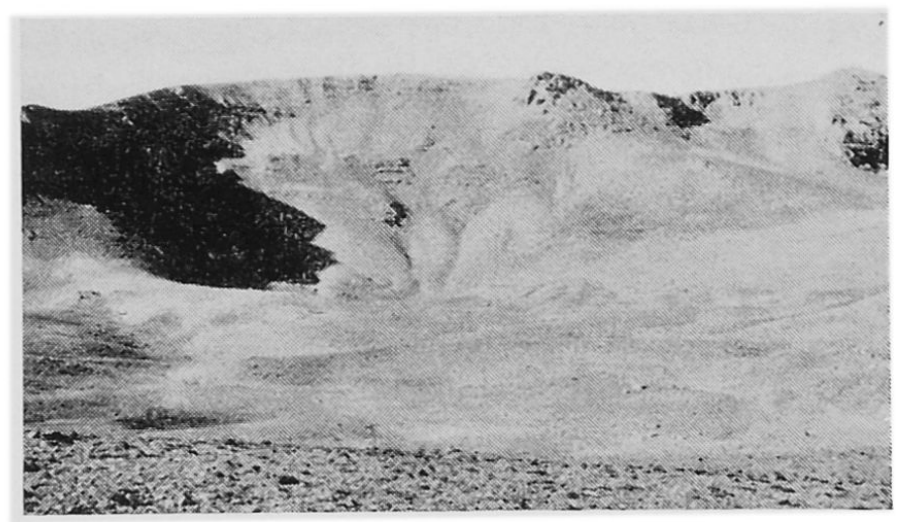

Abb. 32 Bey Dagh. Kar zwischen Ak Tepe und Alasan Tepe. Die Plateaufläche im Vordergrund ist von Moränen überdeckt. Im höher gelegenen Kleinkar am rechten Bildrand eine sich aktiv bewegende Blockmasse.

Kalkbänken genau verfolgt werden kann (146, 147, 326).

Die Waldgrenze legen wir im Ak Dagh auf ca. 2000 $\mathrm{m}$ fest, wobei sich je nach Exposition große Unterschiede ergeben. Die offizielle Karte gibt auf der Südseite die obere Grenze des prächtigen Kiefernwaldes auf $2500 \mathrm{~m}$ an, was keineswegs den Tatsachen entspricht. Im Bey Dagh hat Louis die Waldgrenze in $2100 \mathrm{~m}$ festgelegt, wobei der Baumwachholder in einzelnen geschlossenen Beständen den einzigartigen Zedernwald um $100 \mathrm{~m}$ überragt (184, S. 77). Gesamthaft gesehen scheint auch die leicht ansteigende Waldgrenze vom Ak Dagh zum Bey Dagh den Wandel vom maritim zum kontinental beeinflußten Klimabereich zu bestätigen, doch sind diese Höhenwerte nicht als klar faßbare Grenzlinien, sondern eher als Grenzzonen mit aller Vorsicht $\mathrm{zu}$ interpretieren.

\subsection{Rezente Formen und das Problem der rezenten Schneegrenze}

Im Ak Dagh haben wir in drei nordexponierten Karen des Gipfelmassivs jüngere Ablagerungsformen festgestellt, im Bey Dagh vor allem in einem Kar nördlich des Alasan Tepe. Im Gipfelkar des Ak Dagh sind Wallformen oberhalb $2700 \mathrm{~m}$ erhalten, die spätglazial bis rezent zu datieren sind (Abb. 26). In der Schattenlage der Gipfelwand gibt es einen kleinen Firnflecken, in einem Kar westlich des Gipfels sogar einen winzigen Eisrest (Abb. 29). Auf diese Firn- und Eisflecken ist das anfallende Sturzmaterial abgeglitten, hat sich angehäuft und ist vielfach durch blockstromartige Massenbewegungen 
über ganz kurze Distanzen hangabwärts verschoben worden. Von diesen rezenten Formen unterscheiden sich die älteren Blockwälle im Gipfelkar sehr deutlich, denn sie zeigen bereits Vegetationsansätze und geben mit einem stirnseitigen Böschungswinkel von ca. $30^{\circ}$ ihren stabilisierten Zustand an.

Wir könnten uns die Frage stellen, wie weit diese rezenten Ablagerungs- und Bewegungsformen eine nahe Schneegrenze anzeigen. Im Vergleich mit dem Taurus treten die rezenten Formen im Ak Dagh rund $200 \mathrm{~m}$ tiefer auf. Firnflecken und Wallformen sind aber am Ak Dagh ungleich viel schwächer ausgeprägt, so daß wir höchstens ein Absinken der klimamorphologischen Höhenstufung um 100-200 $m$ annehmen dürfen. Dieser Wert würde mit dem Absteigen der eiszeitlichen Schneegrenze um ca. $150 \mathrm{~m}$ vom Taurus zum Ak Dagh sehr gut übereinstimmen, doch scheint uns ein solcher Vergleich fragwürdig.

Eine Bestimmung der heutigen Schneegrenze ist am Ak Dagh und Bey Dagh kaum möglich. Die Gipfelhöhen sind zu niedrig und die rezenten Formen zu selten. Auch die bis heute vorhandenen klimatischen Unterlagen erlauben keine Schneegrenzberechnung. Als einziger Ausweg bleibt nur der Vergleich mit dem Taurus, der uns wie gesagt kein klares Ergebnis, sondern höchstens einige Anhaltspunkte liefern kann. Berücksichtigen wir die ähnliche geographische Breite, die klimatischen Bedingungen, die um 100-150 m tiefere Waldgrenze, die niedrigere Höhenlage der eiszeitlichen Schneegrenze und der jungen Formen, so leiten wir einen rezenten Schneegrenzwert von $3500 \mathrm{~m}$ für den Ak Dagh und $3600 \mathrm{~m}$ für den Bey Dagh ab, wobei diese Angaben mit größtem Vorbehalt aufzunehmen sind.

\subsection{Die Schneegrenzen der südwestlichen Türkei}

Unsere Werte von 2500-2550 m für den Ak Dagh und $2600 \mathrm{~m}$ für den Bey Dagh mögen sehr hoch erscheinen, besonders im Vergleich mit den Ergebnissen von Planhol (283). Wir müssen aber die unterschiedliche Betrachtungs- und Bestimmungsmethode ganz klar festhalten. Planhol hat die reelle und lokale Schneegrenze in der günstigsten Exposition bestimmt, wir aber haben versucht, eine regionale Schneegrenze aus allen Expositionen zu ermitteln. Deshalb ergeben sich zwischen unsern und Planhols Werten Differenzen von fast $200 \mathrm{~m}$. Im übrigen haben wir selbst die nordseitigen Werte eher vorsichtiger beurteilt als frühere Autoren (Planhol, Louis im Bey Dagh, Onde im Ak Dagh). Die Isochionenkarte Planhols, die nur auf den Gunstexpositionen basiert, ist in dieser Region mit der teilweise fehlenden Südvergletscherung ein konsequent richtiges Vorgehen. Wir müssen aber auf diese Methode verzichten, weil wir eine einheitliche Vergleichsmöglichkeit mit den nördlich und südlich anschließenden Räumen anstreben.

Vergleichen wir unsere Ergebnisse mit den andern Gebirgen des westlichen Taurus. Besonders interessant sind die von Planhol beobachteten Kare am Sandras Dagh (2294 m), ca. 55 km NNW von Fethiye. Dagegen fehlen jegliche Glazialspuren am Yesilgöl Dagh $(2275 \mathrm{~m})$ nordöstlich von Fethiye (281 und 283). Diese beiden fast gleichhohen Massive liegen ca. $50 \mathrm{~km}$ NW_SE auseinander und beweisen offenbar einen kräftigen Schneegrenzanstieg oder, was Planhol annimmt, ein postglaziales tektonisches Absinken des Sandras Dagh. Über.egen wir uns zuerst die Schneegrenzfrage. Der Sandras Dagh befindet sich in einer lokalklimatischen Gunstlage, indem die tief eingeschnittene und W-E-gerichtete Meeresbucht des Kerme Körfezi die niederschlagsbringenden Winde kanalisiert und genau auf das Gebirge zusteuert. Die günstigste lokale Schneegrenze liegt am Sandras Dagh nach Planhol auf 2000 $2050 \mathrm{~m}$, die regionale entsprechend zwischen 2200 und $2300 \mathrm{~m}$. Demgegenüber zeigt der von Planhol zitierte unvergletscherte Yesilgöl Dagh offenbar eine Übergangslage zwischen Sandras Dagh und Ak Dagh. Hebt sich die Schneegrenzfläche vom Sandras Dagh her bloß um $200 \mathrm{~m}$ an, also auf ca. 2400 $2500 \mathrm{~m}$, dann wird bei einer Gipfelhöhe von $2275 \mathrm{~m}$ die Nordseite nicht mehr vergletschert. Genügt zu einem solchen Schneegrenzanstieg eine lokalklimatische Erklärung oder müssen wir wirklich tektonische Vorgänge zu Hilfe nehmen?

- Der Boz Dagh (2421 m, ca. 50 km südlich Denizli) trägt keine Glazialspuren (283) und verlangt deshalb eine regionale Schneegrenze von mindestens 2500-2600 m, da die nordseitig lokale Schneegrenze auf über $2400 \mathrm{~m}$ liegen muß. Diese Folgerung wird durch den Honaz Dagh bestätigt $(2571 \mathrm{~m}$, ca. $20 \mathrm{~km}$ ESE von Denizli), der nach Philippson (zitiert in 185, S. 475) keine und nach Erinç schwache Glazialformen zeigt (83). Die regionalen Schneegrenzen dieser Gebirge stimmen also mit den Angaben aus dem Bey-Gebirge sehr gut überein.

Gesamthaft gesehen fällt also nur der Sandras Dagh mit seiner niedrigen Schneegrenze aus dem allgemeinen Isochionenbild Lykiens heraus.

Gegen tektonische Erklärungen spricht folgendes: Ein Schneegrenzanstieg von 200-300 m vom Sandras zum Ak Dagh kann klimatisch befriedigend erklärt werden, er läßt sich vom Ak zum Bey Dagh konsequent weiterverfolgen. Ferner liegen die Endmoränen am einseitig vergletscherten Ulu Dagh bei Bursa auf gleicher Höhe wie am Sandras Dagh. Das heißt, die beiden Gebirge lassen sich zwischen den Isochionen 2250 und $2350 \mathrm{~m}$ ungezwungen miteinander verbinden; anders gesagt: eine ähnliche Schneegrenzfläche wölbt sich über die westlichen Vorberge der Türkei und umschließt auf natürliche 
Weise den kontinentalen Klimaraum Anatoliens und Lykiens.

Für tektonische Erklärungen spricht folgendes: «Die gravimetrische Vermessung zeigt, daß das östliche Mittelmeer zum großen Teil den Gleichgewichtszustand noch nicht erreicht hat. Die Ausgleichsbewegungen sind in den einzelnen Teilgebieten verschieden weit fortgeschritten, am wenigsten in der Umgebung von Kreta. Die heutige Morphologie dieses Gebietes hat sich wahrscheinlich durch Aufsteigen des Meeresbodens im Aegäisraum und Absinken außerhalb des Inselbogens Kythera_Kreta-Karpathos-Rhodos entwickelt. Diese Inseln mit ihren ausgeprägten Bruchzonen an den Südküsten bilden die südliche Grenze einer Scholle» (Zit. nach Fleischer, 89). Der Kreta-Graben zieht sich bis in die Bucht von Fethiye, und es ist sehr wohl denkbar, daß der Sandras Dagh im Wirkungsbereich dieser Schwerestörungen liegt.

Vergleichen wir zum Schluß die Schneegrenzen im westlichen und zentralen Taurus. Vom Hohen Bolkardagh zum Bey Dag stellen wir ein Absinken der Schneegrenze um $50 \mathrm{~m}$ fest, eine Differenz also, die praktisch innerhalb der Fehlergrenze liegt. Ein Vergleich der klimatischen Verhältnisse bestätigt dieses Ergebnis. Die meernähere Lage des Bey Dagh wird durch die beschriebenen kontinentalen Klimaverhältnisse wieder aufgehoben. Die rasche Senkung der Schneegrenze erfolgt erst unter dem direkten Einfluß des maritimen Klimas. Selbstverständlich sind nicht die milden Wintertemperaturen wesentlich (283), sondern die Mäßigung der kontinentalen Sommerhitze und die Zunahme der Niederschläge. Auf diese Weise erklärt sich das Absinken der regionalen Schneegrenzen auf engstem Raum vom Bey Dagh $(2600 \mathrm{~m})$ zum Ak Dagh $(2500 \mathrm{~m})$ und noch tiefer zum Sandras Dagh.

\subsection{Zusammenfassungen}

\subsubsection{Résumé Ak Dagh-Bey Dagh}

- La structure des montagnes (sommets isolés, hautsplateaux entre 2500 et $2750 \mathrm{~m}$ ) donne des indications décisives pour la limite orographique de la glaciation quaternaire.

- Les hautes températures estivales et les précipitations peu importantes dans la dépression d'Elmali attestent un caractère de climat continental qui doit élever fortement la ligne des neiges. L'Ak Dagh se trouve sous une influence maritime plus prononcée que le Bey Dagh, ce qui se reflète dans le tracé des isochiones.

- Nous avons déterminé la ligne des neiges würmienne de l'Ak Dagh pour toutes les expositions, grâce à de vrais glaciers de vallée sur le versant nord
$(2400 \mathrm{~m})$, ou seulement d'après des formes de nivation sur le versant sud $(2700 \mathrm{~m})$. En moyenne, il en résulte une ligne des neiges régionales à 2500 $2550 \mathrm{~m}$.

- Nous évaluons la ligne des neiges würmienne du Bey Dagh à environ $2600 \mathrm{~m}$, donc $50-100 \mathrm{~m}$ plus haute que celle de l'Ak Dagh. Cette opinion se confirme par les différentes formes et dépôts glaciaires. - Les sols structurés se trouvent au-dessus de $2600 \mathrm{~m}$ à l'Ak Dagh. Les formations de pentes lisses se trouvent bien plus fréquemment au Bey Dagh. La limite de la forêt s'élève légèrement de l'Ak Dagh au Bey Dagh (2000_2100 m).

- Des formes de moraines récentes se trouvent en exposition nord. La ligne des neiges récente ne peut être déterminée qu'approximativement, par comparaison morphologique et climatique avec le Taurus central. Nous l'estimons à $3500 \mathrm{~m}$ pour l'Ak Dagh, à $3600 \mathrm{~m}$ pour le Bey Dagh .

- Les montagnes dans la région de Denizli (Boz Dagh et Honaz Dagh) ont des lignes des neiges correspondant très bien avec celle du Bey Dagh. Le Sandras Dagh, qui est proche de la mer et climatiquement favorisé, a une ligne des neiges régionale de 200-300 m plus basse que l'Ak Dagh. Nous penchons vers l'opinion que les particularités du climat local suffisent à expliquer cette différence de la ligne des neiges. Il nous semble moins probable que des abaissements postglaciaires tectoniques aient joué un rôle.

\subsubsection{Summary Ak Dagh-Bey Dagh}

- We have determined the Würm-age snow-line of the Ak Dagh on all the mountain-sides, either by means of real valley glaciers on the northern side $(2400 \mathrm{~m})$ or merely by nivation hollows on the southern side $(2700 \mathrm{~m})$. On the average it gives a regional snow-line of $2500-2550 \mathrm{~m}$.

- We value the Würm-age snow-line of the Bey Dagh at about $2600 \mathrm{~m}$, i. e. $50-100 \mathrm{~m}$ higher than in the Ak Dagh. This opinion is confirmed by the various glacial forms and depositions.

- Recent wall forms may be found in northern exposure. The recent snow-line may only be determined approximately by morphological and climatic comparison with the central Taurus. We value it at $3500 \mathrm{~m}$ for the Ak Dagh, at $3600 \mathrm{~m}$ for the Bey Dagh.

- The mountains in the region of Denizli (Boz Dagh and Honaz Dagh) have a snow-line corresponding to that of Bey Dagh. The Sandras Dagh, which is near the sea and favoured by climate, has a 200-300 m lower regional snow-line than the Ak Dagh. We tend to attribute this difference rather to particular climatic peculiarities than to postglacial tectonic depressions. 


\section{Ulu Dagh (Mysischer Olymp)}

Am Ulu Dagh bei Bursa sind die ersten eiszeitlichen Formen in Kleinasien entdeckt worden. Philippson hat sie 1904 (274) und Cvijic 1908 (62) beschrieben, später hat Louis in mehreren Publikationen auf sie hingewiesen (185) und in einer neueren Arbeit hat Pfannenstiel die Froststrukturböden besprochen (272). Trotz der mehrfachen, auch historisch bedeutenden Beschreibungen der Glazialformen wollen wir doch einige Hinweise zur regionalen Schneegrenze geben.

\subsection{Grundlagen (Fig. 8)}

Die Gipfelhöhe wird in der Literatur mit den verschiedensten Werten zwischen 2300 und $2600 \mathrm{~m}$ angegeben. Die amtliche Karte 1945 verzeichnet den Hauptgipfel mit 2543 m, Pfannenstiel bestätigt diesen Wert und weist dem östlich gelegenen Karatepe eine mögliche Höhe von angenähert $2600 \mathrm{~m}$ $\mathrm{zu}$.

Die nordseitigen Karböden liegen genau auf der Kontaktfläche Marmor_Granit. Pfannenstiel: «Kein Kar greift tief in den Granit ein. Nur die Karwände bestehen aus Marmor oder einem nach oben diskordant durchbrechenden Gang von Granodiorit. Die hydrologisch bedingte Abhängigkeit der Lage der Karböden von der wasserstauenden Kontaktfläche» gibt uns einen interessanten Hinweis zum Verständnis der strukturbedingten morphologischen Formen (272, S. 332-333). Allerdings bleibt die Frage offen, warum die Südseite keine Glazialformen aufweist, bestehen ihre obersten Partien doch aus den genau gleichen metamorphen Kalken (272, Tafel VII).

In den letzten Jahren sind die Niederschlagsverhältnisse am Ulu Dagh genauer untersucht worden, und die vorläufigen Ergebnisse sind für unseren Zusammenhang von höchstem Interesse $(211,212)$. Der Niederschlag wurde nur im Winterhalbjahr während ca. 230 Tagen gemessen, die folgenden Werte entsprechen dem Mittel aus vier Meßjahren.

$\begin{array}{lrr}\text { Bursa } & 100 \mathrm{~m} & 508 \mathrm{~mm} \\ \text { Yesilkonak } & 1025 \mathrm{~m} & 835 \mathrm{~mm} \\ \text { Sanatorium } & 1500 \mathrm{~m} & 1197 \mathrm{~mm} \\ \text { Hotel Ulu D. } 1950 \mathrm{~m} & 2099 \mathrm{~mm}\end{array}$

(Zum Vergleich: Jahresmittel 1931-1960 in Bursa 725,4 mm.)

Zum ersten Mal haben wir eine genaue Niederschlagsmessung einer türkischen Höhenstation vor uns. Die Niederschlagssteigerung mit zunehmender
Höhe ist äußerst interessant. Wir vermerken vor allem die Werte von mehr als $2 \mathrm{~m}$ bei der Meßstation Hotel Ulu Dagh (1920 m). Dementsprechend müssen die Schneemengen ganz bedeutend sein. Wenn auch die Gipfel des westlichen und des zentralen Taurus 3-4 Breitengrade südlicher liegen, so gehören sie doch zum gleichen Niederschlagsregime. Das Ergebnis vom Ulu Dagh gibt uns den wertvollen Hinweis, daß die Niederschlagsschätzungen im Ak Dagh und im Hohen Bolkardagh wohl berechtigt sind ( $2 \mathrm{~m}$ Niederschlag in der Höhenregion über 3000 m). Die offizielle Niederschlagskarte von 1960 weist dem Ulu Dagh 1250-1500 mm zu. Diese gewaltige Unterschätzung der Höhenniederschläge betrifft nach unserer Meinung genau gleich den Ak Dagh, den Hohen Bolkardagh und möglicherweise sogar den Erciyas Dagh.

Zweifellos ist der NW_SE-gerichtete Gebirgsrükken des Ulu Dagh für die Schneeansammlungen im Lee der Westwinde und für die Karbildung in NEExposition ideal angelegt. Die strahlungsgeschützte Nordostseite wird durch intensive Schneeanwehungen zusätzlich begünstigt, was die Schneegrenzdifferenz zwischen Schatt- und Sonnseite verstärken muß. Jedenfalls haben wir Mitte Juli am mysischen Olymp (Ulu Dagh) eine ausgedehntere Schneelage festgestellt ais am $400 \mathrm{~m}$ höheren griechischen Olymp.

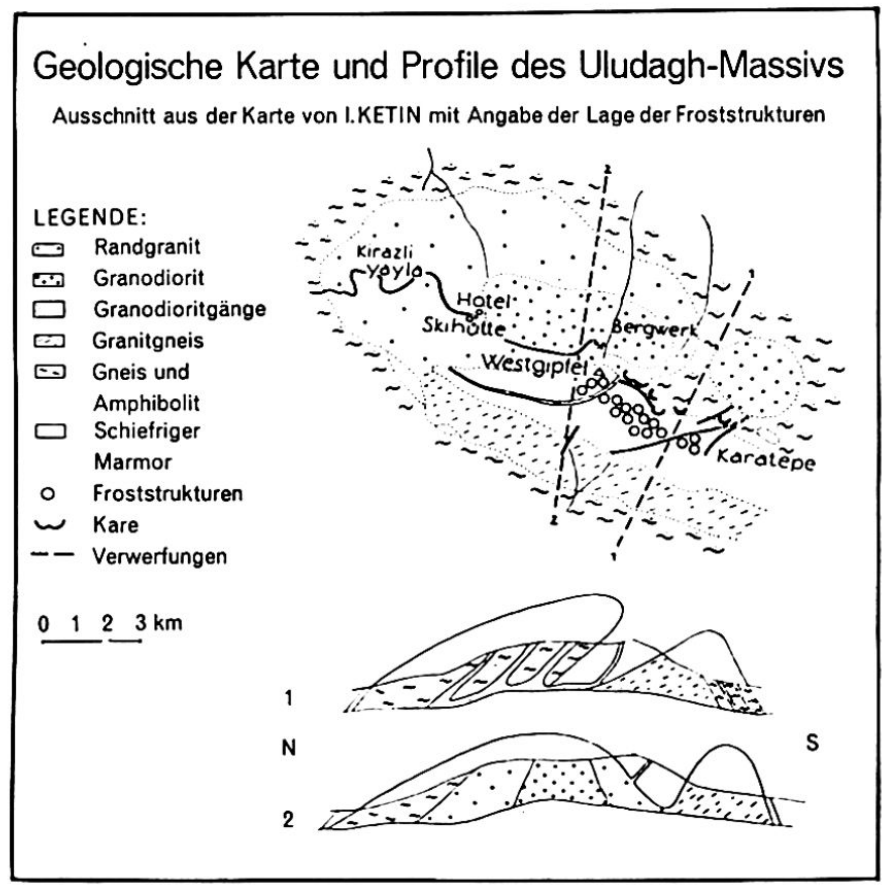

Fig. 8 Aus Pfannenstiel 1956. 


\subsection{Die regionale Schneegrenze}

Die Karböden liegen auf 2200-2400 m, die Moränen enden auf 1900-2000 m (185). Die lokale Schneegrenze beträgt nach der Höferschen Methode 2200-2250 m. Diesen Wert haben Philippson, Cvijic und Louis bereits ermittelt $(62,274,185)$. Nun stellen wir uns aber die Frage, ob wir die Schneegrenze wirklich unter $2300 \mathrm{~m}$ festlegen können. Die Südseite zeigt keinerlei Glazialformen, die lokale Schneegrenze muß mindestens auf $2500 \mathrm{~m}$ gelegen haben. Dagegen könnten wir einwenden, daß die lokalklimatischen Verhältnisse, besonders die luvseitige Schneeverblasung in SW-Exposition, die Schneegrenze unnatürlich hinaufdrücken. Im Vergleich mit andern Gebirgen dürfen wir aber eine Schneegrenzdifferenz von mindestens $250-300 \mathrm{~m}$ zwischen Schatt- und Sonnseite annehmen.

Ähnlich hohe Schneegrenzdifferenzen haben wir an rezenten Beispielen beobachtet (vgl. den Gletscher am Erciyas Dagh, 203). Dort haben wir erläutert, wie die Schneegrenzdifferenz zwischen Schatt- und Sonnseite von der würmeiszeitlich ausgedehnten Vergletscherungsfläche bis zur rezent beschränkten Gipfelvergletscherung ständig zugenommen hat. Die Begründung fassen wir folgendermaßen zusammen: Erstens führt eine große Eisfläche zu einem lokalklimatischen Ausgleich. Zweitens ist eine aus den Ursprungskaren weit ins Vorland ausströmende Vergletscherung orographisch weniger begünstigt; die Nordseite verliert im Unterlauf der Täler (Taurus) oder auf dem offenen Vulkansockel (Erciyas Dagh) ihre besondere Schutzwirkung. Die Endmoränenhöhen differieren auf den verschiedenen Gebirgsseiten nicht mehr stark (Erciyas Dagh, Hoher Bolkardagh). Dagegen ergibt eine räumlich eng begrenzte Gipfelvergletscherung eine bedeutende Schneegrenzdifferenz: Kleine Wandfußgletscher im Schatten der nordseitigen Karwände, völlig aperer Südhang in der direkten Strahlungsexposition. Zusammengefaßt heißt das: Alle Gebirge, die die Schneegrenzfläche in Kaltzeiten oder Warmzeiten nur knapp anschneiden und deshalb nur einseitig vergletschert waren oder sind, weisen im allgemeinen größere Schneegrenzdifferenzen auf (vgl. Seite 189).

Für den Ulu Dagh vermuten wir die regionale Schneegrenze auf über $2300 \mathrm{~m}$, eher gegen $2400 \mathrm{~m}$.

\subsection{Strukturböden und Waldgrenze}

- Pfannenstiel bespricht die rezenten Froststrukturböden auf der Hochfläche in $2400 \mathrm{~m}$ und ihre Beziehungen zum Karst (272).

- Wollsackartige Granitverwitterung stellen wir in fossilen Blockströmen unterhalb der Waldgrenze fest. Während der Kaltzeiten wurden einzelne Gra-

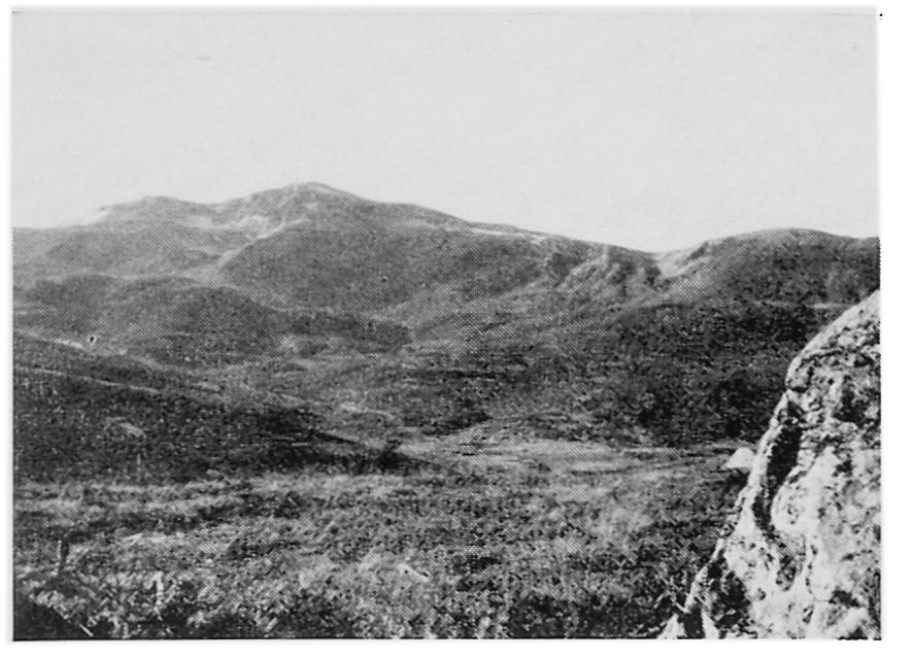

Abb. 33 Ulu Dagh bei Bursa 2543 m. Das Hauptkar zwischen den beiden höchsten Gipfeln 2543 und $2496 \mathrm{~m}$ öffnet sich nach NW. Endmoränen zwischen 1900 und $2000 \mathrm{~m}$. (Aufnahme Mitte Juli 1964.)

nitblöcke bis in die Umgebung von Bursa solifluidal transportiert.

- Die obere Waldgrenze legten Louis und Philippson in $2030 \mathrm{~m}$ fest (184).

\subsection{Zusammenfassungen}

\subsubsection{Résumé Ulu Dagh}

- Les fonds de cirques du versant nord se trouvent sur la surface de contact entre marbre et granit.

- Les mensurations exactes des précipitations à l'Ulu Dagh montrent que toutes les évaluations faites jusqu'ici sur les précipitations dans les montagnes d'Asie Mineure étaient trop basses. Jusqu'ici: Ulu Dagh 1250-1500 mm. Nouveau: Ulu Dagh 2099 $\mathrm{mm}$ pour la demi-année d'hiver (environ 230 jours).

-- Toutes les montagnes qui ne touchent que peu la surface de la ligne des neiges et qui de ce fait ne sont (Erciyas Dagh) ou ne furent (Ulu Dagh) recouverts de glace que sur un versant, montrent en général une plus grande différence entre les lignes des neiges de l'endroit et de l'envers.

- Nous évaluons la limite des neiges régionale würmienne de l'Ulu Dagh à plus de $2300 \mathrm{~m}$, plutôt à $2400 \mathrm{~m}$.

\subsubsection{Summary Ulu Dagh}

-The cirque-floors of the northern mountain-side lie on the contact surface of marble and granite.

- The exact measuring of precipitations on Ulu Dagh show us that all evaluations of the precipita- 
tions in the mountains of Asia Minor have been too low. Until now: Ulu Dagh $1250-1500 \mathrm{~mm}$. New: Ulu Dagh $2099 \mathrm{~mm}$ in winter half-year only (about 230 days).

- All the mountains which are only touched a little by the snow-line surface and which are, therefore, only glaciated on one side (Ulu Dagh in the past, Erciyas Dagh in the present) show, in general, a greater difference between the snow-lines of the sunny and shady sides.

- We estimate the regional Würm snow-line of Ulu Dagh at more than $2300 \mathrm{~m}$, preferably at $2400 \mathrm{~m}$.

\section{Der thessalische Olymp}

Zahlreich ist die Literatur über den sagenumwobenen thessalischen Olymp. Berichte von Botanikern und Geologen überliefern uns aus der zweiten Hälfte des letzten Jahrhunderts die ersten Kenntnisse über das Gebirge. Den entscheidenden Impuls erfuhr die Forschung durch die Vermessungsarbeiten von Kurz, der 1921 die erste Karte im Maßstab $1: 20000$ veröffentlichte (166). Nach seinem Werk, basierend auf der griechischen Triangulation, wird der höchste Gipfel Mitika (mitis = Nadel) mit 2917,9 kotiert. Interessant ist ein Vergleich dieser Höhe mit den übrigen Kulminationspunkten der Balkanhalbinsel. Im Rilagebirge erhebt sich der Musalla auf $2925,4 \mathrm{~m}$ und unmittelbar südlich davon der Jel Tepe im Pirin Planina auf 2920 m (243). Die Bemerkung Oberhummers ist anregend, daß man fast von einer Gipfelflur sprechen könnte, in die sich selbst der Gran Sasso Italiens mit 2914 m einreihen ließe.

\subsection{Einige Hinweise zum Aufbau}

Die Basis des Olymps besteht aus "flyschartigen» (63), wenig resistenten Talk- und Serpentinschiefern, die nach allen Seiten ausstreichen. In Wechsellagerung mit stark gepreßten Kalken sind die Kontaktstellen oberhalb Litochoron schön aufgeschlossen. In höheren Lagen folgen Kalke und Dolomite, deren Mächtigkeit auf $3000 \mathrm{~m}$ geschätzt wird. Die Schichten fallen im E, N, S und SW mantelförmig nach außen, nur im W werden sie vom Gebirgsabfall diskordant geschnitten (356). Beachtenswert ist die Bruchtektonik, vor allem gegen das Becken von Elasson und die schmale Küstenebene.

Durch die gesamte Literatur hindurch spielt das Thema der jungen Hebungen eine große Rolle, besonders auch im Zusammenhang mit der Frage der Vergletscherung. Tatsächlich lassen sich Verwerfungen in den Quartärablagerungen am Gebirgsfuß bei Litochoron feststellen, Cvijic hat sie eingehend besprochen. Diese bedeutenden Akkumulationsmassen führt der gleiche Autor auf eine verstärkte Erosion zurück, die durch die ägäische Senkung und eine entsprechende Tieferlegung der Erosionsbasis ausgelöst wurde. Cvijic glaubt sogar, daß dieser Vorgang bis in die postdiluviale Zeit hineingespielt hat. Im gleichen Zusammenhang wird auch die alte Rumpffläche des Olymps immer wieder erwähnt, wie sie sich in den Hochplateaus der Bara (Abb. 34) und den abgetragenen Gipfelkuppen im SE präsentiert (Abb. 35). Ob wir allerdings mit größeren $\mathrm{He}$ bungen unmittelbar vor der Würmeiszeit operieren können, wie Jaranoff (137) es tut, scheint uns fragwürdig. Seinen gleichartigen Ergebnissen aus der Sierra Nevada stimmen wir nicht zu. Wir haben dort in einer normalen Höhenlage eine ältere Vergletscherung festgestellt, und $\mathrm{zu}$ ähnlichen Feststellungen kommen wir auch im Olymp. Im übrigen sind die Ausmaße einer möglichen postglazialen Bewegung nicht bekannt. Selbstverständlich befinden wir uns am Rande der Aegäis in einem äußerst mobilen Raum und eine nachträgliche Verlagerung der Schneegrenzhöhen ist nicht ausgeschlossen, bis heute aber auch nicht eindeutig bestimmt.

Diese knappen Ausführungen enthalten folgende Hinweise auf die eiszeitliche Vergletscherung (Fig. 9):

- Die eingeebneten Hochflächen einer Bara (2300_ $2360 \mathrm{~m}$ ) und Odas (2300-2350 m) bieten einer Vergletscherung denkbar schlechte Bedingungen.

- An den abgetragenen Gipfelkuppen im Süden können sich keine Karformen entwickeln, die Vergletscherung muß in ihrer Ausdehnung sehr beschränkt bleiben.

- Im Bereich der Hauptgipfel fällt die Südexposition ebenfalls aus. Die deutlichsten Glazialformen konnten sich nur in den tief eingeschnittenen Talungen der Nordseite, im Einzugsgebiet des Xerolakki entwickeln (Megali Kazania und Mikri Gourna).

\subsection{Die klimatischen Verhältnisse}

1963 ist auf dem Gipfel des Aghios Antonio (2817 m) (Karte Kurz: Palimanastri, $2815 \mathrm{~m}$ ) eine sehr gut ausgerüstete meteorologische Station ganzjährig in 
Betrieb genommen worden (Abb. 35). Ihre Ortsund Höhenlage wird den künftigen Untersuchungsergebnissen eine ganz besondere Bedeutung verleihen. Leider verfügen wir noch über keine genauen Meßwerte, sondern stützen uns bloß auf die ersten Erfahrungs- und Beobachtungsergebnisse von Professor Livadas. (209).

\subsubsection{Zirkulation, Schneelage, Strahlung}

Im Winterhalbjahr sind zwei Windrichtungen zu unterscheiden:

- Die Westzirkulation steuert die Depressionen durch den Mittelmeerraum und bevorzugt die Westküsten mit größeren Niederschlagsmengen. Gerade auf der Breite des Olymps tauchen albanische Küstenketten auf, und der Pindos erhebt sich zu seiner größten Höhe (2633 m), was die Kontinentalität in Thessalien verstärkt.

- Von der winterlichen asiatischen Antizyklone strömt ein NE-Wind ab, der den Hochgebirgen des Balkans beachtliche Schneemengen bringen soll. Sowohl im Durmitor Jugoslawiens wie auf dem Olymp Griechenlands wurden wir auf den trockenen, aber ausgiebigen Schneefall aus NE aufmerksam gemacht. Nach Livadas soll sich dieser Niederschlag sogar in süd- bis südwestexponierten Leehängen der Gipfelregion als reichliche Schneebedeckung abzeichnen, aber unter der intensiven $\mathrm{Di}$ rektstrahlung rasch ausschmelzen. Langdauernde oder perennierende Schneeflecken sind nur in gut geschützten Nordhängen möglich, was wieder einmal die elementare Bedeutung der Strahlung im Ablationsgeschehen aufzeigt.

Das Sommerhalbjahr ist durch eine starke Gewittertendenz aus $\mathrm{S}$ und $\mathrm{W}$ gekennzeichnet. Die tägliche Bewölkung ist im Berührungsraum der kontinentalen und maritimen Einflußsphäre außerordentlich groß. Sie hemmt den sommerlichen Strahlungsgang, ist aber räumlich und zeitlich noch wenig erforscht.

\subsubsection{Die Temperaturen}

Der kräftige Gegensatz zwischen kontinentalem (W und SW) und maritimem (E bis NE) Klimaraum mußte sich in Kalt- und Warmzeiten auf das Gebirge auswirken. Nach Livadas sollen Temperaturgegensätze bis zu $7^{\circ}$ zwischen kontinentalem und maritimem Gebirgsfuß auftreten. Wesentlich ist die Ergänzung, daß das gegen den Golf von Saloniki geöffnete Xerolakki mit seinem Einzugsgebiet fast die gesamte Nordseite einnimmt. Das bedeutet: Die Nordseite ist kühler und feuchter als die Südseite, was sich auch eiszeitlich auf die Vergletscherung auswirken mußte. Wir dürfen uns vom Wasserman-

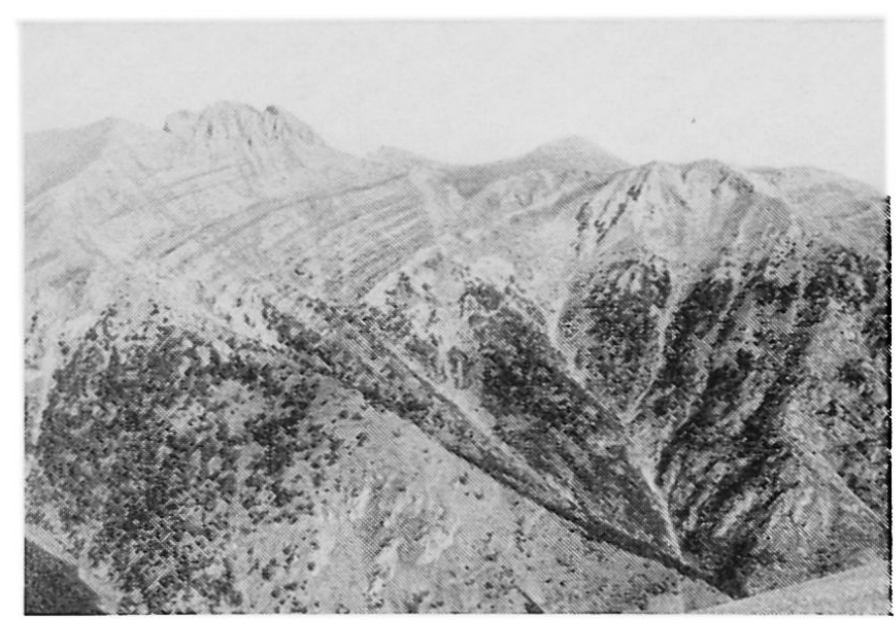

Abb. 34 Der Einzugstrichter des Dionys-Tales. Im Hintergrund links die höchsten Gipfel des Mitika $(2917,9 \mathrm{~m})$ und Stefani $(2909 \mathrm{~m})$. Nach beiden Seiten ist der Übergang in die alten Hochplateaus zu erkennen. Kalk- und Dolomitbänke: Fallen nach SSW. Glatthangbildungen in der Gipfelregion. Waldgrenze auf ca. $2000 \mathrm{~m}$.

gel im Xerolakki ( $=$ Trockental) nicht täuschen lassen, er ist karst- und nicht niederschlagsbedingt. Die Höhenstufung der Temperatur wird gegenwärtig untersucht. Interessant ist bloß der Hinweis, daß die Maximaltemperaturen durch außerordentlich hohe Gradienten von über $1^{\circ} \mathrm{C}$ gestuft sein können. Ähnliche Erscheinungen haben wir in Anatolien und am Hohen Atlas selber festgestellt, doch müssen wir dieses Problem vorläufig offenlassen, weil uns zu wenig Meßdaten zur Verfügung stehen. Vielleicht wird diese Frage die klimatische Schnee-

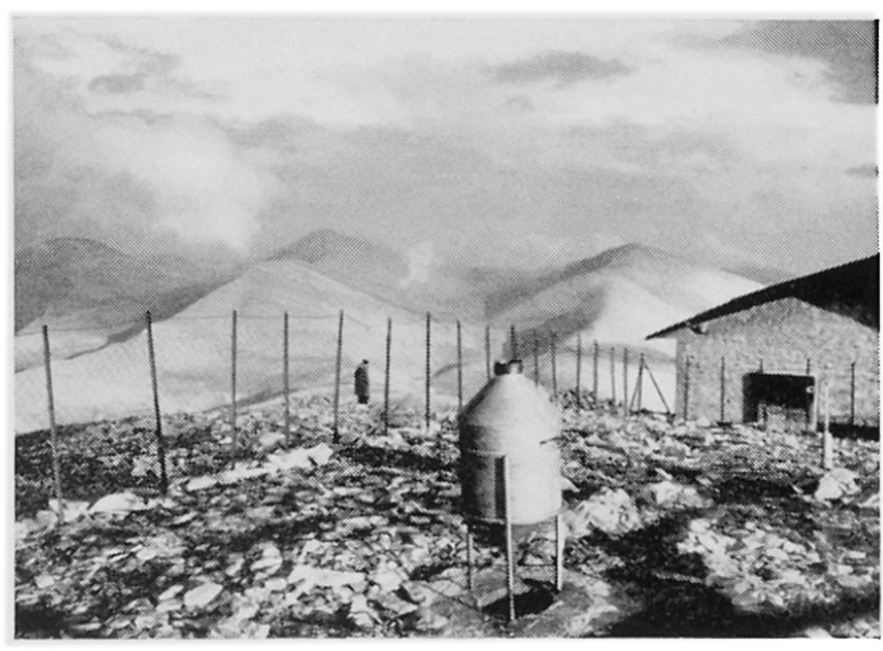

Abb. 35 Die Gipfelreihe südlich der Bara. Standort: Meteorologische Station auf Aghios Antonio $(2817 \mathrm{~m})$. Blick auf die abgetragenen Kuppen südlich der Bara, links hinten der Gipfel Krontz (2679 Meter). Moränenfunde beweisen eine schwache Vergletscherung dieser weiten Talmulden. 


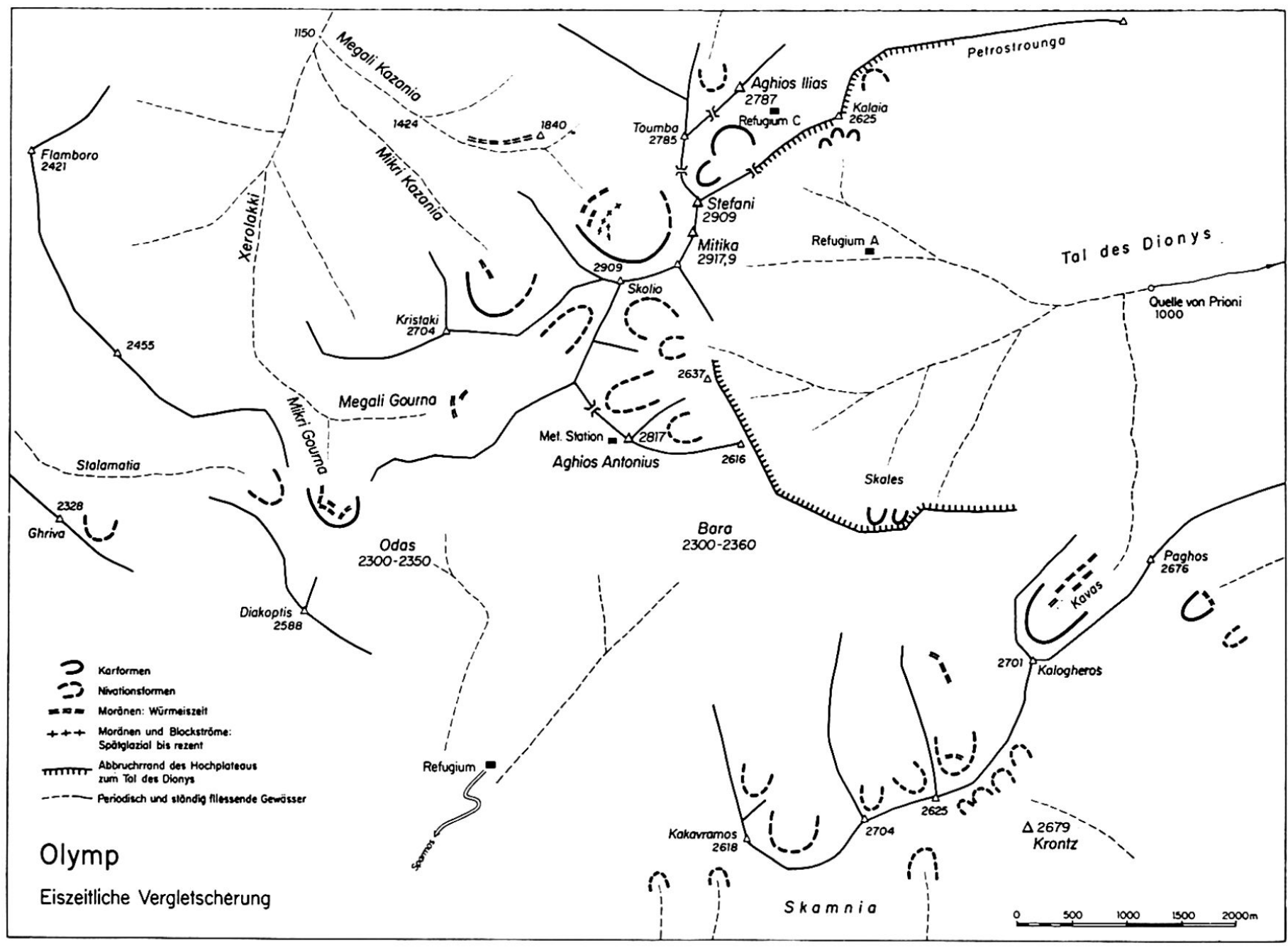

Fig. 9 Olymp. Eiszeitliche Vergletscherung

grenzberechnung im subtropischen Raum in $\mathrm{Zu}$ kunft wesentlich beeinflussen.

\subsubsection{Die Niederschläge}

Im kontinentalen Raum Sparmos, Elassona und Larissa werden Niederschlagsmengen bis zu $400 \mathrm{~mm}$ gemessen. In Litochoron steigert sich dieser Wert im Stau des Olymps bis auf 1000 mm (209). Wiederum zeigt sich die klimatische Gegensätzlichkeit der beiden Gebirgsseiten, was übrigens auch im Wandel von Vegetation und Siedlung zum Ausdruck kommt. Die Niederschlagssteigerung mit zunehmender Höhe wird gegenwärtig untersucht. Wie in der Sierra Nevada (204) ergibt sich nach mündlicher Mitteilung von Livadas eine auffallende Stufung. Die Niederschlagsmengen nehmen bis ca. $1800 \mathrm{~m}$ $\mathrm{zu}$, bleiben bis ca. $2300 \mathrm{~m}$ konstant und erfahren dann eine neue Steigerung bis zum Gipfel. Diese Erscheinung hängt zweifellos mit der Höhenschichtung zusammen, was sich künftighin ebenfalls auf die Schneegrenzbestimmung im mediterranen Raum auswirken könnte. Livadas schätzt die Niederschlagsmenge im Gipfelbereich des Olymps auf über
$2 \mathrm{~m}$, obwohl die bisherigen Pluviographenwerte eher darunter blieben.

\subsection{Die eiszeitliche Vergletscherung}

1955/56 hat Wiche die Ergebnisse seiner morphologischen Untersuchungen im thessalischen Olymp herausgegeben (356). Wir möchten auf die Bedeutung dieser Arbeit ganz besonders hinweisen. In vielen Teilen folgen wir seinen Resultaten, beschränken uns aber auf die Ermittlung der würmeiszeitlichen Schneegrenze. Wiederholungen wollen wir vermeiden und legen deshalb die Schwerpunkte unserer Untersuchungen auf die Verfirnung der Südseite und die Vergletscherung der Nordseite, insbesondere die Formen im schwer zugänglichen Megali Kazania.

\subsubsection{Die einzelnen Regionen (Fig. 9)}

- Gipfel und Täler im Süden und Osten der Bara (Abb. 35):

Die Gipfel von Paghos über Krontz bis zu Kakavra- 
mos zeigen eine auffallende Gleichförmigkeit. Weite Talmulden trennen die von Schutthalden überzogenen Hügelformen; wir erhalten den Eindruck einer alten Abtragungslandschaft. Zwischen P. 2618 (Kakavramos) und 2701 (Kalogheros) konnten sich nach Norden drei kleine Gletscher entwickeln. Eindeutige Moränen der letzten Eiszeit sind aber nur in der östlichsten Talung nachweisbar. Wiche interpretiert die Stelle auf $2300 \mathrm{~m}$ als eine ausgeaperte Ufermoräne und schließt daraus auf eine lokale Schneegrenze von $2350 \mathrm{~m}$. Im Talkessel von Kavos sind glaziale Deponien durch jüngere Schuttbewegungen umgelagert worden. Wir haben diesen tiefen Einschnitt als Karform bezeichnet, doch handelt es sich zweifellos um eine tektonisch bestimmte präglaziale Anlage. Das eiszeitliche Gletscherende kann nicht mehr rekonstruiert werden, da sich das Material im Steilhang verliert. Daß sich im Kavos ein kleiner aber kräftiger Gletscher entwickeln konnte, ist auf die übermäßige lokalorographische und -klimatische Begünstigung zurückzuführen.

Auch südlich der Gipfellinie sind glaziale Formen anzutreffen. Südöstlich des Paghos-Gipfels findet sich ein schönes Kar mit zahlreichen Moränenwällen. In reiner Südexposition dagegen konnten sich bloß noch Nivationsmulden ausbilden, die immerhin auf eine ausgedehnte Verfirnung hinweisen. Dieses Problem wollen wir im folgenden eingehender besprechen.

- Die eiszeitliche Verfirnung der Südseite (Abb. 36, 37):

Vom Refugium auf 1800-1900 m, das auf einem Bergsträßchen von Sparmos her erreicht werden kann, haben wir bis zum Gipfel des Aghios Antonio die folgenden Oberflächenformen nach Höhenstufen typisiert:

Unterhalb $1800 \mathrm{~m}$ beginnt eine gut geschichtete Konglomeratdecke, die eine harte Verkittung zeigt und kleinere Komponenten mit teilweiser Bearbeitung enthält.

1800-2300 m: Kopfgroße und kantenbestoßene Blöcke bedecken die Oberfläche (Abb. 36). Dazwischen liegen kleinere, weniger bearbeitete oder splittrige Stücke. An einigen Stellen ist das gleiche Material in ungeordneter und lockerer Verbackung aufgeschlossen. In dieser gleichen Höhenstufe treten die ersten Solifluktionserscheinungen auf. Selten und undeutlich auf $1900 \mathrm{~m}$, als schöne Girlandenböden, Steinstreifen und Steinringe auf $2300 \mathrm{~m}$.

2300-2600 m: Die gerundeten und kantenbestoßenen Komponenten werden immer seltener, verkittete Horizonte sind nicht mehr anzutreffen, der anstehende Fels liegt unter geringer Bedeckung. Die Solifluktionsformen sind reich entwickelt, werden aber mit zunehmender Steilheit durch Schuttrinnen abgelöst (Abb. 37).

2600-2800 m: Wir betreten die eigentliche Frost-

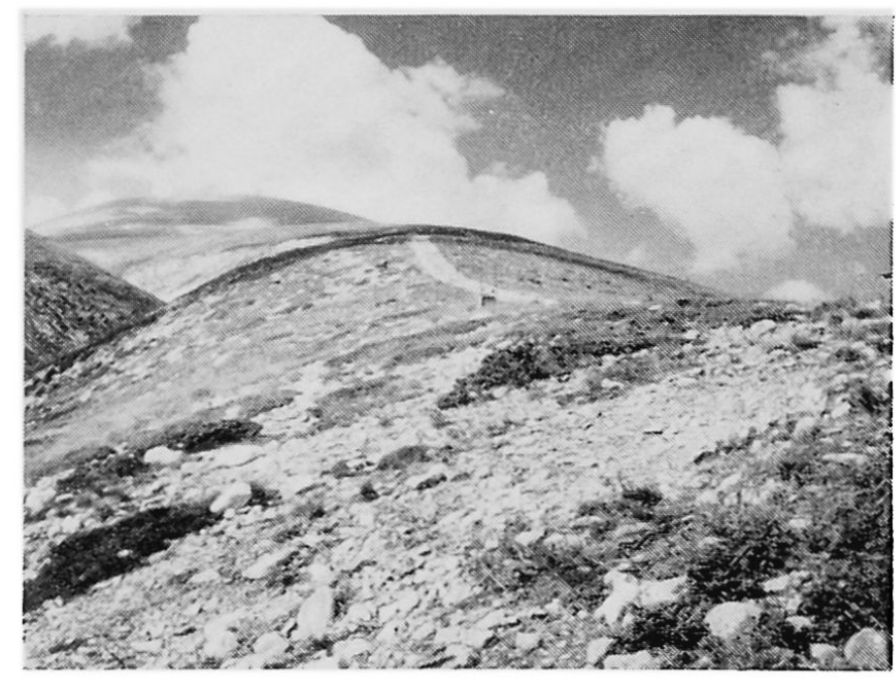

Abb. 36 Südseite Aghios Antonio. Standort ca. 2100 oberhalb Refugium. Blick zur meteorologischen Station auf dem höchsten Punkt (Abb. 35). Im Vordergrund kantenbestoßene, bis kopfgroße Blöcke. Diese Ablagerungsform ist weder eine eindeutige Moräne, noch ein reines Solifluktionsmaterial. Die Häufung zwischen 1900 und 2300 m weist auf den Schmelzbereich einer zeitweiligen Firndecke hin.

schuttstufe, die Vegetation wird spärlicher. Schuttzungen und Schuttrinnen kennzeichnen die flächenhafte Abtragung. In Gipfelnähe tritt der anstehende Fels an die Oberfläche.

Interpretation: Eine Vergletscherung hat nicht existiert, richtige glaziale Erosions- und Akkumulationsformen fehlen. Wir fragen uns aber, ob die beschriebene Materialfolge allein mit solifluidalem Transport erklärt werden kann, vor allem die auffällige Materialhäufung und -rundung zwischen 1800-2300 m. Die eiszeitliche Solifluktionsbewegung ging viel tiefer (fossile Schuttzungen im Xerolakki auf $1200 \mathrm{~m}$ ), und die aktuelle Solifluktion entwickelt kaum eine so beachtliche Transportkraft. Überdies deutet die Zementierung des oberflächlichen Materials eher auf die letzte Kaltzeit hin.

Eine zeitweise Verfirnung bis auf die Höhenstufe 1800-2300 m könnte uns interessante Erklärungsmöglichkeiten bieten. Schwache Transportleistungen wären möglich, weil das Material ja höchstens auf der Bodenoberfläche bewegt oder gerollt werden konnte. (Keine Felswände, kein Sturzmaterial.) Auf diese Weise ergäbe sich von oben nach unten eine zunehmende Abrundung, verstärkt durch Lösungserscheinungen und schließlich eine auffallende Häufung zwischen 1800 und $2300 \mathrm{~m}$.

In dieser Zone hätte sich wohl die eiszeitliche Schnee- und Firndecke immer wieder aufgelöst. Aus diesem Bereich flossen auch größere Schmelzwassermengen $\mathrm{ab}$, so daß unterhalb $1800 \mathrm{~m}$ ein kom- 
pakteres und geschichtetes Konglomerat entstehen konnte. Selbstverständlich entwickelten sich in höheren Lagen bei periodischer Aufschmelzung solifluidale Bewegungsvorgänge, Materialverkittungen und möglicherweise auch Lösungsvorgänge am Kalk.

Im übrigen weisen wir auf die starken Verkittungen der Moränen hin, die Wiche mehrmals erwähnt, und die uns im Megali Kazania ganz besondere Probleme stellten.

\section{- Gourna-Täler:}

Das Megali Gourna zeigt eine glaziale Úberformung, doch hat es keinen bedeutenden Gletscher entwickelt. Die Exposition ist ungünstig, die glazialen Ablagerungen sind spärlich. Die Blockanhäufung auf $2380 \mathrm{~m}$ hat Wiche als Endmoräne bezeichnet und daraus eine lokale Schneegrenze von $2700 \mathrm{~m}$ abgeleitet. Deutlicher sind die glazialen Deponien im Mikri Gourna. Moränenwälle liegen zwischen 2200 und $2400 \mathrm{~m}$ am Fuße der hohen Karwände. Ob sich im Schutz der westlichen Steilwand sogar ein spätglazialer Eisfleck bilden konnte, wagen wir nicht mit Sicherheit zu entscheiden. Der auffällige Unterschied zwischen Megali- und MikriGourna ist lokalklimatisch und -orographisch bedingt. Das Megali Gourna ist gegen W geöffnet, an den Luvhängen des Skolio blieb nur wenig Schnee liegen, währenddem das tief eingeschnittene MikriGourna für eine Schneeanreicherung viel günstiger war. An der Gegenüberstellung dieser beiden Täler erkennen wir wieder einmal, daß für die Gletscherbildung nicht allein die Höhenlage und die Oberflächenausmaße, sondern vielmehr die lokalklimatischen und -morphologischen Bedingungen entscheidend sind.

\section{- Das Einzugsgebiet des Dionys-Tales:}

Eindrücklich ist die Karform zwischen dem Aghios Ilias (Berg Elia) und dem Stefani (Thron der Götter). Die primär tektonische Anlage und spätere fluviatile Ausgestaltung ist durch eine deutliche glaziale Erosion überformt. Moränen sind aber keine mehr erhalten. Sie fehlen ebenfalls in den Karnischen nördlich und südlich des Kalaia (2625 m) und in den Nivationsmulden zwischen Skolio und P.2616. Im Abbruchrand zum Dionys-Tal haben mehrere kleine Gletscher existiert, das Kavos haben wir bereits erwähnt. Eine geschlossene Eismasse konnte sich aber nicht entwickeln, umsomehr, als die Hochfläche der Bara nicht vergletschert, höchstens verfirnt war. Interessant ist der Vergleich von drei Kleinkaren in Südexposition auf ca. 2550 m (südlich Kalaia) mit den deutlicheren Karformen in Nordostexposition auf ca. $2250 \mathrm{~m}$ (Skales). Setzen wir die Karböden der Schneegrenze gleich, so ergibt sich unter ähnlichen Entstehungsbedingungen eine

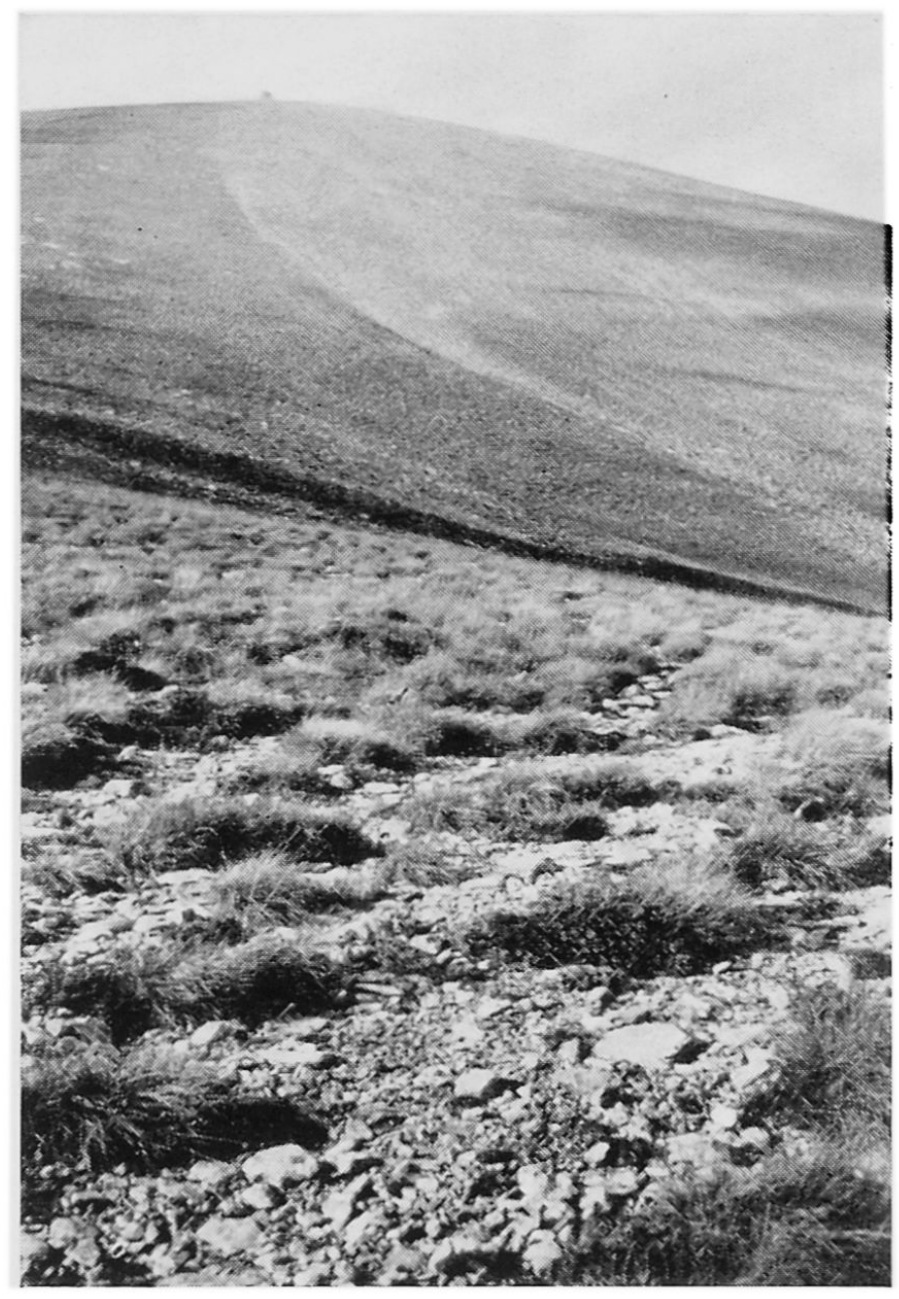

Abb. 37 Südseite Aghios Antonio. Fuß des Gipfelaufbaus, Höhe ca. 2450-2500 m, in den Wolken auf dem höchsten Punkt die meteorologische Station. Im Vordergrund Solifluktionsböden, mit zunehmender Steilheit in Schuttrinnen und Schuttzungen übergehend. Größere und bearbeitete Komponenten treten erst $300 \mathrm{~m}$ weiter unten auf.

Differenz zwischen Schatt- und Sonnseite von ca. $300 \mathrm{~m}$, im Mittel $2400 \mathrm{~m}$.

\section{- Mikri Kazania:}

Über $300 \mathrm{~m}$ hohe Steilabstürze kennzeichnen die Westseite des Mikri Kazania, an die sich die eiszeitliche Vergletscherung anlehnte. Die Endlage können wir nicht mehr rekonstruieren, weil der Gletscher den Steilabfall bei ca. $1900 \mathrm{~m}$ erreicht, überflossen und keinen Haltepunkt mehr gefunden hat. Einzig auf 2200-2300 m sind einige Wallformen erhalten, die wir einer Rückzugszeit zuordnen. Auch hier fällt eine Konglomeratdecke auf, die im Gefällsknick seitlich des Karausgangs ansetzt und talwärts an Mächtigkeit ständig zunimmt. Bearbeitete Komponenten in höchsten Bereichen weisen darauf hin, daß Moränenrelikte darin erhalten sein können und daß die Zementierung während und unmittelbar nach der letzten Kaltzeit zustandekam, 
im Zusammenhang mit intensiverer Hangsolifluktion und größerer Bodenfeuchtigkeit.

- Megali Kazania (Abb. 38, 39, 40):

Es ist das größte und tiefste Kar des Olymps, eingerahmt von den höchsten Gipfeln des Mitika, Stefani und Skolio. Steilabstürze von über $500 \mathrm{~m}$ geben diesem Talkessel ein imposantes Gepräge (Abb. 38). Zahlreiche Erosions- und Akkumulationsformen beweisen die Gletscherbildungen in diesem Gunstraum.

Das jüngste und höchste Wallsystem befindet sich auf ca. $2200 \mathrm{~m}$ (Abb. 39). Es setzt sich aus grobblockigem Sturzmaterial zusammen, das über kurze Distanzen transportiert und zu mehreren Wallformen zusammengeschoben worden ist. Vor allem die westliche Talseite ist von Blockmassen dicht belegt, währenddem die Talmitte durch wechselweise Schmelzwassererosion und -akkumulation ausgeräumt und überschüttet worden ist. Die frischen Blockwälle können wir keinesfalls einem würmeiszeitlichen Rückzugsstadium zuordnen, vielmehr muß es sich um spätglaziale Bildungen handeln, die sehr wahrscheinlich in den geschichtlichen Hochständen blockstromartige Umlagerungen erfahren haben. Heute sind diese Massen stabilisiert, wie die stirnseitigen Böschungswinkel von $33-34^{\circ}$ und die ersten Vegetationsansätze beweisen (Abb. 39).

Ein mittleres Wallsystem ist stark zerstört, einzelne Relikte sind bloß auf der linken Talseite erhalten (Abb. 38).

Ein vorderster und stark bewachsener Wall schließt den Karboden auf ca. $2100 \mathrm{~m}$ ab. Der Altersunterschied zu den jüngsten Wallformen ist auffallend. Hier haben wir es zweifellos mit einem würmeiszeitlichen Rückzugsstadium zu tun, dessen letzte Akkumulationen auf der vordersten Kante des Karbodens gerade noch erhalten geblieben sind.

Ein solcher Reichtum an eindeutig glazialen Ablagerungen ist für olympische Verhältnisse einmalig. Es kann uns nicht erstaunen, daß aus diesem geschlossenen Karraum heraus ein schwer befrachteter Talgletscher abfloß, der sich in mächtige Seitenund Endmoränen auflösen mußte. Tatsächlich wurde am Felskopf P. 1840 (166) die Eismasse nach links abgelenkt, und hier begann die Ablagerung der großen rechten Seitenmoräne (Abb. 40). Das Ende müssen wir auf ca. $1500 \mathrm{~m}$ annehmen, jedenfalls oberhalb der markanten Talverzweigung, die auf der Kurz-Karte mit 1424 m (166) angegeben ist. Der gesamte Wall ist ca. $80 \mathrm{~m}$ hoch, wobei wir die obersten $30-40 \mathrm{~m}$ der Würmeiszeit zuordnen. Auf der höchsten Krete in ca. 1780 m Höhe haben wir eine morphometrische Auszählung vorgenommen und einen Mittelwert von 0,097 erhalten (16). Dieses Ergebnis, wie auch die Gruppenverteilung der einzelnen Komponenten, weist auf den Moränencharakter hin. (0-50: 18. 51-100: 43. 101-150: 21 .

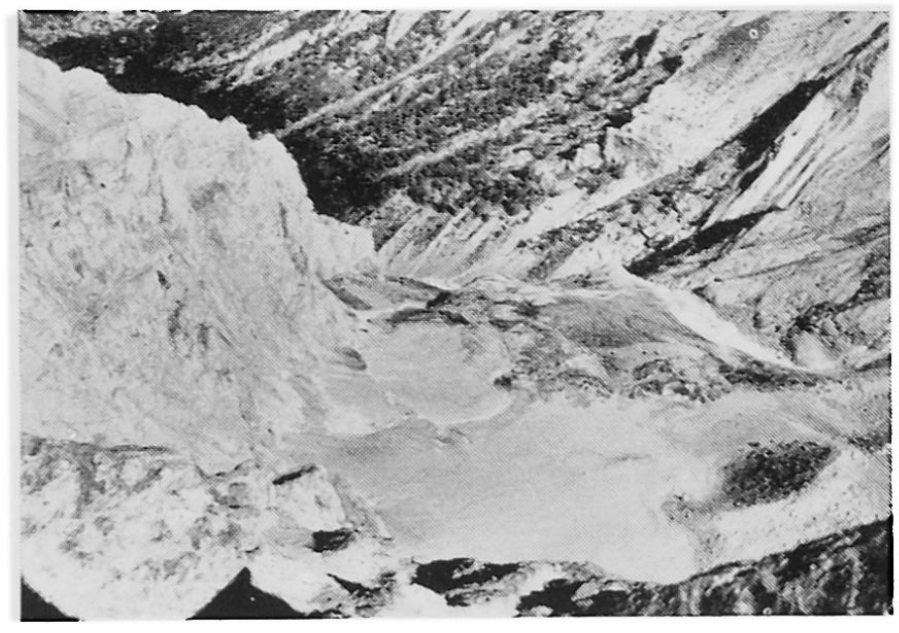

Abb. 38 Tiefblick vom Skolio in das Megali Kazania. Steilabsturz über $500 \mathrm{~m}$. Am rechten Bildrand frische Blockwälle. Links vorgestaffelt die Reste eines zerstörten und überschütteten Wallsystems. Im obersten Vegetationsbereich die Ablagerungsformen des zurückgehenden Würmgletschers. Im Tallauf zahlreiche Rundbuckel. Rechts oberhalb der beginnenden Kerbtalung, von Wald bestanden, die große Seiten- und Endmoräne. (Abb. 40).

151-200: 13. 201-250: 2. 250_300: 2. 350_400: 1.) Ein rein fluviatiler oder solifluidaler Transport ist durch diesen Zurundungsstand ausgeschlossen. 30_ $40 \mathrm{~m}$ unterhalb der Krete setzen die Konglomeratbänke ein. Das Material ist zeitweise grob geschichtet, enthält gerundete und unbearbeitete Komponenten, kleinste Stücke liegen neben $15-30 \mathrm{~m}^{3}$ großen Blöcken. Es ist denkbar, daß es sich bei den untersten, hart verkitteten Schichten um Ablagerungen einer älteren Kaltzeit handelt. Im Talstrich wurden sie wegerodiert, seitlich aber von würmeiszeitlichen Deponien überlagert.

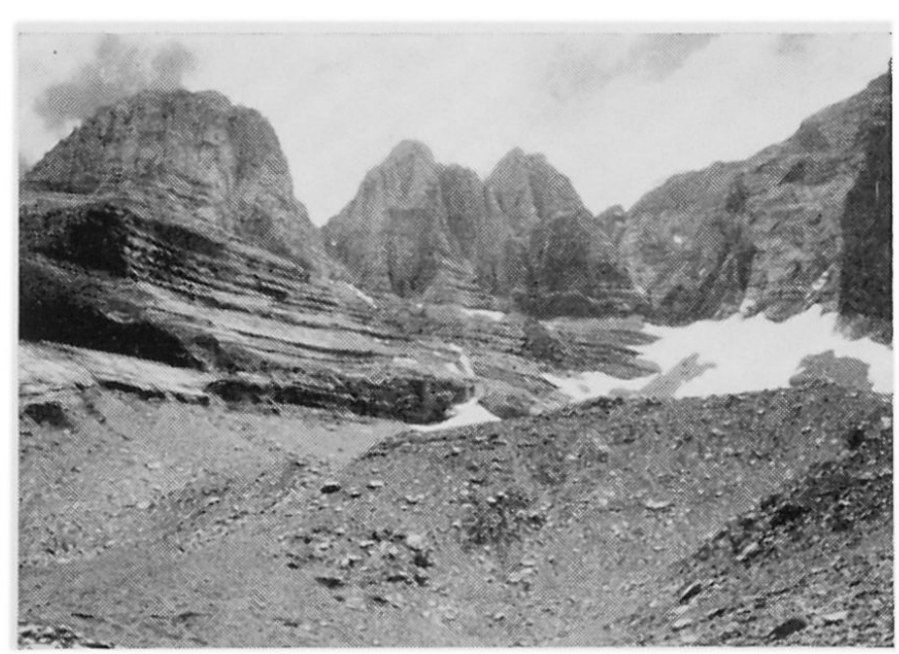

Abb. 39 Megali Kazania. Jüngere Moränenwälle auf ca. $2200 \mathrm{~m}$. Spätglaziale Entstehung, in rezenten Hochständen blockstromartig bewegt. Heute stabilisiert, auf der Stirnseite erste Vegetationsansätze. 
Talabwärts werden die Akkumulationsmassen immer mächtiger und besser geschichtet, die Komponenten immer stärker bearbeitet und härter verkittet. Die Großblöcke bleiben zurück, der glaziale Einfluß hört endgültig auf. Vor der Einmündung ins Xerolakki sind die Konglomeratbänke so einheitlich und kompakt, daß sich darin zahlreiche Höhlen gebildet haben. Wir haben uns gefragt, ob wohl in diesem Raum nicht ein älteres Quartär nachgewiesen werden könnte, wie es bei Litochoron versucht wurde. Viele Probleme müssen wir offen lassen.

Die lokale Schneegrenze bestimmen wir nach der Höferschen Methode aus dem Mittel zwischen 1500 und $2900 \mathrm{~m}$ mit ca. $2200 \mathrm{~m}$.

\subsubsection{Die regionale Schneegrenze}

Die Bestimmung einer letzteiszeitlichen Schneegrenze ist im Olympmassiv nicht in allen Expositionen möglich, obschon der Gipfelbereich die Schneegrenze ganz bedeutend überragte. Die Hochplateaus und die monotonen Südhänge waren nicht vergletschert, sondern verfirnt. Abgesehen von einigen kleinen Karbildungen auf der Südseite (Abbruchrand des Hochplateaus) treten bedeutende Glazialformen nur in strahlungsgeschützter Nord- und maritim exponierter Ostauslage auf. Dort, wo sich diese beiden Vorteile vereinigten, wie im oberen Einzugsgebiet des Xerolakki (Megali Kazania), bildeten sich die größten Eismassen und die besterhaltenen Moränen. Die großen Unterschiede in den lokalen Schneegrenzhöhen machen die Ermittlung einer regionalen Schneegrenze äußerst problematisch. Die nordseitigen Lokalwerte schwanken zwischen 2200 (Megali Kazania) und $2300 \mathrm{~m}$ (Mikri Gourna und Skales), die süd- und westseitigen ergeben $2550 \mathrm{~m}$ (südlicher Kalaia) bis $2700 \mathrm{~m}$ (Megali Gourna). Die Differenz zwischen günstigster und ungünstigster Exposition beträgt 300-500 m, was unsere Erfahrungswerte aus Kleinasien bestätigt.

Interessant ist der Lokalwert aus dem Gipfelraum südlich der Bara, der eine nordseitige Schneegrenze von $2350 \mathrm{~m}$ ergibt und damit die orographisch ungünstige Situation aufzeigt. Die entsprechende lokale Schneegrenze auf der Südseite der abgetragenen Gipfelkuppen müssen wir auf mindestens 2700 $\mathrm{m}$ ansetzen. Jedenfalls so, daß die 100-200 m über die mittlere Schneegrenzfläche aufragenden Kuppen auf ihren ausgeglichenen und offenen Südhängen nicht mehr vergletschert werden konnten.

Wiche gibt die regionale Schneegrenze mit $2350 \mathrm{~m}$ an und stützt sich dabei weitgehend auf die ausgeaperte Ufermoräne südlich der Bara. Die Bestimmung ist sicher richtig, entspricht aber nur einem lokalen Talwert, keinesfalls einem Mittelwert. Louis hat 1933 auf Grund von Karten und Bildern vom

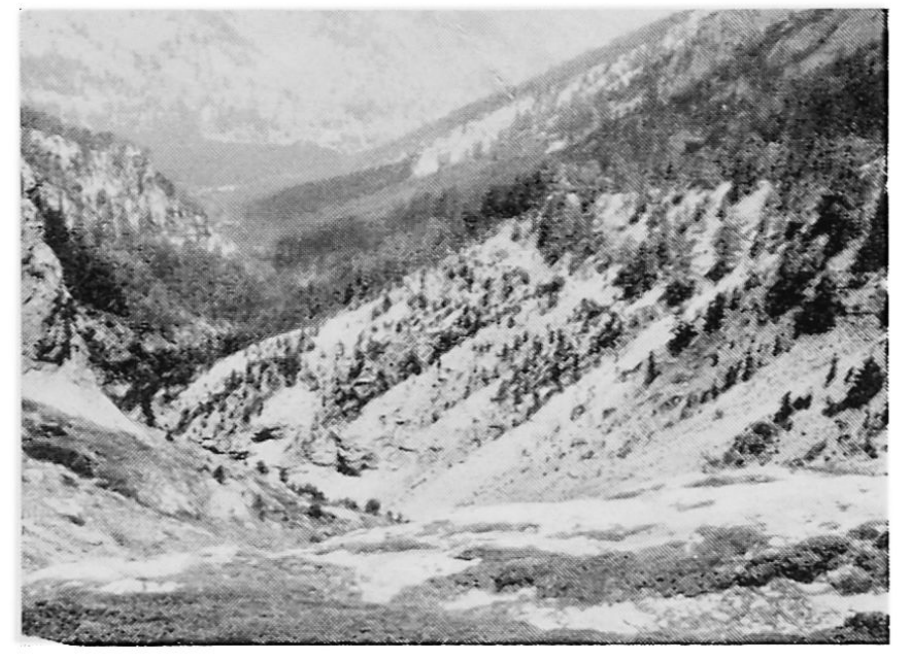

Abb. 40 Blick auf die große Seitenmoräne im Megali Kazania. Sie setzt am rechten Bildrand auf ca. $1800 \mathrm{~m}$ ein und endet auf ca. $1500 \mathrm{~m}$. Die oberen $30-40 \mathrm{~m}$ wurden durch den Würmgletscher abgelagert, die am Fuß austretenden verfestigten Horizonte ordnen wir einer älteren Kaltzeit zu.

Megali und Mikri Kazania die regionale Schneegrenze auf $2300 \mathrm{~m}$ festgelegt (zit. nach 356, S. 35). Dieser Wert ist zu sehr auf die nordseitig maritime Exposition ausgerichtet und berücksichtigt den südwestlich kontinentalen Gebirgsanteil zu wenig. Zusammengefaßt legen wir die regionale Schneegrenze der Würmeiszeit auf mindestens $2400 \mathrm{~m}$ fest. Mit dieser Höhenlage haben wir Gewähr, daß die Gunstlage des Megali Kazania nicht übermäßig betont und die unvergletscherte Südseite sinnvoll berücksichtigt ist.

\subsection{Die eiszeitliche Schneegrenze Griechenlands und das Problem der Aegäis}

Wir werden in der regionalen Besprechung der Schneegrenzen auf die bisher bekannten aber problematischen Angaben aus den griechischen Gebirgen zurückkommen. Wir wollen nur zu bedenken geben, daß der von Klebelsberg 1932 untersuchte $2319 \mathrm{~m}$ hohe Tymphrestos (südlichster Ausläufer des Pindos) keine Vergletscherung erfahren hat. Wenn dort die Schneegrenze in günstigerer Westlage bereits so hoch lag, konnte sie im kontinentaleren Klimaraum des Olymps niemals unter $2400 \mathrm{~m}$ liegen. Im übrigen werden die älteren Angaben aus dem Peloponnes und Pindos neu zu überprüfen sein. Wir zweifeln sehr, ob es sich wirklich um regional gültige Mittelwerte handelt, die in einen großräumigen Vergleich eingeordnet werden können. 
Es scheint uns fraglich, ob wir aus dem sehr raschen Anstieg der würmzeitlichen Schneegrenzfläche über Griechenland von West nach Ost auf einen ägäischen Kontinent schließen dürfen, wie Maull es tut (196). Die Kontinentalität des östlichen Griechenlands beweist noch keinen ägäischen Kontinent. Erstens zeigen sämtliche bedeutenden Glazialformen des Olymps mit ihrer Nord- und Ostexposition an, daß sie auf das feuchtere und maritim gemilderte Klima ausgerichtet waren. Zweitens müßte eine trockengelegte Aegäis zu einem weiteren Schneegrenzanstieg bis in die Westtürkei führen, was durch die dortigen Ergebnisse eindeutig widerlegt wird. Wenn auch zahlreiche Inseln durch den würmzeitlichen Tiefstand des Meeresspiegels an das Festland angeschlossen wurden, z. B. Thasos, Samothraki, Limnos, Chios, Samos usw., so können wir doch nach dem Verhalten der Schneegrenzen keinesfalls von einer trockengelegten Aegäis sprechen.

Aber auch die Auffassung von Négris, der einen Einbruch des ägäischen Kontinents um $700 \mathrm{~m}$ nach der Rißeiszeit annimmt, scheint uns sehr fraglich. Wenn die glazialmorphologischen Befunde am Olymp in zukünftigen Untersuchungen ganz eindeutig für eine Rißvereisung sprechen, hätte das Gebirge seit dieser Zeit keine wesentlichen Höhenverstellungen mehr erfahren. Immerhin wollen wir auf die neueren paläontologischen Untersuchungen in der Aegäis hinweisen, die Pfannenstiel folgendermaßen zusammenfaßt (273, S. 26): "Der tektonische Zusammenbruch der Aegäis muß nach den paläontologischen Befunden im Mittel- bis Jungpleistozän erfolgt und beendet worden sein, nachdem wohl die ersten Einbrüche schon im Altquartär begonnen 'haben.»

Wenn auch der prähistorische Mensch die Insel Mykonos (Kykladen) trockenen Fußes erreichte, Kreta und Cypern im Pleistozän noch Landverbindungen hatten (Elephas antiquus, Hippopotamus usw.) und Kithira sich sehr wahrscheinlich erst Post-Riß vom Festland trennte $(273,56,57,121$ usw.), so bedeuten diese Ergebnisse noch keinen Widerspruch zu unseren glazial- und klimamorphologischen Resultaten. Riß- und Würmeiszeit zeigen am Olymp bereits einen kräftigen maritimen Einfluß von der Aegäis her, was infolge der tiefen Einbruchszone zwischen den nördlichen Sporaden und dem verlandeten Golf von Saloniki zeitlich und räumlich ohne weiteres möglich sein konnte.

Zusammengefaßt: Soweit wir aus den Gebirgsvergletscherungen im östlichen Griechenland und westlichen Kleinasien schließen können, mußte ein großer Teil der Aegäis schon vor der Rißeiszeit, ganz sicher aber vor der Würmeiszeit überflutet worden sein, auch wenn zahlreiche Landverbindungen aus tektonischen oder eustatischen Gründen noch intakt geblieben sind.

\subsection{Zusammenfassungen}

\subsubsection{Résumé Olympe}

-La structure de l'Olympe nous donne de précieuses indications concernant l'extension possible de la glaciation; nous comprenons surtout la concentration des formes glaciaires les plus importantes dans les vallées profondément encaissées du versant nord (Megali Kazania).

- Les premiers résultats d'une nouvelle station de recherches météorologiques confirment les contrastes entre le versant maritime et continental. Le climat en altitude est étudié, des indications intéressantes concernant l'échelonnage des précipitations et des températures dans les différents niveaux sont déjà données.

- En exposition méridionale, nous ne trouvons pas de cirques et de moraines (à l'exception des petits cirques au sud de Kalaia), en exposition occidentale, ils ne sont que très rares; en exposition orientale maritime, ils sont plus prononcés, et sont enfin le plus nettement conservés au début des vallées se trouvant au nord de la zone des sommets. Les lignes des neiges locales varient extraordinairement. L'altitude et l'étendue de la surface ne sont pas décisives, ce sont les conditions locales morphologiques et climatiques.

- Dans le Megali Kazania, des remparts de blocs tardiglaciaires sont conservés, transformés en sortes de glaciers de pierre lors des nouvelles phases d'extension récentes. Une imposante moraine latérale würmienne commence à $1800 \mathrm{~m}$ et se termine à $1500 \mathrm{~m}$. Nous attribuons les horizons plus bas à une époque glaciaire plus ancienne.

- Les lignes des neiges locales varient $300-500 \mathrm{~m}$. La ligne des neiges régionales se trouve au moins à $2400 \mathrm{~m}$.

- Ce résultat peut être très bien comparé avec les lignes des neiges vraiment déterminées de Grèce (p. ex. Tymphrestos $2319 \mathrm{~m}$, contrefort le plus méridional du Pinde, qui n'a pas de glaciation en situation occidentale plus favorable). L'ensemble des résultats obtenus en morphologie glaciaire du côté occidental et oriental de la mer Egée ne permet pas de conclure à de grands mouvements tectoniques des plus hautes montagnes depuis l'époque Würm, probablement même depuis l'époque Riss, à part plusieurs déplacements mineurs locaux.

\subsubsection{Summary Olympus}

- Cirques and moraines may not be found in southern exposure (except the little cirques south of Kalaia), only very rarely in western exposure; they are more distinct on the maritime eastern side and most clearly preserved in the beginnings of the valleys north of the summit area.

- In Megali Kazania late-glacial block ramparts are 
preserved, which were transformed into sorts of block-streams during the recent extension phases. An important side moraine of the Würm-age begins at $1800 \mathrm{~m}$ and ends at $1500 \mathrm{~m}$. We attribute the deeper horizons to an earlier glacial period.

- The local snow-lines vary 300-500 m between sunny and shady sides, between spheres of maritime and continental influence. The regional snowline lies at least at $2400 \mathrm{~m}$.

\section{Sierra Nevada (Andalusien)}

\subsection{Zusammenfassung der glazialmorphologischen Ergebnisse nach 204:}

- Die rezente Schneegrenze lag nach den Reisebeschreibungen bereits im letzten Jahrhundert über den höchsten Gipfeln. (Mulhacen 3478 m). Durch den weiteren Anstieg seit 1850 und die Höhenlage der positiven mittleren Sommertemperaturen schätzen wir die heutige Schneegrenze auf mindestens 3600-3700 m.

- Der Anstieg seit den rezenten Hochständen zeigt sich beim «südlichsten Gletscher Europas» im Corral de Veleta. Im letzten und anfangs dieses Jahrhunderts ist an der Oberfläche blankes Eis beobachtet worden, heute ist es nur mehr ein Firnfleck. Mindestens $600 \mathrm{~m}$ unter der regionalen Schneegrenze gelegen, in morphologischer und klimatischer Gunstlage, bildete der kleine Wandfußgletscher die Sensation der Sierra Nevada.

- Eine spätglaziale Vereisung ist deutlich ausgeprägt. Die Schneegrenze verlief auf der N- und SSeite zwischen 2800 und 2900, in den einzelnen Talungen je nach Relief und Exposition von 2700 bis $3000 \mathrm{~m}$ schwankend. Sie stieg vom Mulhacen nach E langsam an und endete beim Cerro Pelado.

- In der Würmeiszeit stießen die Talgletscher auf 2000-145a m hinunter, die größeren 6-9,5 km lang. Die Schneegrenze befand sich im Mittel auf der Nordseite in $2300 \mathrm{~m}$ (Ostexposition 2200, Westexposition $2400 \mathrm{~m}$ ) und auf der Südseite in $2400 \mathrm{~m}$ (Ostexposition 2300, Westexposition $2500 \mathrm{~m}$ ). Die letzteiszeitliche Schneegrenzdepression beträgt mindestens $1300 \mathrm{~m}$.

- Die Ablagerungen der Rißvereisung, durchschnittlich $4 \mathrm{~km}$ vom Würmende entfernt, lassen keinen Zweifel an einer vorletzten Eiszeit. Die Talgletscher waren 9-13 km lang und lagen auf der Nordseite mit ihrer Stirn bei ca. 1100 m, doch läßt sich eine genaue Endlage nicht rekonstruieren. Die Bestimmung einer Schneegrenze ist sehr problematisch; sie lag schätzungsweise $200 \mathrm{~m}$ tiefer als in der Würmeiszeit.
- This result accords with the confirmed snow-lines of Greece (e. g. Tymphrestos, $2319 \mathrm{~m}$, most southern spur of Pindos, not glaciated in the more favorable western exposure). The actual results of glacial morphology to the west and to the east of the Aegean Sea permit no conclusions concerning great tectonic movements in the higher mountains since Würm glaciation, probably even since Riss glaciation, apart from possible minor local displacements.

- Ob dem quartären Alhambrakonglomerat die Funktion eines Deckenschotters und damit ein $\mathrm{Zu}$ sammenhang mit noch älteren Kaltzeiten zugeschrieben werden kann, ist noch nicht abgeklärt.

\subsection{Sierra Nevada (Andalousie)}

Résumé des résultats de morphologie glaciaire extraits de: Messerli B.: Beiträge zur Geomorphologie der Sierra Nevada (Andalusien). Ed. Juris, Zurich 1965.

- D'après d'anciens récits de voyage, la ligne des neiges récente se trouvait déjà au siècle dernier audessus des plus hauts sommets (Mulhacen $3478 \mathrm{~m}$ ). Vu l'élévation poursuivie depuis 1850 et l'altitude des températures positives moyennes d'été, nous estimons la ligne des neiges actuelle être d'au moins $3600-3700 \mathrm{~m}$.

- Cette élévation depuis les maximums récents se reflète dans le "glacier le plus méridional d'Europe» dans le Corral de Veleta. Au siècle dernier et au début du nôtre, l'on y a observé de la glace ferme, aujourd'hui il ne s'agit plus que d'une tache de névé. Se trouvant au moins à $600 \mathrm{~m}$ au-dessous de la ligne des neiges régionales, en situation morphologique et climatique spécialement favorable, le petit glacier au pied de la paroi était la sensation de la Sierra Nevada.

- Une glaciation tardiglaciaire est nettement attestée. La ligne des neiges se trouvait entre 2800 et $2900 \mathrm{~m}$ sur les versants nord et sud, et variait de 2700-3000 m dans les différentes vallées suivant le relief et l'exposition. Elle s'élevait lentement à partir du Mulhacen vers l'est et se terminait au Cerro Pelado.

- Pendant l'époque glaciaire Würm, les glaciers de vallée descendirent jusqu'à 1450_2000 m, les plus longs étant de 6-9,5 km. La ligne des neiges se trouvait en moyenne à $2300 \mathrm{~m}$ sur le versant nord (exposition orientale 2200 , occidentale $2400 \mathrm{~m}$ ) et à 
$2400 \mathrm{~m}$ sur le versant sud (exposition orientale 2300 , occidentale $2500 \mathrm{~m}$ ). La dépression de la ligne des neiges de la dernière époque glaciaire est d'au moins $1300 \mathrm{~m}$.

- Les dépôts de la glaciation Riss, éloignés de $4 \mathrm{~km}$ en moyenne des moraines terminales Würm ne laissent plus aucun doute sur une avant-dernière époque glaciaire. Les glaciers de vallée atteignaient 9-13 km et leur front se trouvait à environ $1100 \mathrm{~m}$ sur le versant nord; il n'est pourtant pas possible de reconstruire leur situation terminale exacte. La détermination d'une ligne des neiges pose de grands problèmes; nous la voyons à environ $200 \mathrm{~m}$ au-dessous de celle de la glaciation Würm.

- Il n'a pas encore été déterminé que le conglomérat quaternaire de l'Alhambra puisse, en tant que dépôt fluvial, avoir été éventuellement en rapport avec de plus anciennes époques froides.

\subsection{Summary Sierra Nevada (Andalusia)}

-Summary of the results of glacial morphology in: Messerli B.: Beiträge zur Geomorphologie der Sierra Nevada (Andalusien). Ed. Juris, Zurich 1965.

- According to books of travels the recent snowline was already situated in the last century above the highest peaks (Mulhacen 3478). As it has continued to rise since 1850 and according to the altitude of middle positive summer temperatures we estimate the snow-line of today at least at 3600 $3700 \mathrm{~m}$.

- This rising since the recent maximums shows itself in the "most southern glacier of Europe» in the
Corral Veleta. In the last century and at the beginning of ours, tough ice was observed there; today it is merely a firn dot. Lying at least $600 \mathrm{~m}$ beneath the regional snow-line in a situation favoured by morphology and climate, the little glacier at the bottom of a head-wall was the sensation of Sierra $\mathrm{Ne}$ vada.

- A late-glacial glaciation is clearly marked. The snow-line lay between 2800 and $2900 \mathrm{~m}$ on the northern and southern mountain-side, varied between 2700 and $3000 \mathrm{~m}$ in the different valleys following the different landforms and exposures. It rose slowly from Mulhacen eastward and ended at the Cerro Pelado.

- During Würm glaciation the valley glaciers went down as far as 1450 to $2000 \mathrm{~m}$, the bigger ones being $6-9,5 \mathrm{~km}$ long. The snow-line was on the average at 2300 on the northern side (eastern exposure 2200, western $2400 \mathrm{~m}$ ) and at $2400 \mathrm{~m}$ on the southern side (eastern exposure 2300, western $2500 \mathrm{~m}$ ). The depression of the snow-line of the last ice age is at least $1300 \mathrm{~m}$.

- The depositions of Riss glaciation which are on the average at a distance of $4 \mathrm{~km}$ from Würm end moraines leave no doubt about this ice-age. The valley glaciers were 9 to $13 \mathrm{~km}$ long and lay on the northern side with their face at about $1100 \mathrm{~m}$, but an exact end position cannot be reconstructed. The determining of a snow-line is very problematic; we have found it to be about $200 \mathrm{~m}$ lower than in the Würm glaciation.

- Whether the quartenary Alhambra conglomerate could, as a fluvial deposition, have some connection with even older cold periods has not yet been clarified.

\section{Libanon und Hermon}

\subsection{Zusammenfassung der glazialmorphologischen Ergebnisse nach 207:}

- Die drei Gipfelräume des Qornet es Saouda (3088 $\mathrm{m}$, Hochlibanon), Tallat Moussa (2616 m, nördlicher Antilibanon) und Hermon (2814 m, südlicher Antilibanon) zeigen eine übereinstimmende, strukturbedingte asymmetrische Form, indem sie von W her langsam ansteigen und nach $\mathrm{E}$ steil abfallen. Unzertalte windexponierte Hochplateaus im Gipfelniveau bieten für eine eiszeitliche Vergletscherung denkbar schlechte orographische Bedingungen. Karsterscheinungen als rezente und vor allem fossile Formen haben für eine glazialmorphologische Untersuchung einen wesentlichen Aussagewert.

- Aus den Niederschlagsmengen und ihrer Jahres- verteilung schließen wir auf einen mutmaßlichen Schneefall von $1300 \mathrm{~mm}$ in den Gipfelregionen des Hochlibanons und Hermons. Die perennierenden Schneeflecken zeigen eine strenge Abhängigkeit von den geringsten Niederschlagsschwankungen und sind als Anzeiger für eine nahe Schneegrenze nicht brauchbar.

- Die rezente Oberflächenformung ist im differenzierten Verwitterungsprozeß, in Talasymmetrien, Bodenbildungen, Karsterscheinungen usw. zu erkennen. Die perennierenden Schneeflecken sind ein wesentlicher Faktor in der heutigen Oberflächenformung (Karst, Lokalklima usw.). Sie liegen aber noch weit unter der rezenten Schneegrenze, die wir auf mindestens $3700 \mathrm{~m}$ vermuten.

- Im Hochlibanon lassen sich drei Zonen mit glazia- 
len Bildungen ausscheiden, am klarsten in den SEHängen des Hochplateaus, bescheidener in der WExposition und als schwacher Ansatz im steilen Nordabfall. Die tiefsten Moränen liegen auf $2500 \mathrm{~m}$. Am Hermon sind zwei Moränensysteme erhalten, wobei wir eine südseitige Stirnmoräne in ca. $2500 \mathrm{~m}$ als die schönste Glazialform im gesamten libanesischen Gebirgsraum bezeichnen. Im Antilibanon war auch die höchste Gipfelregion unvergletschert. Die würmeiszeitliche Schneegrenze bestimmen wir im Hochlibanon und Hermon mit 2700 m. Die Bedeutung der Luv- und Leelage haben wir diskutiert und kommen für die subtropischen Breiten zum Schluß, $\mathrm{da} ß$ die einer ausgesprochen dominanten Windrichtung ausgesetzten Hang- oder Plateauflächen weit über der Schneegrenze gletscherfrei bleiben, währenddem die vorkommenden südseitigen Gletscher trotz allen nur möglichen Gunstfaktoren im mindesten die notwendigen klimatischen Bedingungen einer Schneegrenze verlangen, um bei der gegebenen Strahlungsintensität überhaupt existieren zu können.

- Spuren einer älteren Vereisung mit einer noch tieferen Schneegrenze konnten aufgefunden werden; dieses Ergebnis ist aber noch nicht gesichert.

- Die eiszeitliche und rezente Schneegrenze steigt vom Taurus zum Libanon und weiter zum Sinai kontinuierlich an. Die rezente Strukturbodengrenze zeigt dagegen vom Taurus zum Libonon eine Depression, die orographisch, klimatisch und anthropogen zu begründen ist. Tiefe Strukturbodenvorkommen am maritimen Libanonhang $(1800 \mathrm{~m})$ und auf der kontinentalen Seite des Antilibanons (2000 m) weisen auf unterschiedliche Entstehungsbedingungen hin. Die Strukturbodengrenze läßt sich nicht mit der Schneegrenze parallelisieren und Schneegrenzdepressionen können nicht Strukturbodendepressionen gleichgesetzt werden. Die Untergrenze des eiszeitlichen Periglazialbereiches ist noch nicht bekannt und muß in Zukunft noch genauer untersucht werden.

- Aus der rezenten und der würmeiszeitlichen Schneegrenze ergibt sich eine Depression von mindestens $1000 \mathrm{~m}$.

- Der Libanon fügt sich mit den vorgelegten Ergebnissen sinnvoll in die großräumige würmeiszeitliche und rezente Höhenstufung zwischen Taurus und Sinai ein.

\subsection{Résumé Liban et Hermon}

Les trois zones de sommets du Qornet es Saouda (Haut-Liban), du Talaat Moussa (Antiliban nord) et de l'Hermon (Antiliban sud) présentent une forme semblable, asymétrique, due à la structure: elles montent doucement à partir de l'ouest et tombent rapidement vers l'est. - N'étant pas creusés par des vallées mais exposés aux vents, les hauts plateaux qui se trouvent au niveau des sommets fournissent de bien mauvaises conditions orographiques pour une glaciation quaternaire. Les phénomènes carstiques, formes récentes et surtout fossiles, sont essentiels pour l'examen glaciomorphologique.

Les précipitations et leur répartition au cours de l'année nous font admettre une chute de neige probable de $1300 \mathrm{~mm}$ dans la région des sommets du Haut-Liban et de l'Hermon. Les flaques de neige pérennes montrent une rigoureuse dépendance des plus petites variations des précipitations, elles ne peuvent être employées comme indicateur de la proximité de la ligne des neiges.

Les configurations récentes de la surface se réflètent dans le processus différencié de la désagrégation, dans les vallées asymétriques, les formations de sols, les phénomènes carstiques etc. Les flaques de neige pérennes sont un facteur essentiel pour la formation de la surface actuelle (Karst, climat local etc.), mais elles se trouvent encore bien au-dessous de la ligne des neiges que nous estimons être d'au moins 3700 m.

Dans le Haut-Liban, nous distingons trois zones de formations glaciaires, la plus évidente se trouve sur les flancs sud-est du haut-plateau, une plus modeste en exposition ouest, et enfin certains vestiges sur le versant nord à pic. Les moraines les plus basses se trouvent à $2500 \mathrm{~m}$. Sur l'Hermon, deux systèmes de moraines subsistent, dont nous désignons une moraine frontale du versant sud à environ $2500 \mathrm{~m}$ comme étant la forme glaciaire la plus évidente. L'Antiliban ne connut point de glaciation, même dans la zone la plus élevée des sommets. Nous déterminons la ligne des neiges de l'époque Würm à $2700 \mathrm{~m}$ pour le Haut-Liban et l'Hermon. Après avoir discuté l'importance de la face au vent et de celle sous le vent, nous tirons la conclusion que dans les latitudes subtropiques, les versants et surfaces de plateau exposés à une direction du vent nettement dominante restent libres de glace jusqu'à une altitude bien au-dessus de la ligne des neiges, tandis que les glaciers existants sur le versant sud requièrent les conditions climatiques d'une ligne des neiges pour pouvoir exister par l'intensité de l'insolation donnée - même si toutes sortes de facteurs spécialement favorables sont là.

Les traces d'une glaciation plus ancienne avec une ligne des neiges encore plus basse ont pu être démontrées, ce résultat n'étant pas encore assuré.

La ligne des neiges glaciaire et récente s'élève du Taurus par le Liban au Sinai. La limite récente des sols structurés par contre s'abaisse du Taurus au Liban, ce qui est dû à une influence orographique, climatique et anthropogène. L'existence de sols structurés à basse altitude sur le versant maritime du Liban $(1800 \mathrm{~m})$ et sur le versant continental de 
l'Antiliban (2000 m) démontre des conditions d'origine différentes. La limite des sols structurés ne peut être parallélisée avec la ligne des neiges, et les dépressions de la ligne des neiges ne peuvent être accordées avec la dépression de la limite des sols gelés. Pour l'époque glaciaire, la limite inférieure du domaine périglaciaire n'est pas encore connue.

En comparant les lignes des neiges récente et wurmienne, nous obtenons une dépression de $1000 \mathrm{~m}$ au moins.

Par ces résultats, le Liban s'insère fort bien dans les grandes zones d'altitude de l'époque Würm et récente entre le Taurus et le Sinai.

\subsection{Summary Lebanon and Hermon}

The three summit areas of the Qornet es Saouda 3088 m (High Lebanon), Talaat Moussa $2616 \mathrm{~m}$ (northern Antilebanon) and Hermon $2814 \mathrm{~m}$ (southern Antilebanon), rising gradually from the $\mathrm{W}$ and sloping down steeply to the E show uniform, asymmetric features controlled by structure. Undissected high plateaus at the summit level which are exposed to the winds provide most unfavourable orographic conditions for a Pleistocene glaciation. Recent and especially relict karst features are important criteria for glacial morphological research.

From the amounts and annual distribution of precipitation a conjectural snow fall of $1300 \mathrm{~mm}$ can be assumed for the summit regions of the High Lebanon and Hermon. Perennial snow patches are strictly controlled by the slightest variations of precipitation and cannot serve as indicators of a neighbouring snow line.

The recent sculpturing of the surface can be perceived by differentiated weathering processes, valley asymmetry, soil formations, karst features a. s. 0 . The perennial snow patches are an essential factor of the present forming of the surface (karst, local climate), but they are located far below the recent snow line which we assume to be at a level of at least $3700 \mathrm{~m}$.

In the High Lebanon three regions with glacial sediments can be discerned, most clearly at the E-slopes of the high plateau, less distinctly with $\mathrm{W}$-exposition and as slight indication at the steep northern descent. The lowest moraines are located at $2500 \mathrm{~m}$. On the Hermon two moraines systems are preserved of which a terminal moraine at the level of about $2500 \mathrm{~m}$ at the S-side must be valued as the best glacial feature in the total Lebanese mountain area. We have discussed the significance of the windward and leeward sides, and concerning the subtropical latitudes arrive at the conclusion that slope or plateau surfaces facing a positively dominant wind direction are left free of snow, far above the snow-line whilst glaciers occuring at the S-side in spite of all favourable conditions possible call for at least the necessary climatic conditions of a snow-line in order to be able to exist at all at the given radiation intensity.

Traces of an earlier glaciation at an even lower snow-line could be established but this result is not yet quite certain.

The Pleistocene and recent snow-line rises continually from the Taurus to the Lebanon and further on to the Sinai. But the recent structure soil limit shows a depression from the Taurus to the Lebanon which can be explained by orographic, climatic and anthropogenic conditions. Low occurrences of structure soil at the sea side of the Lebanon slope $1800 \mathrm{~m}$ and at the country side of the Antilebanon $2000 \mathrm{~m}$ call for differentiated conditions of development. The limit of structure soils cannot be correlated with snow-line and depressions of the snow-line not with depressions of structure soils. The lower limit of the Pleistocene periglacial region is not yet known and must be investigated more precisely in the future.

By the recent and Würm age snow-line a depression of at least $1000 \mathrm{~m}$ can be calculated.

With the results presented above, the Lebanon area fits significantly into the large scale Würm age and recent height regions between Taurus and Sinai. 


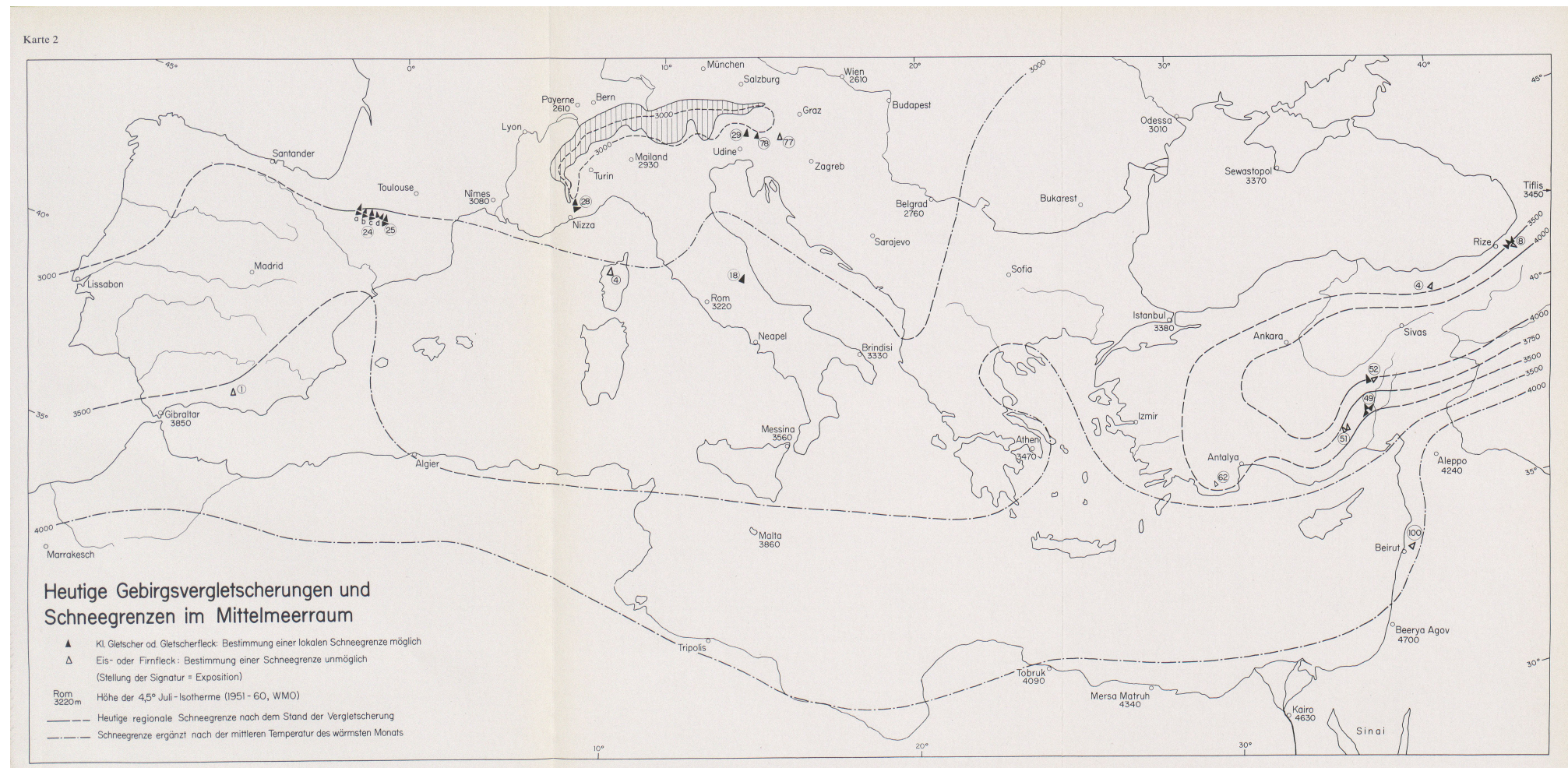




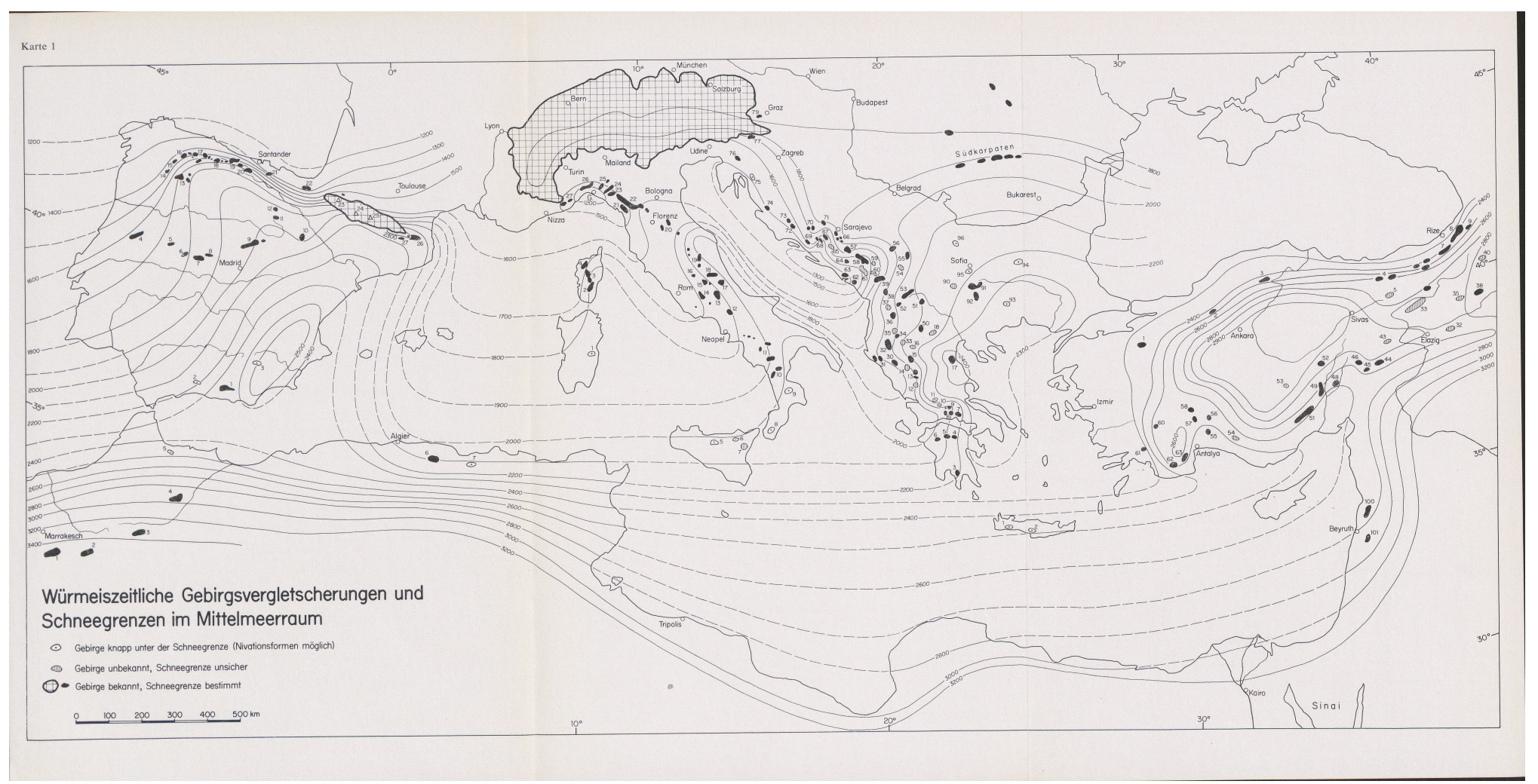




\section{DIE SCHNEEGRENZEN IN DEN EINZELNEN REGIONEN DES MITTELMEERES}

\section{Die Schneegrenzen im östlichen Mittelmeerraum}

\subsection{Die würmeiszeitliche Schneegrenze (Fig. 10)}

Verzeichnis und Karte der eiszeitlichen Gebirgsvergletscherungen Kleinasiens stützen sich zu einem großen Teil auf die grundlegende Arbeit von Louis (185). Selbstverständlich sind seit 1944 neue Resultate dazugekommen, aber der grundsätzliche Verlauf der Schneegrenzen blieb doch unverändert.

Im folgenden besprechen wir die Probleme und Unsicherheiten, die in der Karte der regionalen Schneegrenzen zum Ausdruck kommen und die in Zukunft durch neue Feldarbeiten geklärt oder korrigiert werden müssen. - Große Unsicherheiten entstehen immer dort, wo die Schneegrenzfläche nur knapp oder überhaupt nicht angeschnitten wird. In diesen offenen Räumen haben wir die klimatischen Verhältnisse als Hilfsmittel vergleichend herangezogen. Doch ist zu hoffen, daß künftighin vereinzelte Glazialspuren neu entdeckt werden, wir denken vor allem an die niedrige Gipfelflur im westlichen Taurus und im Pontus. Ferner sind in Zukunft wesentliche Korrekturen aus dem Gebiet Malatya_Van See zu erwarten. Aber schon beim heutigen Stand der Kenntnisse zeigt der Verlauf der Isochionen die Zugstraße der Depressionen an, die der orographischen Leitlinie Taurus-Ala Dagh folgend in das östliche Zentralanatolien hineinführt und weiter nach Osten langsam ausschwächt. Erstaunlich sind die niedrigen Schneegrenzwerte von $2700 \mathrm{~m}$ bei Erzincan, das heißt, sie sind trotz der kontinentalen Lage gleich hoch wie im Taurus und Ala Dagh. Dieser Sachverhalt weist zweifellos auf eine erhöhte Niederschlagstätigkeit während der Kaltzeiten hin. Die verstärkte meridionale Zirkulation hat auch diese anatolische Depressionenbahn intensiviert und die Vegletscherungshöhen wesentlich hinuntergedrückt. Aus den heutigen betont kontinentalen Klimaverhältnissen und der eiszeitlich relativ niedrigen Schneegrenze ergibt sich eine hohe Schneegrenzdepression; eine Tatsache, die wir im Kapitel über den Erciyas Dagh bereits besprochen haben (Seite 123).

Im Raum Van See hat Klaer zahlreiche neue Erkenntnisse publiziert (148). Weiter östlich sind die Verhältnisse noch wenig geklärt. $\mathrm{Da}$ die extrem kontinentale Lage die Schneegrenze immer kräftiger empordrückt, ist offensichtlich. Wie das aber räumlich differenziert in Würmeiszeit und Gegenwart aussieht, wissen wir noch zu wenig genau. Selbst die glazialmorphologischen Kenntnisse vom vielbegangenen Ararat sind noch ungenügend.

Erinç hat im nordostpontischen Salaçor-Gebirge (Fig. 10) eine erstaunlich hohe Schneegrenze von $2800 \mathrm{~m}$ bestimmt, die völlig beziehungslos zu ihrer Umgebung steht (79). In der gleichen Gebirgskette vermuten wir die Schneegrenzhöhe im Kaçkar Dagh zwischen 2300 und $2500 \mathrm{~m}$, stark erniedrigt durch die außerordentlich großen Niederschläge (Rize Mittel 1929-60 = 2440,9 mm). Erinç begründet seinen hohen Wert mit einer postglazialen tektonischen Hebung, eine Deutung, die wir vorläufig als anregendes Problem offen lassen müssen.

- Nach übereinstimmenden Berichten von Klaer und Bartsch fehlen am Hasan Dagh (3252 m) eindeutige Glazialspuren (147). Klebelsberg beschreibt zwar karähnliche Nischen, legt aber keine Schneegrenze fest (154). Vom etwas über $100 \mathrm{~km}$ entfernten Erciyas her muß die Schneegrenze von $2850 \mathrm{~m}$ bis auf schätzungsweise $3100-3300 \mathrm{~m}$ rasch ansteigen, was nicht einfach zu erklären ist. Zweifellos liegt der Erciyas in der Flucht der Silikischen Pforte und des Seyhan-Durchbruchs lokalklimatisch bedeutend günstiger als der Hasan Dagh. Ferner wird die für eine Vergletscherung ungünstige Vulkan-Kegelform beim Erciyas Dagh durch ein bedeutendes Uberragen der Schneegrenzfläche weitgehend aufgehoben. $\mathrm{Ob}$ allerdings diese Erklärungen für eine so beträchtliche Schneegrenzdifferenz genügen, scheint uns fraglich und muß in Zukunft auch mit vulkanologischen Untersuchungen genauer abgeklärt werden. Damit meinen wir nicht nur die postwürmen Hebungen, sondern auch die präwürmen Vorgänge mit der Frage: Welche Formen hat die letzte Vergletscherung bereits vorgefunden? So sind wir z. B. überzeugt, daß die prächtigen Kare des Erciyas schon in einer älteren Eiszeit entstanden sind und eine Würmvergletscherung begünstigt haben.

- In den Gebirgen Lykiens (SW Antalya) sind noch nicht alle Ergebnisse bereinigt und geklärt. Den niedrigen Schneegrenzwert am 2294 m hohen Sandras Dagh (Fig. 10, Nr. 61) hat Planhol tektonisch begründet, wir haben eher auf lokalklimatische Gunstfaktoren hingewiesen. Neuere Schweremessungen im östlichen Mittelmeerraum zeigen zwar deutlich an, daß der Raum Sandras Dagh_Ak Dagh in eine sehr mobile tektonische Zone gehört, was künftighin für die Frage der jung-pleistozänen Bewegungen 
noch genauer ausgewertet werden muß (57, 89, 278, 282). Es wäre aber falsch, dem meernahen Sandras Dagh eine Sonderstellung einzuräumen und auf Grund seiner einseitigen eiszeitlichen Gipfelvergletscherung zu tiefe Schneegrenzen auf Kreta und sogar im Libanon zu postulieren. Wir haben das Problem erörtert (Seite 149) und halten in diesem großräumigen Zusammenhang nur die folgenden Punkte fest:

1. Planhol gibt mit dem Wert 2050-2000 m nicht eine regionale, sondern eine lokal einseitige Schneegrenze an (283, S. 258).

2. Dieser Wert entspricht ziemlich genau der einseitig lokalen Schneegrenze am Taygetos im südlichsten Peloponnes (154, S. 740). Der Taygetos liegt sogar noch etwas südlicher als der Sandras Dagh und damit entfällt die Zwangslage einer tektonisch zu begründenden Schneegrenzhöhe.

3. Die genau gleichen Verhältnisse einer einseitig niedrigen Vergletscherung finden wir am Ulu Dagh (Seite 152). Die regional vergleichbaren Schneegrenzen sind bei diesen geringen Gebirgshöhen mindestens $100-200 \mathrm{~m}$ über dem günstigsten Lokalwert festzulegen. Die Schneegrenzfläohe steigt vom Sandras Dagh zum Ak Dagh ganz natürlich an und entspricht genau der veränderten Klimasituation. (Elmali in Zentrallykien hat kontinentalere Klimaverhältnisse als Kayseri in Inneranatolien; vgl. Seite 143.)

- Die Ergebnisse vom Hochlibanon und Hermon fügen sich sinnvoll in das entworfene Isochionenbild ein. Die Zusammenhänge mit dem Taurus haben wir eingehend diskutiert (207). Den Ergebnissen Kaisers (140), der eine würmeiszeitliche Schneegrenze von 1950_2300 m vertritt, können wir aus morphologischen und klimatischen Gründen nicht beipflichten.

- Ubberlegen wir uns das Ansteigen der Schneegrenze nach Süden, so ist es nach unserer Meinung ganz unmöglich, dem Sinai mit dem 2637 m hohen Katharinenberg eine Vergletscherung zuzuordnen, wie es Schamp auf Grund von karähnlichen Formen versucht hat (310). Büdel und Klaer haben diese Deutung nach eigenen Begehungen ebenfalls abgelehnt $(37,147)$. Wenn wir Klima und Schneegrenzverlauf im anatolischen Steppenraum mit den extremeren Bedingungen auf der Sinai-Halbinsel vergleichen, ferner bedenken, da $ß$ der Katharinenberg 10 Breitengrade südlicher liegt als der Erciyas Dagh, dann ist eine eiszeitliche Schneegrenze unter $3000 \mathrm{~m}$ ganz unmöglich. Wir betrachten die Angabe Klaers als sehr richtig, der die eiszeitliche Schneegrenze über dem Sinai auf ca. $3300 \mathrm{~m}$ vermutet. Selbst wenn wir den Einfluß einer Zyklonenstraße Mittelmeer-Rotes Meer überschätzen, können wir nicht eine so gewaltige Schneegrenzerniedrigung annehmen, daß der Katharinenberg vergletschert wurde.

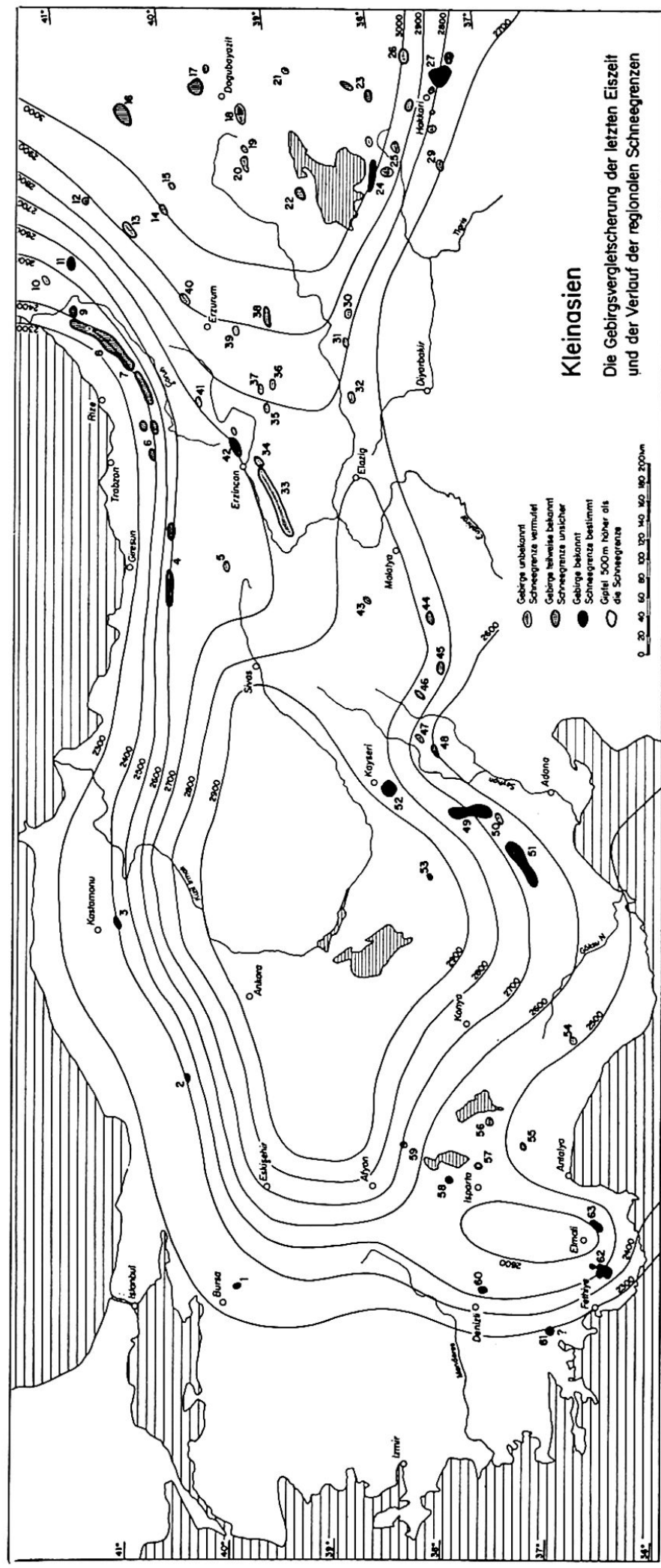

Fig. 10 Kleinasien. Die Gebirgsvergletscherung der letzten Eiszeit und der Verlauf der regionalen Schneegrenzen (vgl. S. 169).

\subsection{Die rezente Schneegrenze (Fig. 11)}

- Wollen wir den Schneegrenzverlauf in der westlichen Türkei und im libanesisch-syrischen Gebirgsraum festlegen, so stehen uns nur wenige Gletscher zur Ermittlung eines Lokalwertes zur Verfügung: 


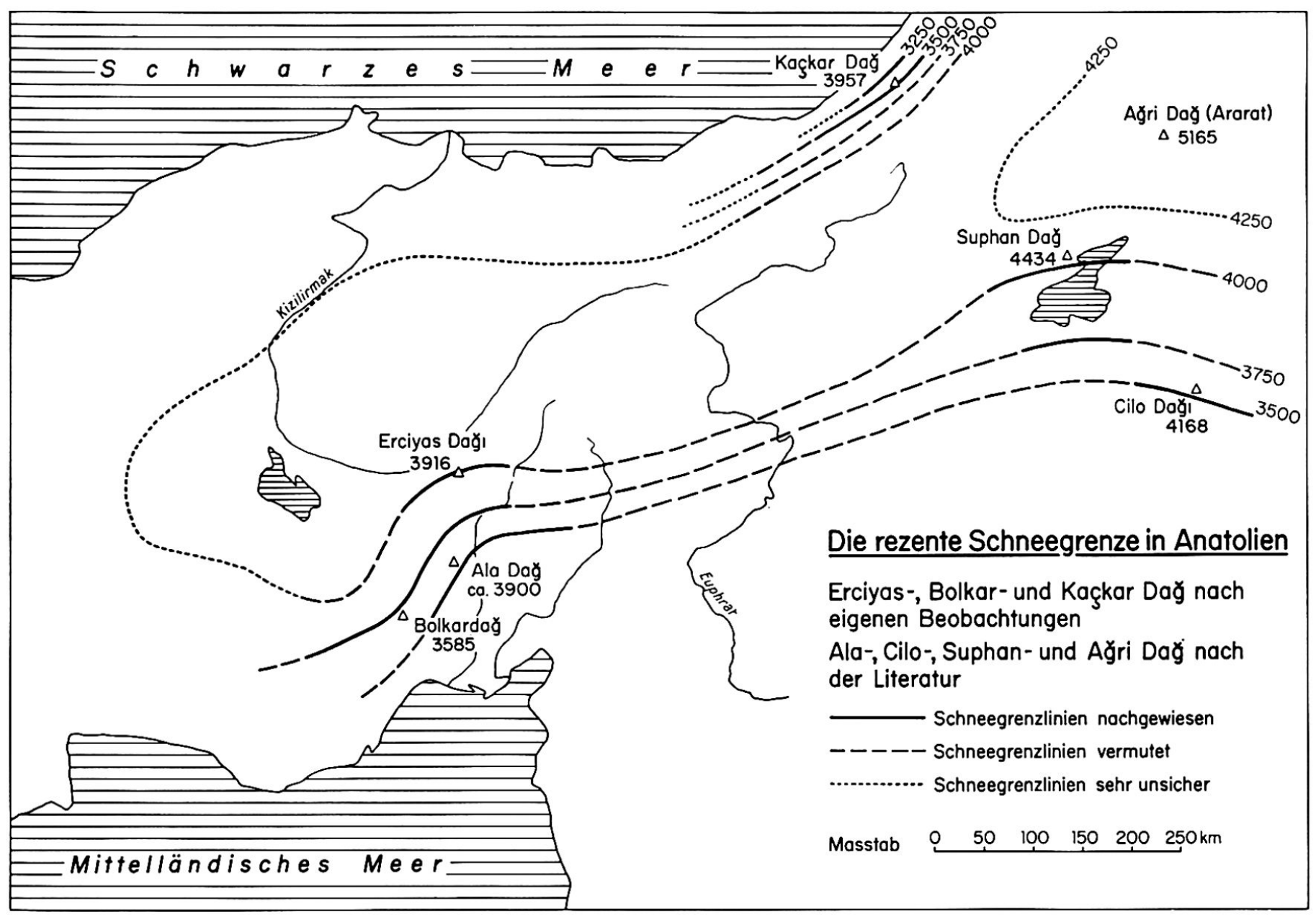

Fig. 11 Die rezente Schneegrenze in Anatolien.

Der Gletscher am Erciyas Dagh (Grundrißzeichnung in 203, S. 22).

Die Gletscherflecken am Ala Dagh (324, S. 434).

- Die kleinen Eis- und Firnflecken in extremster Wandfußlage sind nach unserer Meinung für die Ermittlung eines Lokalwertes völlig ungeeignet, ja sie provozieren uns direkt zur Festlegung einer allzu tiefen Schneegrenze. (Diskussion des Problems Seite 127 und 192). Zum Beispiel:

Im Hohen Bolkardagh (Seite 127, Abb. 15)

Im Ak Dagh (Seite 148, Abb. 29)

Im Hohen Libanon (207, S. 45, Abb. 4).

- Die wenigen Gletscherstandorte sind für die Erstellung einer gesicherten Schneegrenzkarte völlig ungenügend, denn die einseitigen Vergletscherungen in ausgeprochener Gunstlage berühren die Schneegrenzfläche vielfach überhaupt nicht. Es sind typische Erscheinungen einer subnivalen Stufe. Aus diesem Grunde haben wir unsere dargestellten Schneegrenzen zusätzlich auf die Höhenstufung der Sommertemperatur gestützt, ein Verfahren, das wir noch eingehender besprechen werden( Seite 193).
- Überblicken wir die rezente und würmeiszeitliche Schneegrenzkarte, so zeigt sich deutlich ein Unterschied im Kurvenbild. Der Schneegrenzanstieg seit der letzten Eiszeit hat die meisten Gebirge aus dem Schneegrenzbereich entrückt, die häufige lokalorographische und -klimatische Beeinflussung ist aufgehoben worden und die lebhafte Reliefierung der kaltzeitlichen Schneegrenzfläche ist verlorengegangen. Die heutigen Schneegrenzlinien sind viel unsicherer und spiegeln nur noch die weiträumigen Klimaverhältnisse wieder.

\subsection{Die Schneegrenzdepression (Fig. 12, 13)}

Auf Fig. 12 und 13 haben wir versucht, die rezente und eiszeitliche Schneegrenze im Vergleich mit der oberen Waldgrenze darzustellen. Im ersten S_NProfil zeigt sich vom Taurus zum Erciyas der rasche und gleichsinnige Anstieg der rezenten Schneegrenze (von 3650 auf $4000 \mathrm{~m}$ ) und der oberen Waldgrenze (von 2150 auf $2500 \mathrm{~m}$ ), währenddem die eiszeitliche Schneegrenze viel gedämpfter reagiert. (Selbstver- 


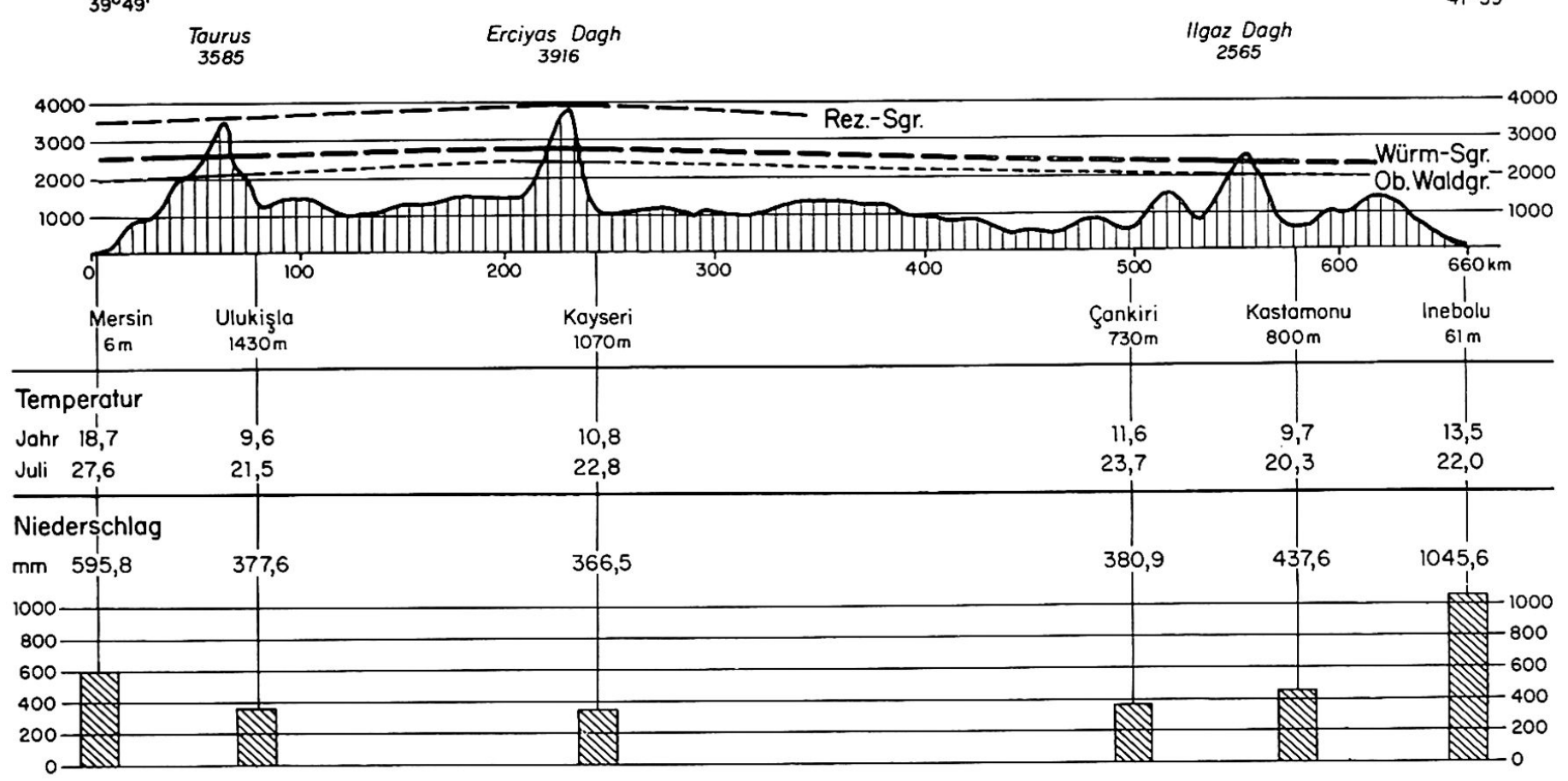

Fig. 12 Schneegrenzen und Waldgrenzen in Anatolien. Profil S_N.

ständlich stimmt dieser Vergleich nur, wenn wir die mittlere Waldgrenze mit der regionalen Schneegrenze vergleichen). Den schwächeren eiszeitlichen Schneegrenzanstieg vom Taurus zum Erciyas haben wir mit einer veränderten ganzjährigen Niederschlagstätigkeit und einer verminderten Kontinentalität Anatoliens begründet.

Das Absinken der Höhengrenzen vom Erciyas zum Ilgaz-Gebirge zeigt einen gleichmäßigen Verlauf von eiszeitlicher Schneegrenze und oberer Waldgrenze. $\mathrm{Ob}$ sich mit der Nordwärtsverlagerung bereits eine Abstandsverminderung Waldgrenze - rezente Schneegrenze auswirkt, können wir nicht entscheiden.

Das Profil Nr. 2 ergibt von West nach Ost einen regelmäßigen Anstieg der Höhengrenzen vom Ulu Dagh zum Erciyas Dagh. Die Zusammenhänge können wir nicht genauer fassen, weil die einseitige Vergletscherung des Ulu Dagh für die Schneegrenzbestimmung eine gewisse Unsicherheit schafft. Östlich des Erciyas folgt eine interessante Zwischenphase mit einer Erniedrigung der eiszeitlichen Schneegrenze zum Kesis Dagh bei Erzincan, entsprechend der niederschlagsreicheren Zone. Die Waldgrenze zeigt demgegenüber keine Reaktion und steigt auch weiter nach Osten bis zum Ararat langsamer an als die kaltzeitliche Schneegrenze. Sie verhält sich ganz ähnlich wie die schwer zu ermittelnde rezente Schneegrenze, was auf bestimmte klimatische Übereinstimmungen hinweist. Aber auch da müssen wir zahlreiche Fragen offen lassen, weil die Höhenwerte aus Ostanatolien noch $\mathrm{zu}$ wenig gesichert sind.

Gesamthaft gesehen reagieren die eiszeitlichen Schneegrenzen lokal beeinflußt rascher und intensiver als die rezenten. Das allgemein formulierte Prinzip von Wißmann, daß die Schneegrenzdepressionen in ariden Gebieten kleiner sind als in humiden (359, S. 217, Abb. 22), ist für Anatolien in Frage zu stellen. Genauer gesagt: Wir haben zu prüfen, ob die heutige Kontinentalität auf die letzte Kaitzeit übertragen werden darf. Die anatolischen Gebirge, die heute in einem sommer-trockenen extrem kontinentalen Raum liegen, gehörten kaltzeitlich $\mathrm{zu}$ einer ganzjährig beregneten, vermindert kontinentalen Klimaprovinz. Jedenfalls zeigen auch Erosions- und Akkumulationsformen bei Ankara die kaltzeitlich veränderte Niederschlagstätigkeit an (45). Geringere Verdunstung und größere sommerliche Abflußmengen aus den Gebirgsvergletscherungen führten $\mathrm{zu}$ flächenhaften Seenbildungen in den ausgedehnten Beckenzonen Anatoliens. (Tuz Gölü heute 1250 km²; Becken von Konya-Eregli heute trocken, eiszeitlich ein See von ca. 150 auf $50 \mathrm{~km}$ usw.; 183, 45.) Als Ganzes ergaben sich bedeutende lokalklimatische Veränderungen mit einer relativ niedrigen Schneegrenzfläche. Im Gegensatz dazu werden die rezenten Schneegrenzen über der kontinentalen Heizfläche Anatoliens kräftig aufgewölbt und dadurch die Schneegrenzdepressionen von der Gegenwart zur letzten Kaltzeit entsprechend ausgeweitet. 


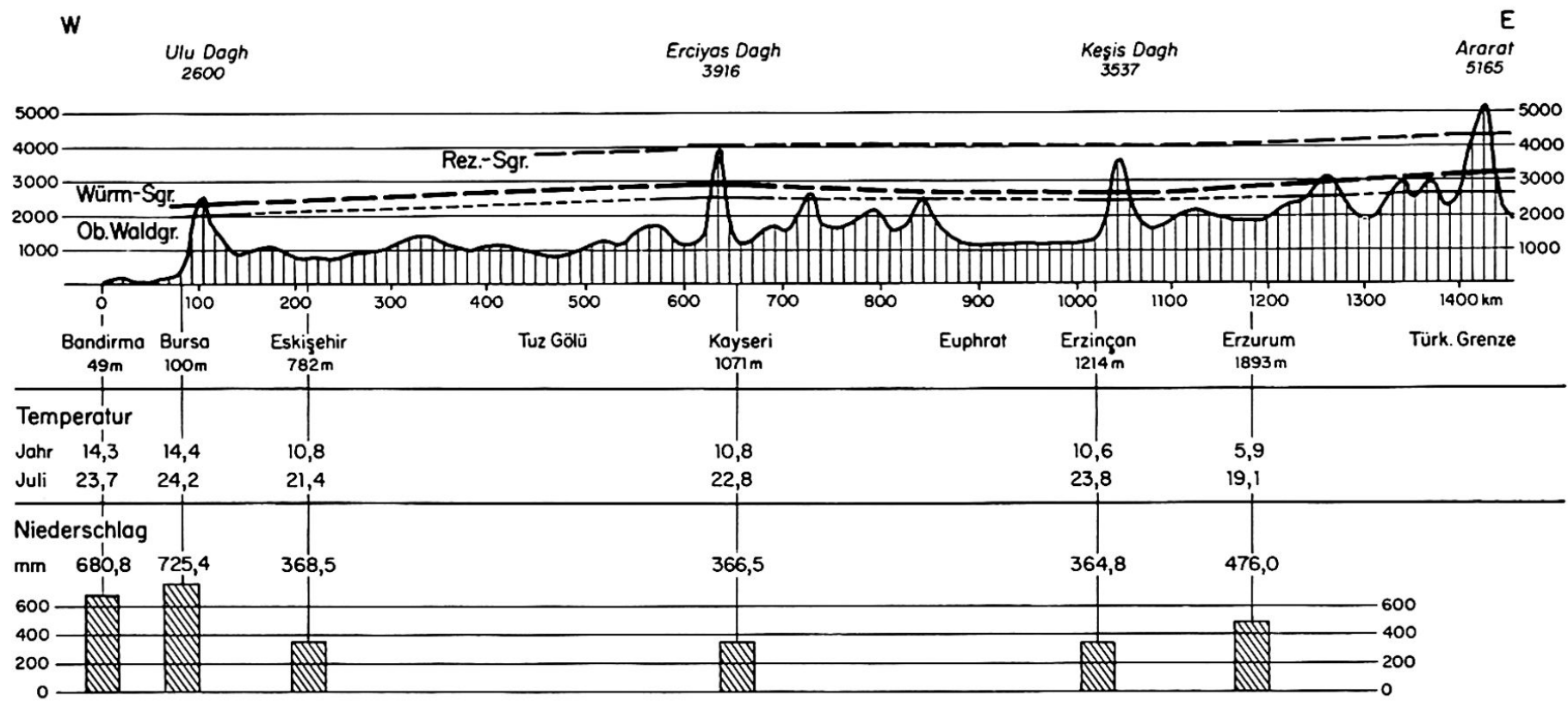

Fig. 13 Schneegrenzen und Waldgrenzen in Anatolien. Profil W-E.

1.4. Die vergletscherten Gebirge (Fig. 10 und 11)

(Höhen der regionalen Schneegrenzen)

Vergletscherte Gebirge

1. Ulu Dagh (Bursa)

2. Köroglu Tepe (SE Bolu)

3. Ilgaz D. (Kastamonu)

4. Gebirge südl. Giresun (Karagöl, Balaban usw.)

5. Kizil Dagh

6. Geb. südlich Trabzon (Soganli D., Çakirgöl D.)

7. Salaçor-Gebirge

8. Kaçkar Dagh

9. Tiryal D. (Kükürt T.)

10. Cayidüzu Dagh

11. Kordevan Dagh

12. Kisir D. (Kars)

13. Allahuekber Dagh (Kars)

14. Ala Dagh

15. Asagi Dagh (S Kar)

16. Alagöz Dagh

17. Ararat (Agri D.)

18. Tendürek D. (NE Van)

19. Ala D. (NE Van See)

20. Muratbasi
Höhe m

2543

2378

2565

3095

2950

3063

37112800 ?

3937

3348

3000

3050

3150

3725

3134 3000-

$3270\} 3100$

4094

5165

3542

3255

3519

$2300-3500$

2500

2400

2500

$N: 2850$

Rezent

Wald-

grenze

2030

2100

2100

2000

2100

2600

N: 2850$$
\text { ? }
$$

3300 ?
Literatur

Philippson 1904, Cvijic 1908, Louis 1944, eig. Beob.

Louis 1944

Louis 1944

Erinç 1944

Louis 1944

Planhol 1964

Erinç 1944

Erinç (tekton. Hebung)

Stratil-Sauer 1961, 1964, 1965, Krenek 1932, Leutelt 1935, Blumenthal 1958, eig. Beob. 1964

$2200 \quad$ Louis 1944

$2300 \quad$ Louis 1944

Louis 1944

Oswald 1912

Paschinger 1912, Blumenthal 1954 und 1958 
\begin{tabular}{ccc}
\multicolumn{2}{c}{ Schneegrenzen } & Obere \\
Würm & Rezent & Wald- \\
& grenze
\end{tabular}

21. Ay Dagh

3313

22. Suphan D. (N Van See)

23. Mengene D. und andere Ge- 3610 birge östlich Van See

24. Artos D. (SE Van See) Hasobesir Dagh

25. Gebirge südl. Van See

26. Mor Dagh

27. Cilo Dagh, Sat Dagh

28. Altindagh

29. Geridan Dagh

30. Anduk Dagh

31. Cotela-Akçakara

32. Ak Dagh (70 km E Elazig)

33. Monzur D. (Erzincan)

34. Mercan D. (Erzincan)

35. Bagirpasa Dagh

36. Seytan Dagh

37. Kosan Dagh

38. Bingöl Dagh

39. Palandöken Dagh

40. Kargapazari Dagh

41. Cosan Dagh

42. Kesis D. (Erzincan)

43. Akbabaçali Dagh

44. Nurihek D. (SW Malatya)

45. Berit Dagh

46. Binboga Dagh

47. Bey Dagh

48. Bakir D. und andere Geb.

49. Ala Dagh

50. Karanfil Dagh

51. Hoher Bolkardagh

52. Erciyas Dagh

53. Hasian Dagh

54. Ak Dagh (E Antalya)

55. Bozburum Dagh

56. Dedegöl Dagh

57. Davras Dagh

58. Barla Dagh

59. Sultan Dagh

60. Honaz Dagh

61. Sandras Dagh

62. Ak Dagh

63. Bey Dagh

100. Hochlibanon

101. Hermon

$3088 \quad 2700$
4434

3475

3500

3675

3810

4168

3250

3220

2830

$3300 \quad 4000$

3100

$3000 \quad 3800$

3000

$2800 \quad 3500$

3600

2400

Bobek 1940, Blumenthal 54

Louis 1944

Louis 1944

Oswald 1912

Oswald 1912, Louis 1944

Stratil-Sauer 1927

3125

3288

2963

3537

2952

3090

3014

2830

3054

2707

3900

3095

3585

3916

$2900 ?$

2700

$2800 ?$

$2700 ?$

2800 ?

2600

2700

3550

2100

2300

Louis 1944

Louis 1944

Louis 1944

Louis 1944

Louis 1944

Spreitzer 1957 und 1958,

Klaer 1962

$2650 \quad 3650 \quad 2000$

2300

Louis 1944, Blumenthal 1955, eigene Beobachtungen

Bartsch 1934/35, Louis, Erinç 1952, eigene Beobachtungen

Klaer 1962

2647

2504

2980

2635

2700

2631

2571

2850

$4000 \quad 2500$

3200 ?

$2400 ?$

2500

2500

2500

2600

$2294 \quad 2300$

$2400 ?$

3024 2500-

2550

$3086 \quad 2650$

$2814 \quad 2700$
Louis 1944

Louis 1944

Louis 1944

Philippson 1914, Erinç 1955

Philippson 1915, Planhol 1962

2000

Onde 1952, eigene Beobachtungen

2100 Louis 1944, eigene Beobachtungen

$3700 \quad 2200$
Diener 1886, Butzer 1958

Klaer 1962, Kaiser 1961, eigene Beobachtungen 


\section{Die Schneegrenzen im Balkan}

Zahlreiche wenig bekannte Gebirge geben dem Schneegrenzverlauf auf der Balkanhalbinsel eine gewisse Unsicherheit. Wir sind uns auch bewußt, $\mathrm{da} ß$ in unserer Zusammenstellung die neuere Literatur aus den betreffenden Staaten nicht vollständig erfaßt worden ist. Der vorliegende Überblick wäre ohne die klassischen und zusammenfassenden Arbeiten von Louis (182), Klebelsberg (154), Maull (196), Nowack (237) u. a. nicht denkbar.

\subsection{Die würmeiszeitliche Schneegrenze (Karte 1)}

- Bei zahlreichen übenommenen Schneegrenzhöhen haben wir uns gefragt, ob wir sie tatsächlich als regional vergleichbare Mittelwerte ansprechen dürfen. So zeigt zum Beispiel der $2409 \mathrm{~m}$ hohe Taygetos im Peloponnes die südlichsten Gletscherspuren Europas $(151,154)$. Aber nur in der Ostexposition ist ein Karboden auf $1925 \mathrm{~m}$ mit Stirnmoräne festzustellen. Die Westseite weist nicht die geringsten Glazialformen auf, somit ergibt sich eine Schneegrenzdifferenz zwischen Luv und Lee von nahezu $500 \mathrm{~m}$. Solche Unterschiede sind im mediterranen Raum nichts Außergewöhnliches, sowohl in der rezenten wie in der eiszeitlichen Vergletscherung (Fig. 19). Die Frage ist nur, ob die Westseite als windexponierte Flanke extrem benachteiligt oder die Ostseite mit einer bedeutenden Schneeanreicherung extrem bevorzugt war. Wenn Maull die Schneegrenze auf 1950-1975 m festlegt (196), dann entspricht das eher einem Lokalwert der Ostseite und nicht einer repräsentativen regionalen Schneegrenze des gesamten Gebirges (vgl. Karte 1). In diesem Sinne sind wohl zahlreiche Angaben aus dem Peloponnes und Pindos zu überprüfen und neu festzulegen.

- Sehr problematisch scheint uns der Schneegrenzverlauf zwischen dem südlichen Pindos und den $\mathrm{Ge}-$ birgen Mittelgriechenlands. Im Raum Vardussia, Ghiona und Parnass werden Schneegrenzen zwischen 2050 und $2200 \mathrm{~m}$ festgestellt (196). Etwas nördlich davon bezeichnet Mistardis die Berge Oeta und Oxya als eiszeitlich vergletschert und ordnet ihnen eine Schneegrenze von 1900-1950 m zu (221). Erstaunlich ist aber, daß diese beiden Gipfel mit den geringen Höhen $2153 \mathrm{~m}$ und $1926 \mathrm{~m}$ vergletschert wurden, währenddem in der nordöstlichen Nachbarschaft der Kalikouda (2104 m) und der Tymphrestos (2319 m) unvergletschert blieben. Eine lokalklimatische Erklärung dieses Sachverhaltes scheint uns fragwürdig, und tektonische Vorgänge können wir ohne klare Beweise nicht annehmen. Unsere Schneegrenzkarte mußte diesem heutigen Stand der Kenntnisse folgen. Aber wir glauben, daß eine künftige einheitliche und sorgfältige Kartierung diese Widersprüche im mittelgriechischen Raum lösen wird. - Am Olymp legten wir die regionale Schneegrenze nach eigenen Untersuchungen auf $2400 \mathrm{~m}$ fest. Die Schneegrenzkarte zeigt uns auf der Breitenlage des Olymps ein aufallendes Ausbuchten der Isochionen nach Westen, das heißt, gerade auf dieser Breite schirmen die auftauchenden albanischen Küstenketten und die höchsten Erhebungen des Pindos $(2633 \mathrm{~m})$ das östliche Griechenland so kräftig ab, daß mit der ausgeprägten Kontinentalität auch die Schneegrenzfläche rascher und kräftiger ansteigt. - Interessant ist der Schneegrenzverlauf im Durchbruch der Neretva bei Mostar (Herzegowina). Die maritime Durchdringung der dinarischen Kettensysteme zeigt sich in einer bedeutenden Schneegrenzerniedrigung an den beidseitigen Gebirgen. Roglic (303) hat diesen Raum erneut bearbeitet und dabei die großen Expositionsdifferenzen hervorgehoben. Seine lokalen Schneegrenzangaben schwanken zwischen 1000 und $1700 \mathrm{~m}$ und es ist sehr schwer, daraus einen regionalen Mittelwert abzuleiten. Jedenfalls erfuhren diese Gebirge eine äuBerst intensive Vergletscherung, ähnlich der südlich anschließenden Zone zwischen Lovcen_Orjen und Durmitor.

- Die tiefen Schneegrenzen in den Küstenketten bei Kotor (Orjen-Lovcen) und Mostar weisen auf die übereinstimmend hohen Niederschläge in der Eiszeit und in der Gegenwart hin. Diese Aussage ist folgendermaßen zu differenzieren:

Die nördliche Adria lag in den Kaltzeiten trocken und bewirkte in ihren Randketten eine 100-200 m höhere Schneegrenze (z. B. Velebi, $1500 \mathrm{~m}$ ) als in den südlicheren Küstengebirgen (z. B. Orjen-Lovcen, 1300-1400 m).

- Südlich der Neretva gibt es keine vorgelagerten Inseln mehr und die Steilküste verhinderte bei der kaltzeitlichen Meeresspiegelsenkung eine große horizontale Küstenverschiebung. Im übrigen befindet sich die größte Adriatiefe (1330 m) auf dieser Breite. - Im südlichen Teil der dalmatinischen Küste konzentrieren sich die Niederschläge auf ein winterliches Maximum, im Unterschied zu einer stärkeren Aufsplitterung in Herbst- und Frühjahrsspitzen weiter im Norden (113). Dadurch wird sehr wahrscheinlich der nivometrische Koeffizient von der nördlichen zur südlichen dalmatinischen Küste erhöht. Diese Folgerung muß in Zukunft noch durch genauere Untersuchungen belegt werden.

- Die jährlichen Niederschlagsmittel steigern sich von der Küste oder vom Gebirgsfuß (Hercegnovi $1787 \mathrm{~mm}$, Mostar $1343 \mathrm{~mm}$ ) bis in die höheren Regionen ganz gewaltig: Cetinje auf $671 \mathrm{~m}=3452$ $\mathrm{mm}$; Crkvice auf $1097 \mathrm{~m}=4934 \mathrm{~mm}$. Diese er- 
staunlich hohen Werte, konzentriert auf das Winterhalbjahr, zeigen sich in den rezenten Schneelagen und entsprechend modifiziert in der kaltzeitlichen Vergletscherung.

- Die wichtigste Rolle dürfte die sommerliche Druckverteilung spielen. In der letzten Kaltzeit konnte sich ein relativ hoher Druck über dem Vergletscherungsgebiet der Alpen bis in die nördliche Adria auswirken. Südlich davon blieb aber das Tiefdruckgebiet über der ungarischen Tiefebene als Steuerungszentrum wirksam. Die Depressionen mit den Zugstraßen Vb und Vc wurden weiter nach Süden verlagert und querten den dinarischen Gebirgsraum zwischen Sibenik und Kotor. Dieser kaltzeitlich verstärkte zirkulationsbedingte Anprall an der mittel- bis süddalmatinischen Gebirgsfront dürfte die Hauptursache der außerordentlich niedrigen Schneegrenzen sein.

- Auf eigenen Begehungen im Orjen und Lovcen konnten wir uns von der tiefen Schneegrenzlage überzeugen, wie sie ältere Beschreibungen und jüngere Untersuchungen dargestellt haben. Am Lovcen hat Liedtke in Südexposition Moränen auf 1430 m entdeckt und eine südseitige Schneegrenze von $1550 \mathrm{~m}$ ermittelt (175). Auf der Nordseite liegen die Endmoränen unter $1000 \mathrm{~m}$, so daß im gesamten die regionale Schneegrenze nicht höher als $1400 \mathrm{~m}$ sein kann. Auch am Orjen sind prächtige Endmoränenwälle in W- und E-Exposition aufgeschüttet, die ein bedeutendes Vergletscherungsareal von über 100 $\mathrm{km}^{2}$ und Gletscherlängen bis zu $10 \mathrm{~km}$ nachweisen. Eine neuere Arbeit soll von Ridanovic erscheinen (301).

- Der gesamte Gebirgsraum Montenegros zwischen Durmitor, Maganik und Komovi ist an einzelnen Punkten sehr gut erforscht, dazwischen aber bleiben viele Lücken, Unsicherheiten und Widersprüche. Am Durmitor selber stehen sich Schneegrenzwerte von $2050 \mathrm{~m}(117,320)$ bis $1550 \mathrm{~m}(217)$ gegenüber. Den älteren, allzu hohen Angaben fehlten offensichtlich die genauen Kenntnisse der Endmoränenlagen, die teilweise und nach eigenen Beobachtungen unter $1000 \mathrm{~m}$ liegen. Bedenken wir ferner, $\mathrm{da}$ das $1400 \mathrm{~m}$ hohe Plateau von Zabljak von einer mächtigen Eiskappe bedeckt war, so konnte die Schneegrenzfläche nicht weit darüber liegen. Es ist noch nicht abgeklärt, welche Ausmaße dieses Gletscherareal hatte und ob es mit den benachbarten Hochflächen in Verbindung stand. Jedenfalls haben die $1500 \mathrm{~m}$ hohen Plateaus zwischen Savnik und Niksic (südl. Durmitor) eine Eigenvergletscherung getragen, Moränen sind bis auf $1000 \mathrm{~m}$ Höhe festzustellen. Diese Beobachtungen werden durch verstreute und unzusammenhängende Untersuchungsergebnisse aus diesem Raum bestätigt. Z. B.: Karformen im Zupa bei Niksic auf $1300 \mathrm{~m}$, Moränen bis $800 \mathrm{~m}$ (320); am Sinjajevina Moränen bis $970 \mathrm{~m}$, an der Mündung des Planica- Tales in die Tara bei
$1050 \mathrm{~m}$ (218) usw. Trotz mangelhafter Kenntnisse fassen wir die Vergletscherung Montenegros folgendermaßen zusammen: Die Schneegrenzen steigen von der dalmatinischen Küste (1300-1400 m) nur langsam zu den Hochflächen zwischen Savnik und Nikisic an (ca. $1400 \mathrm{~m}$ ) und überschreiten beim Durmitor kaum $1500 \mathrm{~m}$.

- Fraglich ist der Anschluß der Balkan-Isoohionen an den alpinen Vergletscherungsraum. In den östlichen Karawanken wird die Schneegrenze auf 1900 m geschätzt (154), in den Steiner Alpen liegt sie auf höchstens $1700 \mathrm{~m}$ und in den Julischen Alpen werden sogar Werte von 1500 m überliefert (199). Diese niedrigen Angaben werden durch die Arbeit Klebelsbergs am Monte Grappa (Vorberg zwischen Piave und Brenta) mit einer regionalen Schneegrenze von $1400 \mathrm{~m}$ gut gestützt (157). Nach diesen Ergebnissen muß also die $1800 \mathrm{~m}$-Isochione vom Balkan her erst in den östlichen Karawanken den alpinen Vergletscherungsraum erreichen (Karte 1). Da aber neuere Arbeiten in der Koralpe (Karte 1, Nr. 79) eine Schneegrenze von $1700 \mathrm{~m}$ verlangen (13), haben wir offenbar im Raum der Drau-Talung und der Gurktaler Alpen die höchste Aufwölbung der würmeiszeitlichen Schneegrenzfläche am östlichsten Alpenrand überschritten.

- Im gesamten zeigen die Schneegrenzlinien im Balkan auf eindrückliche Weise einen von der geographischen Breite unabhängigen Verlauf. Orographie und Lokalklima bestimmen das Isochionenbild, groBe Differenzen zeigen die Gebiete mit maritimer Durchdringung und kontinentaler Isolierung an. Zahlreiche Einzeluntersuchungen sind in Zukunft noch nötig, um unserer Schneegrenzkarte größere Genauigkeit und Sicherheit zu geben.

\subsection{Die rezente Schneegrenze (Karte 2)}

Rezente Gletscherflecken finden wir nur in den Ausläufern der Ostalpen, sozusagen im Anschlußgebiet unserer Schneegrenzkarte:

- Der kleine Gletscher am Triglav wird seit 1946 beobachtet, und auf dem benachbarten Kredarica $(2535 \mathrm{~m})$ ist neuerdings eine meteorologische Station in Betrieb (Fig. 14; Lit. 318; Karte 2, Nr. 78). Dadurch kann künftighin das Zusammenspiel Gletscherschwankungen_Klimaschwankungen auch in diesem Raum genauer verfolgt werden. Es wäre aber falsch, die regionale Schneegrenze an diesen Gletscherflecken in Gunstlage zu binden, sie liegt sehr wahrscheinlich über der Gipfelhöhe des Triglav. Diese Folgerung bedeutet, daß die letzteiszeitliche Schneegrenzdepression in den Julischen Alpen weit mehr als $1000 \mathrm{~m}$ beträgt.

- Ein zweiter, viel kleinerer Firn- oder Gletscherfleck liegt am Fuß der 700 m hohen Skuta-Nordwand in den Steiner Alpen (156; Karte 2, Nr. 77). 
Hier zeigt die Höhenlage von ca. 1700 m noch deutlicher an, daß er weit unter der Schneegrenze in einer außerordentlichen Gunstlage existiert und von einer eigentlichen regionalen Schneegrenze völlig unabhängig ist.

- Ein weiterer Altschnee- oder Firnfleck ist nach 6 am Fuß der Nordwand Cvrsnica (Neretva-Raum, Karte 1, Nr. 68) zu erkennen. Doch scheint uns diese Beobachtung so unsicher, daß wir auf einen Eintrag in unserer Schneegrenzkarte verzichten.

Als Ganzes stehen uns auf der gesamten Balkanhalbinsel überhaupt keine rezenten und für eine Schneegrenzbestimmung einigermaßen repräsentativen Gletscherflecken zur Verfügung. Dementsprechend ist der aufgezeichnete Verlauf der rezenten Schneegrenze fraglich und die Berechnung einer letzteiszeitlichen Schneegrenzdepression wenig sinnvoll.

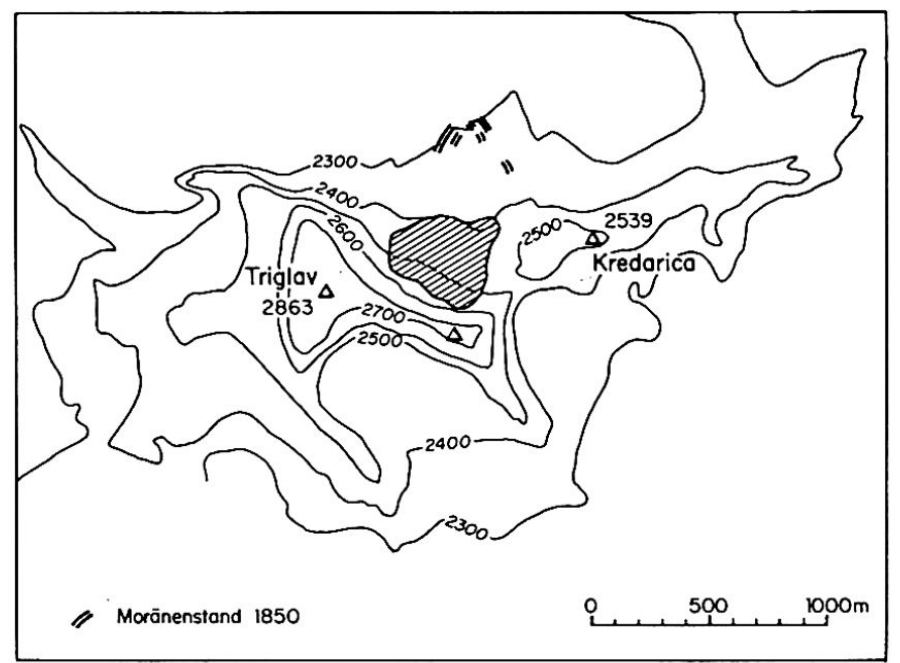

Fig. 14 Der Gletscher am Triglav (Julische Alpen, Jugoslawien) (nach Sifrer 1963).

\subsection{Die vergletscherten Gebirge des Balkans (Karte 1 und 2)}

(Höhen der regionalen Schneegrenzen)

Vergletscherte Gebirge

\section{Griechenland}

1. Kreta, Madara-Berge

2. Kreta, Psiloriti (Ida)

3. Taygetos (südl. Peloponnes)

4. Kyllene (Ziria)

5. Chelmos

6. Erymanthos (Olonos)

7. Parnass

8. Ghiona (östl.)

Vardussia (westl.)

9. Oeta (östl.)

Oxya (westl.)

10. Kaliakuouda

11. Tymphrestos (Pindos)

12. Tsumerka (Pindos)

13. Peristeri (Pindos)

Kakarditsa (Pindos)

14. Tymphi (Pindos)

15. Smolikas (Lyggos)

16. Grammos (Lyggos)

17. Olymp
Höhe m

Schneegrenzen
Würm Rezent

Obere

Wald-

grenze

Literatur

Creutzburg 1928, Poser 1957

Creutzburg 1928, Poser 1957

2000- Maull 1921, Klebelsberg 1931

2100? Eigene Folgerung

Maull 1921, Mistardis 1937

2000- Maull 1921, Mistardis 1937

2100

Maull 1921, Mistardis 1937

Maull 1921, Klebelsberg 49

Maull 1921

Maull 1921

Mistardis 1952

Mistardis 1952

Klebelsberg 1949

19261900

2104

23192200

2393

2295

1900

2000

Klebelsberg 1932, 1949

Sestini 1933, Osswald 1938, Klebelsberg 1949

2200

1900 - Mistardis 1937

$2522 \quad 2100$

2000

Nowack 1929

2000- Cvijic 1908, 1908

2100

Louis 1933, Maull 1921

Wiche 1955/56

Eigene Beobachtungen

18. Voras-Geb. oder Kaimakcalan

Maull 1921 


\section{Albanien}

30. Lunxheries Nemercka

31. Küstenkette Lungara

(Cika und Kiores)

Griva

32. Tomor-Gebirge

33. Ostravica

34. Gur i Topit

35. Polissi-Gebirge

36. Jablanica und Shebenikut

37. Alamanit

38. Mirdita

39. Prokletije (Nordalbaner Berge)

$\begin{array}{ll}2160 & 1900 \\ 2500 & 1900 \\ 2045 & 1900 \\ & \\ 2130 & 1900 \\ & 1900- \\ & 2000 \\ 2385 & 2100 \\ 2379 & 2000 \\ 1978 & \\ 2270 & 1900- \\ & 2000 \\ & 2000 \\ 2150 & 1900 \\ 2692 & 1700- \\ & 1800\end{array}$

Jugoslawien

50. Perister (Baba-Pl.)

2532

51. Jakupica (Geb. südl. Skopje)

52. Korab

53. Sar Planina

Koritnik (in der Sar Planina)

54. Mokra Planina

55. Kopaonik

56. Golija

57. Maglic, Volujak, Bioc

58. Durmitor Gebirge und Plateaus westl., nördl. und östl. von Niksic-Savnik

59. Lukavica, Sinjajevina

60. Komovi Visitor

61. Maganik

62. Lovcen

63. Orjen

64. Lebrsnik

65. Velez-Gebirge

66. Bjelasnica, Visocica Treskavica, Lelija

Stog

67. Prenj Planina

68. Cvrsnica (nördl.) Cabulja (südl.)
2000

1650

$2764 \quad 2300$

$2747 \quad 2000$

$2764 \quad 2300$

2155

$2140 \quad 1900$

19251900 ?

$2395 \quad 1600$

1700 ?

$2528 \quad 1800$

2050

1550

1500

$2203 \quad 1600$

$1700 ?$

2484

2174

2139

$\begin{array}{ll}1759 & 1300- \\ & 1400\end{array}$

$1895 \quad 1300$

1400

$1859 \quad 1600$

19691600 ?

$2067 \quad 1800$

$2088 \quad 1900$

2014

2155

1500

(1200-

1700)

22281600 ?

1780

(1000-1700)
Louis 1926, Nowack 1929

Louis 1926, Nowack 1929

Nowack 1929, Klebelsberg1949

Nowack 1929

Nowack 1929

Nowack 1929

Klebelsberg 1949 und Nowack 1929

Klebelsberg 1949

Nowack 1929

1800 - Nowack 1929, Leutelt 1932 1900

Milojevic 1934

Louis 1933

Jovanovic 1928

Nowack 1929

1800- Nikolic 1912, Cvijic 1917,

1900 Markovic 1962, Blumenthal

1964

Nowack 1929

Cvijic 1908, Jaranoff 1940

Klebelsberg 1949

?1500 Cvijic 1900, 1908

?1900 Bauer 1934, Kayser 32

Hassert 1901, Sobajic 1926

Kayser 1932, Louis 1933

Milojevic 1951

Eigene Beobachtungen

Kayser 1932

Milojevic und Borivoje 1935

Milojevic und Borivoje 1935

Hassert 1901, Cvijic 1904, Liedtke 1962

Eigene Beobachtungen

1800- Penck 1900, Sawicks 1910/II,

1850 Ridanovic 1961, Rathjens 1960

Eigene Beobachtungen

Klebelsberg 1949

1750- Cvijic 1900 und 1908, Louis

1800

1933, Klebelsberg 1949

1750
Nowack 1929

Klebelsberg 1949, Roglic 1959 
69. Biokovo Planina
70. Cincar, Radusa

71. Vranica Planina

72. Troglav

73. Sator

74. Velebit

75. Kapela-Gebirge

76. Krainer Berg

77. Steiner Alpen, Skuta

78. Triglav

79. Koralpe

\section{Bulgarien}

90. Osogavska Pl. (Ruen oder Rujen)

91. Rila-Gebirge

92. Pirin-Gebirge

93. Rhodope-Gebirge

94. Jumrukcal (Balkan)

95. Vitosa (Sofia)

96. Midzor (Stara Pl. oder westliches Balkangebirge)
2227

2925

2920

2187

2373

2286

2169
2863

2141

ca. 1600

1700

1800

1500

1500

1500

1758

1533

1796

2532

1600

ca. 1700

$>2800$

1700

1800
Wald-

grenze

1700

1500

Roglic 1935

Klebelsberg 1949

Louis 1933, Cvijic 1908

Louis 1933, Klebelsberg 1949

Klebelsberg 1949

Klebelsberg 1949

Krebs 1924

Lucerna 1906, Melik 1932, Louis 1933, Srbik 1941, Klebelsberg 1952

Sifrer 1963

Beck-Mannagetta 1953
$>2800 \quad 1800$

$2200 \quad 3000 \quad ? 2000$

2300

2100

$2300 ?$

2200

2200
Cvijic 1898, 1908, 1917, Louis 1930, Annaheim 1939

1900 Louis 1930, 1933, Cvijic 1908

1850

1850

Louis 1933

Louis 1933

Louis 1933

\section{Die Schneegrenzen der Apenninen-Halbinsel}

\subsection{Die würmeiszeitliche Schneegrenze (Karte 1)}

Obschon die Gebirgsvergletscherungen im italienischen Raum eingehend untersucht worden sind, bleiben noch zahlreiche Probleme offen:

- Auf Widersprüche stoßen wir in Korsika, wo die Schneegrenze von Lucerna auf 1650 und von Dresch auf $1800 \mathrm{~m}$ festgelegt wurde (360, S. 298). Auffallend ist die bedeutende Vergletscherung auf den Ostseiten im Unterschied zu der schwächeren glazialen Formung auf den Westseiten. In N_S streichenden Gebirgen werden die Schneeanreicherungen in Leelage zu einem wichtigen Element der Oberflächenformung. (Vgl. Taygetos im Peloponnes.)

- Daß die höchsten Gipfel Sardiniens und Siziliens eine schwache Vergletscherung erfahren haben, ist wenig wahrscheinlich. Einseitige Nivationsformen sind aber denkbar, auch wenn die Gebirge die Schneegrenzfläche nicht erreicht haben.

- Die Auseinandersetzung um die Vergletscherung des Aetna ist durch Paschinger geklärt worden (258). Es darf jedoch als gesichert gelten, daß der Aetna zur Würmeiszeit nicht die jetzige Höhe er- reicht hat. Deshalb die Schwierigkeiten und Mißerfolge in den bisherigen glazialmorphologischen Untersuchungen.

- Der Schneegrenzverlauf ist in Süditalien noch wenig gesichert, tritt aber nordwärts in immer besser untersuchte Gebirgsräume ein.

- An der französisch-italienischen Riviera haben wir sozusagen die Nahtstelle zwischen dem relativ stark abgekühlten Vergletscherungsgebiet der Alpen und dem relativ schwach abgekühlten Mittelmeer (Flohn in 48, S. 219). In dieser Zone instabiler Temperaturschichtung bildete sich ein wolken- und niederschlagsreiches Lokalklima aus, das die außerordentlich niedrigen Schneegrenzen von $1200 \mathrm{~m}$ und weniger im Küstenraum von Genua erklärt.

- Die Frage ist gestellt, ob wir tatsächlich von den Höhenzügen des ligurischen Apennins bis ins Zentrum der Po-Ebene einen Schneegrenzanstieg von 400-600 m zu erwarten haben, gemäß der Zunahme des kontinentalen Klimacharakters (Woldstedt 1958: Eiszeitliche Schneegrenze in der westl. Po-Ebene $1600-1800 \mathrm{~m}$ ). Die Ergebnisse aus den Luganer Bergen mit einer tiefsten würmeiszeitlichen Schneegrenze von $1600 \mathrm{~m}$ (155) scheinen diesen Anstieg zu 
bestätigen. Dagegen ist der Schneegrenzwert $1400 \mathrm{~m}$ vom Monte Grappa (Höhe 1775 m, Vorberg am Rande der Po-Ebene) außerordentlich niedrig. Vielleicht ist diese Angabe nach den beschriebenen Gletschern doch etwas zu tief gegriffen (157). Wir haben auf unserer Schneegrenzkarte die gesamte Po-Ebene zwischen die Schneegrenzlinie $1500 \mathrm{~m}$ im Raum Genua und Venedig und $1800 \mathrm{~m}$ im Randgebiet der Alpenvergletscherung eingeordnet. Diese 300-m-Differenz bedeutet den Schwankungsbereich der Schneegrenzfläche am südlichen Alpenrand. Jedenfalls bewirkte die kaltzeitliche Trockenlegung der nördlichen Adria eine engere klimatische Verbindung der Po-Ebene mit Istrien und Dalmatien. Dementsprechend verlaufen die niedrigen Isochionen von der Balkanhalbinsel westwärts in die PoEbene hinein. $\mathrm{Ob}$ sie hier eine lokale Kulmination beschreiben und zurückschwenken, oder ob sie den Alpenkörper umfahrend nach Osten laufen, lassen wir offen (Karte 1).

- Die südlichsten alpinen Eiszeitgletscher sind in den Alpes maritimes nachgewiesen, nur wenig südlicher als die letzten rezenten Gletscherflecken. Die Endmoränen liegen in den Tälern der Vesubie und Roja auf ca. $800 \mathrm{~m}$ (153). Von hier weg geht die Schneegrenze kontinuierlich auf den ligurischen Apennin über.

- Ebenfalls von den Pyrenäen verläuft eine geschlos_ sene Schneegrenzfläche dem Küstengebirge entlang bis zum Ligurischen Apennin. Mindestens die 1600-m-Isochione müssen wir vom Nordrand der Iberischen Halbinsel ostwärts in das Mittelmeer abschwenken lassen und nicht nordwärts in den vergletscherten Alpenraum hineinziehen (Karte 1).

- Als Ganzes fällt uns auf der italienischen Halbinsel der Schneegrenzanstieg von W nach $\mathrm{E}$ auf. Es ist aber äußerst schwierig, die Schneegrenzlinien den einzelnen Gebirgsrichtungen anzupassen. Zum ersten stören die großen Expositionsdifferenzen zwischen N und S (vgl. Gran Sasso,, Fig. 19) die Ermittlung einer eindeutigen Schneegrenze. Zum zweiten müssen wir bezweifeln, ob die aus der Literatur bezogenen Werte durchwegs eine regionale Gültigkeit haben. Sollte in Zukunft der Formenwandel von $\mathrm{W}$ nach $\mathrm{E}$ an einigen Querprofilen genauer untersucht werden, sind Korrekturen unserer Schneegrenzkarte von 100 bis maximal $200 \mathrm{~m}$ zu erwarten.

\subsection{Die rezente Schneegrenze (Karte 2)}

- Im nachfolgenden Verzeichnis haben wir die äußersten rezenten Gletscher am SW- und SE-Rand der Alpen zusammengestellt. Es sind alles Gletscherflecken des pyrenäischen Typus. Das heißt: Eine eigentliche Zunge ist nicht ausgebildet, sie liegen in ausgesprochener Wandfuß- oder Muldenlage, die

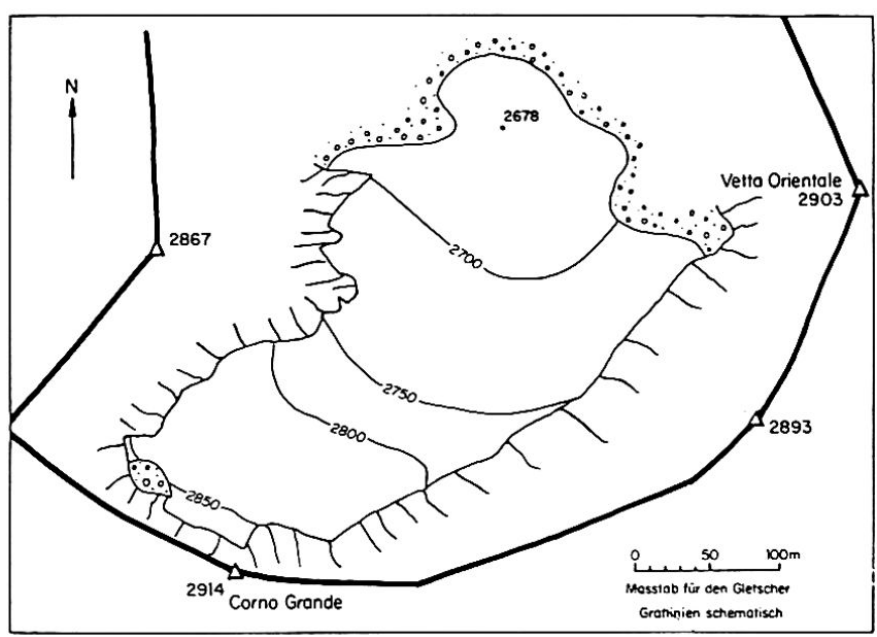

Fig. 15 Der Calderone-Gletsoher am Gran Sasso d'Italia. Der südlichste Gletscher Europas (nach Tonini 1963).

Breite ist oftmals größer als die Länge, die Fläche ist klein und die Exposition durchwegs $\mathrm{N}$ bis $\mathrm{E}$. Da sie alle in extremer Gunstlage auftreten (Wandfuß, Leelage, Ernährung durch Lawinen und Schneerutsche, usw.) ist die Ableitung einer rezenten Schneegrenze äußerst schwierig oder sogar unmöglich (54). Sie reagieren heftig und rasch auf zugeführte Schneemengen und Temperaturveränderungen und sind deshalb ideale Anzeiger der geringsten Zirkulations- und Klimaschwankungen (349).

Besonders instruktiv ist der Calderone-Gletscher am Gran Sasso (Geographische Breite $42^{\circ} 28^{\prime}$; Exposition NNE; Länge $390 \mathrm{~m}$, max. Breite $230 \mathrm{~m}$, Fläche 6,2 ha; siehe Fig. 15). Tonini hat diesen südlichsten Gletscher Europas klimatologisch und glaziologisch hervorragend bearbeitet (339). Auf eigenen Begehungen konnten wir uns wiederum von der außerordentlichen Gunstlage überzeugen, die die Existenz des Gletschers weit unterhalb der klimatischen Bedingungen einer regionalen Schneegrenze erlaubt. Es ist nach unserer Meinung nicht richtig, eine rezente regionale Schneegrenze, repräsentativ für den gesamten Gran Sasso und die höchsten Gipfel der Abruzzen, irgendwo auf dem Gletscherareal zu fixieren (339). Wir haben die Höhenlage der Sommertemperaturen mit verschiedenen Temperaturgradienten berechnet, die großen Expositionsdifferenzen beurteilt, die lokalmorphologische Begünstigung berücksichtigt und schließlich eine regionale Schneegrenze von $3100 \mathrm{~m}$ festgelegt (vgl. Seite 191).

- Zuletzt erwähnen wir noch die perennierenden Firn- oder Altschneeflecken am Fuß der $500 \mathrm{~m}$ hohen Monte-Cinto-N-Wand auf Korsika in einer Höhenlage von 1870-2030 m. Solche Vorkommen sind aber zweifelhaft und für eine Schneegrenzbestimmung bedeutungslos.

Als Ganzes gibt uns die Apenninen-Halbinsel mit den wenigen Gletscherflecken keine genügende 
Grundlage zur Darstellung eines rezenten Schneegrenzverlaufes. Die einzigen Hinweise erhalten wir am Alpenrand und im Gran Sasso. Weiter im Süden zeigt uns der $3274 \mathrm{~m}$ hohe Aetna an, daß die Schneegrenze bedeutend über dem Gipfelniveau liegen muß.

\subsection{Die Schneegrenzdepression}

Die Differenz von der rezenten zur letzteiszeitlichen
Schneegrenze kann auf der Apenninenhalbinsel praktisch nur an einem Punkt, am Gran Sasso, mit einiger Sicherheit bestimmt werden. Die würmeiszeitliche Schneegrenze wurde von verschiedenen Autoren mit $1800 \mathrm{~m}$ bezeichnet, die rezente nehmen wir auf $3100 \mathrm{~m}$ an, folglich ergibt sich eine Depression von $1300 \mathrm{~m}$. Dieses Ergebnis entspricht genau der Sierra Nevada und dürfte ebenfalls mit den Verhältnissen in den Gebirgen Montenegros übereinstimmen.

3.4. Die vergletscherten Gebirge der Apenninenhalbinsel (Höhen der regionalen Schneegrenzen)

Vergletscherte Gebirge

\section{Sardinien und Korsika}

1. Monti del Gennargentu (Sardinien)

2. Monte l'Incudine 2136

3. Monte Rotonde (Paglia Orba, 2629 M. Renoso)

4. Monte Cinto (Corona)

2710
1834

$\begin{array}{ccc}\text { Höhe } \mathrm{m} & \begin{array}{c}\text { Schneegrenzen } \\ \text { Würm }\end{array} & \begin{array}{c}\text { Obere } \\ \text { Rezent }\end{array} \\ & \begin{array}{c}\text { Wald- } \\ \text { grenze }\end{array}\end{array}$

1650

1800
$1800 ?$

1800
Lucerna 1911

Dresch 1941 (Zit. nach Woldstedt 1958), Heybrock 1954, Letsch 1956

\section{Sizilien}

5. M. Madonie

1975

6. M. Nebrodi

7. Aetna

1845

3274

\section{Apenninenhalbinsel}

$\begin{array}{lrrr}\text { 8. Aspromonte (Montalto) } & 1958 & & \\ \text { 9. Sila (Botte Donato) } & 1929 & & 2100- \\ \text { 10. Monte Pollino } & 2271 & \text { ca.2000 } & 2200 \\ \text { Geb. westlich Castrovillari } & 1986 & & \\ \text { 11. Basilicata, Volturino } & 1836 & & \\ \text { Sirino-M. del Papa } & 2005 & 1800- & \\ \text { 12. M. Miletto (Matese) } & 2060 & 1800 & \\ \text { 13. Monti Marsicani } & & & \\ \text { M. Greco } & 2283 & 1700- & \\ \text { La Meta-Petroso } & 2241 & 1900 & \\ \text { Montagna grande } & 2208 & & \\ \text { 14. Monti Simbruini } & & & \\ \text { M. Viglio } & 2156 & \text { ca. } 1750 & \\ \text { M. Cantari } & 1913 & & \\ \text { 15. M. Velino } & 2487 & & \\ \text { M. Sirente } & 2349 & \text { ca. } 1800 & \\ \text { 16. Terminillo } & 2213 & \text { ca. } 1800 & \\ \text { 17. Majella, M. Amaro } & 2795 & 1800- & \\ & & 2000 & \\ \text { 18. Gran Sasso } & 2912 & 1800 & 3100\end{array}$

1800
Paschinger 1956, Sacco 1941

Sacco 1941

Vagliasindi 1948, Cucuzza-Silvestri 1949, Klebelsberg 1949, Maier 1936, Paschinger 1956 Büdel 1952

Klebelsberg 1932, Suter 1939, Woldstedt 1958, Sacco 1941

Lorenzo e Dainelli 1923

Sacco 1941, Suter 1939, Paschinger 1956

Lorenzo e Dainelli 1923

Suter 1933, 1935, 1940, Klebelsberg 1930-1949, Gortani 1930, Sacco 1941

gleich wie Nr. 13, Suter 1939

gleiah wie Nr. 13

Demangeot 1965

Suter 1939

Demangeot 1965

Suter 1940, Klebelsberg 1949, Tonini 1963, Demangeot 1963, 1965, eigene Beobachtungen, Furrer 1966 
Schneegrenzen

Würm Rezent

19. M. Sibellini, Vettore

2473

1825

Monti della Laga

$2422 \quad 1900$
Obere Literatur

Wald-

Klebelsberg 1933, Suter 1939 , Scarsella 1945, Demangeot 1965

Suter 1939, Sacco 1941, Demangeot 1965

Sacco 1941

Region Toskana, Zentr. Apennin

20. M. Falterona Alpe della Luna Gruppo del Catria

$\begin{array}{lll}1654 & - & - \\ 1454 & - & - \\ 1702 & - & - \\ 1946 & 1300- & \end{array}$

\section{Sacco 1941}

Paci 1935, Suter 1936. 1939, Sacco 1941, Beneo 1945, Klebelsberg 1949

Suter 1939

Sacco 1941

Losacco 1949

Klebelsberg 1949
La Nuda

M. Prado-Cusna

M. Giovo-Alpe Tre Potenze

M. Cimone

23. M. Gottero

24. M. Ragola

$$
\begin{aligned}
& \text { M. Maggiorasca } \\
& \text { M. Penna-Ajona }
\end{aligned}
$$

25. M. Lesima

M. Ceppo

26. Gruppo dei Voltri M. Beigua

27. M. Settepani M. Ceppo

28. Die südlichsten rezenten Gletscher im $W$ der Alpen (53)

Italienische Meeralpen zw. $44^{\circ} 07^{\prime}$ und $44^{\circ} 07^{\prime} 40^{\prime \prime}$ N.
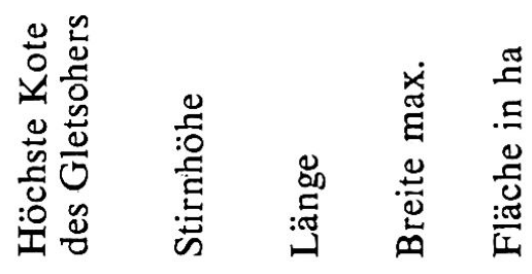

\section{Clapier}

2. Peirabroc

3. Maledia

4. Muraion

5. Ciafraion

6. Gelas
1830

1812

1978

1894

2120

1940

2164

1640

1780

1803

1735

1724

1637

1287

1391

1637
1550

1650

1450

1600

1550

1700

1400 ?

1300

1350

1500

1300

1400

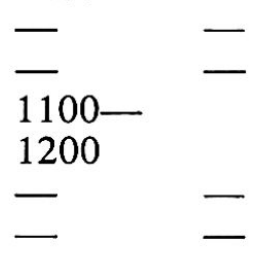

zum Teil ein-

seitige Schneegren-

zen und nicht

regionale
29. Die südlichsten rezenten Gletscher im $E$ der Alpen (53)

Julische Alpen Italiens auf $46^{\circ} 21$ ' 50 " $\mathrm{N}$
Sacco 1941

Losacco 1949

Sacco 1941

Sestini 1937, Suter 1937, Klebelsberg 1949

Sacco 1941 


\section{Die Schneegrenzen auf der Iberischen Halbinsel}

\subsection{Die würmeiszeitliche Schneegrenze (Karte 1)}

Die würmeiszeitlichen Gebirgsvergletscherungen in Spanien und Portugal sind im einzelnen sehr gut untersucht und in mehreren Arbeiten zusammengefaßt worden $(246,240,169,179,322)$.

- Im Süden hat die Sierra Tejeda zur Diskussion Anlaß gegeben, ob die Formen im Gipfelbereich als glazial anzusprechen sind oder nicht $(149,314)$. Die Frage ist nicht eindeutig entschieden, doch sind auch keine großen Änderungen im allgemeinen Schneegrenzverlauf zu erwarten. Da es sich nur um Nivationsformen handeln kann, ist die Schneegrenze ohnehin auf oder knapp über dem Gipfelniveau zu erwarten. Weil sie aber sicher niedriger ist als in der Sierra Nevada, ist der Schwankungsund Fenlerbereich eng begrenzt. Im weiteren ist die ansteigende Schneegrenze gegen den kontinentalen Klimaraum Südostspaniens durch Lautensach in der Sagra Sierra eindeutig belegt (170).

- Im kantabrischen Gebirge sind in mehreren Arbeiten erstaunlich niedrige Schneegrenzen nachgewiesen worden. Lotze 1962: "In der Valnera-Gruppe erreichte die pleistozäne Schneegrenze mit $1350 \mathrm{~m}$ den absolut niedrigsten Wert innerhalb der gesamten Iberischen Halbinsel» (179, S. 15 und 17). Aber schon ein Jahr später ist dieses Ergebnis von Kopp aus der Sierra de Aralar unterboten worden. Doch müssen wir die Schneegrenzhöhe von $1050 \mathrm{~m}$ in Frage stellen, da das Bestimmungsverfahren des Autors kaum einen regionalen Mittelwert ergibt (161). Immerhin enthalten diese neuen Höhenangaben wichtige Hinweise auf die lokalen Klimaverhältnisse der Kaltzeiten. Eine vorwiegend meridionale Zirkulation hat dem Nordhang des kantabrischpyrenäischen Gebirgszuges einen verstärkten Niederschlag gebracht. (Eine Auffassung, die von früheren Autoren abgelehnt wurde, 238.) Nur unter dieser Annahme ist die kräftige Herabsetzung der Schneegrenzfläahe zu verstehen, die selbst unbedeutende Vorberge anschnitt und vergletscherte.

- Die Pyrenäen sind von zahlreichen Autoren bearbeitet worden, wobei wir vor allem die zusammenfassenden Darstellungen von Nußbaum erwähnen müssen. Zu wenig präzis scheint uns die Frage abgeklärt, wie sich die Schneegrenzen am Ostrand der abtauchenden Gebirgskette verhalten. Denn hier fällt die Entscheidung, ob und wie hoch sie nordwärts gegen die Alpen oder ostwärts in den Mittelmeerraum weiterzuführen sind. (Die zwei Auffassungen graphisch dargestellt in 179 und 240; vgl. ferner das Kapitel über den Schneegrenzverlauf auf der Apenninen-Halbinsel.)

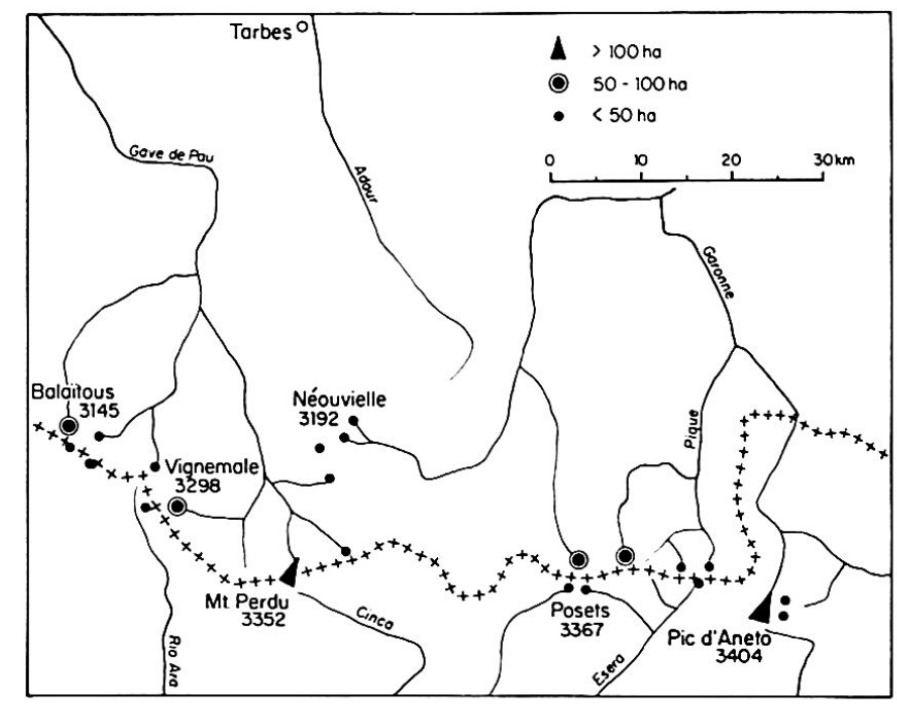

Fig. 16 Die Gletscher der Pyrenäen (nach F. Taillefer 1958).

\subsection{Die rezente Schneegrenze (Karte 2)}

- In der Sierra Nevada können wir kaum mehr vom südlichsten Gletscher Europas sprechen. Der kleine Firnfleck am Fuß der Veleta-Wand liegt mehr als $600 \mathrm{~m}$ unterhalb der regionalen Schneegrenze. Die Abhängigkeit von kleinsten Klimaschwankungen ist außerordentlich groß, und es ist sehr wohl möglich, daß es auch wieder einmal zu einer verstärkten Eisbildung kommen kann.

- Die zahlreichen Gletscher und Gletscherflecken der Pyrenäen haben wir nach Angaben von Taillefer in Fig. 16 zusammengestellt $(335,280)$. Neben tief hinabreichenden, alpin anmutenden Kar- und Talgletschern (z. B. Oulettes de Gaube, Vignemale usw.) herrschen die Gletscherflecken des pyrenäischen Typus vor. Viele von ihnen werden durch Schneeanwehungen ernährt, zeigen kaum eine Gliederung in Nähr- und Zehrgebiet, reagieren auf Klimaschwankungen rasch und heftig und sind mit ihrem Areal an eine streng begrenzte Gunstlage gebunden. Diese Tatsachen sind bei der Schneegrenzbestimmung zu berücksichtigen, selbst wenn kleine südexponierte Gletscherflecken ideale Voraussetzungen für die Festlegung eines Mittelwertes zu bieten scheinen. Im gesamten steigt die rezente Schneegrenzfläche von $\mathrm{W}$ nach $\mathrm{E}$ kräftig an, das heißt, von ca. $3000 \mathrm{~m}$ westlich des Vignemale bis über $3200 \mathrm{~m}$ östlich des Pic d'Aneto.

\subsection{Die Schneegrenzdepression}

In der Sierra Nevada haben wir einen Depressionsbetrag von mindestens $1300 \mathrm{~m}$ bestimmt (204). Im Raum der rezent vergletscherten Pyrenäengipfel 
kommen wir ebenfalls auf Werte, die $1200 \mathrm{~m}$ und mehr betragen (vgl. Karte 1 und 2). Nußbaum hat zwar einen Wert von $1000 \mathrm{~m}$ vertreten, doch ist die rezente Schneegrenze mit $2800 \mathrm{~m} \mathrm{zu}$ niedrig ange- setzt (240). Die neuen Schneegrenzdepressionen von 1200-1300 m fügen sich ausgezeichnet in die übrigen Ergebnisse des westlichen und nördlichen Mittelmeerraumes ein.

4.4. Die vergletscherten Gebirge der Iberischen

Halbinsel (Höhen der regionalen Schneegrenzen)

\begin{tabular}{|c|c|c|c|c|c|}
\hline Vergletscherte Gebirge & Höhe $\mathrm{m}$ & $\begin{array}{l}\text { Schneeg } \\
\text { Würm }\end{array}$ & $\begin{array}{l}\text { enzen } \\
\text { Rezent }\end{array}$ & $\begin{array}{l}\text { Obere } \\
\text { Wald- } \\
\text { grenze }\end{array}$ & Literatur \\
\hline 1. Sierra Nevada & 3478 & 2500 & 3350 & $\begin{array}{l}2100- \\
2300\end{array}$ & $\begin{array}{l}\text { Obermaier } 1916 \\
\text { Obermaier 1921, Sermet 1942, } \\
\text { Garcia Sainz 1943, Paschinger } \\
1954\end{array}$ \\
\hline & & 2350 & 3650 & & Eigene Beobachtungen \\
\hline 2. Sierra Tejeda & $\begin{array}{l}2135 \\
2065\end{array}$ & $2000 ?$ & & & $\begin{array}{l}\text { Klebelsberg 1928, 1949, Sermet } \\
1934\end{array}$ \\
\hline 3. Sagra Sierra & 2381 & 2500 & & 2050 & Lautensach 1958 \\
\hline 4. Sierra da Estrela & 1991 & 1650 & 2750 & & Lautensach 1929, 1942 \\
\hline 5. Sierra de Gata & 2400 & 1700 & & & Klebelsberg 1949, Solé Sabaris \\
\hline 6. Sierra de Béjar (Calvitero) & 2404 & 1700 & & & 1952 (weitere Literatur zitiert) \\
\hline $\begin{array}{l}\text { 7. Sierra de Gredos } \\
\text { (Pico de Almanzor) }\end{array}$ & 2661 & $\begin{array}{l}1800- \\
1900\end{array}$ & & & $\begin{array}{l}\text { Obermaier 1916, 1932; Ober- } \\
\text { maier und Carandell 1917, Solé } \\
\text { Sabaris } 1952 \text {. }\end{array}$ \\
\hline 8. La Serrota & 2294 & 1900 & & & gleich wie Nr. 7 \\
\hline 9. S. de Guaderrama & 2430 & $\begin{array}{l}1900- \\
2100 \\
1900 \\
1950- \\
2000\end{array}$ & & $2150 ?$ & $\begin{array}{l}\text { Obermaier und Carandell 17, } \\
\text { Wernert } 1932 \text {. } \\
\text { Solé Sabaris } 1952 \\
\text { Fränzle } 1959\end{array}$ \\
\hline Somosierra & 2262 & 1900 & & & Fränzle 1959 \\
\hline Cuerda Larga & 2383 & $1900-$ & & & $\begin{array}{l}\text { Wernert } 1932 \text {, Obermaier und } \\
\text { Carandell } 1917\end{array}$ \\
\hline 10. Sierra de Moncayo & 2316 & 1950 & & & Carandell y Llarena 1922 , Ober- \\
\hline $\begin{array}{l}\text { 11. Sierra de Urbion } \\
\text { Sierra de Neila } \\
\text { 12. Sierra de la Demanda }\end{array}$ & 2246 & $\begin{array}{l}2000 \\
2000 \\
1900\end{array}$ & & & $\begin{array}{l}\text { maier } 1932 \text {, Lopez y Riba } 1957 \text {, } \\
\text { Solé Sabaris } 1952 \text {, Lotze } 1962\end{array}$ \\
\hline $\begin{array}{l}\text { 12. Sierra de la Demanda } \\
\text { 13. Sierra Segundera (P. Trevin- } \\
\text { ca, el Teleno) }\end{array}$ & $\begin{array}{l}2305 \\
2188\end{array}$ & $1650-$ & & & Vosseler 1931 \\
\hline Peña Negra & 2112 & & & & \\
\hline 14. Cabeza (Sierra de Queija) & 1788 & & & & $\begin{array}{l}\text { Hermandez Pacheco } 1949 \text { (zit. } \\
\text { nach Lotze 1962) }\end{array}$ \\
\hline $\begin{array}{l}\text { 15. P. Pajaro (Sierra Caurel) } \\
\text { 16. S. de Ancares (Cuiña) }\end{array}$ & $\begin{array}{l}1624 \\
2004\end{array}$ & 1500 & & & $\mathrm{Nußb}$ \\
\hline 17. Peña Rubia, P. Ubiña & 2417 & 1500 & & & Nußbaum und Gygax 1953 \\
\hline 18. Peñas Faro, Mampadre & & 1600 & & & Nußbaum und Gygax 1953 \\
\hline 19. Picos de Europa & 2665 & $\begin{array}{l}1400- \\
1500\end{array}$ & & & $\begin{array}{l}\text { Obermaier } 1914,1921 \text {; Nuß- } \\
\text { baum und Gygax } 1953\end{array}$ \\
\hline 20. Gebirge von Reinosa & 2140 & 1700 & & & $\begin{array}{l}\text { Hernandez-Pacheco 1944, Lot- } \\
\text { ze } 1962\end{array}$ \\
\hline $\begin{array}{l}\text { 21. Valnera } \\
\text { 22. S. de Aralar }\end{array}$ & $\begin{array}{l}1707 \\
1427\end{array}$ & $\begin{array}{l}1350 \\
1050 ?\end{array}$ & 240 & $1500 ?$ & $\begin{array}{l}\text { Lotze } 1962 \\
\text { Kopp } 1963\end{array}$ \\
\hline 23. Pic d'Anie & 2504 & $\begin{array}{l}1700- \\
1800\end{array}$ & $\begin{array}{l}\text { unter } \\
3000\end{array}$ & 2200 & $\begin{array}{l}\text { Nußbaum 1928, 1930, } 1936 \\
\text { Obermaier } 1921\end{array}$ \\
\hline 24. Mt. Perdu & 3352 & & & & Plandé 1939 \\
\hline Rezente Gletscher (Fig. 16): & & & $\begin{array}{l}\text { über } \\
3000\end{array}$ & & $\begin{array}{l}\text { Garcia Sainz } 1940 \\
\text { Klebelsberg } 1949\end{array}$ \\
\hline $\begin{array}{l}\text { a) Gruppe Balaitous } \\
\text { (Glaciers de la Néous) }\end{array}$ & 3145 & & & & $\begin{array}{l}\text { Alimen } 1950 \\
\text { Solé Sabaris } 1952\end{array}$ \\
\hline b) Gruppe Vignemale & 3298 & & & & Nußbaum und Gygax 1953 \\
\hline
\end{tabular}


(Glacier d'Ossoue, Oulettes de

Gaube)

c) Gruppe Mt. Perdu-Gavar- 3352

nie-Néouville

d) Gruppe Posets-Luchonnais

(Seil de la Baque)

25. Pic d'Aneto (Maladetta) 3404

Rezente Gletscher (Fig. 16)

26. Puigmal und Canigou

2909

2200

27. Sierra de Cadi

$2638 \quad 2100$

grenze

Taillefer 1958

Woldstedt 1958

\section{Die Schneegrenzen in Nordafrika}

\subsection{Die würmeiszeitliche Schneegrenze (Karte 1)}

- Hoher Atlas: Im Toubkal haben Dresch, Mensching und Awad die würmeiszeitliche Schneegrenze festgelegt $(68,200,7)$. Dresch auf $3600-3700 \mathrm{~m}$, Mensching auf 3400-3500 m und Awad sogar unter $3300 \mathrm{~m}$. Im Massiv des M'Goun beträgt sie 3500 $3600 \mathrm{~m}(354,201)$ und sinkt dann gegen die Höhen des Ayachi auf 3300-3200 m ab. Lage, Küstenabstand und orographische Verhältnisse sind für diese Schwankungen der Schneegrenzfläche verantwortlich (201). Erstaunlich ist aber, daß im Toubkal keine eindeutigen Moränen gefunden wurden und die Schneegrenze bloß nach der Höhenlage von Karund Nivationsformen bestimmt wurde (200, S. 23), währenddem im M'Goun sichere Moränensysteme zur Verfügung standen $(354,201,202)$. Einzig Heybrock vertritt die Auffassung, daß echte Moränen auf der N-Seite des Toubkal (Mizane-Tal in 2800_ $3000 \mathrm{~m}$ Höhe enden (130). Interessant, aber blo $\beta$ hypothetisch ist die Aussage Embergers, daß die Schneegrenze nach Westen absinkt und über den letzten Gebirgsausläufern 2900 m betragen soll (74, zit. nach 200).

\section{- Mittlerer Atlas:}

Eindeutige Glazialformen sind vorhanden, die Schneegrenze von 2900-3000 m kann als gut gesichert gelten.

\section{- Rif:}

Hier müssen wir die Schneegrenze von $2300 \mathrm{~m}$ nach den Beschreibungen Menschings (1955) in Frage stellen (201). An den höchsten Erhebungen (2456 m) wurden keine eindeutigen Glazialformen beobachtet, unter Vorbehalt dienen firnmuldenähnliche Erscheinungen in Südexpositionen als Grundlage der Schneegrenzbestimmung. 1960 erhalten wir von Mensching folgenden Bericht: «Eine Vergletsche- rung der Tidirhin-Kette $(2450 \mathrm{~m})$ mit Moränenbildung ist nicht festzustellen, und alle vorhandenen Formen (Terrassen, glacier rocheux) lassen sich unter solifluidal-fluviatilen Bildungsbedingungen entstanden erklären. Große Hangnischen treten im westlichen Rif häufig auf, und für ihre Entstehung als «niche de nivation» dürften wohl kaum Beweise vorliegen, zumal ihre Entstehung als Quellnischen sicher erscheint (Quellhorizont in tonig-mergeligem Gestein)»(202, S. 168). Mit dieser Formulierung ist der Hinweis auf eine bedeutend höhere Schneegrenze gegeben. Im übrigen würde eine Schneegrenze von $2300 \mathrm{~m}$ nur sehr schlecht in ein Querprofil Sierra Nevada - Hoher Atlas hineinpassen. Die regionale Schneegrenze liegt in der Sierra Nevada auf 2350 m (204), im Mittleren Atlas auf 2900-3000 m. Warum sollte die Schneegrenze im Rif niedriger sein als in der Sierra Nevada? Im übrigen zeigt der Rif mit seiner Lage ganz ähnliche klimatische Verhältnisse wie die Sierra Nevada, abgesehen von der um ca. $2^{\circ}$ südlicheren Breite. Nehmen wir einen Schneegrenzanstieg von $100-200 \mathrm{~m}$ an, so dürften wir uns in der richtigen Größenordnung bewegen. Das heißt: Die Schneegrenzfläche wölbt sich im Rif knapp über die Gipfelhöhen hinweg, vereinzelte $\mathrm{Ni}$ vationsformen in Gunstlage wären denkbar (Fig. 17).

Algerien:

Mit den Untersuchungsergebnissen in Kabylien (Djurdjura 2308 ) von Barbier, Cailleux und Büdel $(10,34,40)$ ergeben sich äußerst interessante Aspekte für den Sohneegrenzverlauf im westlichen Mittelmeerraum. Barbier-Cailleux ermittelten die Schneegrenze auf 1900 m; Büdel hat bei einem späteren Kontrollgang die regionale Schneegrenze auf $2100 \mathrm{~m}$, vielleicht sagar etwas darüber, festgelegt. (Nach einer freundlichen schriftlichen Mitteilung vom 8.6.66.) Erstaunlich sind aber die niedrigen 
Fig. 17 Schneegrenzen und Waldgrenzen im westlichen Mittelmeerraum. Das Profil ist zwischen Mittlerem und Hohem Atlas um $400 \mathrm{~km}$ nach WSW versetzt.

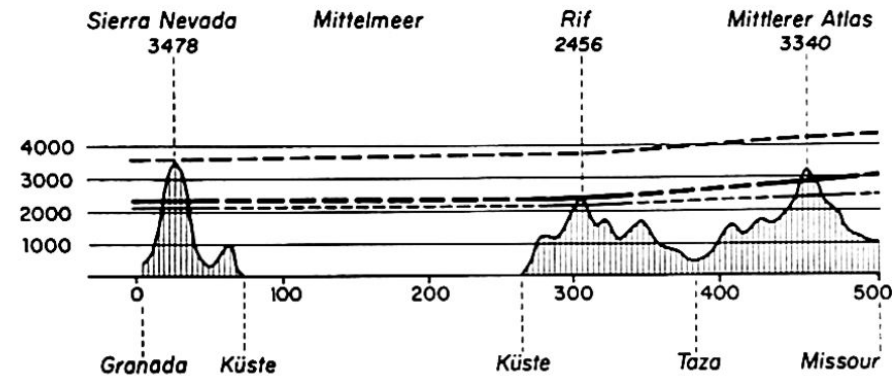

340

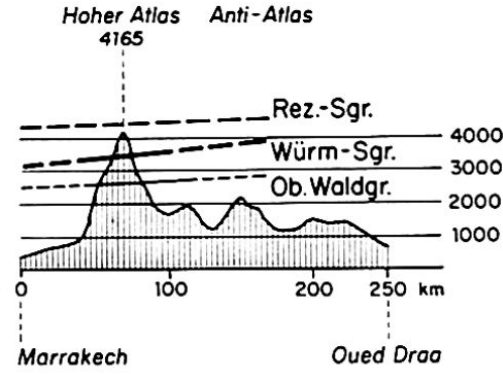

Höhenlagen der nordseitigen Endmoränen, währenddem die Südseite unvergletschert blieb. Barbier-Cailleux geben 1270 und $750 \mathrm{~m}$ an, Büdel bezeichnet drei größere Gletscherenden bei 1600, 1200 und $1000 \mathrm{~m}$. Auf die bedeutende Expositionsdifferenz werden wir auf Seite 188 zurückkommen. Übernehmen wir den regionalen Schneegrenzwert von $2100 \mathrm{~m}$, so ist er immer noch bedeutend niedriger als im Rif. Diese Differenz ist aber durch orographische und klimatische Tatsachen ohne weiteres $\mathrm{zu}$ erklären. Zum ersten stehen die algerischen Küstenketten nach Westen offen (Unterschied zum Rif und zur Sierra Nevada), und die strahlungsgeschützte Nordseite ist durch den maritimen Einfluß zugleich temperatur- und niederschlagsmäßig begünstigt. Zum zweiten liegt die Djurdjura bedeutend nördlicher als der Rif, ungefähr auf der Breite der umstrittenen Sierra Tejeda in Andalusien, die in ähnlicher orographischer und klimatischer Stellung mit einer Gipfelhöhe von $2135 \mathrm{~m}$ die Schneegrenzfläche ganz knapp oder gerade nicht mehr erreicht, das heißt, die beiden Gebirge sind durch ein gleiches Schneegrenzpaar zu verbinden (Karte 1). Zum dritten aber wird die Zyklonenstraße Gibraltar durch die Depressionen Biskaya - Südfrankreich - westlicher Mittelmeerraum verstärkt (34), was sich in den Kaltzeiten noch intensiver auswirken mußte. Alle diese Überlegungen können uns den Einbruch der niedrigen Schneegrenzflächen in die algerischen Küstenketten zwangslos erklären und den Unterschied zu den westlicheren Hochgebirgen ohne weiteres verstehen lassen.

\section{Tunesien:}

In einer neueren Arbeit (119) werden kaltzeitlich kryonivale Formen oberhalb $600 \mathrm{~m}$ nachgewiesen, zum Teil sogar bis auf Meereshöhe (Djebel er Rarauf südöstlich Tunis). Glazialspuren fehlen selbstverständlich auch in den höchsten Gipfelregionen (Djebel Chambi $1544 \mathrm{~m}$ ).

\subsection{Die rezente Schneegrenze (Karte 2)}

Sämtliche bisher bekannten Schneegrenzwerte sind in Ermangelung von aktuellen Gletschern von einer
Arbeit zur andern übernommen und angeglichen worden. Die Hauptstütze dieses Schneegrenzsystems bildet wohl der Wert 4200 m für den Hohen Atlas, den Dresch und Mensching entsprechend der $0^{\circ}$. Jahresisotherme festgelegt haben (200). Eine eigene Begehung des Hohen Atlas (Gipfelbesteigung des Toubkal $4165 \mathrm{~m}$ am 19.10.64) hat uns aber deutlich gezeigt, da $ß$ nur einige wenige und unbedeutende Schneeflecken überdauern. Zudem handelt es sich nicht einmal um Eisreste in günstiger Wandfußlage, sondern um verfirnten Altschnee in Lawinenrunsen. Diese Beobachtung wird auch von Dresch bestätigt, der feststellt, daß in einem Couloir in der Nordwand des Tazarharht (westlich der Ouanoukrim-Kette) ein Streifen Schnee und Eis nie ganz verschwindet. Es ist also von keinem Gletscherfleck die Rede, obwohl für solche Vorkommen morphologische Gunstlagen zwischen 3500 und $4000 \mathrm{~m}$ vorhanden wären. Daraus erkennen wir im Vergleich mit andern Gebirgen des mediterranen Raumes (Erciyas Dagh, Taurus, Libanon, Sierra Nevada) deutlich, daß die rezente Schneegrenze niemals auf Gipfelhöhe, sondern bedeutend höher liegen muß.

Im weiteren sind wir mit der bisherigen klimatischen Beurteilung des Hohen Atlas nicht einverstanden. Die Annahme Embergers, daß eine maximale Niederschlagszone von 500_600 mm zwischen ca. 1500 und $2800 \mathrm{~m}$ liegt, (200, S. 75) wird durch neuere Messungen mit Jahrestotalisatoren eindeutig widerlegt (210).

Die Niederschlagsmessung auf dem Toubkal-Gipfel kann keinesfalls stimmen. Der Pluviometer steht auf dem höchsten Punkt, und in dieser extrem windexponierten Lage ist das Resultat sehr wahrscheinlich negativ verfälscht. Bedenken wir ferner, daß der größte Teil des Niederschlages in fester Form fällt, so muß der Meßfehler ganz bedeutend sein. Aber selbst ohne Korrekturen sind die Niederschlagsmengen auf 4165 und $3200 \mathrm{~m}$ Höhe erstaunlich groß, was für die Schneegrenzbestimmung von höchster Bedeutung ist. Daß die Niederschläge auf der Südseite sehr rasch abnehmen, ist eine natürliche Erscheinung. Ihnen entspricht der morphologische Formenwandel. 
Station (210)

Nordseite Toubkal

Neltner (Rufuge)

1900

$31^{\circ} 07^{\prime}$

Toubkal (Gipfel)

3200

$31^{\circ} 03^{\prime}$

$31^{\circ} 03^{\prime}$

Südseite Toubkal

Azib Bou Izri

2800

Imhilene

2200

1800

Imlil

1500
Mittel der Jahre

Niederschlagsmenge

$1949 / 50-63 / 64$

$1949 / 50-63 / 64$

$1949 / 50-63 / 64$

$514,6 \mathrm{~mm}$

$837,3 \mathrm{~mm}$

$636,5 \mathrm{~mm}$ nur 5 Jahre

nur $8 \mathrm{Jahre}$

1952/53-60/61

1952/53-60/61

$554,0 \mathrm{~mm}$

$373,6 \mathrm{~mm}$

$304,9 \mathrm{~mm}$

$31^{\circ} 00^{\prime}$

$30^{\circ} 53^{\prime}$
Vergleichen wir dieses Ergebnis mit dem Erciyas Dagh und der Sierra Nevada (Meßfehler nicht korrigiert):

Höhe 2000 m, Nordseite: Höhe 2000 m, Nordseite: Höhe 2000 m, Nordseite:

Hoher Atlas Erciyas Dagh Sierra Nevada
Rez. Schneegrenze
ca. $520 \mathrm{~mm}$
ca. $850 \mathrm{~mm}$
ca. $1000 \mathrm{~mm}$

$\min .4500 \mathrm{~m}$

ca. $4000 \mathrm{~m}$

ca. $3650 \mathrm{~m}$
Die Beziehungen zwischen Niederschlagsmengen und rezenten Schneegrenzen zeigen interessante Zusammenhänge. Wie weit die Höhenlage der positiven Sommerisothermen mit dieser Niederschlagsstufung übereinstimmt, können wir noch zu wenig genau beurteilen.

Der Temperaturverlauf wird nach Mensching und Dresch durch die $0^{\circ}$-Jahresisotherme in ca. $4200 \mathrm{~m}$ charakterisiert (200, S. 74). Mit Vorbehalt setzt Mensching die rezente Schneegrenze diesem Höhenwert gleich, bemerkt aber ganz richtig, daß aerologische Messungen eher ein niedrigeres $0^{\circ}$-Jahresmittel anzeigen (über Casablanca ca. $3630 \mathrm{~m} ; 200$, S. 74), und daß Beobachtungen in der Gipfelregion auf eine höhere rezente Schneegrenze hinweisen. Daraus folgert Mensching, daß wir im Hohen Atlas nicht mit positiven Temperaturen an der Schneegrenze rechnen können. Diese Aussage ist aber ebenso unrichtig wie die Annahme, daß die Niederschläge von der humiden Steineichenzone bis zum Gipfel ständig abnehmen. Wir dürfen den Hohen Atlas keinesfalls in den C-Bereich Seifferts einordnen (313), das heißt: Die Niederschläge des Hohen Atlas sind nicht so gering, daß auf der Schneegrenzhöhe die Temperatur der wärmsten Monate unter $0^{\circ} \mathrm{C}$ bleibt (vgl. Seiffert, Beispiel: El Misti). Die Messungen Wiches auf dem Gipfel des M'Goun $4070 \mathrm{~m}$ zeigen die hohen Sommertemperaturen deutlich an $(354$, S. 8). Wir können sie auch mit einem großen Temperatur- gradienten bis zur mutmaßlich hohen Schneegrenze nicht auf Negativwerte reduzieren. Im Hohen Atlas spielen die Sommertemperaturen für die Ablation und die Fixierung der Schneegrenze eine bedeutende Rolle (vgl. Seiffert, Bereich B, Beispiel Pikes Peak), das heißt: Die Sommertemperatur und nicht die Jahrestemperatur wird an der Schneegrenze noch über $0^{\circ}$ sein. Damit sind auch die Komplikationen in den Ergebnissen Menschings gelöst: Die Schneegrenze muß bedeutend über der Gipfelhöhe liegen, und die $0^{\circ}$-Jahresisotherme kann das Gebirge ohne weiteres unterhalb $4200 \mathrm{~m}$ schneiden. $4500 \mathrm{~m}$ scheint uns ein absoluter Mindestwert für die Lage der rezenten Schneegrenze zu sein, nur in dieser Höhenstufung finden die heutigen perennierenden Schneeflecken und die klimatischen Verhältnisse eine sinnvolle Interpretation.

Nach diesem Ergebnis muß auch die von Mensching geschätzte Schneegrenze von $3300 \mathrm{~m}$ im Rif in Frage gestellt werden (201). Es ist ja ohnehin ganz unmöglich, daß die Schneegrenze von der Sierra Nevada auf $3650 \mathrm{~m}$ zum Rif hin absinkt, höohstens könnten wir auf Grund der ähnlichen klimatischen Lage auf eine gleichbleibende oder nur unbedeutend ansteigende Schneegrenze sohließen, was durch die ausgeglichene obere Waldgrenze von ca. $2200 \mathrm{~m}$ bestätigt wird (Fig. 17).

Diese neuen Werte sind bei der Festlegung der rezenten Schneegrenze im Mittleren Atlas künftighin 
zu berücksichtigen. Dagegen erachten wir die Schätzung Büdels in Kabylien ( $3300 \mathrm{~m}$ ) als sehr passend, da sich dieser Wert in Ubereinstimmung mit der eiszeitlichen Schneegrenze vom Rif und von der Sierra Nevada gleichsinnig unterscheidet.

\subsection{Die Schneegrenzdepression (Fig. 17)}

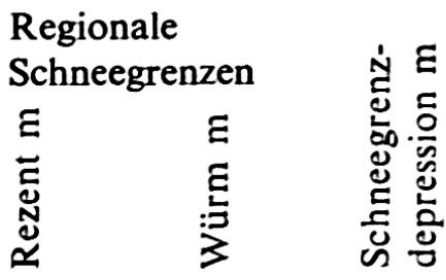
Sierra Nevada
ca. 3650
2350
ca. 1300
Rif
ca. 3700
ca. 2500
ca. 1200
Hoher Atlas
$\min .4500$
ca. $3450 \min .1050$
Djurdjura, Kabylien ca. 3300
2100 ca. 1200

Die aufgeführten Schneegrenzdepressionen sind insofern fragwürdige Werte, als zu ihrer Bestimmung nur geschätzte oder klimatisch unsicher ermittelte rezente Schneegrenzen zur Verfügung stehen. Eine Tatsache aber tritt deutlich heraus: Die eiszeitliche Schneegrenze steigt von der Sierra Nevada zum Hohen Atlas rascher an als die rezente, oder anders gesagt, die Sohneegrenzdepression nimmt von der Sierra Nevada zum Hohen Atlas ab. Würden wir nach Dresch und Mensching eine rezente Schneegrenze von $4200 \mathrm{~m}$ annehmen, so wäre die Verminderung von $\mathrm{N}$ nach $\mathrm{S}$ noch viel ausgeprägter. Die Frage ist gestellt, wie sich die Schneegrenzen im einsetzenden Trockengürtel verhalten. Dieses Problem haben wir an anderer Stelle diskutiert (206). Im Zusammenhang damit wollen wir zwei Folgerungen festhalten:

1. Die Schneegrenzdepression beträgt auch im relativ trockenen Bereich des Hohen Atlas noch mehr als $1000 \mathrm{~m} \mathrm{(vgl.} 359$ und 206).

2. Die genauen Depressionsbeträge sind sehr schwer zu ermitteln. Aber ganz eindeutig zeigt sich ein knickartiges Ansteigen der eiszeitlichen Schneegrenzen von der Sierra Nevada zum Hohen Atlas, genauer noch zwischen Rif und Hohem Atlas (Karte 1). In dieser Erscheinung kommt ein rascher Klimawandel unmittelbar südlich des Mittelmeeres zum Ausdruck.

\subsection{Die vergletscherten Gebirge Nordafrikas}

(Höhen der regionalen Schneegrenzen)

Vergletscherte Gebirge

Hoher Atlas

1. Toubkal

4165

3400
3500

4200

4500

2. M'Goun, Dj. Ouaougoulzat.

3. Ayachi

$\begin{array}{ll}4070 & 3500 \\ & 3600 \\ 3751 & 3200 \\ & 3300\end{array}$

\section{Mittlerer Atlas}

4. Dj. Naceur, Bou Jblane

3340

2900 3000

3600 3700 ?

2400

2600 2700

Dresch 1941 und 1949, Klebelsberg 1949, Mensching 1953 und 1955, Heybrock 1953, Awad 1963

Eigene Beobachtungen Mensching 1955

$3100 \quad$ Wiche 1953

Mensching 1955, Klebelsberg 1949

Dresch und Raynal 1953, Mensching 1955

Rif

5. Tidiguin (Tidirhin)

2453

$2300 ?$

2500

3300 ?

3700

2200

Mensching 1955 und 1960

Nach eigener Schätzung

\section{Tell-Atlas}

6.Djurdjura (Kabylien)

3300

2150

2100
Barbier et Cailleux 1950, Büdel 1952

Büdel 1966 schriftl. Mitt.
7. Chaîne de Babor 


\section{Die Schneegrenzen im gesamten Mittelmeerraum}

Paschinger hat eine Schneegrenzkarte des gesamten Mittelmeerraumes entworfen (257), Büdel hat den westlichen Teil dargestellt (34), Louis hat den Balkan und Anatolien bearbeitet $(182,185)$; Brusch, Hermes und Frenzel bauten den Mittelmeerraum in ihre großräumigeren Betrachtungen ein $(32,126$, 99), Klebelsberg und Woldstedt lieferten unentbehrliches Grundlagenmaterial $(154,360)$.

\subsection{Der allgemeine Verlauf der würmeiszeitlichen Schneegrenzen (Karte 1, S. 164/165)}

Überblicken wir die Schneegrenzkarte des Mittelmeerraumes, so fallen uns vier verschiedene Richtungstendenzen auf.

a) Die West-Ost-Tendenz:

Die Schneegrenzen steigen entsprechend der zonalen Klimaänderung von Norden nach Süden an, die Schneegrenzlinien tendieren in die W-E-Richtung. Uber dem Festland zeigt sich dieses Verhalten, wenn ein unbedeutendes Relief kein bestimmtes Lokalklima auszuprägen vermag. (SW-Spanien, ein Teil Südosteuropas, Libyen und Aegypten usw.) Diese Richtung wird geradezu erzwungen und die Schneegrenzlinien geschart, wenn ein bedeutender Gebirgszug W_E angeordnet ist (Atlas, Pyrenäen, Pontus usw.).

\section{b) Die Nord-Süd-Tendenz:}

Der Schneegrenzverlauf paßt sich den Landmassen und Gebirgssystemen an, die quer oder irgendwie schräg zum dominierenden Zirkulationssystem stehen. Die Westseiten sind nicht nur feuchter, sondern auch milder, besonders in den für die Ablation wichtigen Sommermonaten. Die Ostseiten sind nicht nur trockener, sondern auch sommerlich überhitzter, was die Schneegrenzen zum Ansteigen zwingt. Die Meer-Land-Verteilung und die Anordnung der Gebirgszüge prägt das unruhige Auf und $\mathrm{Ab}$ der Schneegrenzlinien in unserem Kartenbild (Spanien, Korsika-Sardinien, Italien, Balkan, Westtürkei).

c) Die lokale Kulmination:

Ausgeprägt kontinentale Räume zeigen sich in einem ringsum geschlossenen Ansteigen der Schneegrenzen (SE-Spanien, Ostgriechenland, Anatolien). Günstigere Klimaprovinzen riegeln diese Bereiche $a b$ und zwingen uns zu einem lokalen Schließen der Isochionen. Zum Beispiel: Die Depressionenbahn Adana_Sivas trennt die Hochfläche Zentralanatoliens von Ostanatolien ab; die Zugstraßen Gibraltar und Biskaya-Mittelmeer begrenzen den südostspa- nischen Raum; die Vardar_Saloniki-Linie isoliert die thessalische Beckenzone.

\section{d) Die lokale Depression:}

Besondere orographische Anordnungen erzeugen lokalklimatische Gunstregionen, die zu einem geschlossenen Isochionenbild führen. Zum Beispiel: der ligurische Apennin bei Genua, die süddalmatinische Küste bei Kotor. In diesen Gebieten ist es vor allem die maritime Durchdringung mit außerordenlich hohen Niederschlagsmengen, welche die Schneegrenzen energisch hinunterdrücken. (Crkvice bei Kotor mit $4934 \mathrm{~mm}$ die niederschlagsreichste Station Europas.)

\subsection{Der allgemeine Verlauf der rezenten Schnee-} grenzen (Karte 2, S. 164/165)

Die rezenten Gletscherflecken des Mittelmeerraumes, meist in einseitiger und extremer Gunstlage, erlauben keinesfalls, eine Schneegrenzkarte mit dichtem Kurvenbild zu entwerfen. Die wenigen Punkte liefern höchstens streng lokale Schneegrenzen; die Berechnung der regionalen Werte nach Expositionsdifferenzen und morphologischen Verhältnissen, nach Temperatur- und Niederschlagsstufung ist und bleibt ein problematisches Unterfangen. Vielfach sind diese Angaben als Mindestwerte aufzufassen, das heißt, die regionale Schneegrenze liegt sicher nicht tiefer, kann aber nach oben nicht genau abgegrenzt werden (z. B. Libanon, Hoher Atlas usw.). Gesamthaft stellen wir fest, daß eine Fehlergrenze bis zu $100 \mathrm{~m}$ ohne weiteres möglich ist, bei Schneegrenzlagen weit über dem Gipfelniveau sogar bis zu $200 \mathrm{~m}$. Die rezenten und regionalen Schneegrenzwerte aus dem Mittelmeerraum, abgesehen vom Alpenrand, fassen wir nach eigenen Beobachtungen (ausg. Pyrenäen) folgendermaßen zusammen: Pyrenäen (Mt. Perdu-Vignemale) 3000 m, Sierra Nevada 3650 m, Hoher Atlas 4500 m, Gran Sasso $3100 \mathrm{~m}$, Taurus $3650 \mathrm{~m}$, Erciyas Dagh $4000 \mathrm{~m}$, Libanon $3700 \mathrm{~m}$. Diese wenigen Punkte bilden die Kartengrundlage (Karte 2). Die allzu großen Zwischenräume haben wir klimatisch interpretiert, auf die Methode kommen wir zurück (Seite 193).

Ưberblicken wir den gesamten Verlauf der rezenten Schneegrenzlinien, so ergibt sich ein ähnliches Bild wie bei der aussagekräftigeren Eiszeitkarte. Auf eine genauere Interpretation müssen wir verzichten, weil die einzelnen Punkte zu weit gestreut und ihre Aussagen mit einer zu großen Fehlermöglichkeit behaftet sind. 


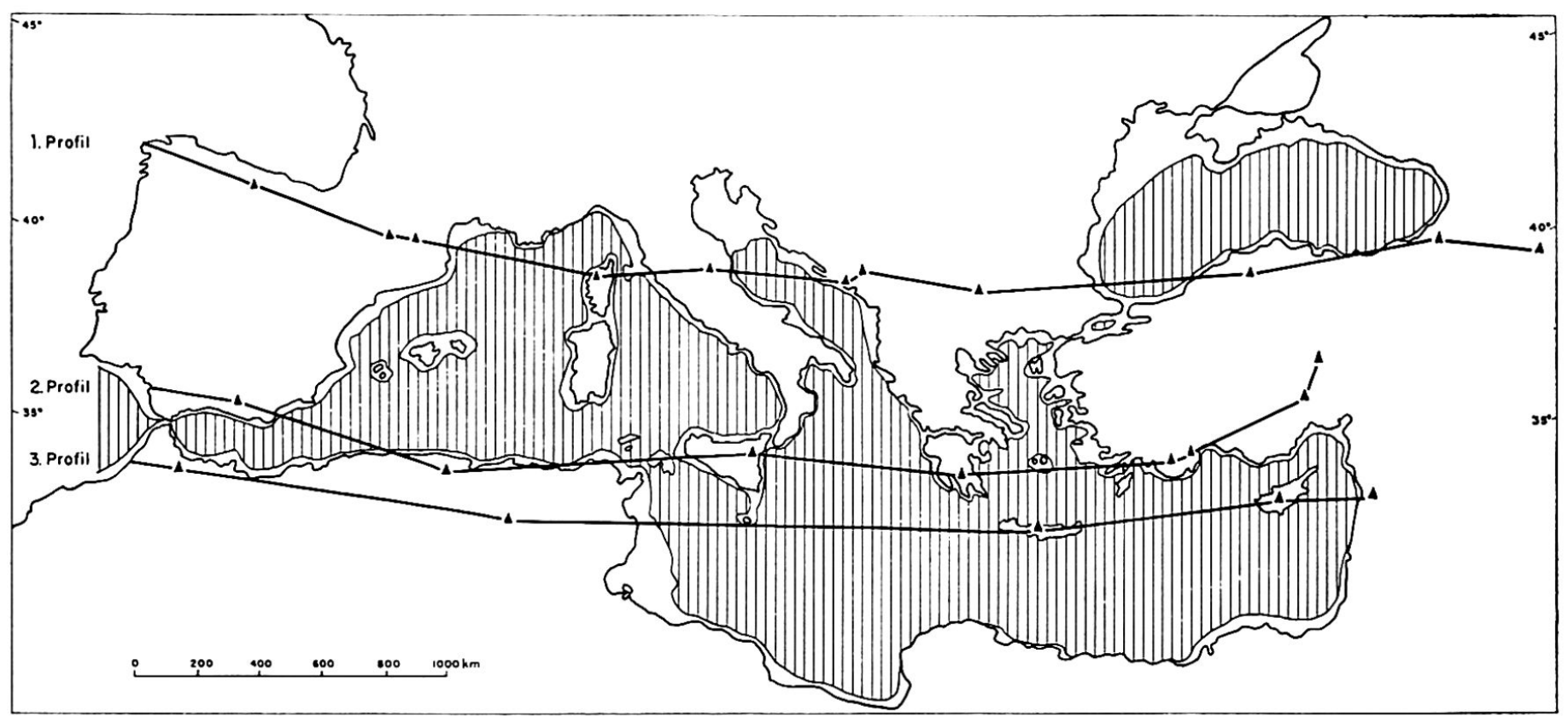

1. Profil: Zwischen $42^{\circ} 10^{\prime}$ und $43^{\circ} 10^{\prime}$ (ausgen. Kaçkar und Ararat südlicher)

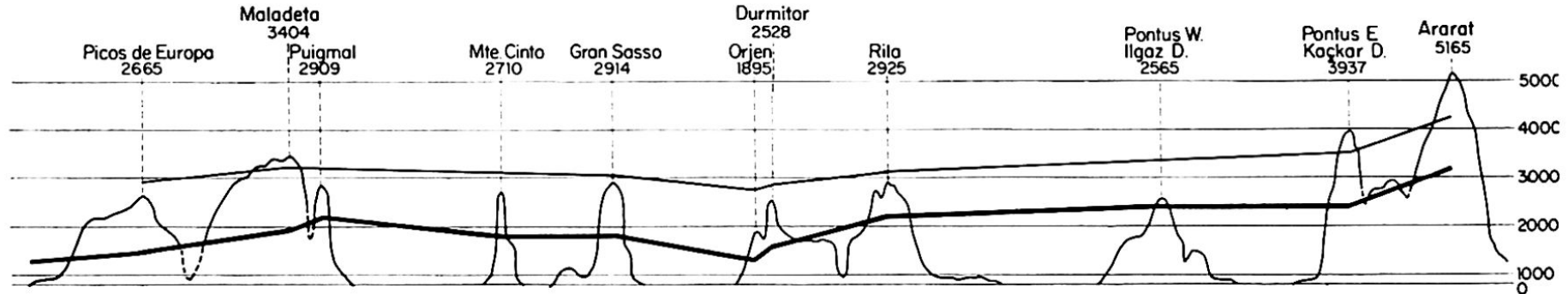

2. Profil: Zwischen $36^{\circ} 20^{\prime}$ und $37^{\circ} 45^{\prime}$ (ausgen. Erciyas nördlicher)
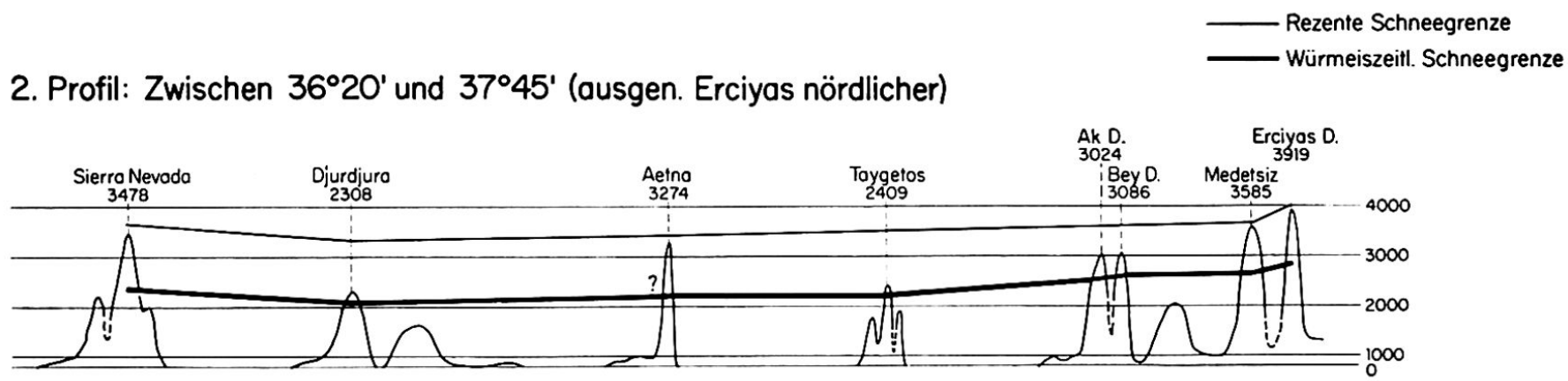

3. Profil: Zwischen $34^{\circ} 30^{\prime}$ und $35^{\circ} 30^{\prime}$

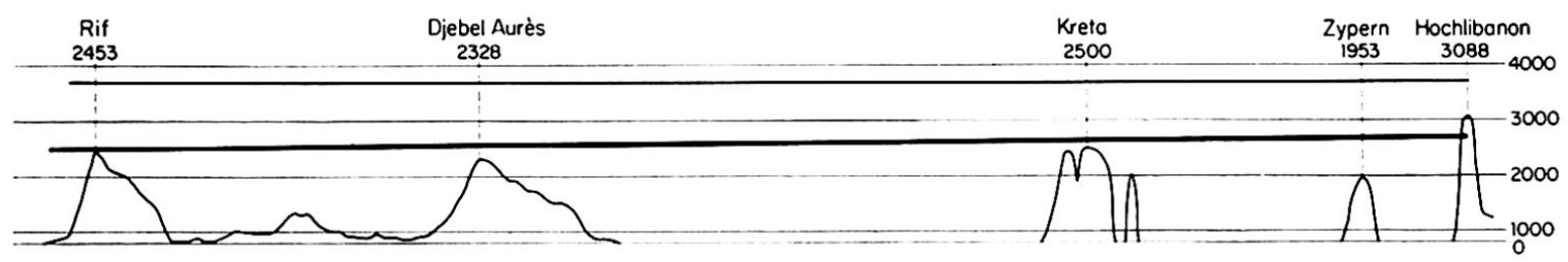

Fig. 18 Eiszeitliche und rezente Schneegrenzen im Mittelmeerraum (3 Profile). 


\subsection{Die Schneegrenzdepressionen (Fig. 18)}

Die Beziehung rezente-letzteiszeitliche Schneegrenze haben wir in drei Querprofilen durch den Mittelmeerraum in Fig. 18 zusammengefaßt:

1. Profil: Im nördlichen Mittelmeerraum (42-43을 n. Br.) zeigt die leblhafte Schwankung der eiszeitlichen Schneegrenze, daß sie mit ihrer niedrigen Lage über jeder Landmasse angeschnitten, lokalklimatisch beeinflußt und höhenmäßig bestimmt wird. Demgegenüber reagiert die rezente Schneegrenze viel schwächer, sie wirkt sich nur noch auf wenige Gebirge aus, und nur noch wenige Gebirge wirken sich auf sie aus. Die Differenzen zwischen den beiden Höhenlinien sind in den humiden Zonen größer als in den ariden; eine Erscheinung, die durch die kräftigere Reaktion der kaltzeitlichen Schneegrenzen bestimmt wird. (Vgl. Seite 206.)

2. Profil: Das mittlere Querprofil $\left(36-38^{\circ} \mathrm{n}\right.$. Br.) ist durch eine Höherrücken der Schneegrenzen gekennzeichnet. Der Verlauf wird ruhiger und ausgeglichener. Die Depressionen nehmen vom westlichen zum östlichen Mittelmeer ab.

3. Profil: Im südlichsten Mittelmeerraum erkennen wir nur noch einen schwachen Anstieg der eiszeitlichen Schneegrenze von West nach Ost. Ob die heutige Isochione genau parallel zu führen ist, kann in- folge ihrer Höhenlage an keinem einzigen Gletscher nachgeprüft werden. Der Übergang zum Trockengürtel zeichnet sich ab und wirft für den Höhenanstieg der Schneegrenzen neue Probleme auf.

Eine Karte der letzteiszeitlichen Schneegrenzdepressionen wagen wir auf Grund der wenigen Anhaltspunkte nicht zu zeichnen, wir beschränken uns auf die Darstellung des 1200-m-Wertes:

- Schneegrenzdepressionen von $1200 \mathrm{~m}$ und mehr sind durch folgende Punkte gegeben: Pyrenäen Sierra Nevada_Rif (?)_Djurdjura (?)_Gran Sasso_ Montenegro (Durmitor).

- Schneegrenzdepressionen von $1200 \mathrm{~m}$ und weniger sind durch folgende Punkte gegeben: Hoher Atlas_Olymp (?)_Rilagebirge_Anatolien_Taurus_Libanon.

Zusammengefaßt: Das östliche Mittelmeerbecken zeigt geringere, das westliche größere Schneegrenzdepressionen. Von $\mathrm{N}$ nach $\mathrm{S}$ nehmen die Schneegrenzdepressionen um 200-400 m ab, weil die eiszeitlichen Schneegrenzen im allgemeinen rascher ansteigen als die rezenten (Fig. 17). Diese Erscheinungen geben uns wesentliche Hinweise auf die kaltzeitlichen Klimaverhältnisse, die sich von $\mathrm{W}$ nach $\mathrm{E}$ und von $\mathrm{N}$ nach $\mathrm{S}$ etwas stärker veränderten als heute. Diese Differenzierung blieb aber so beschränkt, daß eine gewisse klimatische Einheitlichkeit des Mittelmeerraumes auch kaltzeitlich gewahrt blieb. 


\section{Die eiszeitliche Schneegrenze und ihre regionale Bestimmung}

\subsection{Die lokale Schneegrenze}

Die lokalen (realen, orographischen, topographischen) Schneegrenzen jedes Tales und jeder Exposition bilden die Grundlage jeglicher regionaler Schneegrenzbestimmung. Wir wollen an dieser Stelle nicht jede einzelne der unzähligen Bestimmungsmethoden diskutieren (vgl. 71, 90, 154, 360, 186, 359, 66, 176 usw.). Wir sind uns der Unsicherheiten und Ungenauigkeiten der verschiedenen Auffassungen wohl bewußt. Aber es wäre müssig, sie alle mit dem Hinweis abzulehnen, daß uns heute modernere und wissenschaftlich einwandfreiere Methoden zur Bestimmung einer Firnlinie oder Gleichgewichtslinie zur Verfügung stehen. Wir wollen ja eine eiszeitliche Schneegrenze bestimmen und zur rezenten in Vergleich setzen, folglich haben wir innerhalb eines unumgänglichen Fehlerbereiches mit einer Methode zu arbeiten, die den besonderen Verhältnissen unseres Untersuchungsraumes gerecht wird und die mit den wenigen rekonstruierbaren Angaben über einen eiszeitlichen Gletscher auskommt.

Die Gipfelmethode ergibt $\mathrm{zu}$ hohe Werte und ist im subtropischen Bereich nicht anwendbar, weil die kleinen und oftmals isolierten Gebirgsmassive durch sehr große Expositionsdifferenzen gekennzeichnet sind (vgl. 359, S. 52). Eine Festlegung allein mit der Karbodenhöhe scheint uns ungenügend, selbst wenn diese Methode von Demangeot in den Abruzzen verfeinert wurde $(66$, S. 265: Würmeiszeitliche Schneegrenze zwischen mittlerer und minimaler Karbodenhöhe). In vielen Gebirgen, die die eiszeitliche Schneegrenzfläche nur knapp überragten, wurde höchstens ein Karstockwerk ausgebildet oder wurden überhaupt keine richtigen Kare ausgeformt (z.B. Libanon und Hermon). Sämtliche Methoden, die sich an das Ausapern von Seiten- oder Mittelmoränen halten, scheinen uns mit wenigen Ausnahmen für die Bearbeitung eiszeitlicher Verhältnisse zu unsicher, weil sie durch Rückzugsstadien verwischt sind (298). Die Methode Kurowski wurde von zahlreiahen Autoren für die eiszeitliche Schneegrenzbestimmung verwendet, indem man die mittlere Höhe der Gletscheroberfläche rekonstruierte und an Stelle des unbestimmbaren Gletscheranfangs die mittlere Höhe der Firnumrahmung einsetzte. Damit näherte man sich sehr stark der Höferschen Auffassung, die wir selber am häufigsten verwendeten. Sie bestimmt die Schneegrenze aus dem arithmetischen Mittel zwischen der mittleren Höhe des Kammes, welcher das Nährgebiet des Gletschers begrenzt, und der Höhe des unteren Gletscherrandes (132). Für die kurzen Tal- oder Wandfußgletscher (in seltenen Ausnahmen Hang- und plateauartige Gletscher) des mediterranen Raumes schien uns diese Methode am besten geeignet, weil vielfach nur die Endlage und die Höhe des Einzugsgebietes als wirklich gesicherte Werte zur Verfügung standen. Vor allem aber wurden durch die Einbeziehung der Kammhöhen die allzu tiefen Werte Kurowskis vermieden (vgl. Brusch 1949, S. 12), besonders im mediterranen Gebiet, wo die begünstigte Wandfußlage auch in der kaltzeitlichen Vergletscherung eine große Rolle spielte (vgl. Lliboutry 1965, S. 444: Der von Dainelli korrigierte Kurowski nähert sich nach unserer Meinung sehr stark der Methode Höfers).

\subsection{Die Expositionsunterschiede (Fig. 19)}

In den großen Expositionsunterschieden der mediterranen Gebirgsvergletscherungen überlagern sich die Wirkungsanteile der Strahlung (Sonn- und Schattseite) und der Wind- und Niederschlagsrichtung (Luv- und Leeseite) je nach Lage, Höhe und Relief des Gebirges äußerst komplex. Im allgemeinen reagieren N-S gerichtete Gebirge im Westwindbereich lebhafter auf Luv- und Lee-Einfluß,W-E-gerichtete Gebirge eher auf Strahlungswirkung. Häufiger und interessanter sind die komplexen Erscheinungen, die wir stark vereinfacht folgendermaßen gliedern:

a) Kleine Expositionsdifferenzen: Die Sonnseite wird durch stärkere Windanwehungen ausgeglichen. Dieser Fall tritt häufig bei SW-NE-gerichteten Gebirgen ein. Zum Beispiel:

- Sierra Nevada WSW_ENE; starke Schneeanwehung auf südexponierten Kreten und Hängen. Lokale Schneegrenzdifferenzen zwischen $\mathrm{N}$ - und SSeiten gering (Fig. 19, vgl. 204).

- Libanon-Hermon SW_NE; Úberwehung der windexponierten, plateauartigen NW-Seite und Schneeanwehung in geschützter steiler SE-Auslage. Eiszeitliche Gipfelvergletscherung nur in dieser SE-Exposition (207).

b) Große Expositionsdifferenzen: Die Schattseite ist 


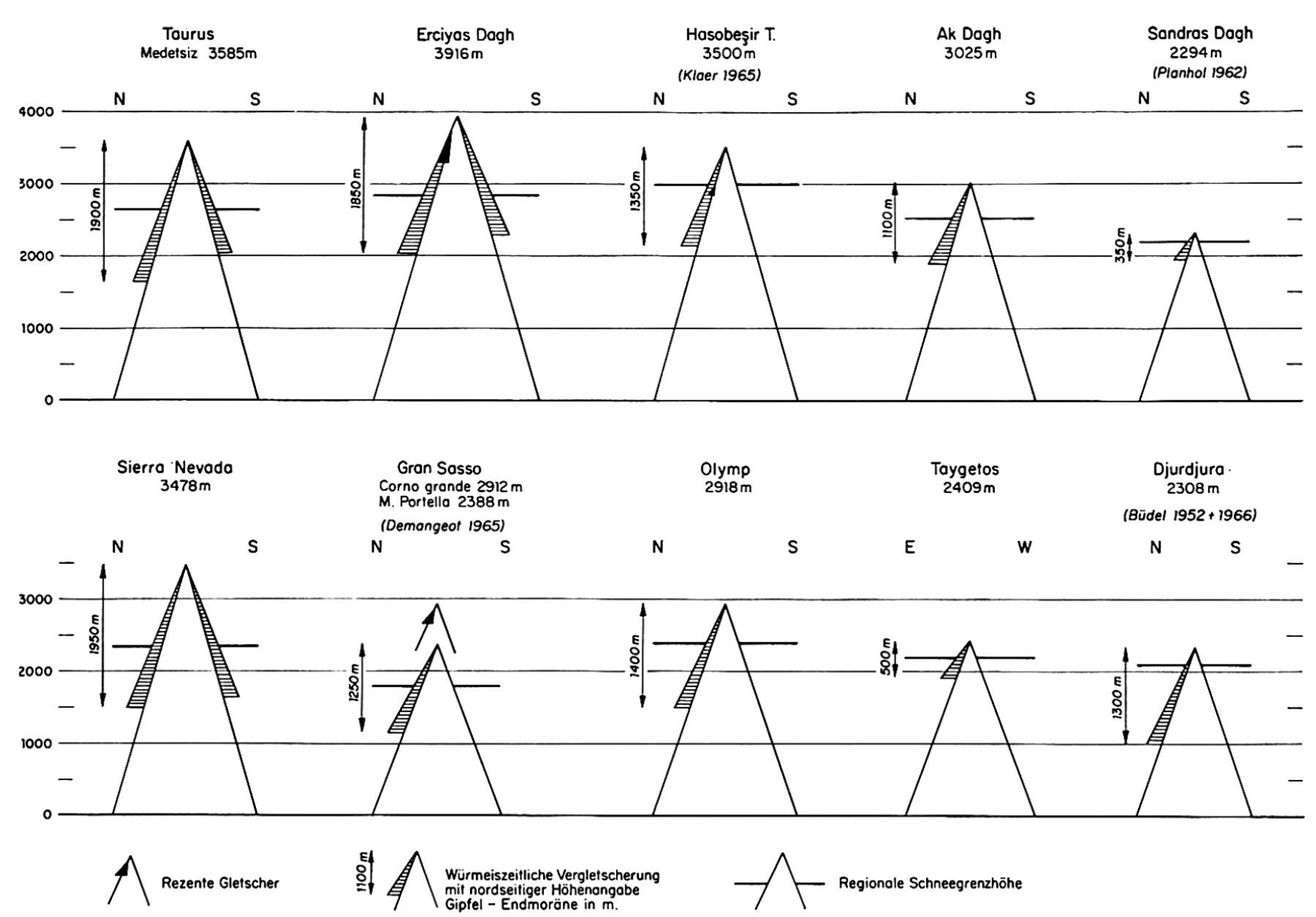

Fig. 19 Expositionsunterschiede in den mediterranen Gebirgsvergletscherungen.

zugleich Leelage. Dieser Fall tritt häufig bei NWSE-gerichteten Gebirgen ein. Zum Beispiel:

- Gran Sasso d'Italia WNW_ESE; die Südhänge sind zugleich Luvhänge mit starker Ausaperung und Verblasung durch W- bis SW-Winde. Winterlich trockener Schneefall aus N bis NE wird in S-Exposition rasch aufgezehrt.

- Ulu Dagh NW_SE; Schneeanwehung in der Leelage und Begünstigung durch die Schattenlage summieren sich zu einem extrem morphologischen Formengegensatz (Seite 152).

c) Große und kleine Expositionsdifferenzen werden durch angrenzende kontinentale oder maritime Klimaprovinzen verstärkt oder gemildert.

- Verstärkender Einfluß: Die Schattseiten werden durch maritime Luftmassen begünstigt und die Sonnseiten durch sommerheißes Kontinentalklima zusätzlich benachteiligt. Dadurch entstehen tiefreichende Nordvergletscherungen und völlig apere Südseiten am gleichen Gebirge. Beispiele: Der griechische Olymp und die algerische Djurdjura (Fig. 19).

- Mildernder Einfluß: Die Nordseiten grenzen an kontinentale Becken oder Hochflächen, währenddem die sommerliche Ablation der Südseiten durch maritime Luftmassen abgeschwächt wird. Beispiele: Sierra Nevada und Taurus (vgl. auch Ala Dagh, Spreitzer 1957; ferner Wißmann 1959, S. 53).

Die größten Expositionsdifferenzen sind offensichtlich Summationseffekte von Gunst- und Ungunstfaktoren. Wir haben aus dem mediterranen Raum einige der uns bekannten Extremfälle zusammengestellt: Gran Sasso, Djurdjura, Olymp, Ak Dagh usw. (Fig 19). Dabei zeigt sich folgendes:

a) Gemeinsames Merkmal

Große Gegensätze sind immer durch nordseitig vergletscherte und südseitig unvergletscherte Expositionen gekennzeichnet. In diesem Verhältnis zeigt sich die überragende Bedeutung des Faktors Strahlung auch in kaltzeitlichen Klimaverhältnissen.

b) Die Gebirge mit extremen Expositionsdifferenzen sind nach meinen bisherigen Kenntnissen an den zentralen und südlichen Teil des Mittelmeeres gebunden und treten am häufigsten zwischen dem 36. und 43. Breitenkreis auf. Weiter nach Süden wirkt der hohe sommerliche Sonnenstand ausgleichend, und weiter naclh Norden schwächt sich die sommerliche Bestrahlungsintensität und -dauer ab. (Extreme Expositionsdifferenzen fehlen in Gegen- 
den mit hohen Niederschlagsmengen, z. B. Dalmatinische Küste und Montenegro.)

c) Schließlich scheint die Aufragung des Gebirges über die Schneegrenzfläche eine bedeutende Rolle zu spielen. Fig. 19 zeigt, daß einseitige Vergletscherungen bis zu $1400 \mathrm{~m}$ unter den Gipfel hinabreichen können. Wird dieser Wert überschritten, setzt offensichtlich auch eine südseitige Vergletscherung ein. Vergleichen wir den Ak Dagh mit dem Taurus: Der Ak Dagh ist einseitig, der Taurus beidseitig vergletschert. Ihre klimatische Stellung ist ähnlich, aber ihre Expositionsdifferenzen sind völlig verschieden. Das zeigt uns folgendes:

- Die Sonnseite muß die regionale Schneegrenze um einige hundert Meter überragen, damit sich eine Vergletscherung festsetzen kann.

- Gebirge mit großer nivaler Stufe schicken ihre Gletscher aus den Gipfelkaren bis ins Vorland hinaus. Dort unterliegen sie auf wenig geneigten Flächen in ungeschützter Lage auf der Sonn-wie auf der Schattseite ganz ähnlichen Ablationsbedingungen. Die Höhen der Endmoränen und die lokalen Schneegrenzen gleichen sich aus.

In Gebirgen mit kleiner nivaler Stufe im Gipfelraum sind die Gletscher auf bestimmte Gunstlagen angewiesen. Die Versteilung der Gipfelwände führt zu einer Ausnutzung der Schattseite und Ausaperung der Sonnseite. Die lokalen Schneegrenzen werden differenzierter.

- Die Asymmetrie der Gebirgsvergletscherung ist nicht konstant, sie verschiebt sich mit auf- oder absteigender Schneegrenzfläche.

Genaue mikroklimatische Untersuchungen in jeder Exposition müßten in Zukunft durchgeführt werden, um das ganze Problem der Asymmetrie für Gletscher- und Hangbildung bei warm- und kaltzeitlichen Verhältnissen besser $\mathrm{zu}$ analysieren. Schließlich zeigt Fig. 19 die Problematik der regionalen Schneegrenzbestimmung. Wenn einseitige Gebirgsvergletscherungen Höhenbereiche van $1400 \mathrm{~m}$ überdecken, könnten die lokalen Schneegrenzdifferenzen nahezu $700 \mathrm{~m}$ ausmachen.

\subsection{Die regionale Schneegrenze}

Die Aussage Lliboutrys ist nicht richtig, daß eine topographische (lokale) Schneegrenze ein Gebirge und eine klimatische Schneegrenze eine größere Region repräsentiert (176, S. 438). Wir wollen gainz deutlich festhalten, daß wir die lokale Schneegrenze an einem Gletscher ermitteln (vgl. Wißmann S. 50) und daß die regionale (oder klimatische) Schneegrenze einen Mittelwent aus sonn- und schattseitigen, luv- und leeseitigen, lokalorographisch stark und schwach gegliederten Vorkommen am gleichen
Gebirgsmassiv darstellt (186 und 359). In diesem Sinn hat jedes Gebirge einen bestimmten Schneegrenzwert, anders gesagt, jedes Gebirge liefert eine bestimmte mittlere Höhenangabe für die regionale Schneegrenzfläche. Die entscheidende Frage ist aber, ob die Schneegrenzfläche im Raum ansteigt, abfällt oder horizontal verläuft.

Damit stehen wir wieder vor der Frage der Expositionsdifferenzen. Wißmann (359, S. 53) vermeidet eine Mittelbildung, wenn ein Gebirge oder ein Kamm eine ausgeprägte Klimascheide darstellt. Folgen wir dieser Anregung aber nicht, und legen wir bei einem Gebirge mit extremen Expositionsgegensätzen eine regionale Schneegrenze fest, so bedeutet diese Höhenangabe die mittlere Höhe der ansteigenden Schneegrenzfläche im Schnittpunkt mit dem Gebirge. Die tieferen Isochionen der ansteigenden Schneegrenzfläche werden durch das vorgelagerte klimatisoh günstigere Gebirge und die höheren Isochionen durch das nächstfolgende klimatisch ungünstigere Gebirge belegt. Die wichtigste Aufgabe besteht nun darin, die Klimascheide durch die Isochionenscharung richtig $\mathrm{zu}$ interpretieren. Wir fügen diese Idee der ausgezeichneten Formulierung Wißmanns bei, weil zahlreiche Gebirge im Mittelmeerraum bedeutende Expositionsdifferenzen aufweisen, ohne eigentliche Klimascheiden zu sein.

Welche Expositionsunterschiede treten normalerweise auf, und wie ist die regionale Schneegrenze zu ermitteln?

Der Erciyas Dagh zum Beispiel wird in sämtlichen Expositionen vom gleichen anatolischen Kontinentalklima beeinflußt. Die Differenz der lokalen Schneegrenzen zwischen $\mathrm{N}$ - und Südseite beträgt nur ca. $300 \mathrm{~m}$ und ist zum größten Teil auf die unterschiedliche Strahlungswirkung zurückzuführen. (Durch Schneeanwehung wird die N-bis E-Seite bevorzugt, was eher eine Verstärkung der Strahlungswirkung bedeutet.) Niemand würde bei der Betrachtung der Erciyas-Südflanke eine kaltzeitliche Vergletscherung erwarten, denn die morphologischen Verhältnisse sind denkbar ungünstig. Wenn sie sich zwischen periglazial überformten Hängen trotzdem entwickelt hat, so gibt uns das ungefähr ein $\mathrm{Ma}$ für die verminderte sonnseitige Vergletscherung in diesem Klimaraum. Aber eine Bedingung war erfüllt: Die regionale Schneegrenzfläche hat den Vulkankegel mehr als $1000 \mathrm{~m}$ unter dem Gipfelraum angeschnitten. Eine $500 \mathrm{~m}$ höhere Lage hätte der Südseite bereits eine sommerliche Ausaperung und damit eine erhöhte Asymmetrie der lokalen Schneegrenzen gebracht.

Im Taurus betragen die extremsten Höhendifferenzen zwischen den würmeiszeitlichen Endmoränen der N- und S-Seite ca. $350 \mathrm{~m}$ (Differenz der lokalen Schneegrenzen 200-250 m), am Ak Dagh in gleiaher Breite und ähnlicher Klimalage über 1000 m (Fig. 19). Wie haben wir diese unterschiedlichen 
Asymmetrien bei der Mittelbildung zu berücksichtigen?

- Lokale Schneegrenzdifferenzen von $300-400$ m in verschiedenen Expositionen des gleichen Gebirges kommen im Mittelmeerraum häufig vor und können in einem Mittelwert als regionale Schneegrenze zusammengefaßt werden.

- Einseitige Gebirgsvergletscherungen können Höhenbereiche bis $\mathrm{zu} 1400 \mathrm{~m}$ überdecken. In diesen Fällen lassen sich auf den Südseiten häufig Verfirnungen und Nivationsformen nachweisen (siehe Olymp und Ak Dagh). Obwahl diese Formen die Bedingungen einer Schneegrenze nicht erfüllen, zeigen sie doch an, daß die Schneegrenze nicht allzu hoch liegen konnte. Es ist sogar möglich, daß die ausgeglichenen Verwitterungshänge der Südseiten eine Vergletscherung verhinderten, obwohl die klimatischen Bedingungen einer Schneegrenze erfüllt waren (Problem der präwürm vorhandenen Formen).
- In jedem Fall ist abzuklären, ob Gebirge mit einseitigen Vergletscherungen und großen Expositionsdifferenzen eine Klimascheide bilden oder nicht. Im ersten Fall ist die Annahme eines Mittelwertes sehr fragwürdig, jedenfalls muß die Neigung der Schneegrenzfläche deutlich zum Ausdruck kommen. Im zweiten Fall ist die übermäßige Asymmetrie auf die zu kleine nivale Stufe zurückzuführen und für die Mitterbildung entsprechend zu reduzieren (Fig. 19). Mit diesen grundsätzlichen Überlegungen lassen sich die lokalen Schneegrenzen zu regionalen Werten verarbeiten. Zusammengefaßt geben sie einen guten Eindruck von der klimamorphologischen Höhenstufung des Mittelmeerraumes während der letzten Kaltzeit. Aber immer wollen wir uns klar sein, daß ein relativ großer Fehlerbereich durch die Mittelung der Expositionsdifferenzen und durch die teilweise allzu subjektive Beurteilung der Klimaverhältnisse (weil Höhenstafionen fehlen) in Rechnung zu stellen sind.

\section{Die rezente Schneegrenze und ihre klimatische Bestimmung}

\subsection{Die lokale Schneegrenze}

Die wenigen Gletscherflecken in einseitiger und besonderer Gunstlage weisen darauf hin, daß die rezente regionale Schneegrenze (mit Ausnahme der Pyrenäen) generell über dem Gipfelniveau der mediterranen Gebirge verläuft. Damit ist die gesamte Problematik der rezenten Schneegrenzbestimmung und -darstellung angetönt (Karte 2). Wir fassen sie in folgenden Punkten zusammen:

Gunstlage: Die meisten Firn- und Gletscherflecken des Mittelmeerraumes finden wir in nordexponierter Wandfußlage der höchsten Gipfel. Zum Beispiel: Sierra Nevada, Gran Sasso, Triglav, Erciyas Dagh, Medetsiz usw. Dadurch unterstehen sie besonderen lokalklimatischen Verhältnissen: Schutz vor allzu langdauernder und direkter Bestrahlung, Schneerutschen und Lawinen aus der Gipfelwand, Schneeanhäufungen durch Windverwehung usw. Alle diese Gunstfaktoren sind an einen eng begrenzten Raum gebunden, das heißt, der Gletscher existiert nur in dieser Begünstigungszone. Bei einem Höherrücken der Schneegrenze kann er nicht ausweichen, höchstens an der gleichen Stelle abschmelzen, und umgekehrt werden die bei einem Absinken der Schneegrenze über die Gunstlage hinausstoßenden Gletscherpartien von einer viel intensiveren Ablation erfaßt. Eine Verschiebung der Schneegrenze wird sich bei diesen Gletschern nicht primär in der Veränderung der Länge und der Zunge, sondern vielmehr in einer Abnahme oder Zunahme der Eismächtigkeit und des vergletscherten Areals zeigen. Zum Beispiel:

- Der Gletscher am Erciyas Dagh hat seit 1902 die gleiche Höhe der Endlage, woraus man nach den üblichen Methoden eine ständig gleichbleibende lokale Schneegrenze berechnen könnte. Daß dies nicht stimmt, zeigt der Arealverlust der vergletscherten Fläche um ca. $50 \%$ und die bedeutende Abnahme der Eismächtigkeit (203).

Nach den Beobachtungen Toninis am CalderoneGletscher des Gran Sasso (339, S. 98) nahm die größte Länge und Breite von 1934-60 nur ca. $10 \mathrm{~m}$ ab. Mächtigkeitsmessungen zeigten aber, daß die Oberfläche im Mittel jährlich 0,27 m abnimmt, was einem Kubaturverlust von $16000 \mathrm{~m}^{3} / \mathrm{Jahr}$ gleichkommt.

Akkumulation und Ablation: Die Ernährung dieser Gletscherflecken geht größtenteils direkt vor sich, meist ohne deutliche Ausbildung eines Firngebietes und eines Zungenbereiches: Schneeauflage durch Windtransport und Windanwehung, Schneerutsche und Lawinen aus den umliegenden Steilwänden. Diese Prozesse sind aber nicht an die klimatischen Bedingungen einer Schneegrenze gebunden, das heißt, der Schnee liegt nicht mehr im primären Ablagerungsbereich, sondern kann über eine Höhendifferenz von mehreren $100 \mathrm{~m}$ umgelagert sein. In dieser sekundären Lagerstätte muß eine gewöhnliche Schneegrenzberechnung fraglich werden. 
Klima und Eishaushalt: Von den mediterranen Gletscherflecken können bis heute nur wenige mit genauen klimatischen Höhenmessungen in Beziehung gebracht werden: Gran Sasso (339), teilweise die Pyrenäen (208), neuerdings der Triglav (318). Im übrigen sind Höhenstationen im Mittelmeerraum mit zuverlässigen und mehrjährigen Meßreihen sehr selten, obwohl sie für die Gletscherbeobachtungen von höchster Bedeutung wären. Wie Vanni in den Alpes maritimes nachgewiesen hat, reagieren die kleinen Gletscherflecken äußerst empfindlich auf die geringsten Klimaschwankungen (349). Kurze Phasen mit vorherrschenden Südwestwinden genügen, um die notwendigen Niederschläge in fester Form zu liefern. Noch genauer: Kleine Vorstoßphasen in den letzten Jahrzehnten haben sich zuerst und am deutlichsten in den kleinen und südlichsten Gletschern ausgewirkt (222).

\section{Zusammengefaßt:}

Es ist problematisch, an den wenigen Gletscherflekken eine lokale Schneegrenze zu bestimmen und es ist unmöglich, daraus eindeutige regionale Schneegrenzwerte abzuleiten. Diese Gletscherflecken geben uns Hinweise, aber keine Zahlenwerte für die Höhenlage der Schneegrenzfläche. Also mußten wir versuchen, die fehlenden Schneegrenzwerte durch eine klimatische Höhenbestimmung zu ersetzen. Die Notwendigkeit eines solchen Hilfsmittels wird noch deutlicher, wenn wir wiederum die großen Expositionsdifferenzen beachten, die kaum in einem Mittelwert zusammengefaßt werden können.

\subsection{Die Expositionsunterschiede}

Zusammengestellt einige Altschnee-, Firn- und Gletscherflecken aus dem Mittelmeerraum:

Sierra Nevada

Gran Sasso

Libanon

Erciyas Dagh

Taurus

Ak Dagh

Skuta (Steiner Alpen)

Triglav

\section{Höhe H 1 \\ Beschreibung}

$2900-3100$
$2680-2850$
3000

$3200-3700$
$2800-3200$
2800
1700
$2400-2550$

Firnfleck

Gletscher

Altschnee, Firn

Gletscher

Firn- und Eisflecken

Altschnee- u. Eisflecken 3500

Gletscherfleck

Gletscher
Höhe der reg.
Schneegrenze
H 2

$3650 \mathrm{~m}$

3100

3700

4000

3650

min. 2800

$\min .2900$

Differenz Literatur
H $2-$ H 1

$550-750 \mathrm{~m}$
$250-400 \mathrm{~m}$
$700 \mathrm{~m}$

Paschinger 1954

Messerli 1965

Tonini 1961

Klaer 1957

Kaiser 1963

Messerli 1966

$300-800 \mathrm{~m} \quad$ Messerli 1964

$450-850 \mathrm{~m}$

$750 \mathrm{~m}$

$1100 \mathrm{~m}$

$350-450 \mathrm{~m}$
Klebelsberg 1952

Sifrer 1963
Aus dieser Statistik geht deutlich hervor, daß Gletscherflecken bis zu $1000 \mathrm{~m}$ unter einem regionalen Schneegrenzniveau entstehen und existieren können. Wenn wir nun bei den häufig auftretenden Differenzen von 400-800 m bedenken, daß sonnseitige Gletscher erst weit über der Schneegrenzfläche einsetzen, dann stehen wir wiederum vor dem Problem der einseitigen Gebirgsvergletscherungen bis $\mathrm{zu}$ $1400 \mathrm{~m}$, wie es bei kaltzeitlich niedrigeren Schneegrenzen kartiert wurde. Die rezenten Erscheinungen ergänzen und beweisen die beschriebenen würmeiszeitlichen Verhältnisse.

Streiff-Becker (331, S. 109) erwähnt ähnliche Beispiele aus den Schweizer Alpen. Im hintern Durnagelthal (Kt. Glaurs) rutscht der Neuschnee in den Steilhängen des gewaltigen Felszirkus in Form von Lawinen vorweg ab und speist einen kleinen Glet- scher, dessen oberer Rand nur 2250 ü. M. liegt und dessen Zunge bis $1800 \mathrm{~m}$ hinabreicht. Wenn wir die Schneegrenze in diesem Gebiet auf ca. $2800 \mathrm{~m}$ schätzen, so ergeben sich ähnliche Differenzen wie im mediterranen Raum. Der kleine Regenerationsgletscher liegt 550-1000 m unter der rezenten regionalen Schneegrenze, seine Höhenlage ist für eine Schneegrenzbestimmung bedeutungslos.

Zusammengefaßt können die Asymmetrien in der rezenten Vergletscherung noch ausgeprägter sein als in der kaltzeitlichen.. Die Differenzen zwischen den verschiedenen Vergletscherungseposxitionen eines Gebirges vergrößerten sich mit dem Höhersteigen der Schneegrenze von der letzten Eiszeit bis zur Gegenwart (203, S. 27). Die vorhandenen Gletscherflecken in extremer Gunstlage sind vielfach nicht mehr direkte Zeugen einer regionalen Schneegrenze. 


\subsection{Die klimatische Bestimmung der Schneegrenze}

Die klimatische Schneegrenzberechnung ist ein Problem, das bis heute nicht eindeutig lösbar ist und es vielleicht nie sein wird. Klimamorphologische, glaziologische und klimatologische Untersuchungen haben dieses Problem berührt, wir können es nicht umfassend besprechen. Für uns stellte sich die Frage: Gibt es einzelne Klimaelemente, die für Gletscherhaushalt und Gletscherschwankung signifikant sind? Läßt sich die Schneegrenze an ein bestimmtes, leicht meßbares Klimaelement binden?

Im Massenhaushalt der Gletscher spielt die Strahlung eine ausschlaggebende Rolle. Da bis zu $80 \%$ der Ablation unserer Alpengletscher auf Strahlungswirkung zurückzuführen sind (133), im tropischen Hochgebirge des Mount Kenya sogar 89,5\% (285, gemessen in der Regenzeit 1960 am Lewis Glacier), werden die sommertrockenen subtropischen Gebirge Höchstwerte verzeichnen müssen. Zweifellos stehen Gletscherrückgänge und Höhenschwankungen der Schneegrenze mit strahlungsreicheren Sommermonaten in Beziehung (338). Strahlungsmessungen von Höhenstationen stehen uns aber im Mittelmeerraum kaum über längere Zeit zur Verfügung; und wie könnten sie schon für die Bestimmung einer Schneegrenze eingesetzt werden? Nach glaziologischen Untersuchungen in Axel Heiberg schlägt Müller vor, die Sonnenscheindauer als nützlichstes Element für den Gletscherhaushalt auszuwerten. Die zweitbeste Möglichkeit bieten die mittleren Sommertemperaturen, währenddem die Niederschläge eine geringere Rolle spielen (Müller 1963, S. 60, Tollner 1954, Seiffert 1950). Marcus hat in Alaska wesentliche Abhängigkeiten des Massenhaushaltes von den Temperatursummen der positiven Tagestemperaturen und der Gesamtniederschlagsmenge während der Akkumulationsperiode festgestellt (193).

Die glaziologisch und klimatologisch wertvollen Methoden konnten uns nicht dienen, weil die vorhandenen Gletscherflecken für die klimatischen Bedingungen einer Schneegrenze kaum repräsentativ sind, und weil die vorhandenen klimatischen Angaben höchstens Temperatur- und Niederschlagsmessungen umfassen. Also mußten wir die allereinfachste Beziehung zwischen Sommertemperatur oder Temperatur des wärmsten Monats und Schneegrenze suchen, wie es schon verschiedene Autoren getan haben (Ahlmann 1924, Seiffert 1950, Troll 1956 usw.). Dadurch wurden einige wesentliche Elemente nicht berücksichtigt, vor allem das Niederschlagsgeschehen. Wo zum Beispiel Sommerschnee fiel (kaltzeitlich) oder fällt (heute in Alpenrandlage), wird die Strahlungswirkung (größere Albedo der Gletscheroberfläche) und Strahlungsdauer (wolkenreich, kühler) vermindert und die Ablation und damit auch die Höhenlage der Schneegrenze

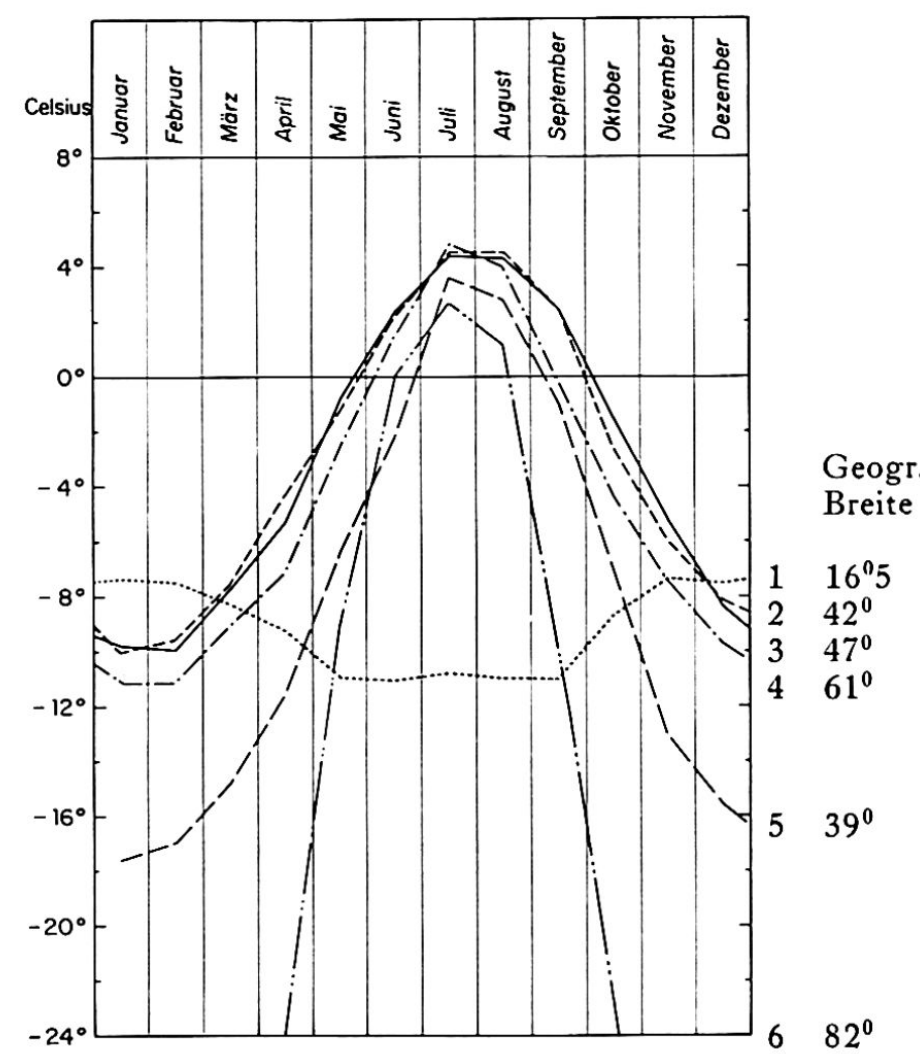

Fig. 20 Die Temperaturen an der Schneegrenze Ziffern: Meteorologische Stationen. 1: El Misti; 2: Gran Sasso; 3. Säntis; 4. Fanaraken; 5. Pikes Peak (nach Seiffert 1950); 6: Lady-Franklin-Bay (nach Seiffert 1950).

wesentlich beeinflußt. Lliboutry (176, S. 452) weist in sommertrockenen Gebirgen auf die brüske Übergangsstufe hin, in der der nivometrische Koeffizient in raschem Anstieg die Ablösung des Regens durch den Schnee anzeigt. Diese Tatsachen sind für die morphodynamischen Prozesse von größter Bedeutung, wir werden darauf zurückkommen. Die uns zur Verfügung stehenden Niederschlagsbeobachtungen waren aber viel zu ungenau und zu vereinzelt, so daß wir uns mit der Auswertung der Sommertemperaturen begnügen mußten. Immerhin zeigen die Temperaturen das Niederschlagsgeschehen bis zu einem gewissen Grade an. Ahlmann hat darauf hingewiesen, daß die Mitteltemperaturen der drei Sommermonate an der Schneegrenze vom Säntis mit $3,5^{\circ}$ zum Sonnblick mit $2,5^{\circ}$ und zu den Ötztaler Alpen mit $1,0^{\circ}$ abnehmen (vgl. in der folgenden Zusammenstellung die Station Gr. St. Bernhard). Zusammengefaßt ist die Relation Sommertemperatur_Schneegrenze nicht eindeutig. Strahlung und Niederschlag kommen darin nur angenähert zum Ausdruck. Die Abweichungen sind in jeder Klimaprovinz verschieden. (Ahlmann 1924, Billwiller 1930, Streiff-Becker 1936, Morawetz 1952, Mortensen 1952, Leidmaier 1953, Tollner 1954.) 
Angaben über die

meteorologischen Höhenstationen

\section{Geographische Breite}

Höhe der Station

Gemessene Jahre

Temperatur des wärmsten Monats Temperatur des kältesten Monats Jahrestemperatur

Jahresniederschlag

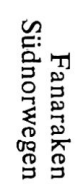

$61^{\circ} 31$

$2064 \mathrm{~m}$

$1934-38$

$3,2^{\circ}$

$-12,1^{\circ}$
$-5,6^{\circ}$

$1282 \mathrm{~mm}$

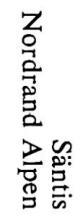

$47^{\circ} 15^{\prime}$

$2500 \mathrm{~m}$

$1931-60$

$5,6^{\circ}$

$-9,0^{\circ}$

$-1,9^{\circ}$

$2900 \mathrm{~mm}$

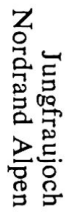

$46^{\circ} 33^{\prime}$

$3576 \mathrm{~m}$

$1931-60$

$-1,0^{\circ}$

$-14,7^{\circ}$

$-8,0^{\circ}$

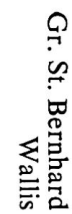

$45^{\circ} 52^{\prime}$

$2479 \mathrm{~m}$

$1931-60$

$7,2^{\circ}$

$-8,6^{\circ}$

$-1,2^{\circ}$

$2140 \mathrm{~mm}$

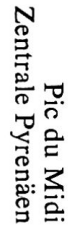

$42^{\circ} 57^{\prime}$

$2863 \mathrm{~m}$

$1921-50$

$7,2^{\circ}$

$-7,4^{\circ}$

$-1,1^{\circ}$

$1510 \mathrm{~mm}$

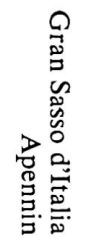

雚

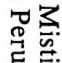

空

$16^{\circ} 16^{\prime} \mathrm{S}$

$5842 \mathrm{~m}$

2 Jahre

$1948-60$

$11,8^{\circ}$

$-4,2^{\circ}$

$3,5^{\circ}$

$-6,0^{\circ}$

$-9,0^{\circ}$

$-7,9^{\circ}$

$263 \mathrm{~mm}$ ?

Angaben über die nahe-

gelegene regionale Schneegrenze

Mittlere Höhe der Schneegrenze

Temperaturgradient ${ }^{\circ} \mathrm{C} / 100 \mathrm{~m}$ für die

Höhendifferenz Station-Schneegrenze

Temperatur des wärmsten Monats

an der Schneegrenze

$1800 \mathrm{~m}$

$2700 \mathrm{~m}$

$2700 \mathrm{~m}$

$3100 \mathrm{~m}$

$3050 \mathrm{~m}$

$3100 \mathrm{~m}$

$6000 \mathrm{~m}$ ?

0,61

0,60

0,60

0,64

0,70

0,74

$0,90 ?$

Literaturangaben

$4,8^{\circ}$

$4,4^{\circ}$

$4,3^{\circ}$

$3,2^{\circ}$

$5,9^{\circ}$

$4,5^{\circ}$

$-7,4^{\circ}$ ?

Ostrem und

Liestol 1963

Seiffert 1950

Plandé 1939 Tonini 1963

Sohüepp 1959, Bögel 1956 und WMO 1965

Météor. franç. Bögel 1956

Seiffert 1950

Bögel 1956

Kessler 1963

WMO 1965 


\section{Fig. 21}

Höhe der $4,5^{\circ}$-Isotherme des wärmsten Monats.

(Mittel 1951-1960, freie Atmosphäre, WMO 1965)

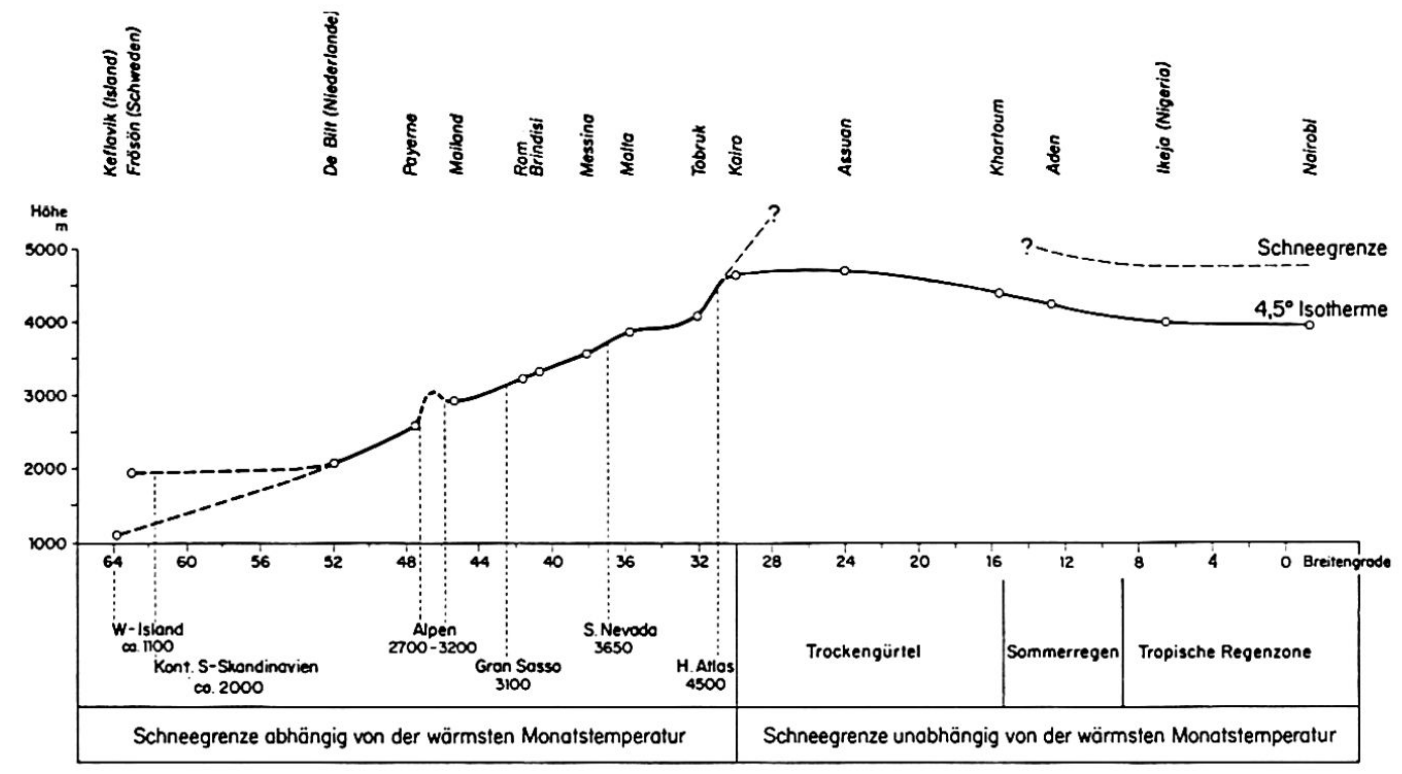

In der Zusammenstellung der Sommertemperaturen an der Schneegrenze sind die wichtigsten Klimadaten einiger ausgewählter Stationen nahe der Schneegrenze aufgeführt. Die Gradienten, mit denen wir die Temperatur von der meteorologischen Station auf die nahegelegene Höhe der angenommenen Schneegrenze umrechneten, haben wir aus der Vergleichsreihe mit verschiedenen Talorten ermittelt und zum Teil mit entsprechenden Daten aus der freien Atmosphäre ergänzt (Lit.-Angaben auf der Tabelle). Durch den relativ geringen Abstand MeßstationSchneegrenze wollten wir die Fehlergrenzen möglichst einschränken, die durch die Unsicherheiten der Schneegrenzhöhen und der Temperaturgradienten gegeben sind. Dabei bleiben Anderungen der eingesetzten Gradienten um einige Hundertstel Grad $C$ bedeutungslos, viel stärker fällt ein Schneegrenzfehler von 100 m oder mehr ins Gewicht. Mit diesen Vorbehalten sind die errechneten Temperaturen an der Schneegrenze aufzunehmen. In Fig. 20 haben wir den jahreszeitlichen Verlauf der Temperaturen an der Schneegrenze dargestellt, wobei die Angaben für den Pikes Peak und von Lady Franklin Bay der anregenden Arbeit von Seiffert (313) entnommen sind. Die übrigen Werte haben wir nach den monatlich differierenden Gradienten umgerechnet, so daß wir den Temperaturverlauf mit großer Genauigkeit auftragen konnten.

Die Auswertung der Tabelle und Fig. 20 ergibt folgendes:

Die kältesten winterlichen Monatstemperaturen an der Schneegrenze zeigen eine gewaltige Streuung von $-38,3^{\circ}$ (Lady Franklin Bay) bis etwa $-10^{\circ}$ (Säntis, Gran Sasso). Demgegenüber fallen die Sommermonate durch die erstaunliche Scharung der Temperaturkurven auf. Abgesehen von der Station Misti schwanken sämtliche Julimittel zwischen $2,7^{\circ}$ u. 5,9 $9^{\circ}$ Klammern wir die arktische Station in Nordamerika aus, so gruppieren sich die Temperaturen des wärmsten Monats von Skandinavien bis in den Mittelmeerraum zwischen 3,2 und 5,9 $9^{\circ}$. Daraus ergibt sich ein Mittel von ca. $4,5^{\circ}$. In dieser Mittelbildung steckt eine Fehlermöglichkeit von $\pm 1,3$ $1,4^{\circ} \mathrm{C}$, das heißt $\pm 200 \mathrm{~m}$ Schneegrenzdifferenz. Im einzelnen wissen wir noch zu wenig, wie viel die einzelnen lokalen Abweichungen betragen können und dürfen, wie Niederschlag, Verdunstung und Strahlungsdifferenzen zu berücksichtigen sind. Solche Untersuchungen müßten in lokal streng begrenzten Räumen aufgenommen werden.

Versuchsweise haben wir die $4,5^{\circ}$-Isotherme des wärmsten Monats nach den. Temperaturmessungen in der freien Atmosphäre (214) von Nordeuropa über den afrikanischen Trockenraum bis zum Aequator berechnet und dargestellt (Fig. 21). Dabei zeigt sich innerhalb des angegebenen Fehlerbereiches eine auffällige Úbereinstimmung mit der Schneegrenze bis zum Hohen Atlas, d. h. bis zum Beginn des Trockengürtels. Von da weg löst sich die Schneegrenze von der bestimmten Isotherme und steigt unabhängig und rasch an. Das Problem der Schneegrenzhöhen über den ariden Zonen haben wir an anderer Stelle diskutiert, wir wollen darauf nicht mehr eintreten (206).

Schließlich haben wir die Temperaturbestimmung an der Schneegrenze folgendermaßen ausgewertet: Der hohen Fehlergrenze wohl bewußt haben wir die Höhe der $4,5^{\circ}$-Isotherme des wärmsten Monats nach den neuesten Angaben der WMO (214) für die gemessenen Stationen des Mittelmeerraumes berechnet und in Karte 2 eingetragen, um einen Anhaltspunkt über die Höhenlage der rezenten Schneegrenze zu gewinnen. Nun frägt sich aber, ob wir die Temperaturgradienten der freien Atmosphäre mit 
Schneegrenzhöhen in Zusammenhang bringen dürfen; sollten wir nicht ausschließlich Meßdaten von meteorologischen Höhenstationen verwenden? Zum ersten sind solche Bergstationen recht selten und zum zweiten sind die Differenzen für die Sommermonate unbedeutend. Nach schweizerischen Messungen weichen die Mitteltemperaturen der Bergstationen (Säntis, Pilatus, Weißfluhjoch, Großer St. Bernhard) nicht über $0,2^{\circ} \mathrm{C}$ von denjenigen der freien Atmosphäre ab. Allerdings ergeben sich in den einzelnen Jahreszeiten etwas größere Differenzen, so daß im allgemeinen die Meßwerte der Bergstationen im Winter etwas kälter und im Sommer etwas wärmer sind als die entsprechenden der freien Atmosphäre (Ackermann 1954). Aus zahlreichen ähnlichen Versuchsanordnungen in Europa, USA und Japan zieht Bögel den Schluß, daß die Wintertemperaturen je nach der geographischen Lage beträchtlich tiefer sein können als diejenigen der Aufstiegsmessungen. Dagegen wird für die extremen Sommermonate, die ja für die Höhenlage der Schneegrenzen entscheidend sind, eine annähernde Übereinstimmung der Temperaturmittel von freier Atmosphäre und Gipfelstationen festgestellt. Flohn führt Werte aus dem mittleren Tien-Schan-Gebirge auf, bei denen die Monatsmittel der Stationen in Hochtallage in den extremen Wintermonaten bis über $10^{\circ} \mathrm{C}$ niedriger waren als die entsprechenden Aufstiegsmessungen von Alma-Ata. Im Sommer dagegen war kein wesentlicher Unterschied festzustellen (nach Bögel 1956, S. 26/14).

Diese Ergebnisse können wir auch aus dem Mittelmeerraum bestätigen, indem die Julitemperatur beim Observatorium Aetna auf $2950 \mathrm{~m}$ Höhe $8,27^{\circ} \mathrm{C}$ beträgt (323) und mit einem Gradienten von $0,65^{\circ} / 100 \mathrm{~m} \mathrm{(214)}$ auf $4,5^{\circ}$ reduziert eine Höhe der mutmaßlichen Schneegrenze von $3530 \mathrm{~m}$ ergibt. Nach der freien Aufstiegsmessung haben wir in Messina 3560 m errechnet (Karte 2), die Übereinstimmung mit dem Aetna ist erstaunlich gut. Diese Ergebnisse berechtigen uns, die sommerlichen Temperaturen und Gradienten der freien Atmosphäre als repräsentativ anzusehen. Zusammengefaßt haben wir den rezenten Schneegrenzverlauf im Mittelmeerraum mit der $4,5^{\circ}$-Mitteltemperatur des wärmsten Monats ergänzt, um die wenigen gesicherten Sohneegrenzhöhen großräumig miteinander zu verbinden und zu vergleichen. Im Augenblick und mit den heute verfügbaren Mitteln schien es uns der einzig gangbare Weg, (über die Korrelation ob. Waldgrenze-rez. Schneegrenze siehe Hermes 1955), vielleicht wird es in Zukunft gelingen, diese klimatische Berechnung nach einheitlicheren Klimaprovinzen $\mathrm{zu}$ verbessern und zu verfeinern.

\section{Zur Problematik des Schneegrenzbegriffs: bisherige und zukünftige Definitionen}

\subsection{Schneegrenze - Gleichgewichtslinie - Niveau 365}

Der Schneegrenzbegriff wird heute so widersprüchlich verwendet, daß er mit Recht in Frage zu stellen ist. Glaziologische und klimatologische Forschungen haben neue Bestimmungsmöglichkeiten eröffnet und uns damit folgendes Problem gestellt: Wie können die bisherigen Schneegrenzangaben mit den neuen Begriffen und Methoden in Übereinstimmung gebracht werden? Wir stehen vor der Auseinandersetzung, die traditionelle Bestimmungsmethode selbst angewendet zu haben und doch einzusehen, daß wir künftighin neue Wege in der Abgrenzung der nivalen Stufe einschlagen müssen. Diese Problematik soll im folgenden kurz erläutert werden.

Klebelsberg hat in seinem grundlegenden Werk deutlich zwischen einer klimatischen (regionalen) und lokalen Schneegrenze außerhalb der Gletscher und einer Firnlinie auf dem Gletscher unterschieden (154, S. 29-32), wie es andere Autoren auch schon getan haben (z. B. Richter 1888, Ratzel 1889, Penck 1938, Streiff-Becker 1947 usw.). Diese Un- terscheidung, zu wenig streng eingehalten, wurde zum Ausgangspunkt zahlreicher Unklarheiten und Unsicherheiten.

- Die Bestimmung einer Schneegrenze außerhalb eines gletscherbedeckten Gebietes ist von zahlreichen Forschern in jüngster Zeit konsequent weiterentwickelt worden (Zingg 1954, Shcheglova 1961 usw.). Zingg hat die klimatische Schneegrenze dort festgelegt, wo die Schneebedeckung auf einem horizontalen Feld bei normaler Exposition 365 Tage dauert. Diese Höhengrenze wird von Zingg als klimatische Schneegrenze, von russischen Forschern als Niveau 365 bezeichnet (176, S. 439).

- Auf dem gletscherbedeckten Gebiet spricht man nicht von Schneegrenze, sondern von Firnlinie (Klebelsberg 1948, S. 31). Neuerdings müßten wir den präziseren Begriff der Gleichgewichtslinie gebrauchen, der in unseren alpinen Bereichen ungefähr mit der Firnlinie übereinstimmt, in polar-subpolaren und tropisch-subtropischen Gebieten aber beträchtliche Abweichungen ergeben kann (176, S. 443; 232, S. 106). 
- Eine klare Trennung in Schneegrenze außerhalb des Gletschers und Firnlinie oder Gleichgewichtslinie auf dem Gletscher ist aber nie eingehalten worden. Klebelsberg selbst braucht bei der Besprechung der Methoden Kurowski, Höfer usw. den Begriff Schneegrenze, obwohl es sich eigentlich um die Bestimmung einer Gleichgewichtslinie (Firnlinie) handelt. Genau gleich werden die Schneegrenzhöhen im 2. Band von Klebelsberg auf Gletschern bestimmt und als lokale Schneegrenzen, ihre Mittelwerte aber als regionale Schneegrenzen bezeichnet. Finsterwalder spricht in seiner hervorragenden Arbeit von Schnee- und Firngrenze und meint effektiv die Gleichgewichtslinie auf dem Gletscher (86, S. $188)$. Louis wendet in seinen grundsätzlichen Betrachtungen den Begriff Schneegrenze für das Gebiet außerhalb und innerhalb der Gletscher an (186). Wißmann ermittelt seine orographischen und klima- tischen Schneegrenzen auf gletscherbedecktem Gebiet» wo die Schneegrenze als Firngrenze das Nährgebiet im Firnbereich vom Zehrgebiet im Bereich der Gletscherzunge trennt» (359). Zahlreiche Autoren ließen sich zitieren, die wie wir Schneegrenzkarten zeichneten und eigentlich Darstellungen der Gleichgewichtslinien meinten.

- Diese Widersprüchlichkeit der Begriffe war so lange bedeutungslos, als man an ihren geringen Höhenunterschied glaubte. Klebelsberg 1948, S. 31 : "Die Firnlinie liegt zufolge der Abkühlung durch den Gletscher etwas, um Beträge bis zu $100 \mathrm{~m}$, tiefer als die Schneegrenze im unvergletscherten Gelände nebenan". Diese Auffassung hat sich in den letzten Jahren völlig verändert. Zwischen Gleichgewichtslinie und Niveau 365 ergeben sich folgende Höhendifferenzen (nach Lliboutry 1965, S. 440, übernommen von Malinovsky und Zingg):

\author{
Franz-Joseph-Land \\ Altai (mittl. Werte) \\ Tien Schan N \\ Tien Schan $S$ \\ Kaukasus
}

Östliche Schweizer Alpen 3200 m

(Zingg)

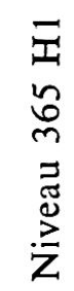

$300 \mathrm{~m}$

$3350 \mathrm{~m}$

$4500 \mathrm{~m}$

$4500 \mathrm{~m}$

$4300 \mathrm{~m}$
Selbst wenn die Werte des Niveaus 365 noch mit großer Vorsicht aufgenommen werden müssen, weil sie eine große Zahl langjähriger Beobachtungsstationen in verschiedenen Höhenlagen verlangen, so sind doch die bedeutenden Höhendifferenzen zur Gleichgewichtslinie generell richtig. Daraus ergibt sich die dringende Notwendigkeit, die Methoden und Begriffe neu zu überdenken und zu definieren.

- Wie wird der Schneegrenzbegriff heute gebraucht? Mit «Schneegrenze» bezeichnet man die Gleichgewichtslinie (russische Bezeichnung nach Lliboutry 1965, S. 440), die Firnlinie (Finsterwalder 1953), die imaginäre Grenzlinie zwischen Vergletscherungsgrenze (Enquist 1916) und Firnlinie (Østrem og Liestøl 1962, S. 337), die dauernde Schneebedeckung außerhalb des Gletscherareals (Klebelsberg 1948).

Der Begriff "klimatische Schneegrenze» wird heute angewendet für die Gleichgewichtslinie (Lliboutry 1965, S. 447) und für das Niveau 365 (Zingg 1954).

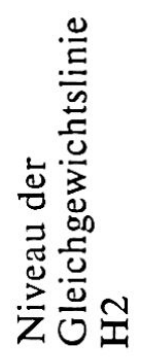

$300 \mathrm{~m}$

$2700 \mathrm{~m}$

$3200 \mathrm{~m}$

$3700 \mathrm{~m}$

$3500 \mathrm{~m}$

$2900 \mathrm{~m}$ ?

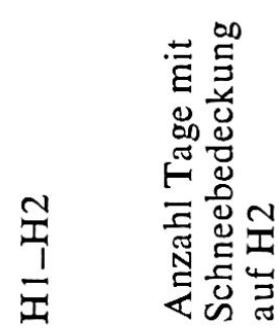

$0 \mathrm{~m} \quad 365$

$650 \mathrm{~m} \quad 293$

$1300 \mathrm{~m} \quad 260$

$800 \mathrm{~m} \quad 300$

$800 \mathrm{~m} \quad 295$

300 ? ca. 300

Diese Zusammenstellung ist erschreckend, sie deckt uns die völlige Verwirrung des Schneegrenzbegriffes auf und damit auch die Problematik, eine nivale Zone und eine nivale Stufe abzugrenzen.

\subsection{Eindeutige Begriffe zur Abgrenzung der nivalen Stufe}

Niveau 365 und Gleichgewichtslinie basieren auf klaren und eindeutigen Definitionen, beide haben einen ganz verschiedenen Aussagewert.

Niveau 365: Die Untergrenze der dauernden Schneedecke ist die eigentliche Abgrenzung der nivalen Stufe außerhalb der gletscherbedeckten Flächen, das heißt, der subnivale Formenschatz mit der gebundenen und freien Solifluktion wird nach oben durch das Niveau 365 abgeschlossen. Beson- 
ders in subtropischen und mediterranen Gebirgen zeigt es sich, daß Gletscher und Frostschuttstufe nebeneinander aufsteigen und sich nicht höhenmäßig ablösen, wie es Frostschuttstufe und Niveau 365 tun würden (vgl. Seite 202). Immerhin müssen wir auch auf die großen Schwierigkeiten zur Bestimmung des Niveaus 365 hinweisen.

- Es braucht zahlreiche Stationen in verschiedenen Höhenlagen mit langjähriger Beobachtungszeit.

- Die Lage der Testgebiete ist nicht einfach. Lokalklimatische Störungen, z. B. Gipfellagen, führen zu starken Abweichungen (364).

- Das Niveau 365 kann meistens nur rechnerisch bestimmt werden, weil in seiner mutmaßlichen Höhe (z.B. Schweizer Alpen über $3000 \mathrm{~m}$ ) Stationen und Beobachtungsmöglichkeiten fehlen. Ferner liegt dieser Höhenbereich größtenteils in der Felsregion, wo horizontale Flächen in normaler Exposition kaum mehr festzulegen sind.

Trotz dieser Schwierigkeiten zweifeln wir nicht daran, daß das Niveau 365 in Zukunft eine immer bedeutendere Rolle in der klimamorphologischen Höhenstufung spielen wird.

Gleichgewichtslinie: Der Gletscher als Klimazeuge wird zur Festlegung einer Höhengrenze immer unentbehrlich sein. Wo Klimastationen fehlen und wo Vergleiche mit der kaltzeitlichen Vergletscherung gesucht werden, können wir uns nur auf die Gleichgewichtslinien der rezenten Gletscher stützen. Sie sind aber durch das lokale Gletscherklima geprägt und liegen entsprechend tiefer als das Niveau 365. In einer neueren Arbeit von Østrem und Liestøl (252, S. 325, 326 und 337) werden in Südnorwegen die Vergletscherungsgrenzen (nach Enquist 1916 $=$ Gipfelmethode) und die Firnlinien (Gleichgewichtslinien) dargestellt und verglichen. Dabei zeigt sich, daß die sogenannten Vergletscherungsgrenzen $200 \mathrm{~m}$ höher liegen als die verbundenen mittleren Gleichgewichtslinien. (Auf die zu hohen Werte der Gipfelmethode hat schon Klebelsberg aufmerksam gemacht, S. 31). Die beiden Autoren vermuten dann eine Schneegrenze außerhalb des Gletscherareals zwischen Gleichgewichtslinie und Vergletscherungsgrenze. Diesem Vorgehen können wir nicht zustimmen. Die Vergletscherungsgrenze ist ein sehr ungenauer Begriff, er bezieht sich ebenfalls auf das gletscherbedeckte Gelände und kann deshalb nicht als obere Begrenzung einer Schneegrenze im Sinne eines Niveaus 365 gebraucht werden. Doch wollen wir aus dieser bedeutenden Arbeit festhalten, daß eine Karte der Gleichgewichtslinien (erarbeitet an 34 Gletschern) entworfen wurde, die uns ein klares Bild über die Höhenlage der Vergletscherung Südnorwegens vermittelt. Zweifellos enthält auch diese Methode bedeutende Schwierigkeiten, wenn wir an den Arbeitsaufwand und die sehr großen jährlichen Sohwankungen der Gleichgewichtslinie denken.
Aber es ist eine sauber definierbare Höhenlinie, die uns in langjähriger Messung für eine bestimmte Periode eine eindeutige Aussage liefern kann.

Zusammengefaßt: Die beiden Begriffe Niveau 365 und Gleichgewichtslinie werden wohl in künftigen Arbeiten eine immer größere Rolle spielen. Diese beiden Höhenlinien lokal in verschiedenen Expositionen und regional in unterschiedlichen Klimaprovinzen zu erarbeiten und zu vergleichen müßte klimamorphologisch äußerst aufschlußreich sein.

\subsection{Probleme und Begriffe in unserer Arbeit}

Für unser Arbeitsgebiet im Mittelmeerraum ergaben sich zahlreiche Schwierigkeiten, die die Anwendung dieser neuen und klaren Definition kaum erlaubten. - Niveau 365: Vorläufig fehlen die notwendigen meteorologischen Höhenstationen zur Beobachtung der Schneelagen. In Zukunft wird ihre Bestimmung an einzelnen isolierten Punkten möglich sein: Pyrenäen, Sierra Nevada, Gran Sasso, Aetna, Triglav, Olymp, Ulu Dagh, Libanon.

- Gleichgewichtslinie: Die wenigen Gletscherflekken im Mittelmeerraum, abgesehen von den Alpenrandlagen und den Pyrenäen, erlauben keinesfalls eine großflächige Darstellung dieser Grenzlinie. Im übrigen fehlen vielerorts genaue Gletscherbeobachtungen (z. B. Erciyas Dagh).

Vor allem aber dürfen wir nicht vergessen, daß unsere Problemstellung folgendermaßen lautete:

- Schwergewicht auf der letzteiszeitlichen Vergletscherung.

- Ergänzung der eigenen Untersuchungsgebiete mit der Literatur, das bedeutet die Verwendung des bisher gültigen Schneegrenzbegriffs.

Somit stellte sich uns die Frage: Können wir den bisherigen Begriff «lokale Schneegrenze» mit dem neueren Begriff "Gleichgewichtslinie» in Beziehung bringen? Uberprüfen wir die bisherigen und am häufigsten angewandten Methoden:

- Die Gipfelmethode von Enquist ergibt durchschnittlich um 100-200 $\mathrm{m}$ zu hohe Werte gegenüber der Gleichgewichtslinie (78, 154, 252).

- Die Methode Kurowskis, der durch das Ausplanimetrieren die mittlere Höhe der Gletscher bestimmte, ergibt $50-100 \mathrm{~m} \mathrm{zu}$ niedrige Ergebnisse gegenüber der Gleichgewichtslinie. (Nach Lliboutry, S. 444: Glacier Olivares bei Santiago de Chile, Kurowskis Schneegrenze 4225, Gleichgewichtslinie $4300 \mathrm{~m}$.

- Die Methode von Penck und Brückner, daß sich Akkumulationsfläche und Ablationsfläche wie $3 \mathrm{zu}$ 1 verhalten, führt zu viel größeren Fehlern, und ist auf eiszeitliche Gletscher angewendet sehr fragwürdig (Lliboutry, S. 445).

- Zahlreiohe weitere Methoden geben noch größere 
Abweichungen, wir wollen auf ihre Besprechung verzichten. Die kurzen Ausführungen zeigen aber doch, da $B$ die etwas zu niedrigen Werte Kurowskis der Gleichgewichtslinie bereits sehr nahe kommen. Korrigieren wir sie noch mit der Methode Höfers, so erhalten wir für die relativ kurzen Gletscher des mediterranen Raumes ziemlich genaue Werte. Genau heißt aber, möglichst übereinstimmend mit der Gleichgewichtslinie.

Somit stehen wir vor dem erstaunlichen Schluß, daß das Ringen um die Bestimmung einer lokalen Schneegrenze im Grunde genommen das Suchen nach einem angenäherten Wert für die Gleichgewichtslinie war. Denn die gegenwärtige und eiszeitliche lokale Schneegrenze hat man immer wieder, entgegen der ursprünglichen Definition, an einem Gletscher bestimmt. Weil man aber die Differenz «Schneegrenze» (gletscherfrei) - Firnlinie (gletscherbedeckt) allzu gering einschätzte, hat man ungewollt dem begrifflichen Übergang von der «lokalen Schneegrenze» zur «lokalen Gleichgewichtslinie» den Weg geebnet.

Das heißt, die gesamte Schneegrenzdiskussion löst sich in zwei Begriffspaare auf:

- Lokales und regionales Niveau 365 für eine bestimmte Periode.

- Lokale und regionale Gleichgewichtslinie für eine bestimmte Periode.
Bewußt haben wir den Ausdruck «klimatische Schneegrenze» weggelassen. Er scheint uns zu sehr mißbraucht und kann kaum mehr sauber eingeordnet werden. In der klimatischen Bestimmung einer Schneegrenze oder Gleichgewichtslinie wird er nochmals anklingen, aber nicht mehr als Schneegrenzdefinition, sondern als sinngemäßes Hilfsmittel zur angenäherten Festlegung einer Schneegrenzhöhe (vgl. Seite 193).

Aufbauend auf früheren Arbeiten haben wir weiterhin die Begriffe der lokalen und der regionalen Schneegrenze verwendet, denn für die Zusammenstellung der letzteiszeitlichen Vergletscherung im Mittelmeerraum waren wir auf die bisherigen wertvollen Ergebnisse angewiesen. Aber sie alle basieren auf der Höhenlage des vergletscherten Areals (Gleichgewichtslinie?) und haben mit einer Schneegrenze außerhalb des gletscherbedeckten Geländes (Niveau 365) nichts zu tun. Im einzelnen konnten wir nicht alle verzeichneten Schneegrenzhöhen überprüfen. Bei vielen war die Bestimmungsmethode unklar, so daß in Zukunft noch manche Änderung zu erwarten ist. Zusammengefaßt bleibt eine gewisse Kontinuität der Begriffe und Methoden gewahrt, doch sollte unsere Diskussion zeigen, wie die bisherigen ungenauen geographischen Begriffe in sauber definierbare glaziologisch-klimatologische Bezeichnungen übergeführt werden könnten.

\section{Die klimamorphologische Bedeutung der Schneegrenzen}

Zwei grundsätzlich Beobachtungen stellen den klimamorphologischen Aussagewert einer lokalen und regionalen Schneegrenze in Frage.

\subsection{Schneegrenzen-Expositionsunterschiede- Kaltzeitliche Klimaverhältnisse}

Wenn sich die Expositionsunterschiede kaum in eine regionale Schneegrenze zusammenfassen lassen, haben dann diese Mittelwerte für die Höhenstufung eines Gebirges überhaupt eine Bedeutung? Wir haben in den vorhergehenden Kapiteln gezeigt, daß die kaltzeitlich gut rekonstruierbaren Expositionsdifferenzen doch gewissen Gesetzmäßigkeiten unterstehen. Einseitige Gebirgsvergletscherungen auf den Schattseiten dehnen sich nicht unbeschränkt aus, die maximale Ausweitung haben wir im Mittelmeerraum mit $1400 \mathrm{~m}$ gemessen (Fig. 19). Dieser gewaltige Asymmetrieeindruck wird durch die Verwitterungsleistung seit dem Hochglazial verstärkt und zugleich auch verfälscht. Damit meinen wir folgendes:

- Wer würde bei der Betrachtung der südseitigen Trockenschutthänge am Erciyas Dagh eine kräftige
Würmvergletscherung vermuten? Alle bisherigen Bearbeiter haben sioh von diesem Bild täuschen lassen, niemand erwartete mitten in Anatolien südexponierte Gletscher (Abb. 7, 8). Zahlreiche weitere Beispiele ließen sioh aus dem Taurus (Abb. 20-23) und der Sierra Nevada zitieren. Diese Befunde lehrten uns, die Vergletscherungsasymmetrien nicht zu überschätzen und die geomorphologische Bedeutung einer Schneegrenze nicht zu unterschätzen.

- Zugleich ließ sich aus dieser unterschiedlichen Hangformung quantitativ und qualitativ ein $\mathrm{Maß}$ für die Verwitterung gewinnen, weil die Schuttmengen vielerorts mit glazialen Formen verknüpft waren (siehe Erciyas Dagh und Taurus). Zukünftige Untersuchungen werden vielleicht ein nach Exposition, Gestein und Zeit differenziertes Abtragungsmaß erarbeiten, das im Vergleich mit andern Klimazonen wesentliche Hinweise auf die klimamorphologische Oberflächenformung geben müßte. Jedenfalls kommen wir heute schon zum Schluß, daß in mediterranen und subtropischen Gebirgen kaltzeitliche Glazialformen völlig verschüttet sein können. Damit aber wird eine falsche und übertriebene Vergletscherungsasymmetrie vorgetäuscht.

- Mit diesen Úberlegungen wollen wir aber nicht 
etwa die Tatsache oder die Bedeutung der großen Expositionsdifferenzen herabmindern. Sie sind erstaunlich groß, und sie müssen für die kaltzeitlichen Klimaverhältnisse zu denken geben. Große Unterschiede zwischen Sonn- und Schattseite sind vor allem einer sommerlichen Ablationswirkung zuzuschreiben. Das niederschlagsreichere und strahlungsärmere Winterhalbjahr ist dafür kaum oder nur zu einem geringeren Teil verantwortlich. Daraus müssen wir schließen, daß die sommerliche Strahlungswirkung auch in den Kaltzeiten außerordentlich groß gewesen sein muß. Wenn wir kaltzeitliche Sommerniederschläge im Mittelmeerraum annehmen, dann müssen sie eher in Form von kurzen und heftigen Güssen aufgetreten sein, ähnlich den heutigen Frühlings- und Herbstspitzen, so daß sich die Strahlung klimamorphologisch voll auswirken konnte.

In keiner andern Klimazone treten so große Expositionsunterschiede auf wie in den Gebirgen des subtropischen Raumes, dementsprechend ist der Aussagewert einer regionalen Schneegrenze in dieser Zone auch am schwächsten. Wir haben aber gezeigt, daß gewisse Gesetzmäßigkeiten existieren (S. 189). Mit diesem Wissen haben wir Lage und Höhe, Orographie und Klimatologie eines Gebirges zu beurteilen. Wenn uns das gelingt, dann bedeuten selbst regionale Schneegrenzangaben schon wesentliche Hinweise auf die klimamorphologische Höhenstufung eines Gebirges.

\subsection{Nivale Stufe - Frostschuttstufe - Kaltzeitliche Klimaverhältnisse}

In subtropischen Gebirgen tritt die nivale Stufe nicht über, sondern vielfach neben die Frostschuttoder Solifluktionsstufe (Klaer 1962). Bedeutende Asymmetrien zwischen glazial und periglazial überformten Hängen treten auf, und über glazialen Karund Talformen steigen Frostschutthänge bis in die höchsten Gipfelregionen. Ist da eine bestimmte Schneegrenzhöhe wirklich noch der Untergrenze einer nivalen Stufe gleichzusetzen? Zur Lösung dieser Frage müssen wir auf die Diskussion des Schneegrenzbegriffes zurückgreifen. Die obere Begrenzung der Frostschuttstufe ist ganz eindeutig das Niveau 365, keinesfalls eine Schneegrenze, die wir aus tiefsten Karen und Talgletsohern ermittelt haben. Das bedeutet für heutige Verhältnisse, daß das Niveau 365 ganz bedeutend über den höchsten Gipfeln des Mittelmeerraumes liegen würde oder ca. 500-1000 $\mathrm{m}$ über den rezenten Schneegrenzen oder Gleichgewichtslinien (geschätzt nach den Beispielen von Lliboutry, S. 440). Kaltzeitliche Verhältnisse waren vielleicht nicht so extrem, immerhin blieben zahlreiche Gipfel unter dem Niveau 365, aber über den Gleichgewichtslinien der sie umgebenden Gletscher.
Das heißt: In bestimmten Klimazonen können Gletscher vollständig in der Frostschuttstufe liegen. Dafür zitiert Lliboutry ein einzigartiges Beispiel: Der Aconcagua (Anden, $32^{\circ} 40^{\prime} \mathrm{S}$ ) ist von großen Gletschern umgeben, aber zwischen $5500 \mathrm{~m}$ und dem Gipfel $6954 \mathrm{~m}$ dehnen sich gewaltige Frostschutthänge aus (Lliboutry S. 451). Diese Erscheinung stimmt mit den Beobachtungen aus dem Mittelmeerraum teilweise überein. Wir möchten sie folgendermaßen interpretieren:

- Feuchte Sommerschneefälle haften in starker Windexposition auf den höchsten Gipfeln, trockener und kalter Winterschnee wird verblasen. In sommertrockenen Gebieten überdauert der Schnee nicht in freier Gipfel- und Hanglage, die Gletscher bilden sich in tieferen Sammelmulden und Talanfängen. (Lliboutry 1965, Galibert 1965).

- DieseTatsachen weisen auf die besonderen Klimaverhältnisse im Hochgebirge hin: Hoher Anteil der direkten Strahlung, geringere Luftfeuchtigkeit zu bestimmten Tages- und Jahreszeiten, hohe Durchlässigkeit der Atmosphäre usw. (Galibert 1965, S. 318). Diese besonderen Erscheinungen sind in ihrer Höhenstufung noch zu wenig genau bekannt und doch für die Oberflächenformung von höchster Bedeutung. Sommertrockene Gebiete müssen in ihren Hochzonen noch extremeren Bedingungen unterliegen, die sich auf die Vergletscherung entscheidend auswirken, und die wir im Augenblick noch zu wenig überschauen.

- Die wichtige Frage ist gestellt, ob das kaltzeitliche Vergletscherungsbild im Mittelmeerraum auf Sommerschneefälle hinweist oder nicht. Dagegen sprechen die großen Vergletscherungsasymmetrien und die häufige Beobachtung, daß Frostschutthänge neben und über den Glazialformen aufsteigen, wie wir es eingangs geschildert haben. Dafür spricht die häufige Beobachtung, daß die eiszeitliche Vergletscherung bis in die Gipfelregionen aufsteigt und höchste Kreten in Kare und Hochmulden auflöst, wie wir es besonders schön im Taurus (Abb. 14, 24, 25), in der Sierra Nevada, im Ak Dagh (Abb. 28, 29) und teilweise sogar am Erciyas Dagh beobachtet haben. Wenn wir uns die kaltzeitliche Vergletscherung einer Sierra Nevada (204, Karte 4), eines Taurus (Fig. 3) oder eines Erciyas Dagh (Fig. 1) vorstellen, so werden wir an alpine Verhältnisse erinnert, wo die Gletscher in den höchsten Gipfelhängen und -karen wurzeln, Einsattelungen im Gratverlauf zu Transfluenzpässen umgestalten und selbst Südseiten zu Firnfeldern werden (z. B. Olymp, Abb. 36). Diese Erscheinungen sind nicht den heutigen Gletscherlagen oder den Verhältnissen am Aconcagua vergleichbar. Wir kommen zum Schluß, daß die eiszeitliche Vergletscherung des Mittelmeerraumes für Sommerschneefälle spricht, aber nicht im gleichen Ausmaße wie in gemäßigten Breiten. Sie waren zu gering oder zu selten, um das Niveau 365 in die 
Nähe der mittleren Gleichgewichtslinien hinunterzudrücken, das heißt, zahlreiche Gletscher befanden sich in der Frostschuttstufe, und die Expositionsunterschiede wurden deutlich ausgeprägt. Sie waren aber doch vorhanden, so daß sich in niederschlagsbegünstigten Gebirgen eine alpin anmutende Vergletscherung bilden konnte, die sich von heute sommertrockenen Gebieten deutlich unterscheidet.

- Eine lokale und regionale Schneegrenze hat ihren klimamorphologischen Aussagewert, aber wir müssen die Begriffe klären und die Gesetzmäßigkeiten kennen. Ein kaltzeitliches Niveau 365 können wir nicht rekonstruieren, nur einen angenäherten Wert der ehemaligen Gleichgewichtslinien, den wir als Schneegrenze bezeichnen. Wenn wir um diese Differenzierung wissen, muten wir einer Schneegrenze auch keine klimamorphologische Aussage zu, die sie nie haben kann.

\section{Die klimamorphologische Höhenstufung in den mediterranen Hochgebirgen}

\subsection{Obere Waldgrenze - Rezente Schneegrenze}

Wir beschränken unsere Zusammenstellung nur auf die wenigen Hochgebirge um und über $3000 \mathrm{~m}$, an denen wir eine rezente Schneegrenzhöhe diskutiert und bestimmt haben. Zum Vergleich fügen wir zwei Werte von der Alpen N- und S-Seite bei.
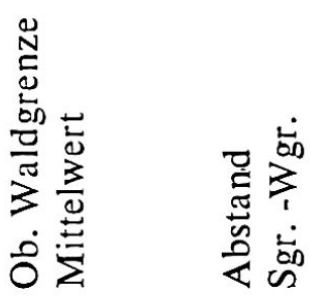

\section{Zentraler Raum}

Alpen N-Seite, Hochalpenrand Berner Oberland

Alpen S-Seite, Hochalpenrand

Tessin-Basodino

Gran Sasso, Abruzzen

\section{Westlicher Raum}

Pyrenäen Mt. Perdu-Maladetta

Sierra Nevada

Hoher Atlas (Toubkal)

\section{Südöstlicher Raum}

Erciyas Dagh

Taurus (Hoher Bolkardagh)

Libanon

$\begin{array}{llr}2800 \mathrm{~m} & 1900 \mathrm{~m} & 900 \mathrm{~m} \\ & & \\ 2950 \mathrm{~m} & 1950 \mathrm{~m} & 1000 \mathrm{~m} \\ 3100 \mathrm{~m} & 1800 \mathrm{~m} & 1300 \mathrm{~m}\end{array}$

$\begin{array}{llr}3100 \mathrm{~m} & 2200 \mathrm{~m} & 900 \mathrm{~m} \\ 3650 \mathrm{~m} & 2200 \mathrm{~m} & 1450 \mathrm{~m} \\ 4500 \mathrm{~m} & 2700 \mathrm{~m} ? & 1800 \mathrm{~m}\end{array}$

$4000 \mathrm{~m} \quad 2500 \mathrm{~m} ? \quad 1500 \mathrm{~m}$

$3650 \mathrm{~m} \quad 2150 \mathrm{~m} \quad 1500 \mathrm{~m}$

$3700 \mathrm{~m} \quad 2200 \mathrm{~m} \quad 1500 \mathrm{~m}$
Aus dieser vereinfachten Zusammenstellung ergibt sich folgendes:

- Gegenüber den Angaben von Hermes (126) erhalten wir im zentralen und südlichen Mittelmeerraum größere Abstandswerte Schneegrenze_Waldgrenze. Die Ursachen sind immer dieselben: Die rezenten Schneegrenzwerte von Hermes sind nach vereinzelten Gletscher-, Firn- und Schneeflecken allzu tief festgelegt und übernommen worden.

- Unsere Abstandswerte, beschränkt auf wirklich vergleichbare Hochgebirge, zeigen eindeutige $\mathrm{Zu}$ nahmen von $\mathrm{N}$ nach $\mathrm{S}$ und zugleich von maritimen naoh kontinentalen Klimaprovinzen. Wir wollen in unserem Zusammenhang nicht auf die Probleme einer Waldgrenzen-Bestimmung eintreten (z. B. im Hohen Atlas), sondern mit diesen vereinfachten Mittelwerten auf eine auffallende Systematik in diesen Abstandsverhältnissen hinweisen.

- Die Frage ist gestellt, wie sich diese Abstandswerte in der südlich anschließenden Trockenzone verhal- 
ten. Einerseits unterstützt Hermes in seiner weitgespannten Arbeit die Annahme Büdels, daß eine hypothetische Waldgrenze über Hoggar und Tibesti auf über $4000 \mathrm{~m}$ festzulegen wäre (Hermes 126, S. 188, 34; S. 125). Anderseits kommt Hermes nach den Befunden in den trockenen Hochanden zum Schluß, daß zunehmende Aridität die Gleichsinnigkeit des Anstiegs nicht nur divergieren läßt, sondern sogar eine gegenläufige Bewegung beider Grenzen auslösen kann: Abstieg der Waldgrenze, rapides Hinaufrücken der Schneegrenze.

Wir wollen diese Widersprüchlichkeit vorläufig offenlassen, es fehlt uns das notwendige Beobachtungsmaterial und vor allem eine genaue Kenntnis der einzelnen Klimaelemente in den Hochgebirgen der Trockengürtel. Schon mit der Annäherung an die aride Zone wird die Bestimmung einer Waldgrenze äußerst problematisch. So ist z. B. der Wert $2700 \mathrm{~m}$ für den Hohen Atlas sehr fragwürdig, Troll spricht von 3000-3200 m (346, S. 135).

Schneegrenzen und Waldgrenzen reagieren auf Lage- und Klimaveränderungen unterschiedlich, wobei die Schneegrenzen bedeutend empfindlicher schwanken als die Waldgrenze. Die Schneegrenze steigt im Mittelmeerraum von $\mathrm{N}$ nach $\mathrm{S}$ viel rascher an als die Waldgrenze; die Abstandswerte vergröBern sich von ca. $1000 \mathrm{~m}$ im nördlichen auf ca. $1500 \mathrm{~m}$ im südlichen Mittelmeer. Diese Erscheinung weist auf die kräftige Ausweitung der Frostschuttstufe von $\mathrm{N}$ nach $\mathrm{S}$ oder von maritimen zu kontinentalen Klimaprovinzen hin.

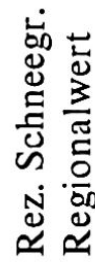

Schweizer Alpen (nach 9, 102, 103)

Sierra Nevada

$2700-3300$

Hoher Atlas - Toubkal (nach 9)

3650

4500

Obwohl die Waldgrenze nicht die Untergrenze der gebundenen und freien Solifluktion bedeuten muß (Kaiser 1965), ist sie doch im alpinen Bereich eine deutliche Abgrenzung der subnivalen Stufe (Frostschuttstufe und Mattenstufe). Im mediterranen Raum und besonders in der Annäherung an Trokkengebiete ist die Waldgrenze als Höhengrenze viel fragwürdiger, weil sie selten geschlossen auftritt, sondern meistens nur nach isolierten und kleinen Beständen festgelegt werden kann (z. B. Erciyas Dagh, Libanon, Hoher Atlas usw.). Deshalb können Frosterscheinungen flächenhaft weit unter einer sogenannten Waldgrenze auftreten (z. B. Libanon: $146,147,140,207)$ und dadurch die Solifluktionsstufe zusätzlich ausweiten.

\subsection{Solifluktionsgrenze - Schneegrenze}

Auf unseren Begehungen haben wir zahlreiche Beobachtungen über gebundene und freie Solifluktionserscheinungen gesammelt. Da wir uns aber aus zeitlichen Gründen streng an das glazialmorphologische Arbeitsziel halten mußten, erfolgte die Kartierung der Frostformen zu wenig systematisch, so daß wir auch auf eine genaue Auswertung und Darstellung verzichten wollen (siehe Hinweise in den einzelnen Kapiteln). Beschränken wir uns auf die folgende Zusammenstellung:

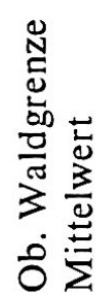

$1800-2200$
2200
2700

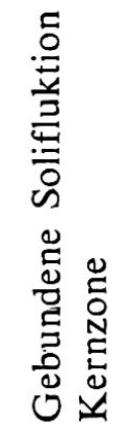

$2200-2600$
$2300-2700$
$2500-3200$

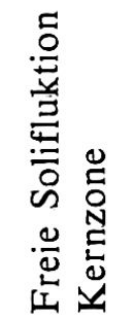

$2600-3100$

$2700-3400$

$3100-4100$

Vergleichen wir die Kernzonen-Untergrenze der gebundenen Solifluktion mit der Schneegrenze, so ergibt sich ein Abstandswert, der von mindestens $500 \mathrm{~m}$ in den Alpen auf $2000 \mathrm{~m}$ im Hohen Atlas ansteigt. Vergleichen wir den gesamten Höhenbereich der gebundenen und freien Solifluktion, so ergibt sich ebenfalls eine Zunahme von ca. $900 \mathrm{~m}$ in den Alpen auf $1600 \mathrm{~m}$ im Hohen Atlas. Wie wir diese Daten auch auswerten, immer zeigt sich die bedeu-

tende Ausweitung der Solifluktionsstufe. Bei der Diskussion des Sohneegrenzbegriffs haben wir auf die Unterscheidung in Schneegrenze außerhalb des Gletschers (Niveau 365) und Schneegrenze auf dem Gletscher (Gleichgewichtslinie) hingewiesen. Diese beiden Grenzlinien klaffen über dem sommertrokkenen Raum des Mittelmeeres und mit der Annäherung an die Trockenzone immer weiter auseinander. Das Niveau 365 als eigentliahe Abgrenzung der ni- 
valen Stufe steigt viel rascher an als die mittlere Gleichgewichtslinie der Gletscher. Das führt zu einer ständigen Erweiterung der Frostschuttstufe nach der Höhe hin. Die gleiche Erscheinung haben wir beim Abstandswert Schneegrenze_Waldgrenze festgestellt. Diese auffallende Gesetzmäßigkeit wird dadurch verstärkt, daß die gebundene Solifluktion unter eine aufgerissene Waldgrenze absteigt (z. B. Libanon) und die freie Solifluktion neben gletscherbedecktem Gelände in extremer Asymmetrie aufsteigt (z. B. Erciyas Dagh).

Schneegrenze und jegliche Art von Solifluktionsgrenze können nicht gleichsinnig verlaufen, sie unterliegen eigenen Entstehungsbedingungen. Für den Mittelmeerraum im besonderen:

- Die Höhenlage der Schneegrenze wird durch die strahlungsreichen Sommermonate bestimmt und standortunabhängig in die Höhe gedrückt. Die Solifluktionsform dagegen entsteht in der günstigsten Frostwechselzeit, der Rest des Jahres wird standortgebunden inaktiv überdauert.

- Die Schneegrenze wird durch geringe Niederschläge in die Höhe gezwungen. Die Solifluktionsform dagegen entsteht in der kurzen Zeit der größten Feuchtigkeit und Frostwechselwirkung, die Trockenperiode überdauert sie als fertige Form.
- Zusammengefaßt: Die Schneegrenze wird durch die ungünstigsten Verhältnisse bestimmt, weil sie ständig mit dem Klima oszilliert und nicht in einer Art Stillstandslage auf einer bestimmten Höhe überdauern kann. Die Soliflukionsform dagegen ist standortgebunden, entsteht in kürzester Zeit bei optimalsten Bedingungen, überdauert die ungünstige Jahreszeit und wartet als tote Form bis zur erneuten Reaktivierung.

Mit diesen Ubberlegungen ist eindeutig ausgesagt, daß Schneegrenzen und Solifluktionsgrenzen nicht gleichsinnig reagieren können (vgl. Hövermann 1962). Wenn auch zahlreiche Fragen der Definition und Abgrenzung noch nicht endgültig geklärt sind, so zeigt sich doch in der allgemeinen Höhenstufung, daß die Solifluktionsstufe oder subnivale Stufe von $\mathrm{N}$ nach $\mathrm{S}$, vom sommerfeuchten zum sommertrokkenen, vom humiden zum ariden Bereich kräftig ausgeweitet wird.

Schneegrenze, Solifluktionsgrenze und Waldgrenze folgen eigenen Entstehungs- und Lebensbedingungen, sie reagieren auf Lage- und Klimaveränderungen nicht gleichsinnig. Aber ihre Abstandsverhältnisse zeigen doch bestimmte Gesetzmäßigkeiten, die die morphologische Höhenstufung der Gebirge je nach Lage, Breite, Klima und Orographie prägen.

\section{Schneegrenzdepression und kaltzeitliche Klimaverhältnisse}

\subsection{Probleme der Schneegrenzdepression}

Die Umrechnung einer letzteiszeitlichen Schneegrenzdepression in eine kaltzeitliche Temperaturerniedrigung ist mit vielen Unsicherheiten und Problemen belastet, die von zahlreichen Autoren diskutiert worden sind (Klute 1921, Paschinger 1923, Machatschek 1913/14 und 1944, Mortensen 1952 und 1957, Flohn 1953, Weischet 1954 und 1960, Morawetz 1960 usw.). Wir wollen nicht im einzelnen auf diese komplexen Fragen eingehen, aber doch die Einwände und Überlegungen zusammenfassen, die den thermischen Aussagewert einer Schneegrenzdepression in unserem Untersuchungsraum betreffen.

\subsubsection{Tektonische Bewegungen}

Postglaziale Hebungen und Senkungen können die letzteiszeitliche Schneegrenze versetzen und die J̌chneegrenzdepression verfälschen (190). Wir haben diese Probleme beim Ak Dagh, am Olymp und im östlichen Mittelmeerraum diskutiert. Schneegrenzdifferenzen ließen sich überall lokalklimatisch erklären und führten nie zu eindeutigen tektonischen Aussagen. Vergessen wir nicht, daß die Fehlergrenze in der Schneegrenzbestimmung so groß sein kann, daß tektonische Folgerungen immer anfechtbar sind. Im übrigen ist es typisch, daß postglaziale tektonische Versetzungen nur in Gebirgsräumen postuliert werden, die knapp unter oder nur wenig über der eiszeitlichen Schneegrenzfläche lagen und deshalb in der Schneegrenzbestimmung durch große Unsicherheiten gekennzeichnet sind (z. B. Kreta 290, Sandras Dagh 283, Olymp usw.). Wir zweifeln aber nicht daran, daß tektonische Bewegungen, verknüpft mit eustatischen Vorgängen, bis in die jüngste Zeit angedauert haben. In Kreta, Beispiel eines sehr mobilen Raumes, ergaben sich seit dem Altertum Landhebungen von weniger als $10 \mathrm{~m}$, vor dem Altertum spielten sich wechselhafte positive und negative Strandverschiebungen $a b$ (121), und jungquartäre Verstellungen größeren Ausmaßes blieben lokal eng begrenzt (57). Im weiteren hat Giermann (111, S. 5 und 10) die epirogenetischen Krustenbewegungen an der spanischen 
Südküste untersucht und kommt zum Ergebnis, daß die relativen Landhebungen seit der Prä-Günz-Zeit (Siciliano 1 und 2) ca. $50 \mathrm{~m}$, seit der Würmzeit weniger als $5 \mathrm{~m}$ betragen haben. Alle diese Resultate zeigen uns, daß wir nur mit größter Vorsicht und Zurückhaltung tektonische Vorgänge und letzeiszeitliche Schneegrenzhöhen in Zusammenhang setzen dürfen.

\subsubsection{Eiszeitliche Gletscherstände in den Firnmul- den}

Wenn die Firnmulden in der letzten Eiszeit nicht höher lagen als heute (228), müssen sich die letzteiszeitlichen und rezenten Schneegrenzen vom Gebirgsrand bis ins Gebirgszentrum ständig näherkommen, das heißt, die Schneegrenzdepression muß abnehmen. Liegen ähnliche Erscheinungen vor, wenn ein rezenter Gletscherfleck im gleichen Gipfelkar erhalten blieb, aus dem ein kleiner eiszeitlicher Gletscher hervorging? Wir haben mehrmals auf die Gefahr aufmerksam gemacht, daß auf Grund von kleinen Wandfußgletschern zu geringe Schneegrenzdepressionen angenommen werden.

Jedenfalls können eiszeitlich und rezent gleich hohe Firnmulden nicht mit einer jährlichen Temperaturinversion von $10-15^{\circ}$ erklärt werden, wie es Mortensen versucht (228). Kaltzeitlich ähnliche sommerliche Einstrahlungsverhältnisse und verminderte Niederschläge sind wesentlichere Argumente, um diese eigenartige Erscheinung $\mathrm{zu}$ erklären, die in Zukunft wohl noch gründlicher untersucht werden muß.

\subsubsection{Schneegrenzen, Sommertemperatur, Sommer- trockenheit}

Die ermittelten Depressionswerte im Mittelmeerraum stützen sich auf eiszeitlich genaue und rezent ungenaue Angaben. Die kaltzeitlichen Schneegrenzen sind meistens regional gesicherte Befunde, währenddem die rezenten Werte nach vereinzelten Gletschern geschätzt und mit Temperaturberechnungen ergänzt wurden. Unsere rezenten Schneegrenzhöhen im südlichen und östlichen Mittelmeerraum (z. B. Hoher Atlas und Libanon) sind Minimalwerte, eine Erhöhung ist in Zukunft aus folgenden Gründen möglich: Die extrem sommertrockenen Gebiete können niedrigere Julitemperaturen an der Schneegrenze aufweisen als $4,5^{\circ}$, das heißt, wir sollten möglicherweise die Temperatur des wärmsten Monats an der Schneegrenze um ca. 1_ $3^{\circ}$ herabsetzen, um die sommerliche Trockenheit und Erwärmung zu kompensieren (vgl. Lliboutry, S. 499: Der sommertrockene andine Nevado Juncal auf $33^{\circ} \mathrm{S}$ hat eine mittlere Sommertemperatur an der Schneegrenze von $-1^{\circ} \mathrm{C}$, das Berner Oberland $3,5^{\circ} \mathrm{C}$ ). Das würde aber bedeuten, daß wir die rezenten Schneegrenzen um 200-500 m zu erhöhen und die Schneegrenzdepressionen entsprechend zu vergrößern hätten. Wir haben die Zusammenhänge Juliisotherme und Schneegrenze besprochen, gewisse Übereinstimmungen haben sich im nördlichen und zentralen Mittelmeer gezeigt. Die klimatische Einheitlichkeit des Raumes gab uns die Berechtigung, die gleiche Schneegrenztemperatur auch an der Süd- und Ostküste anzunehmen (Fig. 21). Vielleicht werden künftige Untersuchungen gewisse Korrekturen bringen.

\subsubsection{Eiszeitliche und gegenwärtige Niederschläge}

Niederschlagsmenge und Niederschlagsverteilung bestimmen den nivometrischen Koeffizienten und beeinflussen den Temperaturgradienten. Sie sind für die Schneegrenzdepression von höchster Bedeutung. Wir werden auf das Problem der kaltzeitlichen Niederschläge zurückkommen (Seite 209). Wir können aber jetzt schon festhalten, daß die Zeit der höchsten Gletscherstände geringere Niederschläge aufwies als heute. Für die Frage der Schneegrenzdepression bedeutet diese Aussage, daß die sommerlichen Temperaturgradienten mindestens so hoch waren wie heute. Es ist kaum anzunehmen, daß sporadische Sommerniederschläge die Gradienten wesentlich beeinflussen konnten.

\subsection{Schwankungen der Schneegrenzdepression}

\subsubsection{Maximale Niederschlagszone und Schnee- grenzdepression}

Klute (158) und Paschinger (260) haben die Meinung vertreten, daß die Schneegrenzdepressionen in mittleren Breiten sehr groß sein müssen, weil die rezenten Schneegrenzen über und die eiszeitlichen unter der Höhenstufe mit den maximalsten Niederschlägen liegen. Nach der Auffassung der beiden Autoren ergibt sich in dieser Zone ein rasches $\mathrm{Ab}$ sinken der eiszeitlichen Schneegrenzen und dadurch auch ein kräftiges Erhöhen der Schneegrenzdepressionen (ausführlich besprochen in Woldstedt 1961, S. 311). Wir müssen aber zu bedenken geben, daß die Höhenbereiche der maximalen Niederschläge, unterteilt in Regen- und Schneefall, weder für die letzte Eiszeit noch für die Gegenwart genügend geklärt sind. 
(Nach 10jährigen Mittelwerten 1951-1960, WMO 1965)

Kursiv gedruckte Gradienten repräsentieren den mutmaßlichen Höhenbereich der Schneegrenze.

\begin{tabular}{|c|c|c|c|c|}
\hline Ort & $\begin{array}{l}\text { Geogr. } \\
\text { Breite }\end{array}$ & $\begin{array}{l}\text { Höhe } \\
\text { in gp } \mathrm{m}\end{array}$ & \multicolumn{2}{|c|}{$\begin{array}{l}\text { Temperaturgradient } \\
\text { in }{ }^{\circ} \mathrm{C} / 100 \mathrm{~m}\end{array}$} \\
\hline Frösön (Schweden) & $63^{\circ} 11^{\prime}$ & $\begin{array}{l}1444-3013 \\
3013-5618\end{array}$ & 0,56 & 0,62 \\
\hline De Bilt (Niederlande) & $52^{\circ} 06^{\prime}$ & $\begin{array}{l}1488-3065 \\
3065-5680\end{array}$ & 0,51 & 0,60 \\
\hline Payerne (Schweiz) & $46^{\circ} 49^{\prime}$ & $\begin{array}{l}1529-3120 \\
3120-5756\end{array}$ & 0,55 & 0,58 \\
\hline Mailand & $45^{\circ} 28^{\prime}$ & $\begin{array}{l}1510-3110 \\
3110-5750\end{array}$ & 0,66 & 0,62 \\
\hline Nîmes & $43^{\circ} 52^{\prime}$ & $\begin{array}{l}1523-3133 \\
3133-5789\end{array}$ & 0,57 & 0,61 \\
\hline Rom & $41^{\circ} 48^{\prime}$ & $\begin{array}{l}1520-3140 \\
3140-5800\end{array}$ & 0,62 & 0,60 \\
\hline Messina & $38^{\circ} 12^{\prime}$ & $\begin{array}{l}1520-3150 \\
3150-5830\end{array}$ & 0,65 & 0,57 \\
\hline Gibraltar & $36^{\circ} 09^{\prime}$ & $\begin{array}{l}1547-3188 \\
3188-5878\end{array}$ & 0,73 & 0,55 \\
\hline Malta & $35^{\circ} 50^{\prime}$ & $\begin{array}{l}1543-3180 \\
3180-5873\end{array}$ & 0,68 & 0,60 \\
\hline Aleppo & $36^{\circ} 11^{\prime}$ & $\begin{array}{l}1454-3108 \\
3108-5831\end{array}$ & 0,62 & 0,68 \\
\hline Tobruk & $32^{\circ} 05^{\prime}$ & $\begin{array}{l}1519-3158 \\
3158-5869\end{array}$ & 0,60 & 0,55 \\
\hline Kairo & $30^{\circ} 08^{\prime}$ & $\begin{array}{c}1505-3154 \\
3154-5897 \\
5897-7608\end{array}$ & 0,54 & $\begin{array}{l}0,51 \\
0,60\end{array}$ \\
\hline Assuan & $24^{\circ} 02^{\prime}$ & $\begin{array}{l}1514-3181 \\
3181-5932 \\
5932-7684\end{array}$ & 0,50 & $\begin{array}{l}0,81 \\
0,56\end{array}$ \\
\hline Khartum & $15^{\circ} 36^{\prime}$ & $\begin{array}{l}1503-3170 \\
3170-5897 \\
5897-7646\end{array}$ & 0,59 & $\begin{array}{l}0,79 \\
0,73\end{array}$ \\
\hline
\end{tabular}

\subsubsection{Unterschiedliche Temperaturgradienten und Schneegrenzdepression}

Zum Problem der verschiedenen Schneegrenzdepressionen finden wir in Wißmann (359, S. 224) folgende Hinweise von Flohn: «Einer reinen Temperatursenkung im Sommer um $4^{\circ} \mathrm{C}$ entspricht in (sommerlich) ariden Gebieten eine Schneegrenzdepression von $400 \mathrm{~m}$; unter humiden Bedingungen (im Sommer) entspricht einer reinen sommerlichen Temperatursenkung um $4^{\circ} \mathrm{C}$ eine Schneegrenzdepression von $800 \mathrm{~m}$. Dies ergibt sich aus dem Unterschied zwischen trockenadiabatischem und feuchtadiabatischem Tempenaturgefälle und kann einem Stüve-Diagramm entnommen werden.»
Dieser Hinweis scheint uns die zahlreichen Schwankungen der Schneegrenzdepression zwischen maritimen und kontinentalen Bereichen zu erklären. Wir haben in der obigen Tabe.le einige repräsentative Temperaturgradienten aus dem Mittelmeergebiet und der beidseits anschließenden humiden und ariden Zone zusammengestellt (214).

Aus dieser Zusammenstellung geht deutlich hervor, daß die Gradienten im Höhenbereich der heutigen Schneegrenzen von Mailand 0,66 über Rom 0,62, Messina 0,65, Gibraltar 0,73, Malta 0,68 bis Tobruk 0,60 und Aleppo 0,62 auffallend ausgeglichen sind. Sie zeigen vom nördlichen zum südlichen Mittelmeerraum keine gesetzmäßigen Veränderungen. Auf jeden Fall ergibt sich keine Gradienterhöhung, 
die auf eine Verminderung der Schneegrenzdepressionen hinweisen würde. Da wir aber bloß mit gegenwärtigen Temperaturgradienten operieren, sind verschiedene Fragen nach den kaltzeitlichen Temperaturverhältnissen gestellt:

- Wenn die eiszeitlichen Schneegrenzen größere Schwankungen aufwiesen als die rezenten (Fig. 18), wurden sie von differenzierteren Sommergradienten beeinflußt? Wir haben schon vom geomorphologischen Standpunkt aus auf Sommerniederschläge geschlossen, doch konnten sie kaum so bedeutend sein, daß dadurch die sommerlichen Gradienten wesentlich gemildert wurden.

- Wenn die eiszeitlichen Schneegrenzen vom nördlichen zum südlichen Mittelmeer rascher ansteigen als die rezenten (Fig. 17), dann muß offenbar die eiszeitliche Temperaturerniedrigung im südlichen Randbereich geringer gewesen sein als im nördlichen. 200_400 m unterschiedliche Schneegrenzdepressionen zwischen $\mathrm{N}$ - und S-Regionen bedeuten eine Temperaturdifferenz von ca. $1,5-3^{\circ} \mathrm{C}$, das heißt, die kaltzeitliche Temperatursenkung war im Süden des Mittelmeeres geringer als im Norden.

- Wenn wir diese Aussage bezweifeln, indem wir mit der Einheitlichkeit des mittelmeerischen Klimaraumes eine gleichmäßige kaltzeitliche Temperatursenkung verlangen, dann müssen wir konsequenterweise eine Abnahme der Niederschläge von $\mathrm{N}$ nach $\mathrm{S}$ annehmen. Dadurch hätten sich die Temperaturgradienten vergrößert und die Schneegrenzdepressionen verkleinert.

- Zusammengefaßt sehen wir keine Möglichkeit, zur Zeit des maximalen Vergletscherungsstandes eine Pluvialzeit (evtl. mit Sommerniederschlägen) im südlich einsetzenden Trockengürtel in diese Tatsachen und Überlegungen einzubauen. Größere Niederschläge im Hochglazial würden einem eiszeitliah verstärkten Schneegrenzanstieg widersprechen (206). Höchstens könnten die rezenten Schneegrenzen im Hohen Atlas, Libanon und Taurus künftighin bedeutend höher veranschlagt und dadurch die Schneegrenzdepressionen entsprechend vergrößert werden. Genauere Kenntnisse des mediterranen Hochgebirgsklimas könnten solche Korrekturen verlangen.

\subsubsection{Relief, Lokalklima und Schneegrenzdepres- sionen}

Wo bedeutende Massenerhebungen (Skandinavien, Alpen, Balkan) oder ausgedehnte Hochländer mit geschlossenen Gebirgsrändern (Anatolien, Iran, Hochasien) vorhanden waren, stand die erniedrigte Schneegrenze der letzten Eiszeit unter einem viel stärkeren Einfluß der Exposition und des Reliefs. Senkung der Schneegrenze und Zunahme der Niederschläge in fester Form (womit nicht eine abso- lute Niederschlagszunahme gemeint sein muß) brachte die Exposition zu kräftigerer Wirkung, als dies bei einer hochliegenden, knapp die Gipfelflur berührenden Schneegrenze möglich ist. Die Gebirgsränder oder klimatischen Gunstlagen zeichneten sich in tief hinuntergedrückten Schneegrenzen wirkungsvoll ab, die inneren Beckenzonen oder Hochländer dagegen blieben wie heute im Niederschlagsschatten und zwangen die Schneegrenze in die Höhe. Bedenken wir, daß zum Beispiel im Mittelmeerraum würmeiszeitlich über 200 Gebirge vergletschert waren, heute aber nur noch $2-3$, dann verstehen wir das unterschiedliche Verhalten der beiden Schneegrenzen. Weil sich niederschlagsreiche und niederschlagsarme Zonen in einer niedrigen Schneegrenze kräftiger auswirken als in einer hochliegenden (Staulagen, Schattenlagen), verändert sich die Schneegrenzdepression zu größeren Werten in regenreichen und zu kleineren Werten in regenarmen Zonen.

\subsection{Temperaturdepression und Schneegrenzdepres- sion}

\subsubsection{Die letzteiszeitliche Temperaturdepression nach verschiedenem Beobachtungsmaterial}

Fassen wir die verschiedensten Beobachtungstatsachen summarisch zusammen, so müssen wir nördlich der Alpen mit einer Juli-Temperaturdepression von mindestens $10^{\circ}$ rechnen $(321,287,112,352$ usw.). Liedtke schloß nach Eiskeilfunden am Lovcen in Dalmatien auf eine kaltzeitliche Jahrestemperatursenkung von mindestens $10^{\circ}(175)$. Demangeot schlägt für Rom eine würmeiszeitliche Temperatur von $-5^{\circ}$ für den Januar und von $13^{\circ}$ für den Juli vor. Das würde eine Temperaturerniedrigung von ca. $12^{\circ}$ für den Januar und von $11,5^{\circ}$ für den Juli ergeben (66). Alle diese Werte dürften sich eher auf bodennahe Luftschichten beziehen und müßten bis zur mittleren Troposphäre um ca. $1-3^{\circ}$ reduziert werden.

Die Meerestemperaturbestimmungen von Emiliani sind im Augenblick noch nicht vollständig überschaubar. Einerseits wird uns aus dem östlichen Mittelmeer eine Verminderung der Oberflächentemperaturen um $6-7^{\circ}$ überliefert $(76$, S. 59), anderseits liegen Angaben von kaltzeitlichen Sommertemperaturen des Oberflächenwassers im östlichen Mittelmeer von $8-12^{\circ}$ vor (nach 66 , S. 266), was auf größere sommerliche Depressionen hinweisen würde.

Fassen wir die bisherigen Ergebnisse für die letzteiszeitliche Temperaturdepression des wärmsten Monats zusammen, so ergibt sich folgendes provisorische Bild: Nördlich der Alpen mehr als 10; 
südlich der Alpen und im Mittelmeerraum in maritimer Lage weniger als $10^{\circ}$, in kontinentaler Lage bis $10^{\circ}$; an der Süd- und Ostküste im Einflußbereich der Trockengebiete schätzungsweise $6-7^{\circ}$. Differenz zwischen nördlichem und südlichem Mittelmeer ca. $3^{\circ}$. Stimmen diese Werte mit den Schneegrenzdepressionen überein?

\subsubsection{Die letzteiszeitliche Temperaturdepression berechnet nach der Schneegrenzdepression}

Wir haben die Beziehung Schneegrenze_Sommertempenatur diskutiert und gesehen, daß innerhalb einer relativ großen Fehlergrenze ein Zusammenhang besteht. Auf Grund dieser Beziehung wurden zahlreiche letzteiszeitliche Temperaturdepressionen berechnet, die aber fast durchwegs zu niedrig ausfielen. Wo sind die Ursachen? Statt noch einmal auf das komplexe Klimaproblem einzutreten, wollen wir uns die grundsätzliche Frage stellen, ob denn eigentlich unsere bisherigen Depressionsbeträge richtig sind.

Alpen-Nordseite: Die letzteiszeitliche Schneegrenze ist im schweizerischen Mittelland sehr wahrscheinlich etwas unter $1200 \mathrm{~m}$ anzusetzen. Jedenfalls weist eine Schneegrenze von weniger als $900 \mathrm{~m}$ im Schwarzwald darauf hin (85). Überdies wäre die gewaltige Ausdehnung der Vorlandvergletscherung kaum denkbar, wenn nicht die Eishöhen um 1100 m bereits die "Schneegrenze» erreichten.

Die rezente Schneegrenze liegt heute im Berner Oberland in der Schattseite auf ca. $2700 \mathrm{~m}$, in der Sonnseite auf ca. $2900 \mathrm{~m}$ (Aletschgletscher nach 144, S. 3), im Mittel auf ca. 2800 m. Daraus ergibt sich eine Schneegrenzdepression von ca. $1700 \mathrm{~m}$, bedeutend größer als bisher angenommen. Sehen wir von der Idee Mortensens ab, der kaltzeitlich nur die untersten Luftschichten bis $2500 \mathrm{~m}$ abkühlen läßt (228), so ergibt sich mit einem Juli-Temperaturgradienten von $0,6^{\circ} / 100 \mathrm{~m}$ (gemäß den geringeren Niederschlägen) eine kaltzeitliche Temperatursenkung des wärmsten Monats von ca. $10^{\circ}$.

Alpen-Südseite: Die letzteiszeitliche Schneegrenze ist im Tessin auf $1600 \mathrm{~m}$, am Monte Grappa sogar auf $1400 \mathrm{~m}$ festgelegt worden $(155,157)$. Die regionale rezente Schneegrenze schätzen wir im Tessin (z. B. Raum Basodino) auf 2900-3000 m. Das ergibt eine Schneegrenzdepression von 1300-1600 m. Rechnen wir einen Mittelwert mit einem Juli-Gradienten von $0,65^{\circ} / 100 \mathrm{~m}$ um, so erhalten wir eine Temperatursenkung des wärmsten Monats von 9$9,5^{\circ} \mathrm{C}$.

Mittelmeerraum: Die Schneegrenzdepressionen schwanken zwischen $1300 \mathrm{~m}$ im zentralen und ca. $1000 \mathrm{~m}$ im südlichen und südöstlichen Mittelmeerraum. Die Unsicherheit dieser Angaben haben wir diskutiert. Da es sich um Mindestwerte handelt, sind auch die entsprechenden Temperaturergebnisse als Minimalwerte anzusehen. Rechnen wir die Depressionsbeträge mit einem Juli-Gradienten von $0,65^{\circ} / 100 \mathrm{~m}$ um, so ergeben sich kaltzeitliche Temperaturerniedrigungen im zentralen Mittelmeer von ca. $8,5^{\circ}$, im südöstlichen Mittelmeer von ca. $6-7^{\circ}$. Ordnen wir diese Ergebnisse in unser heutiges Wissen über die kaltzeitlichen Klimaverhältnisse ein, so zeigen sich interessante Übereinstimmungen. Nördlich der Alpen wird eine sommerliche Temperatursenkung von mehr als $10^{\circ}$ vertreten, südlich des Mittelmeeres vermindert sie sich bis in die Tropenzone auf einen Jahreswert von ca. $4^{\circ}(94,38)$. Unsicherheiten bleiben aber bestehen, z. B. sind die französischen Ergebnisse aus den persischen Hochgebirgen, die eine kaltzeitliche Temperatursenkung von $3^{\circ}$ postulieren, nur schwerlich in diese Depressionsfolge einzuordnen (31).

\section{Zusammengefaßt:}

- Der Mittelmeerraum ist ein Übergangsbereich zwischen verschiedenen Klimazonen, das zeigt sich im Verlauf der eiszeitlichen und gegenwärtigen Schneegrenzen.

- Eine gewisse Einheitlichkeit des mittelmeerischen Klimaraumes bindet auch die südlichsten Bereiche an die allgemeinen Zirkulations- und Klimaverhältnisse der Kaltzeit. Ähnliche Frostbodenerscheinungen finden wir in vergleichbarer Höhenlage im nördlichen (49, 342 usw.) und im südlichen (119 usw.) Mittelmeer. Genau gleich steigen die Schneegrenzen von $\mathrm{N}$ nach $\mathrm{S}$ nur langsam an, erst unmittelbar südlich des Mittelmeeres folgt ein knickartiger Anstieg.

- Die eiszeitlichen Sommertemperaturerniedrigungen iassen sich mit den Schneegrenzdepressionen berechnen. Sie nehmen von $\mathrm{N}$ nach $\mathrm{S}$ um $1,5-3^{\circ} \mathrm{ab}$, sehr wahrscheinlich würden sie sich nach Eintritt in die Trockenzone sprunghaft vermindern.

- In diesen Überlegungen sind die eisbürtigen Inversionsbildungen nicht berücksichtigt, die über allen Vergletscherungsgebieten auftreten (94). Da wir uns aber auf die Temperaturdepression des wärmsten Monats beschränkt haben, dürfte die Reduktion für die Luftschichten zwischen 1000 und $3000 \mathrm{~m}$ nicht sehr bedeutend sein und vor allem für die kleinen Gebirgsvergletscherungen des Mittelmeerraumes überhaupt außer Betracht fallen.

- Aus dem aufgezeichneten Schneegrenzverlauf (Karte 1 und 2) ergeben sich Depressionsbeträge, die in Temperatursenkung umgerechnet mit den bisherigen Ergebnissen anderer Forschungsrichtungen annähernd übereinstimmen. Sollte man in $\mathrm{Zu}-$ kunft die schwer faßbaren rezenten Schneegrenzen noch höher ansetzen, so würden sich größere Depressionsbeträge und somit auch etwas höhere kaltzeitliche Temperaturerniedrigungen ergeben. 


\section{Das Mittelmeer in der Eiszeit und in der Gegenwart}

\subsection{Das Meer}

\subsubsection{Die Bedeutung der eiszeitlichen Meeresre- gression (vgl. Fig. 18)}

Bezogen auf heute können wir mit einer letzteiszeitlichen Meeresspiegelsenkung von ca. $90 \mathrm{~m}$ rechnen, bezogen auf die letzte Interglazialzeit sogar mit ca. 105 m (268, S. 88). Die für unseren Zusammenhang bedeutendsten Küstenveränderungen seien im folgenden kurz zusammengefaßt:

\section{Straße von Gibraltar:}

Die 500-1100 m tiefe Straße von Gibraltar hat sich mit ihren Steilufern während der letzteiszeitlichen Meeresregression nicht wesentlich verengt. Dagegen erfuhr der westliche Zugang zur Meeresstraße eine ganz bedeutende Veränderung. Nördlich von Tanger verbreitert sich der Schelf und die Wassertiefe nimmt ab. Eine Europa und Afrika verbindende Schwelle quert das Meer, nur durch 3 E-W-Rinnen zerfurcht. "Diese drei Rinnen dürften auf die Erosionskraft der starken E-W-Bodenströmung zurückzuführen sein, die maximal $2 \mathrm{~m} / \mathrm{sec}$ erreichen kann, wobei $2,5 \mathrm{~cm}$ große Gerölle noch erodierend wirken. Das Maximum an Tiefe wird in der südlichsten Rinne mit etwa 330 m erreicht. Es ist durchaus möglich, daß die Schwelle während der Mindelvereisung, die im Mittelmeer eine Spiegelsenkung um $200 \mathrm{~m}$ hervorrief, trocken lag und daß die Rinnen erst nachher entstanden sind». (Zitiert nach Giermann 1961, S. 21). Für die Würmeiszeit haben wir auf dieser Linie der geringsten Wassertiefen (109, Karte 1 und 4) folgende Breiten und Tiefen errechnet, wobei wir mögliche tektonische Verstellungen und erosive Eintiefungen seit dem Beginn des Postglazials vernachlässigen:
Breite
Breite mit über
$100 \mathrm{~m}$ Wassertiefe
ca. $10 \mathrm{~km} \quad$ ca. $25 \mathrm{~km}$
Breite mit über
$200 \mathrm{~m}$ Wassertiefe

$$
\text { ca. } 5 \mathrm{~km} \mathrm{ca.} 10 \mathrm{~km}
$$
ca. $1 \mathrm{~km}$ ca. $5 \mathrm{~km}$

Die eiszeitliche Einengung ist ganz bedeutend und die Frage ist gestellt, wie weit der heute intensive Wasseraustausch durch die Straße von Gibraltar unterbunden oder gedrosselt wurde. Eine Verminderung der warmen Ausgleichsströmung AtlantikMittelmeer hätte sich zweifellos auf die Oberflächentemperaturen und das Klima des gesamten Raumes ausgewirkt. Stehen die relativ niedrigen Solifluktions- und Schneegrenzen im westlichen Mittelmeer- raum mit dieser Erscheinung in Beziehung? (vgl. Guillien et Rondeau 1966, S. 266: "La Mediterrannée - peut-être privée de l'arrivée des eaux chaudes atlantiques - ...»). Wir können diese komplexe Frage im heutigen Zeitpunkt nicht eindeutig entscheiden; genauere Untersuchungen werden nötig sein, um die kaltzeitlichen Strömungsverhältnisse qualitativ und quantitativ besser zu verstehen und zu deuten.

Adria:

In der trockengelegten nördlichen Adria sammelte der Po die Flüsse der Umrandung und endete im Pomo-Tief zwischen Pescara und Sibenik (268). Diese gewaltige Vergrößerung der «Po-Ebene» ließ eine relativ einheitliche Klimaprovinz zwischen Norditalien und Norddalmatien entstehen, was im kaltzeitlichen Schneegrenzverlauf zum Ausdruck kommt (Seite 176).

\section{Aegäis:}

Zahlreiche Inseln wurden dem Festland angegliedert. Z. B. Euböa, ein Teil der nördlichen Sporaden, Thasos, Samothraki usw. an die griechische Küste und Imbros, Lemnos, Lesbos, Khios, Samos, Kos usw. an die türkische Küste. Die Kykladen hatten kaum eine feste Landverbindung, so daß ein Eindringen des Meeres während der letzten Kaltzeit bis in die nördliche Aegäis angenommen werden darf. Diese Tatsache hat sich auf die Gebirgsvergletscherungen des östlichen Griechenlands (Olymp) und der westlichen Türkei (Ulu Dagh) ausgewirkt (Seite 160).

\section{Straßen von Messina und Tunis:}

Neuere Lotungen zwischen Sizilien und Kalabrien zeigen eine Schwelle von -90 bis $-96 \mathrm{~m}$, so daß in der letzten Kaltzeit auch diese Meeresstraße weitgehend trockengelegt war (271, S. 59). Vom westlichen zum östlichen Mittelmeer blieb nur ein ca. $14 \mathrm{~km}$ breiter Durchgang zwischen Sizilien und Tunesien, der mit geringer Tiefe noch durch zahlreiche neu auftauchende Inseln und Landverbindungen behindert wurde. Offenbar kam der Wasseraustausch zwischen dem westlichen und dem östlichen Mittelmeer weitgehend zum Stillstand, wie Bildungen von Faulschlamm und leichtflüssigem Erdöl in den Sedimenten der letzten Eiszeit beweisen (271, S. 59). Dieses erstaunliche Ergebnis zeigt unter anderem die Stagnation und Abgeschlossenheit des östlichen Mittelmeerbeckens, was sich zweifollos auf die kaltzeitlichen Klimaverhältnisse ausgewirkt hat.

Bosporus und Dardanellen:

In der letzten Eiszeit waren Bosporus und Dardanel- 
len trockengelegte Talrinnen, dazwischen lag das völlig abgeschnürte Becken des Marmarameeres. Das Schwarze Meer war tief abgesenkt und das östliche Mittelmeer wurde von einem bedeutenden $\mathrm{Zu}$ strom abgeschnitten.

\subsubsection{Auswirkungen auf Klima und Schneegrenzen}

Die knappen Ausführungen zeigen, daß wir kaltzeitlich mit einem ganz anders strukturierten Mittelmeer rechnen müssen. Die Veränderungen der horizontalen und vertikalen Strömungsverhätlnisse können wir noch zu wenig genau beurteilen, folgende Konsequenzen sind aber denkbar:

- Im westlichen Mittelmeerbecken fiel der warme atlantische Zustrom aus oder wurde stark gedrosselt. Versohiedene Ursachen sind denkbar (Schwankungen der Zirkulation, Temperatur, Verdunstung, Strömungsrichtungen usw.), unter anderem könnten die Veränderungen in der Straße von Gibraltar eine Rolle spielen. Die Oberflächentemperaturen wurden entsprechend erniedrigt. Zwar sollte der Atlantik durch Eisküsten und Eisberge stärker abgekühlt sein als das Mittelmeer (vgl. 343, S. 416). Doch weisen die Temperaturbestimmungen Emilianis darauf hin, daß die Schwankungen der sommerlichen Oberfläohentemperaturen von einem Interglazial zu einem Glazial nie weniger als $15^{\circ}$ betragen haben (118, S. 32), das heißt, die kaltzeitliche Temperatursenkung des Mittelmeerwassers war außerordentlich groß.

- Im östlichen Mittelmeerbecken war die Zirkulation weitgehend unterbunden, wie die bitumen- und erdölhaltigen Sedimente zeigen. Der bedeutende Wasserzuschuß aus dem Schwarzen Meer blieb aus. Über die Wasserspende des Nils gehen die heutigen Auffassungen noch weit auseinander. Pfannenstiel spricht von einer eiszeitlich großen Wasserführung $(268,270)$, Fairbridge von einem nahezu ausgetrockneten Fluß zwischen 25000 und 10000 BP (84). Vielleicht lassen sich diese gegensätzlichen Meinungen durch eine deutliche Phasen- und Klimagliederung der Würmzeit ausgleichen, wir wollen diese Frage noch offen lassen. Jedenfalls war das östliche Mittelmeer viel stärker isoliert und konnte sich ohne große Zirkulations- und Austauschmöglichkeiten mit seinen Oberflächentemperaturen dem lokalen jahreszeitlichen Klimagang besser anpassen.

Betrachten wir nun unsere Feldbefunde: Im südlichen Teil des Mittelmeeres ziehen die heutige Waldgrenze und Schneegrenze auf gleicher Breite in ähnlicher Höhenlage von $W$ nach $E$, die eiszeitliche Schneegrenze aber steigt kräftig an (z. B. Sierra Nevada-Bolkardagh Taurus in gleicher Breiten- und Klimalage: Rezente Wald- und Schneegrenze auf gleicher Höhe, eiszeitlicher Schneegrenzanstieg ca. $300 \mathrm{~m}$ ). Die Folgerung scheint naheliegend, daß sich in der letzten Kaltzeit das östliche Mittelmeerbecken gegenüber dem westlichen in den Sommermonaten stärker erwärmte als heute. Durch die Abgeschlossenheit wirkte sich die südlichere Lage des östlichen Beckens vor allem in höheren Sommertemperaturen aus: Ein etwas verstärkter kontinentaler Klimacharakter konnte sich entwickeln, was vorwiegend in den Vergletscherungen der südlichen und östlichen Küstengebirge zur Geltung kommen mußte. Eine erhöhte sommerliche Erwärmung um 2-3 ${ }^{\circ}$ hätte genügt, um die Schneegrenzfläche $200-400 \mathrm{~m}$ in die Höhe zu drücken und entsprechend auch die letzteiszeitliche Sommertemperatur- und Schneegrenzdepression zu verringern. Doch wollen wir nochmals festhalten, daß diese Zusammenhänge noch viel zu wenig gesichert sind und in Zukunft noch genauer abgeklärt werden müssen. Eines aber ist sicher, eine Aufteilung des Mittelmeeres in geschlossene Beckenzonen mußte auch zu einer Auflösung in verschiedene Klimaprovinzen führen, und auf solche Erscheinungen weisen die eiszeitlichen Schneegrenzhöhen hin.

\subsection{Zirkulation und Klima}

\subsubsection{Geomorphologische Problemstellung}

Beweise für erhöhte Niederschläge während der letzten Kaltzeit.

- Eiszeitliche Schneegrenzen: Die relativ niedrige Erciyas-Schneegrenze verlangt im Vergleich mit dem Taurus einen erhöhten Niederschlag in Anatolien. Die extrem tiefen Schneegrenzen in der algerischen Djurdjura oder an der dalmatinischen Küste können nicht allein mit einer Temperatursenkung erklärt werden, sie verlangen kaltzeitlich größere Niederschlagsmengen.

- Abtragungsformen: Die gewaltigen extramoränen Schuttkörper am Taurus, Erciyas, Olymp usw. weisen auf eine erhöhte Niederschlagstätigkeit hin, die sich durch unregelmäßige, heftige Gußregen auszeichnete (Torrentielle Ablagerungen, Franenbildung usw.).

- Glazialformen: Die glaziale Überformung der höchsten Kreten und Gipfel weist auf gut haftende Sommerschneefälle hin (Seite 200).

Beweise für verminderte Niederschläge während der letzten Kaltzeit.

- Verwitterungsleistung: Die Trockenschuttbildung ist so groß, daß sie unmöglich einer Postglazialzeit allein zugeschrieben werden kann. Fossile Frostschuttdecken und Glatthangbildungen, zugeschüttete Tal- und Glazialformen (Taurus, Erciyas usw.) weisen auf eine relativ trockene und kalte Klimaperiode hin. Sie müßte aber am Schluß der letzten 
Kaltzeit angesetzt werden, weil es zu keinem fluviatilen Abtransport der gewaltigen Schuttdecken mehr kam.

- Asymmetriebildungen: Die bedeutenden eiszeitlichen Vergletscherungsasymmetrien (Fig. 19) zeigen strahlungsreiche und niederschlagsarme Klimaphasen an, die die südexponierten Gletscher benachteiligten und die nordexponierten begünstigten.

Die Probleme sind gestellt. Der geomorphologische Befund scheint widersprüchlich. Wie sind niederschlagsreiche und niederschlagsarme Phasen in die gleiche Kaltzeit einzuordnen?

\subsubsection{Klimatologische Problemstellung}

Nach diesem geomorphologischen Befund sind wir mit zwei extremen Formulierungen über die kaltzeitliche Niederschlagstätigkeit im Mittelmeergebiet nicht einverstanden:

1. Wenn von einer generellen Trockenheit gesprochen wird. Nach Klein (zit. nach 160, S. 278) erhielt der Mittelmeerraum nur 70\% der theutigen Niederschläge, nach Galloway (105) gingen die Niederschläge zwischen $40^{\circ} \mathrm{N}$ und $40^{\circ} \mathrm{S}$ um ca. $20 \%$ zurück, nach Guillien (118) war das Mittelmeer «une immense région sèche». Alle diese Aussagen stützen sich entweder auf klimatologische Úberlegungen (verminderte Verdunstung - reduzierte Niederschläge) oder auf morphologische und stratigraphische Beobachtungen aus einer Phase der Würmzeit.

2. Wenn von einem richtigen mediterranen Pluvial gesprochen wird, das das Frühwürm dominierte und im Hochwürm ausklang $(43,48)$. Die Pollenuntersuchungen und absoluten Altersbestimmungen van der Hammens in Griechenland (123) zeigen uns, daß wir während der gesamten Würmzeit mit einer steppenhaften Vegetation rechnen müssen. Der Wechsel im Vegetationsbild von Früh- zu Spätwürm ist nicht sehr groß. Artemisia ist durchgehend dominant. Im Frühwürm erscheint neben Pinus noch Quercus, zwischen Hochwürm und Spätwürm ist Pinus der einzige Baum, Waldlosigkeit muß angenommen werden. Im Unterschied zu dieser würmeiszeitlichen Vegetation zeigt das Holocän eine dichte Bewaldung und ein relativ humides Klima (evtl. Sommerund Winterniederschläge, vgl. Lamb 1963 [167] und Disk.-beitr. Flohn in Butzer 1963 [48]. Mit diesen Ergebnissen können wir kaum von einem letzten mediterranen Pluvial in der früheren Würmzeit sprechen. Die eindrücklichen Resultate stimmen zwar mit zahlreichen bisherigen Angaben nicht überein (vgl. 360, S. 310; 312, S. 163; 66, S. 267 usw.). Vielleidht liegt die Untersuchungsstelle van der Hammens in einem relativ kontinentalen Raum (Mazedonien, ca. $120 \mathrm{~km}$ NE Thessaloniki), doch werden die vorgelegten Ergebnisse in neueren Arbeiten aus Spanien und Italien bestätigt (123, S. 39).

Im folgenden soll keine umfassende Darstellung der Zirkulationsbedingungen und Zirkulationsveränderungen von der letzten Eiszeit bis zur Gegenwart gegeben werden. Wir verweisen auf die ausgezeichneten Arbeiten von Poser, Büdel, Flohn, Butzer, Lamb, Fairbridge usw. Wir beschränken uns auf eine knappe Zusammenfassung derjenigen Elemente, die für das Verständnis der Glazialgeschichte und der Glazialformen im Mittelmeerraum von Bedeutung sind.

\subsubsection{Niederschlagsreiches Früh- und Hochglazial (Vorstoß der Gletscher)}

Mit dem Einsetzen einer langfristigen meridionalen Zirkulationsstruktur schwächt sich der subtropische Hochdruckgürtel $a b$, und in der unteren Atmosphäre verlagert sich die maximale Frontalzone äquatorwärts, begleitet von einer kontinuierlichen Temperatursenkung. Ein allgemein feuchteres Klima in Mitteleuropa $(289,39)$ zeichnet sich auch in den Sedimentationsformen des Mittelmeergebietes $\mathrm{ab}$ (48). Nun stellt sich aber die Frage, wie die heterogenen Ablagerungen mit teilweise bedeutenden Transportwegen niederschlagsmäßig zu interpretieren sind. Zweifellos sind solche Vorgänge im heutigen Niederschlagsregime undenkbar. Schließen wir daher auf ein allgemein feuchteres Klima, kommen wir mit der steppenhaften Vegetation van der Hammens in Widerspruch. Das führt uns zu folgenden grundsätzlichen Überlegungen: Wo es zu flächenhafter Denudation kommt (sheet-flood-erosion Butzers), Massenbewegungen auf wenig geneigten Hängen auftreten, Massentransporte durch torrentielle Abflüsse über weite Strecken vorkommen, die Ablagerungsformen einen wenig sortierten und heterogenen Eindruck machen, können wir gewisse Schlüsse auf den Niederschlagscharakter und das Vegetationsbild ziehen: Die Niederschläge werden nicht regelmäßig verteilt auftreten, sondern in heftigen und seltenen Güssen fallen. Tricart weist in scharfsinnigen Überlegungen auf die klimamorphologische Tatsache thin, daß grobe und unregelmäBige Ablagerungen eher das Kennzeichen eines trockeneren Klimas sind (343). Wenn wir für das Frühglazial nach C-14-Rechnungen ca. 35000 Jahre annehmen (39, S. 12: -75000 bis -40000 ), so mußte die geomorphologische Wirkung auch bei seltenen Ereignissen immer noch außerordentlich groß sein. Dies trifft besonders bei niederen und mittle- 
ren Gebirgshöhen zu, die in dieser Zeitspanne noch keine Vergletscherung erfahren haben und deshalb auch kein ausgeglichenes Abflußregime aufweisen konnten.

Dazu kommt ein weiteres: Solche Abtragungsprozesse in geringen Höhenlagen wären bei dichter Vegetationsdecke und Bewaldung nicht möglich, sie sind nur bei steppenhafter Oberflächenbedeckung denkbar. Im Durmitor haben wir würmzeitliche Moränenablagerungen in Karstformen beobachtet, die für eine sehr geringe chemische Verwitterung während der letzten Eiszeit sprechen und auf eine vorangegangene feuchte und warme Klimaperiode im letzten Interglazial hinweisen. Auch Kubiena diskutiert dieses Problem, indem die Terra-rossaBöden Spaniens in einem feuchteren und wärmeren Interglazial gebildet wurden und bis jetzt noch nicht als rezente Formation datiert werden konnten (Disk.beitr.. Kubienas in 48, S. 220). Alle diese Bemerkungen sollen darauf hinweisen, daß der Begriff «Pluvial» im Mittelmeerraum mit größerem Recht für einen Teil des letzten Interglazials oder Postglazials angewendet werden könnte als für das Frühwürm.

Doch wollen wir die zahlreichen Beweise für eine intensivere Niederschlagstätigkeit im Frühwürm nicht unterschätzen; sie wird vor allem auch durch Untersuchungen an Höhlensedimenten im nördlichen und südlichen Mittelmeer angezeigt (42, 41 usw.). Darin kommt der Unterschied zu den hochglazialen Schichten mit starker mechanischer Verwitterung (kaltes und trockenes Klima) deutlich zum Ausdruck.

Diese Ưberlegungen führen uns zu einem letzten Punkt: Die intensivere Niederschlagstätigkeit des Frühwürms könnte auf Sommerregen hinweisen, bedingt duroh die südwärts verlagerte Frontalzone. Es ist denkbar, daß gerade die Sommerniederschläge den torrentiellen Charakter verstärkten, wie ihn die Abtragungs- und Ablagerungsformen zeigen. Damit wären auch die Sommerschneefälle erklärt, die wir nach dem glazialen Formenschatz der Hochgebirge postuliert haben (Seite 200). In diesem Zusammenhang zitieren wir eine Stelle aus der interessanten Arbeit von Fliri $(91$, S. 8): «Es kann kein Zweifel bestehen, daß die Häufigkeit sommerlicher Schneefälle (Schneefallbereitschaft und größte Mengen) in erster Linie von der Zyklonalität in der allgemeinen Westströmung, damit aber von einer gewissen meridionalen Zirkulationskomponente abhängt.» Wie weit wir diese nordalpinen Verhältnisse mit der kaltzeitlich verstärkten Meridionalzirkulation bis in den Mittelmeerraum verlängern dürfen, können wir noch nicht beurteilen. Jedenfalls bekräftigen sie unsere Ansicht, daß Sommerschneefälle im eiszeitlichen Formenschatz der mediterranen Hochgebirge möglich und nachweisbar sind.

\subsubsection{Niederschlagsarmes Hoch- und Spätglazial}

(Stillstand und Rückzug der Gletscher)

Im Hochwürm mit Erreichen der größten Gletscherausdehnung, beginnt sich eine wesentliche Klimaänderung abzuzeichnen. Die Temperaturen gehen gegenüber dem Frühwürm weiter zurück (1-2 ${ }^{\circ}$ nach 66) und enreichen ihr absolutes Minimum gegen Ende des Hochglazials (118). Vor allem aber nehmen die Niederschläge ab, so daß die Oberflächenformen im Hoch- und zum Teil im Spätglazial von zunehmender Trockenheit geprägt sind. Dieser Prozeß der Selbstverstärkung von Abkühlung und Eisbildung (Flohn 1953, S. 268), von einer Art Gefriertrocknung (vgl. Frenzel 1959, II, S. 90) oder sógar von einer besonderen Zirkulationsform (Butzer 1957) wird mit Beginn des Spätglazials unterbrochen. Eine langsam einsetzende Erwärmung und die Auflösung der Inlandeismassen verlangen eine grundsätzliche Umstellung der Zirkulation. Auf diese Probleme wollen wir in unserem Zusammenhang nicht weiter eintreten. Wesentlich ist die Aussage, daß das Hoch- und zum Teil das Spätglazial für die Sedimentations- und Formungsprozesse in Mitteleuropa und im Mittelmeerraum von besonderer Bedeutung wurde. Nach Milankowitsch war die sommerliche Zustrahlung vor 22100 Jahren nur um 1,5\% niedriger als heute, die winterliche um 3,3\% höher (Zit. nach Flohn 1953, S. 271). Jedenfalls erhöhten die verminderten Niederschläge und die geringere Bewölkungsdauer die direkte Strahlung während des Tages und die Ausstrahlung während der Nacht. Da schließlioh die allgemeine Temperaturdepression nach unserer Meinung auch im Mittelmeerraum ganz bedeutend war, entwickelte sich in höheren Lagen ein äußerst intensiver Frostwechsel, der mit heutigen Verhältnissen nicht vergleichbar ist. Diese Klimaverhältnisse führten zu den mehrmals erwähnten gewaltigen Verwitterungsleistungen.

Zahlreiche Gebirgsvergletscherungen, vor allem südexponierte Anteile, lösten sich in dieser Trokkenphase bereits auf, und ihre Formen wurden in der Folgezeit durch Frostschuttmassen überdeckt (vgl. Erciyas Dagh, Taurus usw.).

Überblicken wir die gesamte Würmzeit, so können wir keinesfalls mehr von einem eiszeitlichen Klima und einer eiszeitlichen Formbildung sprechen. Eine einfache Gleichsetzung von Glazial in höheren Breiten und Pluvial in niederen Breiten ist nicht mehr haltbar. Sowohl ein niederschlagsreicheres Frühwürm hat sich bis ins Zentrum des heutigen Trokkengürtels ausgewirkt (Eiszeit $=$ "Regenzeit»), als auch ein niederschlagsarmes Hoch- bis Spätglazial (Eiszeit = "Trockenzeit»). Entstehung, Höhepunkt und Auflösung einer Kaltzeit, abgesehen von kurzen Wärmephasen oder Interstadialen, basieren auf wechselnden Zirkulationsformen und Klimaverhältnissen. 


\subsection{Vergletscherung und Vergletscherungsformen}

\subsubsection{Art und Dauer der Vergletscherung}

Im Frühwürm beginnt der Aufbau der großen nordischen Inlandeismassen. Die mediterranen Gebirgs. vergletscherungen setzen gestaffelt ein, zuerst an den höchsten und niederschlagsreichsten Gebirgen, dann allmählich tiefergreifend und in ungünstigere Räume ausholend. Genau gleich differenziert spielt sich die Auflösung der Gletscher ab. Zwischen 17000 und $11000 \mathrm{BP}$ schmelzen die großen Inlandeismassen aus. Im Mittelmeergebiet reagieren die kleinen Gebirgsvergletscherungen viel rascher, vor allem in ungünstigen Expositionen. Diese Überlegungen bedeuten: Die Dauer der Vergletscherung ist für jedes Gebirge verschieden. Die Rekonstruktion einer maximalen Gebirgsvergletscherung kommt einer Momentaufnahme gleich. In einer Sohneegrenzkarte sind diese Momentaufnahmen durch Isochionen miteinander verbunden, ohne Rücksicht auf eine mögliche räumliche und zeitliche Differenzierung.

Absolute Altersdatierungen ergeben im Raum Pisa ein Aussetzen von Pinus und Abies zwischen $26300 \pm 500 \mathrm{BP}$ und $16400 \pm 500 \mathrm{BP}$. Wenn sich die Folgerungen Guilliens (118, S. 35) weiterhin bestätigen, daß in diese Zeitspanne die Vergletscherung der Apuanischen Alpen einzuordnen ist, dann wäre auf einzigartige Weise die kurze Vergletscherungsdauer in diesem Massiv festgelegt. Im Vergleich dazu hätte dann der zentrale Apennin, der bedeutend höher über die Schneegrenze aufragte, eine unvergleichlich längere Vergletscherung und entsprechend auch einen tiefgreifenderen Formenwandel erlebt.

Aber selbst wenn man den Aussagewert dieser Walddatierungen für die Vergletscherungsdauer bezweifelt, so muß man doch die Zeitspanne zwischen ca. 24000 und $18000 \mathrm{BP}$ als die klimatisch günstigste Vergletscherungsphase anerkennen. Nachdem das Eis zwischen ca. 34000 und $28000 \mathrm{BP}$ zu gewissen Zeitpunkten in den Alpen weit zurückgegangen war, erfolgte ein neuer Vorstoß, der zwischen 22000 und 18000 BP die größte Ausdehnung der Würmzeit erreichte. Eine verstärkte Niederschlagstätigkeit (die sich in den Kulturschichten zwischen 24000 und $18000 \mathrm{BP}$ zeigt) und ein Trend zur größten Temperaturdepression (niedrigste Temperatur im Atlantik und Mittelmeer zwischen 18000 und $17000 \mathrm{BP}$, Lit. 118) drückte die Schneegrenzen auch im Mittelmeerraum kräftig hinunter und schnitt für kurze Zeit zahlreiche Gebirge an, die vorher nicht vergletschert waren. Das bereitstehende Verwitterungsmaterial wurde zu bedeutenden Akkumulationsformen umgewandelt, währenddem die glazialen Erosionsformen durch die kurze Einwirkungszeit relativ bescheiden blieben.

In unseren Ausführungen haben wir mehrmals betont, daß das Mittelmeer zur Würmzeit morphoklimatisch eine Einheit bildete. Raynal und Tricart (296, S. 595) haben aber gezeigt, daß in früheren Kaltzeiten deutliche Klimaunterschiede festzustellen sind, indem z. B. eine Kältephase auf das Nordufer beschränkt blieb und das Südufer nicht erreichte. Für die letzte Kaltzeit kommen wir zum Schluß, daß sich bedeutende Veränderungen erst südlich des Mittelmeeres abzuzeichnen beginnen. Die erhöhte Niederschlagstätigkeit im Früh- und teilweise im Hochwürm spielte bis in die zentrale Sahara hinein, wie Seenbildungen und absolute Altersbestimmungen beweisen. Da aber die Temperatursenkung äquatorwärts stark abnahm, ist es wohl denkbar, daß eine Vergletscherung im Einflußbereich der großen Kontinentalräume ausblieb oder zum mindesten stark gehemmt wurde. (Hohe Sommertemperaturen). Wohl bildeten sich durch die Winterniederschläge Schneeansammlungen und entsprechende Nivationsformen aus, wie die Untersuchungen in Tunesien (119) und im Hoggar (304) beweisen, aber es konnte sich kaum eine langdauernde und wirkungsvolle Vergletscherung entwickeln. Nur in den höchsten Gebirgen (z. B. Hoher Atlas) kam es bei optimalsten Bedingungen von Niederschlagssteigerung und Temperatursenkung zu zeitlich begrenzten Vergletscherungen: Zunehmende Kontinentalität wirkte sich auf Art und Dauer der Vergletscherung aus.

Zusammengefaßt: Die über 200 vereisten Gebirgsmassive des Mittelmeerraumes haben alle eine Vergletscherung von unterschiedlicher Dauer erlebt. Diejenigen Gebirge, die heute einen rezenten Gletscher beherbergen, wurden zweifellos schon im Frühwürm vergletschert und aperten erst gegen Ende des Spätwürms aus. Die Vergletscherungsdauer konnte nach Berücksichtigung der verschiedenen Wärmewellen 40 000-50 000 Jahre betragen. Diejenigen Gebirge, die die Schneegrenze kaltzeitlich nur ganz knapp anschnitten, wurden möglioherweise nur in der günstigsten Klimaphase, d. h. während einigen 1000 Jahren vergletschert. Wenn wir bedenken, daß sich diese Zeitunterschiede auch in früheren Kaltzeiten wiederholen konnten, so erkennen und verstehen wir die bedeutenden Differenzen in den Vergletscherungsformen.

\subsubsection{Ablauf und Formen der Vergletscherung}

(Fig. 22)

Die grundsätzliche Klimagliederung der Würmzeit und ihre Auswirkungen auf die Vergletscherung und die Vergletscherungsformen haben wir in Fig. 22 an einem mediterranen "Durchschnittsgebirge» 


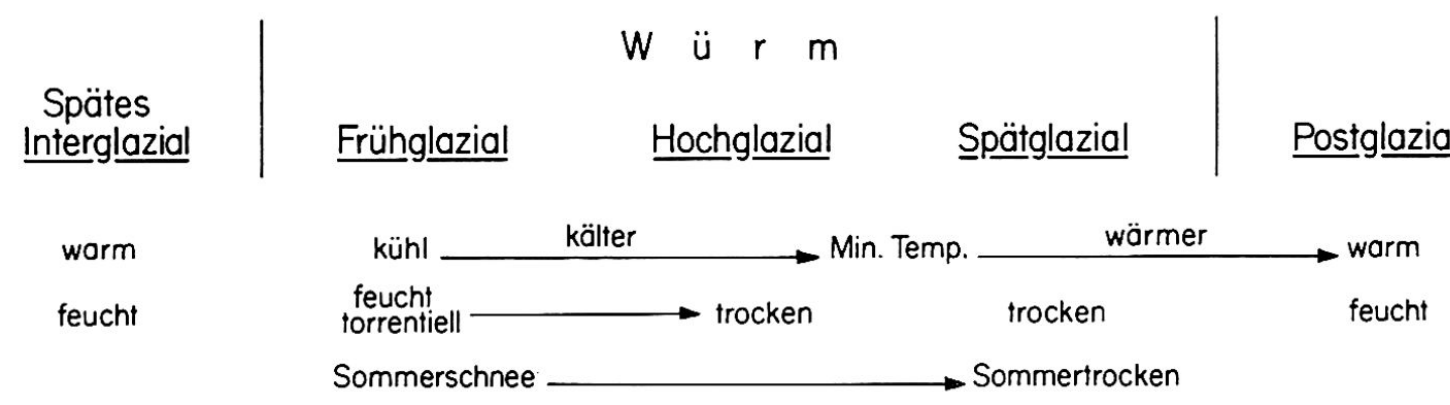
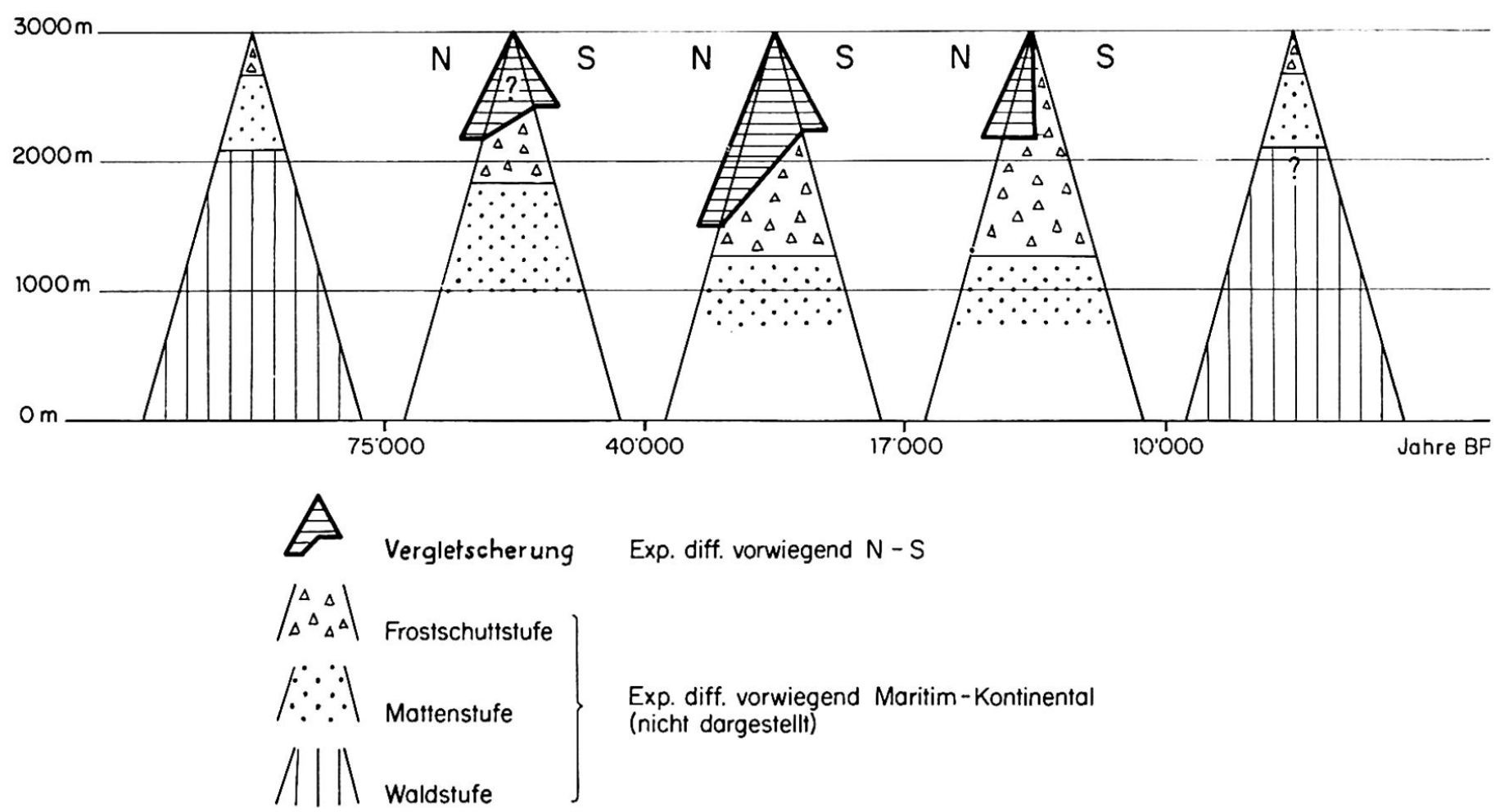

Fig. 22 Glazialgeschichte der mediterranen Hochgebirge (schematisch)

schematisch und hypothetisch dargestellt. Es ist im Viereck Sierra Nevada_Gran Sasso_Olymp_Taurus beheimatet, ist weder extrem kontinental noch maritim beeinflußt und hat mit einer Höhe von ca. $3000 \mathrm{~m}$ eine bedeutende kaltzeitliche Vergletscherung erfahren.

Nach einem relativ warm-humiden Ende-Interglazial entwickeln sich im Frühwürm die ersten Gletscher. Ihre Ausdehnung läßt sich kaum mehr rekonstruieren. Sommerschneefälle mindern die Expositionsdifferenzen und überformen die höchsten Gipfel und Kreten. Die Frostschuttstufe wird hinuntergedrückt.

Das Hochwürm mit zunehmender Trockenheit erzeugt trotz verstärkter Temperaturdepression eine sommerliche Einstrahlung, die der heutigen fast ebenbürtig ist. Die Expositionsdifferenzen werden größer, die Verwitterungsvorgänge steigern sich zu höchster Intensität und die Frostschuttstufe erreicht ihren tiefsten Stand. Die Vorstoßphase am Ende des Hochglazials formt in den meisten Gebirgen die
Endmoränen in N- und S-Exposition und markiert den ausgedehntesten Vergletscherungsstand der letzten Kaltzeit.

Im trockenen Spätglazial gehen die Gletscher zurück. Die Erwärmung setzt nur sehr langsam ein, so daß der größte Teil dieses Zeitabschnittes durch ein intensives Frostwechselklima gekennzeichnet ist. Extreme Expositionsdifferenzen werden gebildet und die glazialen Erosions- und Akkumulationsformen vielerorts durch Frostschuttmassen überdeckt. Genauer gesagt: Glazialformen in höheren Regionen (größere Frostwechselwirkung) und in unmittelbarer Hangfußlage werden verschüttet (z. B. Erciyas Abb. 8, 10; Taurus Abb. 23). Glazialformen in niedrigeren Regionen (geringere Frostwechselwirkung) und abgelöst von unmittelbarer Hangfußlage (Endmoränen) bleiben ausgezeichnet erhalten (z. B. Sierra Nevada, Lit. 204, Abb. 24; Taurus Abb. 19; Ak Dagh Abb. 27).

Die Postglazialzeit bringt Wärme- und Kältephasen in mehrmaligem Wechsel. Die Niederschlagszu- 
nahme verändert das Vegetationsbild (123) und die klimamorphologischen Höhenstufen wandern aufwärts.

Klimaverhältnisse und Klimaablauf von der Würmeiszeit bis zur Gegenwart haben jedes Gebirge nach
Höhe, Lage und vorgefundenem Relief verschieden lange und verschieden intensiv vergletschert, so da $\beta$ sich aus den glazialen Formen und ihrer Höhenlage wesentliche Hinweise auf Klimaverhältnisse und Klimaablauf von der Würmeiszeit bis zur Gegenwart gewinnen lassen.

\section{ZUSAMMENFASS UNGEN}

\section{Teil}

Jedes einzelne Untersuchungsgebiet ist am Schluß französisch und englisch zusammengefaßt. (Siehe Inhaltsverzeichnis.)

\section{Teil}

Eine Schneegrenzkarte ist eine ungemeine Vergröberung jeder genauen Untersuchungsarbeit. Jedes Tal und jede Exposition haben eiszeitlich und rezent ihre lokalen Schneegrenzen, die durch ein komplexes Zusammenspiel von orographischen und klimatischen Faktoren bestimmt werden. Die Zusammenfassung in einen regionalen Mittelwert ist eine Verallgemeinerung, die dem wahren Inhalt kaum gerecht wird, aber für einen großräumigen Vergleich doch notwendig ist (vgl. Karte 1 und 2).

Wenn wir die eiszeitliche Schneegrenze als Mittelwert aus den verschiedenen Expositionen bestimmen, dann müssen wir bei der Ermittlung der rezenten Schneegrenze ein gleiches Vorgehen versuchen. Vereinzelte Gletscher in Gunstlage dürfen nicht überschätzt und die zugehörige regionale Schneegrenze nicht zu tief angesetzt werden, sonst ergeben sich $\mathrm{zu}$ geringe letzteiszeitliche Schneegrenzdepressionen.

Die Schneegrenzen im Mittelmeerraum passen sich der Meer-Land-Verteilung und den Gebirgsrichtungen an. Z.B. verläuft die würmeiszeitliche 2000-m-Isochione vom westlichen Andalusien bis an den Südfuß der Pyrenäen, dann wieder südwärts bis in die algerischen Küstenketten und wieder nordwärts über den Balkan bis zum Abschwenken nach Osten. Das Anpassen an Relief und Klima ist viel ausgeprägter als ein Ansteigen von $\mathrm{N}$ nach $\mathrm{S}$. Darin zeigt sich eine gewisse klimatische Einheit des gesamten Mittelmeerraumes.

Ein knickartiges Ansteigen der gegenwärtigen und eiszeitlichen Schneegrenzen ergibt sich unmittelbar südlich des Mittelmeeres. Von den Alpen (ca. $46^{\circ}$; Schneegrenzen N-Rand 2700, Zentrum über 3200 Meter) steigen die rezenten Schneegrenzen über
9-12 Breitengrade bis zur Sierra Nevada (37\%; Schneegrenze $3650 \mathrm{~m}$ ) oder zum Libanon (34; Schneegrenze $3700 \mathrm{~m}$ ) im Mittel ca. $800 \mathrm{~m}$. Kurz darauf erfahren sie in ihrem weiteren Verlauf nach Süden einen ungewohnten Aufschwung mit nochmals $800 \mathrm{~m}$ innerhalb weniger Breitengrade bis zum Hohen Atlas ( $31^{\circ}$; Schneegrenze min. 4500 m). Die eiszeitlichen Schneegrenzen verhalten sich ganz ähnlich. Von den Alpen (Schneegrenze N-Rand unter $1200 \mathrm{~m}$, Zentrum über $1800 \mathrm{~m}$ ) steigen sie im Mittel etwas mehr als $800 \mathrm{~m}$ zur Sierra Nevada an (Schneegrenze $2350 \mathrm{~m}$ ) und wölben sich dann über wenige Breitengrade um mehr als $1000 \mathrm{~m}$ zum Hohen Atlas auf (Schneegrenze ca. $3450 \mathrm{~m}$ ). Die gegenwärtige und eiszeitliche Schneegrenzfläche erfährt einen knickartig raschen Anstieg: Im Westen zwischen Rif und Hohem Atlas, im Osten zwischen Libanon und Sinai. Wiederum zeigt sich die ausgleichende Wirkung des Mittelmeeres und der schlagartige Wechsel mit dem Überschreiten der südlichen (Rif, Kabylien) und östlichen (Libanon) Küstenketten. Diese Erscheinung war in der letzten Kaltzeit noch viel ausgeprägter als in der Gegenwart.

Lösen wir uns vom unruhigen Auf und Ab der Isochionen, so erkennen wir im allgemeinen Schneegrenzverlauf die westliche Randlage unseres Untersuchungsgebietes am großen eurasiatischen Kontinent. Betrachten wir die niedrigste von $\mathrm{W}$ nach $\mathrm{E}$ durchgezogene Schneegrenzlinie $1800 \mathrm{~m}$ : Sie betritt auf ca. $36^{\circ}$ Breite die Iberische Halbinsel und verläßt zwischen 42 und $45^{\circ}$ den europäischen Raum. Die höchste durchgezogene Isochione 3200 Meter: Sie erreicht unseren westlichen Kartenrand auf ca. $31^{\circ}$ und verliert sich nordwärts ansteigend in der syrischen Trockenzone auf ca. $37^{\circ}$. Als Ganzes erkennen wir die niedrigeren Schneegrenzhöhen im Westen, die unabhängig vom turbu lenten Verlauf im Mittelmeerraum nach Osten ansteigen und damit auf den Klima- und Landschaftswandel vom Kontinentalrand zum Kontinentinnern hinweisen.

Die Schneegrenzdepressionen sind im westlichen Mittelmeerbecken eher mehr als 1200 m, im östli- 
chen eher weniger als $1200 \mathrm{~m}$. Die eiszeitlichen Schneegrenzen steigen von $\mathrm{W}$ nach $\mathrm{E}$ stärker an als die rezenten (z. B. Sierra Nevada_Bolkardagh-Taurus in gleicher Breite und ähnlicher Klimalage: Rezente Schneegrenze und Waldgrenze auf gleicher Höhe, aber würmeiszeitlicher Schneegrenzanstieg von 2350 auf $2650 \mathrm{~m}$ ). Dieser Sachverhalt weist auf Zirkulationsprobleme und die Abgeschlossenheit des östlichen Mittelmeerbeckens während der letzten Kaltzeit hin.

Zahlreiche lokale Besonderheiten haben wir diskutiert und daraus interessante Hinweise auf die kaltzeitlichen Klimaverhältnisse gewonnen. Z. B. die relativ großen Schneegrenzdepressionen in Zentralanatolien, die Probleme des ägäischen Raumes, die außerordentlich niedrigen Schneegrenzen in Dalmatien und Montenegro, die kaltzeitliche Vergletscherung der algerischen Küstenkette, die Höhenstufung beidseits der Straße von Gibraltar usw. Auf eine genauere Zusammenfassung der eiszeitlichen und gegenwärtigen Schneegrenzhöhen in den einzelnen Regionen des Mittelmeerraumes müssen wir verzichten, weil die Zusammenstellung im Text schon sehr knapp gehalten ist.

\section{Teil}

Die Bestimmung einer eiszeitlich regionalen Schneegrenze ist problematisch: Es gibt keine Idealmethode und die Expositionsdifferenzen sind im Mittelmeerraum sehr groß. Die Vergletscherungsassymmetrien richten sich nach bestimmten orographischen und klimatischen Gesetzmäßigkeiten (Fig. 19). Die größten Differenzen treten zwischen dem 36. und 43. Breitengrad auf und maximale einseitige Vergletscherungen überdecken Höhenbereiche bis $\mathrm{zu}$ 1400 m. Die Expositionsdifferenzen sind nicht konstant, sie verschieben sich mit auf- oder absteigender Schneegrenze: sie vergrößern sich von einer eiszeitlich niedrigen zu einer rezent hohen Schneegrenzfläche.

Die wenigen rezenten Gletscherflecken in streng begrenzten Gunsträumen können bis zu 1000 m unter der regionalen Schneegrenzfläche auftreten, von Schneerutschen und Lawinen ernährt werden und von den klimatischen Bedingungen einer Schneegrenze völlig unabhängig sein. Zur Rekonstruktion der rezenten Schneegrenzfläche haben wir die Temperatur des wärmsten Monats herangezogen. Diese Beziehung stimmt innerhalb einer Fehlergrenze von $\pm 200 \mathrm{~m}$ von den Alpen bis in den südlichen Mittelmeerraum, löst sich aber über dem einsetzenden Trockengürtel auf (Fig. 21).

Der Schneegrenzbegriff wird heute in verschiedenster Bedeutung angewandt. Wir sollten zu einer klaren Trennung in Schneegrenze außerhalb des Gletschers (Niveau 365) und Schneegrenze auf dem
Gletscher (Gleichgewichtslinie oder Firnlinie) zurückkehren. Die beiden Grenzen unterscheiden sich höhenmäßig von einigen $100 \mathrm{~m}$ bis zu über $1000 \mathrm{~m}$. Die bisherigen eiszeitlichen und rezenten Schneegrenzen wurden entgegen der ursprünglichen Definition immer wieder auf Gletschern bestimmt und bedeuten deshalb angenäherte Werte für die Gleichgewichtslinien. Die Frage ist aber, ob wir in Zukunft die ungenauen geographischen Begriffe in genau definierbare glaziologisch-klimatologische Bezeichnungen überführen können.

Große Expositionsdifferenzen in der kaltzeitlichen Vergletscherung weisen auf strahlungsreiche Sommerhalbjahre mit großer Ablationswirkung hin. Meridionale Zirkulationskomponenten brachten aber sporadische Sommerschneefälle bis in die mediterranen Hochgebirge. Feuchter und gut haftender Sommerschnee wurde in den höchsten Gipfelregionen in Firn und Eis umgewandelt und hat die Oberflächenformung der niederschlagsgünstigen Hochregionen wesentlich beeinflußt.

Die großen Expositionsdifferenzen dürfen aber auch nicht überschätzt werden (S-Gletscher am Erciyas, Taurus, Libanon, Sierra Newada usw.). Die gewaltige Verwitterungsleistung seit dem Hochwürm hat vielfach südexponierte Glazialformen verschüttet.

In den mediterranen Gebirgen treten vergletscherte Flächen vielfach nicht über, sondern neben dem Frostschutt- oder Solifluktionsbereich auf. Diese Erscheinung erklärt sich mit der besprochenen Aufgliederung des Schneegrenzbegriffs: das Niveau 365 , die eigentliche Untergrenze der nivalen Stufe, löst die Frostschuttstufe nach oben ab. Die mittlere Gleichgewichtslinie der Gletscher kann bedeutend tiefer liegen, in strahlungsintensiven und sommertrockenen Gebirgen entstehen und existieren die Gletscher häufig in Gunstlagen der Frostschuttstufe. Niveau 365 und mittlere Gleichgewichtslinie konnten in einer kaltzeitlichen mediterranen Gebirgsvergletscherung 500-1000 m differieren.

Die Schneegrenze steigt im Mittelmeerraum von $\mathrm{N}$ nach $\mathrm{S}$ viel rascher an als die obere Waldgrenze. Die Abstandswerte vergrößern sich von ca. $1000 \mathrm{~m}$ im nördlichen auf ca. $1500 \mathrm{~m}$ im südlichen Mittelmeer. Diese Erscheinung weist auf die kräftige Ausweitung der Frostschuttstufe von $\mathrm{N}$ nach $\mathrm{S}$ und von maritimen nach kontinentalen Klimaprovinzen hin, was auch ein Vergleich Schneegrenze_Solifluktionsgrenze bestätigt. Alle diese Höhengrenzen haben eigene Entstehungs- und Existenzbedingungen und können niemals gleichsinnig verlaufen.

Die letzteiszeitliche Schneegrenzdepression unterliegt großen Schwankungen, sie läßt sich nirgends eindeutig mit tektonischen Vorgängen in Beziehung setzen. Im kleinräumigen Verhalten wirken sich niederschlagsreiche und niederschlagsarme Zonen in einer kaltzeitlich niedrigen Schneegrenze kräf- 
tiger aus als in einer hochliegenden rezenten, deshalb verändert sich die Schneegrenzdepression zu größeren Werten in regenreichen und zu kleineren Werten in regenarmen Zonen. Die Bedeutung der Temperaturgradienten für die Schneegrenzdepression haben wir eingehend diskutiert. Mit allen Vorbehalten ermittelten wir aus den Schneegrenzdepressionen folgende kaltzeitliche Temperatursenkungen des wärmsten Monats: nördlicher Mittelmeerraum in maritimer Lage etwas weniger als $10^{\circ}$, in kontinentaler Lage bis $10^{\circ}$ und mehr. Südlicher und östlicher Mittelmeerraum im Einflußbereich der Trokkengebiete $6-7^{\circ}$.

Die kaltzeitliche Meeresregression hat die Struktur des Mittelmeeres ganz bedeutend verändert, was sich an zahlreichen Stellen auf Klima und Schneegrenzverlauf ausgewirkt hat. Besonders interessant ist die Aufteilung in zwei fast getrennte Becken. Der Klimaraum des östlichen Mittelmeeres war etwas kontinentaler geprägt als der westliche, wie es die Schneegrenzhöhen andeuten.

Vergletscherung und Vergletscherungsformen des Mittelmeerraumes weisen auf ein niederschlagsreicheres Früh- bis Hochwürm und ein niederschlagsarmes Hoch- bis Spätwürm hin. Unregelmäßige Starkgüsse mit torrentiellem Abfluß und heterogenen Ablagerungen in tieferen Lagen, Sommerschneefälle in höheren Lagen, kennzeichnen die Morphodynamik des Frühwürms. Die Niederschlagsverteilung erlaubt keine dichte Vegetation und Bewaldung, so daß wir kaum von einem richtigen Pulvial sprechen dürfen. Ein kalt-trockenes Hoch- bis Spätwürm mit hoher Strahlungsintensität in den Hochgebirgen verstärkt die Verwitterungsleistung und fördert die extremen Hang- und Vergletscherungsasymmetrien. Als Ganzes können wir keinesfalls mehr von einem würmeiszeitlichen Klima und einer würmeiszeitlichen Formenbildung sprechen. Eine einfache Gleichsetzung von Glazial in höheren Breiten und Pluvial in niederen Breiten ist nicht mehr haltbar. Sowohl ein niederschlagsreicheres Früh- und Hochglazial hat sich bis ins Zentrum des heutigen Trockengürtels ausgewirkt (Eiszeit $=$ Regenzeit), als auch ein niederschlagsarmes Hochund Spätglazial (Eiszeit $=$ Trockenzeit).

Die über 200 vereisten Gebirgsmassive des Mittelmeenraumes haben alle eine unterschiedliche Vergletscherungsdauer erlebt. Diejenigen Hochgebirge, die heute noch einen rezenten Gletscher beherbergen, wurden zweifellos schon im Frühwürm vergletschert und aperten erst gegen Ende des Spätglazials aus. Die würmzeitliche Vergletscherungsdauer konnte 40 000-50 000 Jahre betragen. Diejenigen Gebirge, die die Schneegrenze kaltzeitlich nur knapp anschnitten, wurden nur in der günstigsten Klimaphase (22 000-18 000 BP) während einiger 1000 Jahre vergletschert. Diese gewaltigen Zeitunterschiede wiederholten sich auch in früheren Kalt- zeiten, was sich in den bedeutenden Differenzierungen der Vergletscherungsformen widerspiegelt.

\section{RÉSUMÉS}

\section{lère partie}

Chaque région est résumée à la fin du chapitre en français et anglais (voir table des matières).

\section{IIe partie}

Une carte des lignes des neiges est une généralisation grossière de chaque travail de recherches précises. Chaque vallée et chaque exposition ont leurs lignes des neiges réelles et locales pour l'époque actuelle et glaciaire. Elles sont fixées par un ensemble complexe de facteurs orographiques et climatiques. Leur synthèse en une moyenne régionale est une généralisation qui ne rend guère justice à l'énonciation véritable, mais qui est pourtant nécessaire pour une comparaison des grands espaces (voir cartes 1 et 2). $\mathrm{Si}$ nous obtenons la ligne des neiges glaciaire comme valeur moyenne des différentes expositions, nous devons tenter le même procédé pour déterminer la ligne récente des neiges. Des glaciers isolés en situation favorable ne doivent pas être surestimés, et la ligne régionale des neiges ne doit donc pas être fixée trop bas, sinon nous obtenons de trop petites dépressions de la ligne des neiges de la dernière époque glaciaire.

Les lignes des neiges dans le domaine méditerranéen s'adaptent à la répartition de mer et de terre et aux directions des montagnes. Par exemple l'isochione würmienne de $2000 \mathrm{~m}$ passe de l'Andalousie occidentale au pied méridional des Pyrénées, ensuite vers le sud jusqu'aux chaînes côtières algériennes, et retourne vers le nord par le Balkan pour enfin se tourner vers l'est. L'adaptation au relief et au climat local est bien plus marquée que l'élévation des lignes des neiges du nord au sud. Ainsi apparaît une certaine unité climatique du domaine méditerranéen. Une élévation brusque de la ligne des neiges actuelle et glaciaire se montre immédiatement au sud de la Méditerranée. Des Alpes (env. $46^{\circ}$, lignes des neiges rebord N: $2700 \mathrm{~m}$, centre: plus de $3200 \mathrm{~m}$ ) à la Sierra Nevada $\left(37^{\circ}\right.$, ligne des neiges $\left.3650 \mathrm{~m}\right)$ ou au Liban $\left(34^{\circ}\right.$, ligne des neiges $3700 \mathrm{~m}$ ) les lignes des neiges récentes s'élèvent environ $800 \mathrm{~m}$ sur 9-12 degrés de latitude. Peu après, dans leur parcours vers le sud, elles montent extrêmement vite, encore 
une fois de $800 \mathrm{~m}$ en l'espace de peu de degrés de latitude jusqu'au Haut Atlas $\left(31^{\circ}\right.$, ligne des neiges min. $4500 \mathrm{~m}$ ). Les lignes des neiges glaciaires ont un tracé tout à fait semblable. Des Alpes (l. d. n. rebord nord à moins de $1200 \mathrm{~m}$, centre plus de $1800 \mathrm{~m}$ ), elles montent en moyenne un peu plus que $800 \mathrm{~m}$ jusqu'à la Sierra Nevada (l. d. n. à env. $2350 \mathrm{~m}$ ) et se bombent ensuite plus de $1000 \mathrm{~m}$ audessus de peu de degrés latitude vers le Haut Atlas (l. d. n. env. $3450 \mathrm{~m}$ ). La surface des lignes des neiges actuelle et récente se bombe donc brusquement: à l'ouest entre Rif et Haut Atlas, à l'est entre Liban et Sinai. L'effet égalisant de la Méditerranée se montre à nouveau, ainsi que le changement subit au moment où l'on franchit les chaînes côtières méridionales (Rif, Kabylie) et orientales (Liban). Ce phénomène était encore plus prononcé lors de la dernière époque glaciaire qu'actuellement.

Si nous nous détachons des hauts et des bas agités des isochiones, nous reconnaissons dans l'ensemble du tracé des lignes des neiges würmiennes la situation de notre région en bordure occidentale du grand continent eurasien. Suivons la ligne des neiges de $1800 \mathrm{~m}$ la plus basse qui se poursuive de l'ouest à l'est: elle pénètre la péninsule ibérique à $36^{\circ}$ de latitude et quitte l'Europe entre 42 et $45^{\circ}$. La ligne la plus haute de $3200 \mathrm{~m}$ atteint la limite occidentale de notre carte à environ $31^{\circ}$ et se perd, montant vers le nord, dans la zone aride du Proche Orient à env. $37^{\circ}$. En général, nous reconnaissons les lignes des neiges plus basses à l'ouest, lesquelles - indépendamment du parcours turbulent dans le domaine méditerranéen - s'élèvent vers l'est et indiquent ainsi le changement de climat et de paysage du bord du continent vers l'intérieur.

Les dépressions des lignes des neiges ont tendance à dépasser $1200 \mathrm{~m}$ dans le bassin méditerranéen occidental, à être moins grandes que $1200 \mathrm{~m}$ dans le bassin oriental. Les lignes des neiges glaciaires s'élèvent plus fortement de l'ouest à l'est que les récentes. (P. ex.: Sierra Nevada - Bolkardagh Taurus, même latitude, situation climatique semblable: ligne des neiges récente et limite de la forêt à la même altitude, mais élévation de la ligne des neiges würmienne de 2350 à $2650 \mathrm{~m}$.) Cet état des choses indique des problèmes de circulation atmosphérique et un isolement du bassin méditerranéen oriental durant la dernière époque glaciaire.

Nous avons discuté de nombreuses particularités locales et en avons obtenu d'intéressantes indications concernant la situation climatique glaciaire. P. ex. les dépressions de la ligne des neiges relativement grandes en Anatolie centrale, les problèmes de l'espace de la Mer Egée, les lignes des neiges extrêmement basses en Dalmatie et dans le Montenègre, la glaciation des deux côtés du détroit de Gibraltar etc. Nous devons renoncer à un résumé plus particulier des lignes des neiges glaciaires et ac- tuelles dans les différentes régions méditerranéennes, car le texte en lui-même a déjà dû être tenu très bref.

\section{IIIe partie}

La détermination d'une ligne des neiges glaciaire régionale est problématique. Il n'y a pas de méthode idéale, et les différences d'exposition sont très grandes dans le domaine méditenranéen. Les asymmétries de glaciation dépendent de certaines lois orographiques et climatiques (Fig. 19). Les plus grandes différences apparaissent entre le $36 \mathrm{e}$ et le $43 \mathrm{e}$ parallèle, et les glaciations unilatérales maximales recouvrent une différence de niveau allant jusqu'à $1400 \mathrm{~m}$. Les différences d'exposition ne sont pas constantes, elles diffèrent avec l'élévation ou l'abaissement de la ligne des neiges: elles s'agrandissent en passant d'une surface des lignes glaciaires vers une même surface récente plus élevée.

Les rares taches glaciaires récentes en situations particulièrement favorables strictement délimitées peuvent apparaître jusqu'à $1000 \mathrm{~m}$ au-dessous de la surface de la ligne des neiges régionales, se nourrir de glissements de neige et d'avalanches et être totalement indépendantes des conditions climatiques d'une ligne des neiges. Pour reconstruire la surface des lignes des neiges récentes, nous avons eu recours à la température du mois le plus chaud. Cette relation s'avère juste sous réserve d'une erreur de \pm $200 \mathrm{~m}$ des Alpes jusqu'au domaine méditerranéen méridional; elle se dissout au-dessus des débuts de la zone aride (Fig. 21).

La notion de la ligne des neiges est employée aujourd'hui pour les significations les plus diverses. Nous devrions revenir à une distinction claire entre la ligne des neiges à l'extérieur du glacier (niveau 365 ) et la ligne des neiges sur le glacier (ligne d'équilibre ou ligne du névé). Ces deux lignes diffèrent de quelque $100 \mathrm{~m}$ d'altitude à plus de $1000 \mathrm{~m}$. A l'encontre de la définition originale, les lignes des neiges glaciaires et récentes ont constamment été délimitées sur des glaciers et sont donc des valeurs approximatives de lignes d'équilibre. Mais la question se pose de savoir si nous pouvons à l'avenir passer des notions géographiques imprécises vers des désignations glaciologiques-climatiques exactement définissables.

Les grandes différences d'exposition dans la glaciation indiquent des étés avec forte insolation et grande influence de l'ablation. Mais des composants de la circulation suivant les méridiens apportaient sporadiquement des chutes de neige estivales jusque dans les hautes montagnes méditerranéennes. La neige d'été humide et bien adhérante était transfor- 
mée en névé et glace dans la région des plus hautes cimes, et a sensiblement influencé la formation de la surface des hautes régions favorisées par les précipitations .

Les grandes différences d'exposition ne doivent pourtant pas non plus être surestimées (glaciers sud à l'Erciyas, dans le Taurus, le Liban, la Sierra Nevada etc.). Les puissants matériaux résultant de la désagrégation depuis le maximum de la glaciation Würm ont souvent enfoui les formes glaciaires exposées au sud.

Dans les montagnes méditerranéennes, les surfaces recouvertes de glace apparaissent souvent non seulement au-dessus, mais à côté du domaine des sols structurés et de la solifluction. Ce phénomène s'explique par la subdivision de la notion de la ligne des neiges dont nous avons parlé: le niveau 365, vraie limite inférieure de l'étage nival, fait suite vers le haut à l'étage des sols structurés. La ligne d'équilibre moyenne des glaciers peut se trouver bien plus bas; dans les montagnes ayant une forte insolation et des étés secs, les glaciers apparaissent et existent souvent dans les situations favorables de l'étage des sols structurés. Le niveau 365 et la ligne d'équilibre moyenne ont pu différer de $500-1000 \mathrm{~m}$ pendant une glaciation méditerranéenne quaternaire.

Dans le domaine méditerranéen, la ligne des neiges s'élève bien plus rapidement du nord au sud que la limite supérieure de la forêt. L'éloignement entre les deux augmente, passant d'environ $1000 \mathrm{~m}$ dans le nord de la Méditerranée à environ $1500 \mathrm{~m}$ dans le sud. Ce phénomène indique un fort élargissement de l'étage des sols structurés du nord au sud et des provinces de climat maritime à celles de climat continental, ce qui est confirmé par une comparaison: ligne des neiges - limite de la solifluction. Toutes ces limites d'altitude ont leurs propres conditions d'apparition et d'existence et ne peuvent jamais se dérouler de manière égale.

La dépression de la ligne des neiges de la dernière époque glaciaire est soumise à de grandes variations. Nulle part, elle ne peut être mise en relation absolument évidente avec des phénomènes tectoniques. Dans le comportement en petit espace, les zones riches ou pauvres en précipitations ont un effet plus prononcé, lorsque la ligne des neiges est basse comme à l'époque glaciaire, que lorsqu'elle est haute, comme à l'époque actuelle. C'est pourquoi la dépression de la ligne des neiges augmente dans les zones riches en précipitations et diminue dans celles qui en ont peu. - Nous avons discuté en détail l'importance des gradients des températures pour la dépression de la ligne des neiges. Sous toutes réserves, nous déterminons la baisse suivante des températures de l'époque glaciaire dans les couches d'air basses pour le mois le plus chaud: Domaine méditerranéen nord en situation maritime: un peu moins de $10^{\circ}$, situation continentale: $10^{\circ}$ et plus. Domaine méditerranéen méridional et oriental, dans la zone d'influence des régions arides: $6-7^{\circ}$.

La régression de la mer à l'époque glaciaire a changé la structure de la Méditerranée de manière tout à fait importante, ce qui a eu des conséquences à de nombreux endroits sur le climat et le tracé de la iigne des neiges. La division en deux bassins séparés est spécialement intéressante. Le domaine climatique de la Méditerranée orientale était de caractère un peu plus continental que l'occidental, comme l'altitude des lignes des neiges le fait présumer.

La glaciation et ses formes dans le domaine méditerranéen indiquent un Würm, des débuts jusqu'au maximum, plus riche en précipitations, et un Würm, maximum jusqu'à final, pauvre en précipitations. De fortes averses irrégulières avec écoulement torrentiel et dépôts hétérogènes en situations plus basses, précipitations estivales en situations plus élevées, caractérisent la morphodynamique des débuts de l'époque Würm. La répartition des précipitations ne permet ni végétation ni forêt denses, si bien que nous ne pouvons guère parler d'un vrai pluvial. Un Würm maximum jusqu'à final froid et sec avec grande intensité d'insolation dans les hautes montagnes renforce la capacité de désagrégation et favorise les extrêmes asymétries de pente et de glaciation. En résumé, nous ne pouvons en aucun cas parler d'un climat würmien et d'une formation du relief würmienne. Il n'est plus possible de soutenir une simple juxtaposition de glaciaire dans les latitudes plus septentrionales et de pluvial dans les latitudes méridionales. Les débuts et le maximum de l'époque glaciaire riches en précipitations ont aussi bien eu leurs répercussions jusqu'au centre de la zone aride actuelle (époque glaciaire $=$ époque pluviale) que le maximum et le tardiglaciaire pauvres en précipitations (époque glaciaire $=$ époque sèche).

Les plus de 200 massifs couverts de glace du domaine méditerranéen ont tous connu une différente durée de glaciation. Les hautes montagnes qui possèdent aujourd'hui encore un glacier récent ont certainement déjà reçu la glace aux débuts de l'époque Würm et se sont déglacés seulement vers la fin du tardiglaciaire. La durée de la glaciation würmienne a pu être de 40-50 000 ans. Les montagnes qui, par contre, ne coupaient qu'à peine la ligne des neiges à l'époque glaciaire ne furent recouvertes de glace que pendant la phase climatique la plus propice, (ca. 22 000-18 000 BP), soit durant quelques millénaires. Ces immenses différences dans le temps se sont répétées pendant les époques glaciaires antérieures, ce qui se réflète dans les importantes différences des formes ayant résulté des glaciations. 


\section{SUMMARIES}

\section{Par: I}

A french and english summary may be found at the end of each examinated region (see index).

\section{Part II}

The snow-lines in the Mediterranean area adapt themselves to the distribution of sea and land and to the direction of the mountains. The adaptation to relief and local climate is much more distinct than the rising from north to south. This shows a certain climatic unity of the Mediterranean area from the northern to the southern coasts (map 1).

A most sudden rising of both the recent and the glacial snow-lines appears on the southern and eastern border of the Mediterranean. E. g. they rise about $800 \mathrm{~m}$ from the Alps to Sierra Nevada (difference 9-12 degrees of latitude) and then about 800 $1000 \mathrm{~m}$ to the High Atlas which is much nearer. We find this rising in the west between Rif and High Atlas, in the east between Lebanon and Sinai. It shows again the stabilising effect of the Mediterranean sea and the sharp change with the crossing of the southern (Rif, Kabylia) and the eastern (Lebanon) coastal chains. This phenomenon was even more accentuated during the last glaciation than at present.

If we take away extreme up and downs of the isochiones we recognize from the general course of the Würm snow-lines the situation of our area on the western border of the big eurasian continent. On the whole the snow-lines are lower in the west, they rise to the east (independently from the turbulence in the mediterranean area) and point by that to the changes of climate and landscape from the continental border to the interior.

The depressions of the snow-lines tend to be higher than $1200 \mathrm{~m}$ in the western mediterranean basin, lower than $1200 \mathrm{~m}$ in the eastern. The snow-lines of the glacial period rise more from $W$ to $E$ than the recent ones (e. g. Sierra Nevada-Bolkardagh Taurus, at the same latitude and in similar climatic situation: the recent snow-line and the timberline are at the same height, but the würm snow-line rises from 2350 to $2650 \mathrm{~m}$ ). This matter of fact points to the circulation problems and to the isolation of the eastern mediterranean basin during the last cold period.

Numerous local particularities have been discussed and interesting details concerning the ice-age climatic situation obtained. Examples: the relatively great snow-line depressions in central Anatolia, the pro- blems of the Aegean area, the extremely low snowlines in Dalmatia and Montenegro, the ice-age glaciation of the Algerien coastal range, the scale of height regions on both sides of the straits of Gibraltar. We must renounce to give a more exact summary of the ice-age and recent altitudes of the snow-lines in the different regions of the Mediterranean, because the text is already very concise in itself.

\section{Part III}

The determination of a regional ice-age snow-line is problematical: there is no ideal method and the exposure differences are very important in the mediterranean area. The asymmetries of glaciation depend on certain orographic and climatic laws (Fig. 19). The greatest differences appear between the 36th and the 43rd parallel and the largest unilateral glaciations cover height regions up to $1400 \mathrm{~m}$. The exposure differences are not constant, they shift with the heightening or lowering of the snow-line: they increase from a lower ice-age snow-line surface to a high recent one.

The few recent glacier patches in strictly delimitated favoured situations may appear up to $1000 \mathrm{~m}$ below the regional snow-line surface, they may be fed by snow-slides and avalanches and may be totally independent of the climatic conditions of a snow-line. To reconstruct the recent snow-line surface we use the temperature of the warmest month. This relation is accurate within $\pm 200 \mathrm{~m}$, from the Alps to the southern Mediterranean area, but it no longer exists above the beginning of the arid zone (Fig. 21).

The notion of the snow-line is used to-day with the most varied significations. We ought to return to a clear distinction between the snow-line on the outside of the glacier ("niveau»= level 365) and the snow-line on the glacier (equilibrium line or firn line). The two lines may differ from some $100 \mathrm{~m}$ in altitude to more than $1000 \mathrm{~m}$. The glacial and recent snow-lines have again and again been determinated on the glaciers, contrary to the original definition. So their meaning corresponds approximately to the value of the equilibrium line. But the question arises as to whether we shall be able, in the future, to transfer the vague geographical notions into clearly definable glaciological-climatological designations.

Great exposure differences in the cold age glaciation point to summers with heavy insolation and great ablation effect. But components of the circulation which follows the meridians brought sporadical summer-snowfalls as far as the high mediterranean mountains. Moist, adhering summer snow was transformed into firn and ice in the highest summit regions and has sensibly influenced the forming of 
the surface of the high regions favored by precipitations.

But the great exposure differences should also not be overestimated (southern glaciers on Erciyas, Taurus, Sierra Nevada etc.). The huge depositions, results of weathering since the Würm maximum, have often buried glacial forms in southern exposure.

In the mediterranean mountains, ice-covered surfaces often do not appear above but beside the belt of structure soils or solifluction. This fact is explained by the subdivision of the notion of the snow-line of which we have spoken: "niveau", level 365 , the real lower limit of the niveal belt, proceeds upward to the structure soil belt. The middle equilibrium line of the glaciers can lie much lower, in intensively insolated and summer-dry mountains the glaciers often appear and exist in favored situations of the structure soil belt. Level 365 and the middle equilibrium line could differ .500-1000 $\mathrm{m}$ in an ice-age mediterranean mountain glaciation.

The snow-line in the mediterranean area rises much more quickly from $\mathrm{N}$ to $\mathrm{S}$ than the upper timberline. The differences between both increase from about $1000 \mathrm{~m}$ in the northern to about $1500 \mathrm{~m}$ in the southern Mediterranean region. This phenomenon points to a strong widening of the structure soil belt from $\mathrm{N}$ to $\mathrm{S}$ and from maritime to continental climatic provinces, which is confirmed by a comparison of snow-line - solifluction-limit. All these altitudinal limits have their own conditions of origin and existence and can never develop in an even way.

The depression of the snow-line of the last ice-age is subject to great variations and can nowhere be put in unequivocal relation to tectonic processes. Within the small areas, the zones of rich or poor precipitation have a greater effect when the snow-line is low as in ice-age, than when it is high, as in the recent period. This is why the snow-line depression increases in regions which are rich in rain and decreases in those which are drier. We have discussed in detail the importance of the temperature gradients for the snow-line depression. With reservations we have determined from the snow-line depression the following depressions of the ice-age temperatures in the lower air layers of the warmest month: northern mediterranean area in maritime situation something less than $10^{\circ}$, in continental situation as much as $10^{\circ}$ or more. Southern and eastern mediterranean space in the influence sphere of the arid regions $6-7^{\circ}$.

The regression of the sea greatly altered the structure of the Mediterranean, and this has had consequences in many places on climate and on the course of the snow-lines. Especially interesting is the subdivision into two separated basins. The climatic sphere of the eastern Mediterranean was a little more of continental character than the western, as the snowlines suggest.

The glaciation and the glacial forms point to an early-to-maximum Würm with richer precipitation and to a maximum-to-final Würm with low precipitation. Irregular strong downpours with torrential run-off and heterogeneous depositions in lower situations, summer snow-falls in higher situations are characteristics of the morphodynamic of early Würm. The distribution of the precipitation allows neither dense vegetation nor forests, so that we can scarcely speak of a real pluvial period. A cold dry maximum-to-late Würm with strong insolation intensity in the high mountains strengthens the weathering power and favors the extreme slope and glaciation asymmetries. On the whole, we can in no case speak of one würm-age climate and of one würm-age shaping of forms. We can no longer admit a simple parallelism of glacial period in higher latitudes with pluvial period in lower latitudes. An early and high glacial period with higher precipitation has had its consequences as far as the centre of to-days arid zone (ice-age = pluvial age) as well as a high and late glacial period poor in precipitations (ice-age $=$ dry age).

The more than 200 glaciated mountain massives of the mediterranean area have all known a different length of glaciation. Those high mountains which still have a recent glacier have doubtlessly been glaciated already in early Würm and deglaciated only towards the end of the late glacial period. The duration of Würm-age glaciation could be from 40000 50000 years. Those mountains which barely reached the ice-age snow-line were only glaciated a few thousand years during the most favorable climatic phase (22 000-18 000 BP). These huge differences in time recurred during earlier cold ages; this is reflected in the important differenciations of the forms which have resulted from glaciation. 
1. Ackermann, P., 1954: Vergleich der Temperatur der freien Atmosphäre mit derjenigen des schweiz. klimatol. Netzes. Annalen MZA, S. 6/ 53.

2. Ahlmann, H. W., 1924: Le niveau de glaciation comme fonction de l'accumulation d'humidité sous forme solide. Geogr. Ann. 6, S. 223.

3. - 1953: Glacier variations and climatic fluctuations. Am. Geogr. Soc. Bowman Mem. Lectures. Ser. 3, New York.

4. Alimen, H., 1950: Les formations glaciaires et fluvioglaciaires de la vallée de l'Ousse. Bull. France 20.

5. Annaheim, H., 1939: Die Eiszeit im Rilagebirge. Peterm. Geogr. Mitt. S. 41.

6. Atlas de la Société de Géogr. de Beograd, 1935: Fasc. 13, Hautes Montagnes Yougoslaves.

7. Awad, H., 1963: Some aspects of the Geomorphology of Marocco related to the quaternary climate. The Geogr. Journal.

8. Balout, L., 1952: Pluviaux interglaciaires et préhistoire saharienne. Trav. de l'hist. de Rech. sahar., p. 9.

9. Bär, O. und Leemann, A., 1963: Klimamorphologische Untersuchungen in Marokko. Vierteljahresschr. d. Natf. Ges. Zürich, H. 3.

10. Barbier, A. et Cailleux, A., 1950: Glaciaire et periglaciaire dans le Djurdjura occidental (Algérie). C. r. Ac. Sc. 231, p. 365.

11. Bartsch, G., 1934/35: Das Gebiet des Erciyas Dagi und die Stadt Kayseri in Mittel-Anatolien. Jahrb. d. Geogr. Ges. Hannover.

12. Bauer, B., 1934: In den Berger Montenegros. Z. d. deutschen und österreichisohen Alpenver.

13. Beck-Mannagetta, P., 1953: Die eiszeitliche Vergletscherung der Koralpe. Z. f. Gletscherkunde, H. 2.

14. Beneo, E., 1945: Nuova localita fossilifera e nuovo ghiacciaio nelle Alpi Apuane. Boll. Soc. Geol. Ital. 64.

15. Billwiler, E., 1930: Temp. und Niederschlag im schweiz. Alpenrandgebiet während des letzten Gletschervorstoßes und einige Rückschlüsse auf die eiszeitlichen Verhältnisse. Annalen der MZA.

16. Blenk, M., 1960: Ein Beitrag zur morphometrischen Schotteranalyse. Z. f. Geomorphologie, H. 3/4.

17. Blumenthal, M., 1938: Der Erdschias Dagh 3916 m. Die Alpen.

18. - 1946: Die neue geol. Karte der Türkei. Ecl. geol. Helv., Vol. 39.

19. - 1954: Im südostanatolischen Hochland zwischen Van-See und den Cilo-Ketten. Die Alpen 1954.

20. - 1955: Geologie des Hohen Bolkardagh. Veröff. des Inst. für Lagerstättenkunde der Türkei, Serie D 7. Ankara.

21. - 1958: Vom Agri Dagh (Ararat) zum Kaçkar Dagh. Die Alpen 1958.
22. - 1964: Eine Umschau in dinarischen Bergketten Jugoslawiens. Die Alpen 1964.

23. Blüthgen, J., 1964: Allgemeine Klimageographie. Lehrbuch der Allg. Geogr. Bd. II. Berlin.

24. Bobek, H., 1937: Die Rolle der Eiszeit in Nordwest-Iran. Z. f. Gletscherkunde.

25. - 1940: Die gegenwärtige und die eiszeitl. Vergletscherung im Zentralkurdischen Hochgebirge. Z. f. Gletscherkunde.

26. - 1953: Zur eiszeitl. Vergletscherung des Alburzgebirges. Mitt. d. Nat. wiss. Ver. Kärnten.

27. - 1963: Nature and implications of quaternary changes in Iran. Arid Zone Research. UNESCO and WMO 1963.

28. Boesch, H., 1951: Beiträge zur Kenntnis der Blockströme. Die Alpen.

29. Bögel, R., 1936: Untersuchungen zum Jahresgang des mittl. geogr. Höhengradienten der Lufttemp. in den versch. Klimagebieten der Erde. Ber. d. deutschen Wetterdienstes Nr. 26.

30. Bourcart, J., 1960: Carte topogr. du fond de la Méditerranée occ. Bull. de l'Inst. océanogr. Monaco. Nr. 1163.

31. Bout, P., Derruau, M., Dresch, J., Péguy, Ch. P., 1961: Observations de Géogr. phys. en Iran sept. Mém. et Doc., Tome VIII, Paris.

32. Brusch, M., 1949: Die Höhenlage der heutigen und der eiszeitlichen Schneegrenze in Europa, Vorderasien und den angrenzenden Gebieten. Diss. Göttingen.

33. Büdel, J., 1949: Die räumliche und zeitliche Gliederung des Eiszeitklimas. Die Naturwissenschaften, H. 4 und 5.

34. - 1952: Bericht über klimamorphologische u. Eiszeitforschungen in Niederafrika. Er.dkunde H. 2/3.

35. - 1952: Die Klimazonen des Eiszeitalters. Eiszeitalter und Gegenwart.

36. - 1953: Die periglazial-morphologischen Wirkungen des Eiszeitklimas auf der ganzen Erde. Erdkunde.

37. - 1954: Sinai, Wüste der Gesetzesbildung. Raumf. und Landespl., Abh. 28.

38. - 1956: Probleme des Pleistozäns in Afrika. Actes du IV Congr. Internat. du Quatern., Rome -Pise 1953.

39. - 1960: Die Gliederung der Würmkaltzeit. Würzburger Geogr. Arb., H. 8.

40. - 1966: Freundl. schriftl. Mitt. über die Vergletscherung der Djurdjura in Algerien.

41. Burney, Mc. C. B. M., 1956: Evidence of a Post-Würm II cold climate oscillation in eastern Libya. Actes du IV Congr. Internat. d. Quatern., Rome_Pise 1953.

42. Butzer, K. W., 1957: Late glacial and postglacial climatic variation. Erdkunde, H. 1.

43. - 1957: Mediterranean Pluvials and the general circulation of the Pleistocene. Geogr. Annaler. S. 48. 
44. - The recent climatic fluctuation in lower latitudes and the general circulation of the Pleistocene. Geogr. Annaler. S. 105.

45. - Quaternary Stratigraphy and Climate in the Near East. Bonner Geogr. Abh. H. 24, 1958.

46. - 1958/59: Studien zum vor- und frühgesch. Landschaftswandel der Sahara. Ak. d. Wiss. u. d. Lit., Nr. 1 und 2.

47. - 1960: Dynamic climatalogy of large-scale European circulation patterns in the Mediterranean area. Meteor. Rundschau. Vol. 13.

48. - 1963: The Last Pluvial Phase of the Eurafrican Sub-Tropics. Arid Zone Research. UNESCO and WMO.

49. - 1964: Pleistocene cold-climate phenomena of the Island of Mallorca. Z. f. Geomorphologie, H. 1.

50. Cailleux, A. et Taylor, G., 1954: Cryopédologie. Editions pol. fr., Paris.

51. Cailleux, A. et Tricart, J., 1959: Initiation à l'étude des sables et de galets, 3 Bde. Paris.

52. Carandell J. y Llarena, G., 1922: El glaciarismo cuaternario en los Montes Ibericos. Mus. Cienc. Nat., Madrid.

53. Catasto dei Ghiacciai Italiani 1959 ff.: Comitato glaciologico italiano. Torino.

54. Colbertaldo, D., 1949: I ghiacciai del Canin e del Montasio nel 1949. Boll. del Com. glaciol. it.

55. Creutzburg, N., 1928: Kreta, Z. d. Ges. f. Erdkunde, Berlin.

56. - 1960: Die mykonischen Inseln. Regio Basiliensis. Bd. 1.

57. - 1966: Die südägäische Inselbrücke. Erdkunde, H. 1.

58. Cucuzzi-Silvestri, S., 1949: Sulla presenta età pliocenica dell'Etna. Boll. Acc. Gioenia. Ser. 4, fasc. 2.

59. Cvijic, J., 1898: Das Rilagebirge und seine ehemalige Vergletscherung. Z. d. Ges. f. Erdkunde. Berlin.

60. - 1900: Morphologische und glaciale Studien aus Bosnien, der Herzegowina und Montenegro. Abh. Geogr. Wien 2.

61. - 1904: Neue Ergebnisse über die Eiszeit auf der Balkan-Halbinsel. Mitt. d. kk. geogr. Ges. Wien 47.

62. - 1908: Beobachtungen über die Eiszeit auf der Balkan-Halbinsel. Z. f. Gletscherkunde 3.

63. - 1908: Grundlinien der Geogr. und der Geol. von Mazedonien und Altserbien. Petermanns Erg. Hefte 162.

64. - 1917: L'époque glaciaire dans la péninsule Balkanique. Ann. de Géogr., Paris.

65. Demangeot, J., 1963: Glacier rissien de Pietracamela (Apennin Abbruzais). Méditerranée 1.

66. - 1965: Géomorphologie des Abruzzes Adriatiques. Mém. et Documents, Paris.

67. Diener, C., 1886: Libanon, Grundlinien der phys. Geogr. und Geol. von Mittelsyrien. Wien.

68. Dresch, J., 1941: Recherches sur l'évolution du relief dans le Massif central du Grand Atlas, le Haouz et le Sous. Tours.

69. - 1949: Sur des formations de remblaiement continental et la présence de formes glaciaires dans le Haut Atlas calcaire. C. r. somm. Soc. Géol. fr. Paris.

70. - et Raynal, R., 1953: Formes glaciaires et périglaciaires dans le Moyen Atlas. C. r. somm. Soc. Géol. fr. 11. Paris.

71. Drygalski, E. und Machatschek, F., 1942: Gletscherkunde. Wien.

72. Dubief, J., 1956: Note sur l'évolution du climat Saharien au cours des derniers millénaires. IV. Congr. Internat. du Quatern. Rome_Pise 1953.

73. - 1963: Contribution au problème des changements de climat survenus au cours de la période couverte par les observations météor. faites dans le nord de l'Afrique. Arid Zone Research. UNESCO.

74. Emberger, L., 1939: Aperçu général sur la végétation du Maroc. Veröff. Geobot. Inst. Rübel, H. 14.

75. Emiliani, C., 1955: Pleistocene temperature variations in the Mediterranean. Quaternaria, Rome.

76. - 1956: Angaben über Meerestemp. best.im Jahrb. der Ak. d. Wiss. und d. Lit., Mainz.

77. - und Mayeda, T., 1964: Oxygen isotopic analysis of some molluscan shells from fossil littoral deposits of Pleistocene age. Am. J. Sc. 262. I.

78. Enquist, F., 1916: Der Einfluß des Windes auf die Verteilung der Gletscher. Bull. Geol. Inst. Uppsala. Vol. 14.

79. Erinç, S., 1944: Glazialmorph. Untersuchungen im nordostanatolischen Randgebirge. Publ. de la Fac. d. Lettres, Univ. Istanbul No. 1.

80. - 1951: The glacier of Erciyas in pleistocene and post-glacial epoches. Rev. of the Geogr. Inst. Univ. Istanbul No. 2.

81. - 1951: The influences of continentality in Turkey. Rev. of the Geogr. Inst. Univ. Istanbul. No. 2.

82. - 1952: Glacial evidences of the climatic variations in Turkey. Geogr. Annaler, H. 1-2.

83. - 1955: Mount Honaz and Boz Dag from standpoint of periglacial morphology. TCD, no. 13-14.

84. Fairbridge, R. W., 1965: Eiszeitklima in Nordafrika. Geol. Rundschau. H. 1.

85. Fezer, F., 1966: Angaben über die Würm-Vergletscherung des Schwarzwaldes. Nach einem Vortrag DEUQUA-Kongr. Göttingen.

86. Finsterwalder, R., 1953: Die zahlenmäßige Erfassung des Gletscherrückganges an Ostalpengletschern. Z. f. Gletscherkunde, H. 2.

87. Firbas, F., 1939: Vegetationsentwicklung und Klimawechsel in der mitteleurop. Spät- u. Nacheiszeit. Die Naturwissenschaften 27.

88. - 1951: Die quartäre Vegetationsentwicklung zw. den Alpen und der Nord- und Ostsee. Erdkunde V.

89. Fleischer, U., 1964: Schwerestörungen im östl. Mittelmeer nach Messungen mit einem AskaniaSeegravimeter. Deutsche Hydr. Z. H. 4. Hamburg.

90. Flint, R. F., 1947: Glacial geology and the Pleistocene Epoch. New York.

91. Fliri, F., 1964: Zur Witterungsklimatologie 
sommerlicher Schneefälle in den Alpen. Wetter und Leben, Jg. 16.

92. Flohn, H., 1949: Zur Kenntnis des Klimas der freien Atmosphäre über Sizilien. Geofisica pura e appl. 15. Milano.

93. - 1952: Allg. atmosphärische Zirkulation und Paläoklimatologie. Geol. Rundschau, H. 1.

94. - 1953: Studien über die atmosphärische Zirkulation in der letzten Eiszeit. Erdkunde, H. 4.

95. - 1955: Neue Vorstellungen über die Formen der atmosphärischen Zirkulation in trop.-subtrop. Breiten. Leopoldina III.

96. - 1963: Zur meteorol. Interpretation der pleistozänen Klimaschwankungen. Eiszeitalter und Gegenwart, Bd. 14.

97. - 1965: Grundfragen der Paläoklimatologie im Lichte einer theoretischen Klimatologie. Geol. Rundschau, H. 1.

98. — Fränzle, O., 1959: Glaziale und periglaziale Formbildung im östl. Kastilischen Scheidegebirge. Bonn.

99. Frenzel, B., 1959: Die Vegetations- und Landschaftszonen Nord-Eurasiens während der letzten Eiszeit und während der postglazialen Wärmezeit. Ak. d. Wiss. u. d. Lit. Abh. der math.nat. Kl. Nr. 13. Mainz.

100. Furrer, E., 1966: Uber die Waldgrenze am Gran Sasso. Nach einem Vortrag in der Bern. Bot. Ges.

101. Furrer, G., 1959: Untersuchungen am subnivalen Formenschatz in Spitzbergen und in den Bündner Alpen. Geogr. Helv. 4.

102. - 1965: Die Höhenlage von subnivalen Bodenformen. Hab.-schrift, Zürich.

103. - 1965: Die subnivale Höhenstufe und ihre Untergrenze in den Bündner und Walliser Alpen. Geogr. Helv.

104. Galibert, G., 1965: La haute montagne alpine. Toulouse.

105. Galloway, R. W., 1965: A note on world precipitation during the last glaciation. Eiszeitalter und Gegenwart.

106. Garcia Sainz, G., 1940: Morphologische Skizze des Zentralabschnittes der span. Pyrenäen. Peterm. Mitt. 86.

107. - 1943: El glaciarismo cuaternaria de Sierra Nevada. Est. Geogr. 2.

108. Geol. Karten der Türkei 1963 ff.: Div. Blätter $1: 500$ 000. Maden Tektik ve Arama Enstitüsü, Ankara.

109. Giermann, G., 1961: Erläuterungen zur bathymetrischen Karte der Straße von Gibraltar. Bull. del'Inst. océanogr. Monaco. No. 1218 A.

110. - 1962: Erläuterungen zur bathymetrischen Karte des westl. Mittelmeeres. Bull. de l'Inst. oc. Monaco. No. 1254 A.

111. - 1964: Epirogene Krustenbewegungen im Quartär. Bull. de l'Inst. oc. Monaco. No. 1294.

112. Göhrs, J., 1951: Die Klimate der ewigen Gefrornis. Diss. Göttingen.

113. Golubic, S., 1958: Beitrag zur Klimakenntnis des jugoslawischen Küstenlandes mit Benützung der Walter'schen Klimadiagramme. Geografski Glasnik XX, Zagreb.
114. Gortani, M., 1930: Sui ghiacciai quaternari dell'Italia Centrale. Atti 11, Geogr. it. Napoli.

115. Götzinger, G., 1954: Neue Erkenntnisse über die Spiegelschwankungen des Mittelländischen Meeres während des Eiszeitalters. Mitt. Geogr. Ges. Wien, 96.

116. Grund, A., 1902: Eiszeitforschung in Bosnien und Herzegowina. Verh. d. Ges. deutsch. Naturforscher und Ärzte.

117. - 1910: Beiträge zur Geomorphologie des Dinarischen Gebirges. Geogr. Abh. VII, H. 3.

118. Guillien, Y., 1962: Néoglaciaire et tardiglaciaire: Géochimie, palynologie, préhistoire. Ann. de Géogr.

119. - et Rondeau, A., 1966: Le modelé cryonival de la Tunisie centra'e et septentrionale. Ann. de Géogr.

120. Hader, F., 1955: Klimazahlen zur Beurteilung der alpinen Frostverwitterung. Mitt. d. Geogr. Ges. Wien, 97.

121. Hafemann, D., 1965: Die Niveauänderungen an den Küsten Kretas seit dem Altertum. Ak. d. Wiss. und der Lit. Mainz. Nr. 12.

122. Hamilton, W. J., 1842: Researches in Asia Minor, Pontus and Armenia. 2 Bde. London.

123. Hammen, van der, T., Wijmstra, T. A., Molen van der, W. H., 1965: Palynological study of a very thick peat section in Greece and the Würm-glacial Vegetation in the Mediterranean region. Geol. en Mijnbouw. Jg. 44.

124. Hassert, K., 1901: Gletscherspuren in Montenegro. Verh. d. 13. deutsch. Geogr.-tages. Breslau.

125. Hempel, L., 1966: Klimamorphologische Taltypen und die Frage einer humiden Höhenstufe in europäischen Mittelmeerländern. Peterm. Geogr. Mitt. H.2.

126. Hermes, K., 1955: Die Lage der oberen Waldgrenze in den Gebirgen der Erde und ihr Abstand zur Schneegrenze. Kölner Geogr. Arbeiten, H. 5.

127. Hernandez-Pacheco, F., 1914: Fenomenos de glaciarismo cuaternario en la Cordillera Cantabrica. Bol. real Soc. esp. Hist. nat. 14.

128. - 1944: Fisiografia, geologia y glaciarismo cuaternario de las montanas de Reinosa. Mem. real. Ac. Cienc. exact. fis. nat. Madrid.

129. Hesse, W., 1961: Handbuch der Aerologie. Leipzig.

130. Heybrock, W., 1953: Eiszeitliche Gletscherspuren im Hohen Atlas. Z. f. Gletscherkunde u. Glazialgeol. H. 2, 319.

131. - 1954: Firnverhältnisse auf Korsika. Z. f. Gletscherkunde, H. 1, S. 77.

132. Höfer, R., 1879: Gletscher und Eiszeitstudien. Sitz. Ber. d. Ak. d. Wiss. Wien.

133. Hoinkes, H. und Untersteiner, N., 1952: Wärmeumsatz und Ablation auf Alpengletschern. Geografsika Annaler 34.

134. Hövermann, J. und Poser, H., 1951: Morphometrische und morphologische Schotteranalyse. Proc. 3. rd. Internat. Congr. of Sedimentology.

135. Hövermann, J., 1962: Über Verlauf und Ge- 
setzmäßigkeit der Strukturbodengrenze. Biuletyn Peryglacjalny, nr. 11, Lodz.

136. Jäckli, H., 1957: Gegenwartsgeologie d. bündnerischen Rheingebietes. Ein Beitrag zur exogenen Dynamik alpiner Geb. Landschaften. Zürich.

137. Jaranoff, D., ?: Die tektonischen Bewegungen der Balkanhalbinsel während des Quartärs. Verh. der III. INQUA.

138. - 1939: La péninsule Balkanique pendant le Quaternaire. Z. Bulg. Geogr. Ges. 11.

139. Jovanovic, P., 1928: La glaciation de Jakupica. Ed. spec. de la Soc. de Géogr. de Beograd.

140. Kaiser, K., 1963: Die Ausdehnung der Vergletscherung und perigl. Erscheinungen während der Kaltzeiten innerhalb der syrisch-libanesischen Gebirge und die Lage der klimat. Schneegr. zur Würmeiszeit im östl. Mittelmeerraum. Rep. of the VI. internat. Congr.on Quatern. Warsaw 1961.

141. - 1965: Ein Beitrag zur Frage der Solifluktionsgrenze in den Gebirgen Vorderasiens. Z. f. Geomorphologie H. 4.

142. Kanter, H., 1930: Kalabrien. Abh. aus dem Geb. d. Auslandkunde, 33. Hamburg.

143. Kayser, E., 1932: Morphologische Studien in West-Montenegro. Z. d. Ges. f. Erdkunde. Berlin.

144. Kasser, P., 1959: Der Einfluß von Gletscherrückgang und Gletschervorstoß auf den Wasserhaushalt. Wasser- und Energiewirtschaft 6.

145. Kick, W., 1964: Der Chogo-Lungma-Gletscher im Karakorum. Z. f. Gletscherkunde, Bd. V., H. 1.

146. Klaer, W., 1957: Beobachtungen zur rezenten Schnee- und Strukturbodengrenze im Hochlibanon. Z. f. Geomorphologie.

147. - 1962: Untersuchungen zur klimagenetischen Geomorphologie in den Hochgebirgen Vorderasiens. Heidelberger Geogr. Arbeiten, H. 11.

148. - 1965: Geomorphologische Untersuchungen in den Randgebirgen des Van-See. Z. f. Geomorphologie.

149. Klebelsberg, R. v., 1928: Beiträge zur Geologie der Sierren zw. Granada und Malaga. Z. d. Geol. Ges. Bd. 80.

150. - 1930, 1932, 1933: Die eiszeitliche Vergletscherung der Apenninen. Z. f. Gletscherkunde.

151. - 1931: Vom Westhang des Taygetos. Z. Ges.

f. Erdkunde, Berlin.

152. - 1932: Der Tymphrestos im Aetolischen Pindos. Jahrb. Geol. B. A., 82, Wien.

153. - 1947: Eiszeitliche Gletscherrekorde. Die Alpen. S. 371.

154. - 1948/49: Handbuch der Gletscherkunde und Glazialgeologie. 2 Bde. Wien.

155. - 1949: Spuren eiszeitlicher Lokalvergletscherung in den Luganer Bergen. Z. f. Gletscherkunde.

156. - 1952: Der nördlichste und der östlichste Firnfleck in den Alpen. Z. f. Gletscherkunde.

157. - 1952: Die eiszeitliche Vergletscherung des Monte Grappa. Z. f. Gletscherkunde.
158. Klute, F., 1921: Über die Ursachen der letzten Vereisung. Geogr. Z. 27.

159. - 1928: Die Bedeutung der Depression der Schneegrenze für eiszeitl. Probleme. Z. f. Gletscherkunde 16

160. - 1951: Das Klima Europas während des Maximums der Weichsel-Würmeiszeit und die Änderungen bis zur Jetztzeit. Erdkunde 4.

161. Kopp, K. O., 1963: Schneegrenze und Klima der Würmeiszeit an der baskischen Küste. Eiszeitalter und Gegenwart 14.

162. Krebs, N., 1924: Fragmente einer Landeskunde von Innerkrain. Cvijic Festschrift. Belgrad.

163. Krenek, L., 1932: Gletscher im Pontischen Gebirge. Z. f. Gl.-kunde.

164. Kuls, W. und Semmel, A., 1965: Zur Frage pluvialzeitlicher Solifluktionsvorgänge im Hochland von Godjam (Aethiopien). Erdkunde, H. 4.

165. Kurowski, L., 1891: Die Höhe der Schneegrenze mit bes. Berücksichtigung der Finsteraarhorngruppe. Penck, Wien.

166. Kurz, M., 1923: Le mont Olympe (Thessalie). Mit Karte 1:20 000. Paris.

167. Lamb, H. H., 1963: On the nature of certain climatic epoche which differred from the modern (1900-1939) normal. Arid Zone Research, UNESCO.

168. Lautensach, H., 1929: Eiszeitstudien in der Sierra de Estrela (Portugal). Z. f. Gl.-kunde.

169. - 1942: Portugal in der Eiszeit. Z. f. Gl.-kunde.

170. - 1958: Die Sagra Sierra in der südostspan. Umwelt. Die Erde, H. 3/4.

171. Leidlmair, A., 1953: Die jüngsten Gletscherschwankungen in ihrer Abhängigkeit von Niederschlag, Temp. u. Strahlung. Peterm. Geogr. Mitt.

172. Letsch, K., 1956: Firnverhältnisse auf Korsika. Z. f. Gl.-kunde, S. 268.

173. Leutelt, R., 1932: Glazialgeologische Untersuchungen in den Nordalbanischen Alpen. Z. f. Gl.-kunde.

174. - 1935: Glazialgeologische Beobachtungen im Lasistanischen Hochgebirge. Z.f.Gl.-kunde,

175. Liedtke, H., 1962: Vergletscherungsspuren und Periglazialerscheinungen am Südhang des Lovcen östl. von Kotor. Eiszeitalter und Gegenwart.

176. Lliboutry, L., 1964/65: Traité de Glaciologie, 2 Bde. Paris.

177. Lopez-Gomez, A. y Riba, O., 1957: El glaciarismo en la Sierra de Neila. INQUA V, Madrid.

178. Lorenzo, G. e Dainelli, G., 1923: Il glaciale dei dintorni di Lagonegro in Basilicata. Atti Acc. Fis. e Mat. Napoli 2, vol. 17.

179. Lotze, F., 1962: Pleistozäne Vergletscherung im Ostteil des Kantabr. Gebirges. Ak. d. Wiss. und der Lit., Mainz.

180. Louis, H., 1926: Glazialmorphologische Beobachtungen im Albanischen Epirus. Z. d. Ges. f. Erdkunde, Berlin.

181. - 1930: Morphologische Studien in SüdwestBulgarien. Geogr. Abh. 3, H. 2, Stuttgart. 
182. - 1933: Die eiszeitliche Schneegrenze auf der Balkanhalbinsel. Festschrift Irschirkov, Sofia.

183. - 1938: Eiszeitliche Seen in Anatolien. Z. d. Ges. f. Erdkunde, Berlin.

184. - 1939: Das natürliche Pflanzenkleid Anatoliens. Geogr. Abh. Stuttgart.

185. - 1944: Die Spuren eiszeitlicher Vergletscherung in Anatolien. Geol. Rundschau 34.

186. - 1954: Schneegrenze und Schneegrenzbestimmung. Geogr. Taschenbuch.

187. - 1958: Der Bestrahlungsgang als Fundamentalerscheinung der geogr. Klimaunterscheidung. Kinzl-Festschrift, Innsbruck.

188. Lucerna, R., 1911: Die Eiszeit auf Korsika. Abh. Geogr. Ges. Wien.

189. Machatschek, F., 1913/14: Die Depression der eiszeitlichen Schneegr. Z. f. Gl.-kunde.

190. - 1944: Diluviale Hebung und eiszeitliche Schneegrenzdepression. Geol. Rundschau 34.

191. - 1955: Das Relief der Erde, 2 Bde. Berlin.

192. Maier, W., 1936: Zur Morphologie des Aetna. Z. D. Geol. Ges. 88.

193. Marcus Merlvin, G., 1964: Climate-glacier studies in the Juneau Ice field region. Alaska. Research paper Chicago, Univers.

194. Markovic, M., 1962: Sar-Berg in Mazedonien. Die Alpen.

195. Martonne, E. de, 1906/07: L'évolution morphologique des Alpes de Transylvanie. Rev. d. Géogr.Annuelle I, Paris.

196. Maull, O., 1921: Beiträge zur Morphologie des Pelopponnes und des südl. Mittelgriechenlands. Geogr. Abh. Bd. X.

197. Mayr, F., 1964: Untersuchungen über Ausmaß und Folgen der Klima- und Gletscherschwankungen seit dem Beginn der postglazialen Wärmezeit. Z. f. Geomorphologie.

198. Melik, A., 1929/30: Le glacier diluvial de Bohinj. Geogr. Vestnik, Ljubljana.

199. - 1932: La glaciation quaternaire dans les Karawanken. Geogr. Vestnik, Ljubljana.

200. Mensching, H., 1953: Morphologische Studien im Hohen Atlas von Marokko. Würzburger geogr. Arbeiten, H. 1.

201. - 1955: Das Quartär in den Gebirgen Marokkos. Peterm. Geogr. Mitt., Erg. H. 256.

202. - 1960: Ber. u. Gedanken zur Tagung der Kommission für Periglazialforschung in der IGU in Marokko, 1959. Z. f. Geomorphologie.

203. Messerli, B., 1964: Der Gletscher am Erciyas Dagh und das Problem der rezenten Schneegr. im anatolischen und mediterranen Raum. Geogr. $\mathrm{H}$.

204. - 1965: Beiträge zur Geomorphologie der Sierra Nevada. Diss. Zürich.

205. - 1965: Der Erciyas Dagh. Die eiszeitliche Vergletscherung eines Vulkans. Die Alpen.

206. - 1966: Die Schneegrenzhöhen in den ariden Zonen und das Problem Glazialzeit-Pluvialzeit. Mitt. d. Naturf. Ges. Bern. Bd. 23.

207. - 1966: Das Problem der eiszeitlichen Vergletscherung am Libanon und Hermon. Z.f. Geomorphologie.

208. Meteorologie Frankreich: Schriftliche Mitteilung über die Höhenstation Pic du Midi (Pyre- näen). Serv. Mét. Métropolitain, BordeauxMerignac.

209. Meteorologie Griechenland: Mündliche Mitteilungen von Prof. Livadas. Chef der met. Station Aghios Antonio, Universität Saloniki.

210. Meteorologie Marokko: Schriftl. Mitt. über den Niederschlag am Hohen Atlas. Serv. de Phys. du Globe et de Météor., Casablanca.

211. Meteorologie Türkei: Schriftliche Mitteilungen über Temperatur und Niederschlag am Erciyas, Ulu Dagh, Antalya und Elmali, Taurus.

212. - 1962: Meteorolji Bülteni. Niederschlagskarte 1929-59. Ankara.

213. - 1962: Kar Oerüsü (Schneefall-Statistik). Ankara.

214. Meteorologie WMO 1965: World Meteor. Organization. Short-Period Averages for 195160 and prov. average values for Climat Temp. WMO/OMM. No. 170, Geneva.

215. Milojevic, B., 1934: Les montagnes de Crna Prst, Bielasica et Perista. Ed. spec. Soc. Géogr. Beograd, 16.

216. - 1939: Les hautes montagnes dans le royaume de Yougoslawie. Beograd.

217. - 1951: Durmitor, Recherches de Géogr. régionale. Ac. Serbe des Sciences. Recueil de l'Inst. de Géogr. 2.

218. - und Borivoje, 1935: Sinjejevina, Visitor, Zeletin. Geografski Vestnik. Ljubljana.

219. Mistardis, G., 1935: Recherches géomorphologiques dans le NE de l'Epire. Athen. (Siehe Z. f. Gl.-kunde 1937.)

220. - 1937: Sur les traces de glaciation dans la partie montagneuse du Nord du Peloponnes. Z. f. Gl.-kunde 1937.

221. - 1952: Recherches glaciologiques dans les parties supérieures des Monts Oeta et Oxya (Grèce centrale). Z. f. Gl.-kunde.

222. Monterini, V., 1937: Les conditions météor. sur les Alpes et les variations périodiques des glaciers italiens. Bull. Comm. Glac. It., 17, Turin.

223. Morawetz, S., 1941: Zur Frage der Schneegrenzverschiebungen. Peterm. Geogr. Mitt. 87.

224. - 1952: Klimabeziehungen des Gletscherverhaltens in den Ostalpen. Z. f. Gl.-kunde.

225. - 1955: Zur Frage der eiszeitlichen Temperaturerniedrigung. Mitt. d. Geogr. Ges. Wien.

226. - 1961: Schneegrenze, Gletscherablation, Temperatur und Sonnenstrahlung in den Ostalpen. Peterm. Mitt. 105.

227. Mörikofer, W., 1932: Das Hochgebirgsklima. SA aus Physiologie des Höhenklimas von A. Loeny, Davos und Berlin.

228. Mortensen, H., 1952: Heutiger Firnrückgang und Eiszeitklima. Erdkunde, 2/3.

229. - 1957: Temperaturgradient und Eiszeitklima am Beispiel der pleist. Schneegrenzdepr. in den Rand- und Subtropen. Z. f. Geomorphologie.

230. Müller, F., 1961/62: Axel Heiberg Island Research Rep., Mc. Gill Univers. Montreal. Preliminary Rep., Dez. 1963.

231. - 1963: An Arctic Res. Expedition and its re- 
liance on large-scale maps. The Canadian Surveyor. Vol. XVII.

232. - 1963: Photogrammetric and Cartographic Results of the Axel Heiberg Expedition. The Canadian Surveyor XVII.

233. Münchner Hindukusch-Kundfahrt 1963: Verlauf, wissenschaftliche und bergsteigerische Ergebnisse. München.

234. Négris, P.H., 1922: Phases glaciaires en Grèce, leur relation avec le morcellement de l'Egeis C. r. Ac. Sc. Paris.

235. Neumayr, M., 1880: Geol. Beobachtungen im Gebiet des thessalischen Olymps. Denkschrift der kk. Ak. d. Wiss., Wien.

236. Nicolic, R. T., 1912: La glaciation du Sar-Planina et du Korab. Bull. Soc. Serbe de Géogr.

237. Nowack, E., 1929: Die diluvialen Vergletscherungsspuren in Albanien. Z. f. Gl.-kunde.

238. Nußbaum, F., 1928: Die diluviale Vergletscherung der östl. Pyrenäen. Geogr. Zeitschr. 2.

239. - 1930: Morphologische Studien in den östl. Pyrenäen. Z. f. Ges. f. Erdkunde. Berlin.

240. - 1936: Die eiszeitliche Schneegrenze in den Pyrenäen. INQUA Wien.

241. - 1946: Orographische und morphologische Untersuchungen in den östl. Pyrenäen. Jahresber. Geogr. Ges. Bern.

242. - und Gygax, F., 1953: La glaciation quaternaria en la cordillera cantabrica. Estudios geogr. 51.

243. Oberhummer, E., 1935: Die höchsten Erhebungen der Balkanhalbinsel. Peterm. Mitt.

244. Obermaier, H., 1914: Estudio de los glaciares de los Picos de Europa. Trab. Mus. Cienc. Nat., Madrid.

245. - 1916: Contribucion al estudio del glaciarismo cuaternario de la Sierra de Gredos. Trab. Mus. Cienc. Nat., Madrid.

246. - 1921: Die eiszeitliche Vergletscherung Spaniens. Peterm. Mitt. 67.

247. - 1932: Beiträge zur Kenntnis der quartären Vereisung der Iberischen Halbinsel. Z. f. Gl.kunde, Bd. XX.

248. - y Carandell, J., 1917: Los glaciares quaternarios de la Sierra de Guaderrama. Trab. Mus. Cienc. Nat., Madrid.

249. Onde, H., 1952: Formes glaciaires dans le Massif lycien de l'Ak Dagh. XIX, Congr. géol. internat. Alger, fasc. XIII.

250. Osswald, K., 1938: Geologische Geschichte von Griechisch-Nordmakedonien. Geol. Landesanstalt von Griechenland. Athen.

251. Oswald, F., 1912: Armenien. Handbuch der reg. Geologie V. Heidelberg.

252. Ostrem, G. og Liestol, O., 1963: Glasiologiske undersokelser i Norge. Norsk Geografisk Tidsskrift, Bind XVIII, H. 7/8, 1961-62.

253. Paci, M., 1935: Revisione dei terreni morenici quaternari delle Alpe Apuane. Proc. Verb. Soc. tosc. Sc. Nat., Pisa.

254. Panzer, W., 1932: Die eiszeitlichen Endmoränen von Puigderda (Ostpyrenänen). Z. f. Gl.kunde.

255. Paschinger, H., 1954: Würmvereisung und
Spätglazial in der Sierra Nevada. Z. f. Gl.-kunde.

256. - 1954: Der südlichste Gletscher Europas. Z. f. Gl.-kunde.

257. - 1955: Die würmeiszeitliche Schneegrenze im Mittelmeergebiet. Mitt. Geol. Ges. Wien, Klebelsberg-Festschrift.

258. - 1956: Neue Arbeiten über die Vergletscherung des Aetna während der letzten Kaltzeit. Z. f. Gl.-kunde, Bd. III/2.

259. Paschinger, V., 1912: Die Schneegrenzen in verschiedenen Klimaten. Pet. Mitt., Erg. H. 173.

260. - 1923: Die Eiszeit, ein meteor. Zyklus. Z. f. Gl.-kunde.

261. - 1957: Begriff und Wirkungen der Massenerhebung. Festschr. 100-Jahr-Feier der Geogr. Ges. Wien.

262. Penck, A., 1883: Die Eiszeit in den Pyrenäen. M. d. Ges. f. Erdkunde, Leipzig.

263. - 1884: Höhenkarte der Schneelinien in Europa während der Gegenwart und Eiszeit. Verh. d. IV. D. Geogr. Tages, München.

264. - 1900: Die Eiszeit auf der Balkanhalbinsel. Globus 78, Braunschweig. S. 133, 159, 173.

265. - 1936: Europa zur letzten Eiszeit. Festschr. N. Krebs. Stuttgart.

266. - 1938: Das Klima der Eiszeit. INQUA.

267. Penther, A., 1905: Eine Reise in das Gebiet des Erdschias Dagh. Mit Beilagen von Zederbauer und Tschamler. (Karte 1: 80 000.) Abh. kk. geogr. Ges. Wien, Bd. VI.

268. Pfannenstiel, M., 1951: Quartäre Spiegelschwankungen des Mittelmeeres und des Schwarzen Meeres. Vierteljahresschr. Natf. Ges. Zürich, 96.

269. - 1954: Die Schwankungen des Mittelmeerspiegels als Folge der Eiszeiten. Freiburger Universitätsreden, N. F. 18.

270. - 1956: Die eiszeitlichen Schwankungen des Mittelmeerspiegels im Raume des Nildeltas. Actes du IV. Congr. Internat. d. Quatern., Rome_Pise 1953.

271. - 1956: Ergebnisse der VEMA-Tiefsee-Exp. im Jahrbuch der Ak. d. Wiss. u. d. Lit., Mainz. S. 59.

272. - 1956: Rezente Froststrukturböden und Karst des Ulu Dagh. Ak. d. Wiss. u.d. Lit., Nr. 5. Mainz.

273. - 1960: Erläuterungen zu den bathymetrischen Karten des östl. Mittelmeeres. Bull. de l'Inst. oc. Monaco. No. 1192A.

274. Philippson, A., 1904: Das westliche Kleinasien. Z. d. Ges. f. Erdkunde.

275. - 1913, 1914, 1915: Reisen und Forschungen im westlichen Kleinasien. Peterm. Mitt. Erg. H. 177, 180, 183.

276. - 1930: Beiträge zur Morphologie Griechenlands. Geogr. Abh.

277. Pillewizer, W., 1957: Untersuchungen an Blockströmen der Oetztaler Alpen. Abh. des Geogr. Inst. Univ. Berlin. Festschrift Maull.

278. Pinar, N., 1956: Le Quaternaire en Turquie et les phases de l'effondrement de l'Egeide. Actes 
du IV. Congr. Internat. du Quatern., Rome_Pise 1953.

279. Piwowar, A., 1903: Über Maximalböschungen trockener Schuttkegel und Schutthalden. Vierteljahresschr. Natf. Ges. Zürich.

280. Plandé, R., 1939: Neiges et Glaces d'aujourd' hui dans les Pyrénées. Rev. Géogr. des Pyr. et du Sud-Ouest, Fasc. 1.

281. Planhol, X. de, 1953: Les formes glaciaires du Sandras dag et la limite des neiges éternelles quaternaires dans le S.-O. de l'Anatolie. C. r. somm. Soc. Géol. fr., p. 263.

282. - 1956: Position stratigraphique et signification morphologique des travertins subtaurique de l'Anatolie Sud-occ. Actes du IV. Congr. In. du Quatern., Rome_Pise 1953.

283. - 1962: Carte de la limite quaternaire des neiges persistantes dans le sud-ouest de l'Asie mineure. Rev. d. Géogr. Alpine.

284. - 1964: Glaciaire et périglaciaire quaternaires et actuels dans le massif du Karagöl (Châ̂nes pontiques). Rev. d. Géogr. Alpine.

285. Platt, C. M., 1966: Beobachtungen über das Klima am Lewis Glacier (M. Kenya). Journal of Glaciology, Vol. 6, Nr. 44. (Frei zit. nach «Die Alpen» 66).

286. Poser, H., 1933: Das Problem des Strukturbodens. Geol. Rundschau. Bd. 24.

287. - 1947: Dauerfrostboden und Temperaturverhältnisse während der Würm-Eiszeit im nicht vereisten Mittel- und Westeuropa. Die Naturwissenschaften, 34.

288. - 1947: Auftautiefe und Frostzerrung im Boden Mitteleuropas während der Würm-Eiszeit. Die Naturwissenschaften 34.

289. - 1948: Boden- und Klimaverhältnisse in Mittel- und Westeuropa während der Würmeiszeit. Erdkunde.

290. - 1957: Klimamorphologische Probleme auf Kreta. Z. f. Geomorphologie.

291. - und Hövermann, J., 1951/52: Beiträge zur morphometrischen und morphologischen

Schotteranalyse. Abh. der Braunschweig. Wiss. Ges.

292. Rathjens, C., 1960: Beobachtungen an hochgelegenen Poljen im südl. Dinarischen Karst. Z. f. Geomorphologie.

293. - 1965: Ein Beitrag zur Frage der Solifluktionsgrenze in den Gebirgen Vorderasiens. Z. f. Geomorphologie.

294. Ratzel, F., 1889: Höhengrenzen und Höhengürtel. Z. d. Deutsch-Österr. Alpenvereins.

295. Raynal, R. et coll., 1956: Deux exemples régionaux de glaciation quaternaire au Maroc: Haut Atlas et Moyen Atlas. Act. IV. Congr. Internat. du Quatern., Rome 1953.

296. - et Tricart, J., 1963: Comparaisons des grandes étapes morphogénétiques du Quaternaire dans le Midi méditerranéen français et au Maroc. Bull. Soc. Géol. de France, V. S. 587.

297. Reichel, E., 1932: Die Niederschlagsverhältnisse der Türkei. Ann. d. Hydrographie. Bd.60.

298. Reid, F. H., 1896: The mechanics of glaciers. J. of glaciology 4.

299. Reinhard, A., 1925: Glazialmorphologische
Studien im westl. u. zentr. Kaukasus. Z. f. Gl.kunde.

300. Richter, E., 1888: Die Gletscher der Ostalpen. Stuttgart.

301. Ridanovic, J., 1961: Les Conditions spécifiques de la glaciation de l'Orjen. Abstracts of Paper of 6. INQUA. Warschau.

302. Roglic, J., 1935: La montagne de Biokovo. Ed. spéc. d. l. Soc. de Géogr. de Beograd. Fasc. 18.

303. - 1959: Contribution à la connaissance de la glaciation et de l'évolution du relief des montagnes autour de la Neretva moyenne. Geografski Glasnik, Zagreb XXI.

304. Rognon, M. P., 1963: Le modelé de haute montagne dans l'Atakor. (Sahara central.) Bull. de l'Ass. de Geogr. fr.

305. Rubin, M., 1963: Simultaneity of glacial and pluvial episodes from C-14 chronology of the Wisconsin glaciation. Arid Zone Research. UNESCO.

306. Sacco, F., 1941: Il glacialismo nell'Apennino. L'Universo, Num. 9.

307. Salomon-Calvi, W., 1940: Das Erdbeben des Erciyes vom 20. Februar 1940. MTA, Sene 5, Sayi 2/19. Ankara.

308. Sawicki, R. von, 1910/11: Die eiszeitliche Vergletscherung des Orjen in Süddalmatien. Z.f. Gl.-kunde.

309. Scarsella, F., 1947: Nuove trace di antichi ghiacciai nei Monti Sibillini e nei Monti della Laga. Boll. Soc. Geol. It. 64, 1945.

310. Schamp, H., 1951/52: Das Hochgebirge der südlichen Halbinsel Sinai und die Frage nach seiner diluvialen Vereisung. Die Erde.

311. Schüepp, M., 1959: Lufttemperatur. Klimatologie der Schweiz. Beiheft zu den Ann. der MZA, Abschn. C.

312. Schwarzbach, M., 1961: Das Klima der Vorzeit. Stuttgart.

313. Seiffert, H., 1950: Das Klima an der Schneegrenze. Diss. Göttingen.

314. Sermet, I., 1934: Sobre unos vestigios de topografia glaciar en la Sierra Tejeda (Andalusien). Bol. Soc. Esp. Hist. Nat. 34.

315. - 1942: Sierra Nevada. Estudios Geogr., Num. 9.

316. Sestini, A., 1937: Sugli antichi ghiacciai delle Alpi Apuane e dell'Apennino. Sett., Boll. Soc. Geogr. It.

317. Shcheglova, O. P., 1962: Using of snow-cover surveying for the snowline hight determination. Nachr. Geogr. Ges. Sowjetunion, 2, 1961. (Nach Bespr. Z. f. Geomorphologie 1962, S. 245.)

318. Sifrer, M., 1963: New findings about the glaciation of Triglav. Geografski zbornik VIII. Ljubljana.

319. Sivall, T., 1957: Sirocco in the Levant. Geogr. Annaler.

320. Sobjic, P., 1926: Traces glaciaires dans la Zupa de Niksic-Montnegro. Bull. de la Soc. d. Géogr. Beograd. T. 12.

321. Soergel, W., 1942: Die eiszeitliche Temperaturerniedrigung in Mitteleuropa. Jahresber. u. Mitt. des Oberrhein. Geol. Ver., XXXI. 
322. Solé Sabaris, L., 1952: España, geografia fisica. - In Manuel de Teran: Geografia de España y Portugal I, Abh. 58/59.

323. Speranza, F., 1960: Dei limiti altimetrici della vegetazione sull'Etna. Catania.

324. Spreitzer, H., 1957. Zur Geographie des Kilikischen Ala Dagh im Taurus. Festschr. 100 Jahre Geogr. Ges. Wien.

325. - 1958: Frührezente und rezente Hochstände der Gletscher des Kilikischen Ala Dagh im Taurus. Schlern-Schriften, Bd. 190, Innsbruck.

326. - 1960: Hangformung und Asymmetrie der Bergrücken in den Alpen und im Taurus. $Z$. f. Geomorphologie, Suppl. Bd. 1.

327. Srbik, R., von, 1941: Glazialgeologie d. Kärntner Karawanken. N. Jb. für Min., Sonderband III, S. 188.

328. Stratil-Sauer, G., 1927: Der östliche Pontus. Geogr. Zeitschr.

329. - 1961, 1964, 1965: Beobachtungen im Ostpontischen Gebirge, unter bes. Berücksichtigung der Kaltzeitformen. Mitt. der Oesterr. Geogr. Ges., Wien.

330. Streiff-Becker, R., 1936: Zwanzig Jahre Firnbeobachtung. Z. f. Gl.-kunde.

331. - 1947: Die Schneegrenze in den Alpen. Leben und Umwelt. Naturwiss. Monatszeitschr., H. 7, S. 107.

332. Suter, K., 1933, 1935, 1936: Die eiszeitliche Vergletscherung der Apenninen. Z. f. Gl.-kunde.

333. - 1937: Zur eiszeitlichen Vergletscherung des Nordapennins. Schweiz. Geograph.

334. - 1939/1940: Die eiszeitliche Vergletscherung des Zentralapennins. Diss. Zürich 1939 und Vierteljahresschrift der Natf. Ges. Zürich 1940.

335. Taillefer, F., 1958: Les glaciers des Pyrénés françaises. Ungedrucktes Manuskript mit beigelegtem Kartenblatt 1958.

336. Tchihatcheff, P., von, 1867: Reisen in Kleinasien und Armenien 1847-1863. Peterm. Geogr. Mitt. Erg. H. 20.

337. - 1867: Asie mineure, 4 Bde., 1. Bd. Geologie. Paris.

338. Tollner, H., 1934: Die meteor.-klimatischen Ursachen der Gletscherschwankungen in den Ostalpen während der letzten zwei Jahrhunderte. Mitt. der Geogr. Ges. Wien, Bd. 96.

339. Tonini, D., 1961: Il Ghiacciaio del Calderone del Gran Sasso d'Italia. Boll. Com. Glac. It., No. 10 , Torino.

340. Tozer, H. F., 1881: Turkish Armenia and Eastern Asia Minor. London.

341. Trevisan, L., 1940: I limiti nivali attuali e würmiani in Italia. Boll. Com. Glac. It., Torino.

342. Tricart, J., 1951: Das Quartäre Palaeoklima und die klimatische Morphologie im mediterranen Süden. Eiszeitalter und Gegenwart.

343. - 1963: Oscillations et modifications de caractère de la zone aride en Afrique et en Amérique latine lors des périodes glaciaires des hautes latitudes. Arid Zone Research. UNESCO.
344. Troll, C., 1944: Strukturböden, Solifluktion und Frostklimate der Erde. Geol. Rundschau 34.

345. - 1956: Die Klimatypen an der Schneegrenze. Actes du IV Congr. Internat. du Quatern. Rome_Pise 1953.

346. - 1966: Oekologische Landschaftsforschung und vergleichende Hochgebirgsforschung. Erdkundliches Wissen, H. 11.

347. Vagliasindi, C., 1948: Origine glaciale della Valle del Bove, altro ghiacciaio etneo. Boll. dell'Acc. Gioenia, Catania. Ser. 3. fasc. 22.

348. - 1949: Osservazioni sul periodo glaciale e nuove manifestazioni dell'azione glaciale quaternaria sul Monte Etna. Boll. Acc. Gioenia, Ser. 4, fasc. 2, Catania.

349. Vanni, M., 1954: Considération sur les variations frontales des glaciers italiens au cours des quarante dernières années. Publ. no. 39 de l'Ass. Internat. d'Hydrologie. Rome.

350. Vosseler, P., 1931: Eiszeitstudien im nordwestlichen Spanien. Z. f. Gl.-kunde.

351. Weischet, M., 1954: Die gegenwärtige Kenntnis vom Klima in Mitteleuropa beim Maximum der letzten Vereisung. Mitt. d. Geogr. Ges. in München.

352. - 1960: Zum Problem der Stabilität der Klimabedingungen in Westsibirien während der Glaziale und Interglaziale. Eiszeitalter und Gegenwart.

353. Wernert, P., 1932: Diluviale Vergletscherungsspuren in der Cuerda Larga der Südkette der Sierra Guadarrama. Z. f. Gl.-kunde.

354. Wiche, K., 1953: Klimamorphologische und talgeschichtliche Studien im M'Goungebiet. Mitt. d. Geogr. Ges. Wien, 95.

355. - 1953: Pleistozäne Klimazeugen in den Alpen und im Hohen Atlas. Mitt. d. Geogr. Ges. Wien, 95.

356. - 1955/56: Beiträge zur Morphologie des Thessalischen Olymp. Geogr. Jahresbericht aus Österreich. Bd. XXVI.

357. Willet, H. C., 1949: Long-period fluctuations of the general circulation of the Atmosphere. Journal Meteor. 6.

358. - 1950: The general circulation at the last glacial maximum. Geogr. Annal. 31.

359. Wissmann, H. von, 1959: Die heutige Vergletscherung und Schneegrenze in Hochasien mit Hinweisen auf die Vergleiche der letzten Eiszeit. (Mit einem Beitrag von H. Flohn). Ak.d. Wiss. u. d. Lit., Nr. 14, Mainz.

360. Woldstedt, P., 1958, 1961, 1965: Das Eiszeitalter. 3 Bde. Stuttgart.

361. Wright, H. E., 1962: Pleistocene glaciation in Kurdistan. Eiszeitalter und Gegenwart.

362. Zeuner, F., 1939: Schwankungen der Sonnenstrahlung und des Klimas im Mittelmeergebiet während des Quartärs. Geol. Rundschau.

363. - 1953: Das Problem der Pluvialzeiten. Geol. Rundschau 41.

364. - Zingg, T., 1954: Die Bestimmung der klimatischen Schneegrenze auf klimatologischer Grundlage. Mitt. des Eidg. Inst. für Schneeund Lawinenforschung. Nr. 12. Davos. 